Sebastian Florian Weiner - Eriugenas negative Ontologie 

Sebastian Florian Weiner

\section{Eriugenas negative Ontologie}





\section{Inhaltsverzeichnis}

\begin{tabular}{ll|l}
1 & Einleitung 1 & 1
\end{tabular}

1.1 Allgemeines . . . . . . . . . . . . . . . . . . 1

1.2 Zum zeitlichen Entstehungsrahmen des Periphyseon . . . 6

1.3 Die neue Textedition $\ldots \ldots \ldots \ldots$

1.4 Der deutungsschwere Textanfang . . . . . . . . . . . . 9

2 Interpretation des Periphyseon, ausgehend vom Anfang 19

2.1 Der erste Satz: ein metaphysisches Fundament? . . . . . 22

2.1.1 Untersuchung der einzelnen Satzteile . . . . . . . 25

2.1.2 Nachdenken und Erfassen: eine epistemologische Grundunterscheidung ............ 26

2.1.3 Die Bedeutung des Ausdrucks ea quae sunt . . . . 33

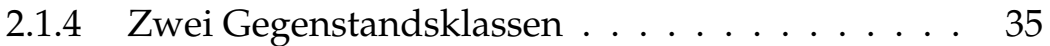

2.1.5 Exkurs: Ein Vergleich mit Boethius' Naturbestim-

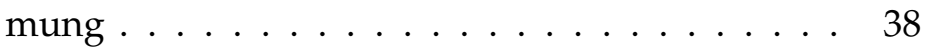

2.2 Die Einteilung der Natur . . . . . . . . . . . . . . . . . . 41

2.2.1 Von Natur als generale vocabulum zur Einteilung

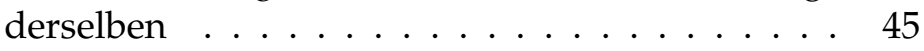

2.2.2 Die Gegenstände der einzelnen Naturarten . . . . . 53

2.2.3 Der Untersuchungsplan des Werks. . . . . . . . . 59

2.3 Eine negative Ontologie $\ldots \ldots \ldots \ldots$. . . . . . . . 61

2.3.1 Sein und die Aussage >zu sein

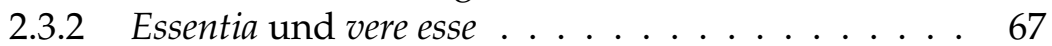

2.4 Der Kern der negativen Ontologie . . . . . . . . . . . . 73

2.4 .1 Dass-Sein und Was-Sein . . . . . . . . . . . . . 82

2.4 .2 Das unbestimmbare subiectum . . . . . . . . . . 84

2.5 Die übrigen vier Auslegungsweisen und ihre Funktion . 90

2.5 .1 Die zweite Auslegungsweise $\ldots \ldots$. . . . . . . . 90

2.5 .2 Die dritte Auslegungsweise . . . . . . . . . . . . . . 93

2.5 .3 Die vierte Auslegungsweise . . . . . . . . . . . . . . . . 96

$2.5 .4 \quad$ Die fünfte Auslegungsweise $\ldots \ldots \ldots$. . . . . 98 
2.6 Ergebnisse dieser ersten Textuntersuchung . . . . . . . . 99

2.7 Die Ontologie im ersten Buch . . . . . . . . . . . . . . . 101

2.7.1 Zur Unbegreiflichkeit der rationes dei und zur Theo-

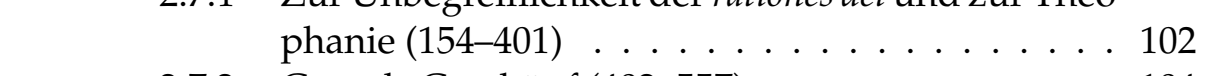

2.7 .2 Gott als Geschöpf (402-557)] . . . . . . . . . . . . 104

$2.7 .3 \quad$ creari als se ipsum creare $\ldots$. . . . . . . . . . . . . . . . . 109

$2.7 .4 \quad$ Der Name trinitas (558-665) $\ldots$. . . . . . . . . . . . 109

2.7.5 Die erstrangigen Ursachen als göttliche Namen $(666-886) \ldots \ldots \ldots \ldots \ldots \ldots \ldots \ldots \ldots \ldots 111$

2.7.6 Eriugenas Kategorieninterpretation (887-2009)] . . 113

2.7.7 Die Verwerfung einer dialektischen Unterscheidung .......................... 115

2.7 .8 Die circumstantiae locus und tempus . . . . . . . . . 118

2.7.9 $\quad$ Eriugenas Lehre von der geschaffenen Wirklichkeit 120

2.7.10 Von der Differenz zwischen ousia und Körper (1606-

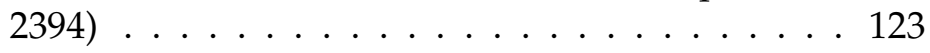

2.7 .11 Von der Materie (2395-2635) . . . . . . . . . . 126

2.7 .12 Das Akzidenz . . . . . . . . . . . . . . . . 127

2.7.13 Der Name >Schöpfer $<$ (2636-3496) . . . . . . . . . 127

2.7.14 Ergebnisse der Untersuchung . . . . . . . . . . . . 132

2.8 Zur Ontologie in den übrigen vier Büchern . . . . . . . . 133

2.9 Eine Bedingung für Eriugenas Ontologie: Natur als Einheit 139

2.9 .1 Zur Einheit der Natur in Buch II . . . . . . . . . . . 139

2.9 .2 Zur Einheit der Natur in Buch III] . . . . . . . . . 141

2.10 Der Grundgedanke im viergliedrigen Aufbau des Werks 144

3 Die Grundlagen der negativen Ontologie 149

3.1 Die Bestimmung Gottes als essentia omnium . . . . . . . . 149

3.1.1 Die theologische Tradition . . . . . . . . . . . . . . 149

3.1.2 Dionysius Areopagita als mögliche Vorlage von Eriugenas Substanzlehre . . . . . . . . . . . . . . 156

3.2 Gott als creari $\ldots \ldots \ldots \ldots$. . . . . . . . . . . . . 158

3.3 Zur Bedeutung des griechischen ousia und des lateinischen essentia . . . . . . . . . . . . . . . . . . . . . . . . 161

3.3.1 Zur Verwendung von ousia in der griechischen Tradition ................. 162 
3.3.2 Zur Übersetzung von ousia in der lateinischen Tradition .................... 165

3.3.3 Ein Bestimmungsversuch von ousia . . . . . . . . 168

3.3.4 Weitere Quellen für Eriugenas ousia- und essentia-

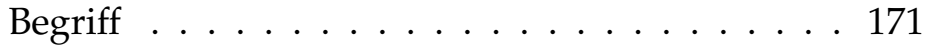

3.3.5 Die frühere Unterscheidung zwischen essentia und substantial. .................. 173

3.4 Die Individuation der ousia . . . . . . . . . . . . . . . 175

3.4 .1 Eriugenas Körperlehre . . . . . . . . . . . . . . . . 178

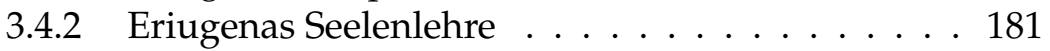

3.4.3 Der Ausdruck vere esse und die Rolle der Theophanie .................. . 183

3.4.4 Verborgenes im Geschöpf . . . . . . . . . . . . . 186

3.4.5 Essentia und natura: zwei Synonyme? . . . . . . . 189

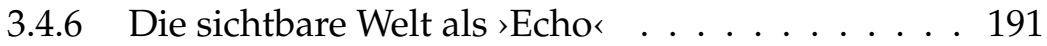

3.5 In der Wegspur der Griechen . . . . . . . . . . . . . . 194

Anhang:

Philosophiegeschichtliche Einordnung des Werks 201

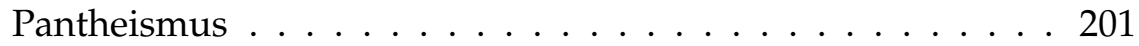

Neuplatonismus . . . . . . . . . . . . . . . . . 202 



\section{Einleitung}

\subsection{Allgemeines}

Ohne das Euvre des Iren Johannes Scottus Eriugena ließe sich vielleicht feststellen, in der Zeit zwischen Boethius und Anselm habe die lateinische Literatur nichts von größerem philosophischem Belang hervorgebracht. Wie aus dem Nichts heraus beginnt Eriugena in der zweiten Hälfte 9. Jh. sein literarisches Schaffen, die Orte, an denen er Dialektik, Theologie und sogar Griechisch lernte, sind nicht bekannt. Umso mehr überrascht der Umfang seines Hauptwerkes mit dem griechischen Titel Periphyseon, das mit seinen fünf Büchern in der neuesten Edition über fünfhundert Seiten umfasst und eine gewaltige Menge an Anleihen und Zitaten aus den Schriften der Antike aufweist. Nähere Gründe für das Entstehen solch eines umfangreichen Werks zu dieser Zeit sind schwer anzugeben. Man mag sich darauf berufen, Eriugena habe als einer der ersten im lateinischen Westen über die Schriften des Pseudo-Dionysius Areopagita, des Maximus Confessor und des Gregor von Nyssa verfügt und im Zuge seiner intensiven Übersetzertätigkeit den Inhalt auf dem lateinischen Westen Bekanntes hin reflektiert. Doch beschränkt sich das Periphyseon nicht auf eine Exegese dieser Schriften, und ebensowenig finden sich klare Konturen in ihm, die es vorrangig als Vermittlungsversuch zwischen griechischer und lateinischer Theologie ausweisen. Bereits hinsichtlich der Form ist eine eindeutige $\mathrm{Zu}-$ ordnung schwer. Es beginnt als Dialog, doch überwiegen im hinteren Teil lange Monolog-Passagen und Zitatanführungen sowie Erläuterungen. Sowohl Untersuchungsmethode als auch der Untersuchungsgegenstand variieren im Verlaufe des Werks gewaltig. Es ist, vereinfacht gesagt, der Form und dem Inhalt nach ein Hybrid. Kurt Flasch merkt dazu treffend an, das Werk sei »(...) trotz seiner formal-strengen Gliederung ein Konglomerat von Ideen, Zitaten und Interpretationen. Es ist bald Religionsphilosophie, bald Logik, bald Kirchenvätererklärung.<1

\footnotetext{
${ }^{1}$ Kurt Flasch: Das philosophische Denken im Mittelalter, Stuttgart ${ }^{2} 2000$, S. 183.
} 


\section{Einleitung}

Umgekehrt ist dem Periphyseon auch nicht eine vorrangig enzyklopädische Absicht zu unterstellen, wie sie vielleicht Isidor oder Hrabanus Maurus nahe lag, weil dafür viele Fragestellungen zu ausführlich diskutiert werden und textexegetische Abschnitte viel Raum einnehmen.

Bereits hinsichtlich des Anfangs der Schrift, welcher die Form einer dialektischen Untersuchung aufweist, sind kritische Worte bezüglich Systematik und Lesbarkeit geäußert worden. So sagt Wolfgang Gombocz: »Überhaupt sind die Anfangsteile voller Überraschungen; sie stellen höchste Anforderungen an den Leser und sind stellenweise unlesbar, gelegentlich sogar systematisch sinnlos. «2 In der Tat wirkt das Werk auf den systematisch ausgerichteten Leser oft als ein unwegbares Dickicht aus Quellengedanken und deren Auslegungen, wo selbst der durch die Dialogform vorgegebene Weg nicht stolperfrei hindurchführt. Zudem, so zeigen es etwa Maïeul Cappuyns und René Roques, ist das im Anfang präsentierte dialektische Konzept der Natureinteilung und Seinsinterpretation scheinbar ohne Bedeutung für den Fortgang der Untersuchung, ein Umstand, der den Periphyseon-Editor Sheldon-Williams zu der mittlerweile widerlegten Ansicht brachte, der Anfang sei eine eigenständige und zeitlich früher abgefasste Abhandlung $!^{3}$

Angesichts der Vielzahl an langen Quellenverweisen im Periphyseon liegt zudem der Schluss nahe, die ernüchternde Aussage Beryl Smalleys, »to study Carolingian Exegetes is simply to study their sources", gelte auch für das Periphyseon 4

Ist es aufgrund der angeführten Feststellungen überhaupt sinnvoll, sich mit diesem Werk systematisch auseinandersetzen?

Es gibt kaum eine Geschichtsdarstellung der Philosophie des Abendlandes, in welcher Eriugena keine halbwegs ausführliche Erwähnung findet $\left.\right|^{5}$ Demnach war Eriugena ein Philosoph, und einer aktuellen Pu-

${ }^{2}$ Wolfgang L. Gombocz: Geschichte der Philosophie, Bd. IV, München 1997, S. 373.

${ }^{3}$ Maïeul Cappuyns: Jean Scot Erigène, sa vie, son œvre, sa pensée, Louvain-Paris 1933, p. 311; René Roques: Remarques sur la signification de Jean Scot Erigène, in: Divinitas XI (1967), p. 253.

${ }^{4}$ Beryl Smalley: The study of the Bible in the Middle Ages, Oxford ${ }^{2} 1983$, p. 37-38.

${ }^{5}$ Siehe als Auswahl etwa: Johannes Hirschberger: Geschichte der Philosophie, Bd I, Freiburg 1949, S. 349-351; Frederick Copleston: History of Philosophy, Vol. II, London 1950, p. 112-135; The Cambridge History of Later Greek and Early Medieval Philosophy, ed. by A.H. Armstrong, Cambridge 1967, p. 518-531; Wolfgang L. Gom- 
blikation nach sogar »der Philosoph der karolingischen Renaissance« $[6$ Doch was ist seine philosophische Leistung, aufgrund der er als bedeutender Philosoph zu gelten hat?

Die bisherigen Forschungen zum Periphyseon, mittlerweile von grossem Umfang, lassen sich wie folgt klassifizieren:7] Der wohl populärste Strang geht auf die Arbeiten Stephen Gershs und Werner Beierwaltes' zurück, wonach Eriugenas Denken den Neuplatonismus des Proklos und Pseudo-Dionysius Areopagita ${ }^{8}$ in einem gewissen Sinne fortführt: ${ }^{9}$ Ein weiterer Strang wird vor allem von Gangolf Schrimpf stark gemacht, der eine logisch-systematische Annäherung an das Periphy-

bocz: Geschichte der Philosophie, Bd. IV, München 1997, S. 365-381; Carlos Steel und D. W. Hadley: John Scotus Eriugena, in: A Companion to Philosophy in the Middle Ages, ed. by Jorge Gracia, Maldon / Oxford / Melbourne 2003, p.397-406

${ }^{6}$ Johann Kreuzer: Von der Insel der Heiligen ins Zentrum der karolingischen Renaissance: Johannes Scottus Eriugena, in: Markus Knapp/Theo Kobusch (Hrsg.): Querdenker - Visionäre und Außenseiter in Philosophie und Theologie, Darmstadt 2005, S. 84-94.

${ }^{7}$ Siehe zum Überblick über die Literatur die Bibliographie von Gerd van Riel: A Bibliographical Survey of Eriugenian Studies 1987-1995, in: Iohannes Scottus Eriugena - the Bible and Hermeneutics, Proceedings of the Ninth International Colloquium of the Society for the Promotion of Eriugenian Studies, held at Leuven and Louvain-la-Neuve, June 7-10, 1995; ed. by Gerd van Riel, Carlos Steel and James McEvoy, Leuven 1996, p. 367-400; sie knüpft an zu Mary Brennan: A Guide to Eriugenian Studies. A Survey of Publications 1930-1987 (Vestigina. Etudes et documents de philosophie antique et médiévale, 5), Fribourg/Paris 1989, p.341ff; bei beiden konnten nicht alle Publikationen erfasst werden, da sich zusätzlich Vieles in eigentlich fachfremden Sammelbänden findet, etwa Thomas Böhm: Adnotationes zu Maximus Confessor und Johannes Scottus Eriugena, in: Deutsche Mystik im abendländischen Zusammenhang, Hg. Walter Haug und Wolfram SchneiderLastin, Tübingen 2000, S. 51-60.

${ }^{8}$ Die Bezeichnung spseudo in Pseudo-Dionysius Areopagita wird im Folgenden nicht nur aus praktischen Gründen weggelassen, sondern auch, weil es sich für Eriugena tatsächlich um den Paulus-Schüler von Areopag handelt, dessen Schriften er übersetzt, kommentiert und rezipiert. Bei aller Anerkennung der Falschheit dieser Autorenzuschreibung ist nicht $\mathrm{zu}$ vergessen, dass der Glaube an diese falsche $\mathrm{Au}-$ torenschaft die Schriften für lange Zeit erst zu der Autorität machte, die sie insbesondere im frühen Mittelalter und damit auch für Eriugena eingenommen haben.

${ }^{9}$ Stephen Gersh: From Iamblichus to Eriugena, Leiden 1978; ders.: Middleplatonism in the Latin Tradition II, Notre Dame 1986, p. 790 ff; ders.: Per se ipsum - The Problem of Immediate and Mediate Causation in Eriugena and his Neuplatonic Predecessors, in: Jean Scot Erigène et l' histoire de la philosophie, éd. par René Roques, Paris 1977, p. 367-376; Werner Beierwaltes: Eriugena, Frankfurt 1984; ders.: Denken des Einen, Frankfurt 1985. 


\section{Einleitung}

seon vor dem Hintergrund der artes liberales versucht ${ }^{10}$ Edouard Jeauneau und sein Umfeld gehen einen Mittelweg, indem sie zumeist theologische, lateinische wie griechische Quellen bei der Interpretation berücksichtigen und verstärkt die Bedeutung Maximus Confessors und Augustins für das Denken Eriugenas herausarbeiten $[11$ Zudem interpretieren einige das Periphyseon als ein Werk der Mystik, in welchem, ähnlich wie bei Dionysius Areopagita, augenscheinliche Paradoxien gerade die verhüllte und unbegreifliche Wahrheit zu benennen versuchen ${ }^{12}$ Darüberhinaus wird kontrovers diskutiert, in welchem Umfang

${ }^{10}$ Gangolf Schrimpf: Das Werk des Johannes Scottus Eriugena im Rahmen des Wissenschaftsverständnisses seiner Zeit, Münster 1982; ders.: Die systematische Bedeutung der beiden logischen Einteilungen (divisiones) zu Beginn von Periphyseon, in: Giovanni Scoto nel suo tempo - Atti del XXIV Convegne storico internazionale Todi, 11-14 ottobre 1987; (publ.: Spoleto 1989), S. 113-151; denselben Ansatz verfolgt zuvor bereits Guy H. Allard: Quelques remarques sur la >disputationis series‘, in: Jean Scot Erigène et l'histoire de la philosophie, éd. par René Roques, Paris 1977, p. 211-224. Auf Schrimpfs Arbeiten basiert die Untersuchung von Dirk Ansorge: Johannes Scottus Eriugena: Wahrheit als Prozess - eine theologische Interpretation von Periphyseon, Innsbruck/Wien 1996; zudem Giulio d'Onofri: Über die Natur der Einteilung. Die dialektische Entfaltung von Eriugenas Denken, in: Begriff und Metapher - Sprachform des Denkens bei Eriugena, Vorträge des VII. internationalen Eriugena-Colloquiums Bad Homburg 26.-29. Juli 1989, herausgegeben von Werner Beierwaltes, Heidelberg 1990, S. 17-38.

${ }^{11} \mathrm{Zu}$ Augustinus als wichtigste Quelle neben den griechischen siehe Inglis Patrick Sheldon-Williams: Eriugena's Greek Sources, in: The Mind of Eriugena - Papers of a Colloquium, Dublin, 14-18 July 1970, ed. by John J. O'Meara and Ludwig Bieler, Dublin 1973, p.1-15; vor allem Goulven Madec hat den Einfluss von Augustinus auf Eriugena ausführlich dargelegt in ders.: Jean Scot et ses auteurs, Paris 1987; siehe auswahlhaft zum umfangreichen Evre von Edouard Jeauneau, ders.: Etudes Erigéniennes, Paris 1987.

${ }^{12}$ Etwa Bernard McGinn: Eriugena Mysticus, in: Giovanni Scoto nel suo tempo, Atti del XXIV Convegno storico internazionale, Todi 11-14 ottobre 1987, S. 235-260; oder Thomas O' Loughlin: Biblical Contradictions in the Periphyseon and the Development of Eriugena's Method; in: Iohannes Scottus Eriugena - the Bible and Hermeneutics, Proceedings of the Ninth International Colloquium of the Society for the Promotion of Eriugenian Studies, held at Leuven and Louvain-la-Neuve, June 7-10, 1995; ed. by Gerd van Riel, Carlos Steel and James McEvoy, Leuven 1996, p. 103-126; ebenso: Rainer Brueren: Die Schrift als Paradigma der Wahrheit - Gedanken zum Vorbegriff der Metaphysik bei Johannes Scotus Eriugena, in: Begriff und Metapher - Sprachform des Denkens bei Eriugena, Vorträge des VII. internationalen Eriugena-Kolloquiums Bad Homburg 26.-29. Juli 1989, herausgegeben von Werner Beierwaltes, Heidelberg 1990, S. 187-201. 
Eriugena überhaupt griechisches Gedankengut seiner Lehre zugrundelegt ${ }^{13}$

Die vorliegende Untersuchung lässt vorrangig den Autor selbst zu Wort kommen, seine Behauptungen und Argumente. Es geht nicht darum, eine interessante Theorie am Text zu entwickeln, sondern dem Text so zu folgen, wie ihn der Autor vorgibt, mag er zunächst auch stellenweise konfus oder bar einer schlüssigen Argumentation wirken. Ich nenne dies >den Text ernst nehmen ‘. Folglich beginnt die Untersuchung auch mit dem unbequemen Anfang des Periphyseon und nicht mit einer spektakulären Aussage inmitten eines der fünf Bücher.

Solch eine am Text ausgerichtete Untersuchung drängt sich auf, seit für das Periphyseon dank der Arbeiten Jeauneaus eine optimale Textgrundlage, nämlich eine Edition des Autographen, vorliegt. So lässt sich davon ausgehen, dass dasjenige, was im Text steht, auch von Eriugena so geschrieben wurde; mögliche Textkorruption als Verwerfungsgrund einer Aussage entfällt.

Im hier gegebenen Rahmen ist es allerdings nicht möglich, solch eine Textuntersuchung für das gesamte Periphyseon vorzunehmen. Ziel der Untersuchung ist ein Leitfaden, anhand dessen sich der Leser im Werk orientieren kann. Viele weitläufige Theorien und Überlegungen aus dem Periphyseon bleiben in dieser Untersuchung außen vor oder werden nur kurz angerissen. Nicht Vollständigkeit ist hier Gebot, sondern Wesentlichkeit. Verständlicherweise sucht die Untersuchung daher nach einer Systematik im Werk, nach Ordnung und Beweisziel, und zwar auch dort, wo auf den ersten Blick nichts dergleichen vorliegt. Insbesondere der Textanfang wird dabei einer eingehenden Prüfung unterzogen, auch wenn sich Eriugena an keiner späteren Stelle explizit darauf zurückberuft. Wie sich dabei zeigt, entfaltet Eriugena von Beginn an seine eigentümliche Ontologie, die allem darauf Folgenden zugrunde liegt.

${ }^{13}$ Dermot Moran etwa macht sich für einen massiven Einfluss der Griechen auf Eriugena stark, in ders.: The Philosophy of John Scottus Eriugena, Dublin 1990; Georgi Kapriev hält dem entgegen, Eriugena habe wesentliche Gedanken aus seinen griechischen Quellen dem Wortlaut nach zwar übernommen, aber nicht richtig verstanden und wiedergegeben, in ders.: Eodem sensus utentes? - Die Energienlehre der `Griechen ‘ und Eriugenas causae primordiales; in: Göttinger Theologische Quartalsschrift Jg. 2000, S. 289-307. 


\section{Einleitung}

Er macht es dabei seinem Leser nicht leicht, sein Werk aus dem Schatten der Theologen Pseudo-Dionysius Areopagita und Maximus Confessor heraustreten zu lassen; zu sehr beruft er sich immer wieder auf die von ihm so verehrten, im lateinischen Westen neu zu etablierenden Autoritäten. Und eine genaue Lektüre der beiden genannten Denker gibt einen Einblick darin, wie Eriugena ganze Gedankengänge von ihnen übernimmt. Auch seine Ontologie glaubt er dort vorzufinden. Indes wird zu zeigen sein, dass dies nicht der Fall ist und es sich dabei um Eriugenas Innovation handelt. In ontologischer Hinsicht tritt er so aus der neuplatonischen Tradition heraus, in die er immer wieder, und oft zurecht, gestellt wird.

\subsection{Zum zeitlichen Entstehungsrahmen des Periphyseon}

Weil manchem Leser das Entstehungsumfeld von Eriugenas Schaffen sicherlich wenig vertraut ist, sei hier eine kurze Darstellung angefügt.

Das fünfbändige lateinische Werk mit dem griechischen Titel Periphyseon entstand zwischen 860 und 865 im höfischen Umfeld des karolingischen Königs Karl dem Kahlen durch den Iren Johannes Scottus, der sich selbst, seine irische Abstammung kennzeichnend, Eriugena nennt. Woher aus Irland er genau stammte und wo er seine exzellenten Lateinund Griechischkenntnisse erworben hat, ist bis heute ungeklärt. Der Quellenlage nach taucht er zwischen 840 und 850 am Hofe Karls auf und beginnt sein literarisches Schaffen mit einer Glossensammlung zur Schrift De nuptiis philologiae et mercurii des Martianus Capella, was ihn als Lehrer der artes liberales ausweist. Im Streit der Kirche mit dem aufsässigen Mönch Gottschalk erhält der Laie Eriugena den Auftrag, ein Schlichtungsgutachten anzufertigen, das unter dem Namen De praedestinatione liber überliefert ist und ihm seinerzeit mehr Kritik als Wertschätzung einbringt. Das Geschehnis indes, ohne welches er das Periphyseon wohl nie geschrieben hätte, ereignete sich zu einer Zeit, als Eriugena wahrscheinlich noch nicht einmal auf dem Kontinent weilte.

Im Jahr 824 überreichten Gesandte des byzantinischen Kaisers Michael dem karolingischen König Ludwig dem Frommen eine Prachthandschrift des zu dieser Zeit im Frankenland wohl schon sagenumwobenen Corpus Dionysiacum. Sein Verfasser gibt sich selbst als Schüler des Apostels Paulus aus, wenngleich dessen wahre Provenienz aus der 
neuplatonischen Schule des Proklos heute als erwiesen gilt. Sogleich fertigten die Karolinger eine lateinische Übersetzung von diesem Werk an, doch der des Griechischen mächtige Abt Hilduin konnte sich mühen, wie er wollte: die durch die mystische und mit Paradoxien angehäufte Sprache gegebene Sperrigkeit des Originaltextes wurde seiner Übersetzungsleistung angekreidet und man beauftragte ein paar Jahrzehnte später Eriugena mit einer Neuübersetzung. Auch für seine Übersetzung blieb Kritik nicht aus, diesmal von päpstlicher Instanz, doch machte der päpstliche Bibliothekar Anasthasius dem Iren Eriugena zugleich ein überaus wertvolles Geschenk: eine Abschrift des Scholienwerkes Ambigua ad Iohannem (so der lateinische Titel) des Byzantiners Maximus Confessor, von dem außerhalb Roms im lateinischen Westen niemand Kenntnis hatte 14 Es wird im Verlauf der Arbeit noch Vieles zu dieser Schrift des Maximus Confessor zu sagen sein, doch es sei schon vorab erwähnt, dass mit ihr für Eriugena ein intellektueller Stern aufgeht. Er übersetzt sie ebenso wie im Anschluss daran De imagine (bei Migne griechisch ediert als De opificio hominis) des Kappadokiers Gregor von Nyssa sowie später, wohl nach Abfertigung des Periphyseon, ein weiteres Werk von Maximus, die Quaestiones ad Thalassium 15

Dem Periphyseon lässt Eriugena einen Kommentar zum Buch von Dionysius über die himmlischen Hierarchien folgen sowie Homilien und einen Kommentar zum Johannes-Evangelium. Ort und Zeitpunkt seines Todes sind unbekannt, und ähnlich wenig lässt sich über die unmittelbare Rezeption des Periphyseon erfahren. Der erste Nachweis für eine intensive Auseinandersetzung mit diesem Werk ist ein eher tragischer, nämlich das Verbot der Schrift im 12. Jh., welches in den darauffolgenden Jahrzehnten noch zweimal erneuert wird ${ }^{16}$

\footnotetext{
${ }^{14}$ Eine übersichtliche Darstellung dieser historischen Gegebenheiten findet sich in der Einleitung von Chevalier zur Edition der Dionysiaca, Paris 1937.

${ }^{15}$ Siehe zur Datierungsschwierigkeit letzterer Übersetzung das Vorwort der Edition von Laga/Steel: Maximi Confessoris Quaestiones ad Thalassium, I-LV, Louvain 1980.

${ }^{16}$ Siehe zur Rezeption Eriugena Revivus: Zur Wirkungsgeschichte seines Denkens im Mittelalter und im Übergang zur Neuzeit. Vorträge des V. internationalen EriugenaColloquiums, Bad Homburg 26.-30.8.1985, Hg. Werner Beierwaltes, Heidelberg 1987. Zudem werden insbesondere für das 11. Jh. immer wieder Spuren des Werks nachgewiesen, siehe etwa Christophe Erismann: Alain de Lille, la métaphysique érigénienne et la pluralité des formes, in: Alain de Lille, le docteur universelle, éd. par Jean-Luc Solére, Anca Vasiliu et Alain Galonnier, Turnhouti 2005, p. 13-19.
} 


\section{Einleitung}

\subsection{Die neue Textedition}

Die vor wenigen Jahren fertiggestellte Neu-Edition des Periphyseon von Edouard Jeauneau bietet eine Arbeitsgrundlage, wie sie besser nicht sein kann 17 Im Rahmen seiner Editionsarbeit hat Jeauneau das Manuskript R (Reims) als Autographen Eriugenas identifiziert und darüberhinaus die ein- und beigefügten Anmerkungen in der Handschrift zwei verschiedenen irischen Schreiberhänden, $\mathrm{R} i^{1}$ und $\mathrm{R} i^{2}$, zugeordnet. Dabei handelt es sich, wie er darlegt, bei $i^{1}$ um Eriugenas eigene Hand, bei $i^{2}$ hingegen um die eines uns unbekannten Iren 18

Diese Unterscheidung ist deshalb wertvoll, da in den übrigen späteren Handschriften, wie Jeauneau gezeigt hat, die von der zweiten irischen Hand nachträglich eingefügten Anmerkungen ohne sichtbare Kennzeichnung in den Textfluss übernommen wurden. Leider ist für das fünfte Buch der Reimser Autograph nicht mehr vorhanden, und in den übrigen Handschriften für dieses Buch ist folglich nicht ersichtlich, ob es sich bei einer Aussage um Eriugenas eigene Worte handelt oder um eine in den Textfluss übernommene Randbemerkung von $\mathrm{R} i{ }^{2}$. Daher ist dieses Buch nur unter diesem Vorbehalt in die Untersuchung miteinzubeziehen.

Der vorliegenden Arbeit ist sowohl die zusammengefasste Edition zugrundegelegt, die Jeauneau Synopsis versionum nennt, als auch die jener ersten Spalte (Manuskript R) in der angefügten kritischen ParallelEdition aller wichtigen Handschriften. Zitiert wird der Text nach der zusammengefassten Edition (Synopsis Versionum), mit Ausnahme des zweiten Buchs. Dort weist der Reimser Autograph derart viele Anmerkungen von $\mathrm{R}^{2}$ auf, die in der Synopsis Versionum nicht als solche ersichtlich sind, dass die Parallel-Edition für dieses Buch die bessere Textgrundlage bietet (erste Spalte), ausgehend von der Urfassung $R^{*}$ nebst Eriugenas eigenen Anmerkungen, die Jeauneau mit $\mathrm{R} i^{1}$ kennzeichnet.

Die verwendeten Stellenangaben, die der Zeilennummer aus Jeauneaus Synopsis Versionum entsprechen, stehen nicht in der Tradition der Eriugena-Forschung, wo Textverweise stets nach der Migne-Ausgabe

\footnotetext{
${ }^{17}$ Iohannis Scotti seu Eriugenae: Periphyseon Libri 1-5, édité par Edouard Jeauneau, Corpus Christianorum Series Latina CLXI-CLXV, Paris 1996-2003.

${ }^{18}$ Siehe hierzu die Ergebnisse der Handschriftuntersuchungen Jeauneaus in ders.: The Autograph of Eriugena, Turnhout 1996.
} 
angegeben sind, d.h. deren Seitenzahl und den die Seite unterteilenden Buchstaben A bis D. Die Zeilenangaben in den jeweiligen Büchern 1-5 der Jeauneau-Edition sind jedoch präziser und erleichtern das schnelle Auffinden der Textstellen erheblich. Stellenangaben aus dem zweiten Buch sind in Klammern angeführt, da sie, wie gesagt, der Edition von $\mathrm{R}^{*} / \mathrm{R} i^{2}$ entstammen, und nicht der Synopsis Versionum.

Dankenswerterweise sind die Quellenuntersuchungen, die Goulven Madec im Laufe der Jahre angestellt hat, als Verweise in den Textapparat von Jeauneaus Edition nebst einigen Erweiterungen miteingeflossen $\sqrt{19}$ Dies ist eine wertvolle Nachschlagehilfe, auch wenn, wie sich zeigen wird, manche Verweise nicht weiterhelfen. Die hervorragende Arbeitsgrundlage runden die Indices von Allard ab, welche das schnelle Auffinden von einzelnen Wörtern oder Ausdrücken im Periphyseon ermöglichen 20

\subsection{Der deutungsschwere Textanfang}

Damit Missverständnisse nicht aus unklaren Übersetzungsweisen resultieren, ist es angebracht, den in der Folge zu untersuchenden, weil schwer verständlichen Anfang des Periphyseon zunächst ins Deutsche zu übersetzen ${ }^{21}$ Zwar gibt es bereits eine ältere Übersetzung von Ludwig Noack, doch ist sie oft zu ungenau, um für den vorliegenden Zweck als Grundlage dienen zu können ${ }^{22}$ Zunächst ist der lateinische Text nach Jeauneaus Edition vorausgeschickt. Bei der Textuntersuchung und damit auch der Übersetzung wird der Nebensatz in Zeile 79-83 aus Jeauneaus synoptischer Edition ausgelassen, da er nachträglich von $\mathrm{R}^{2}$ eingefügt wurde und die darin angegebene Einschränkung den Text zusätzlich verkompliziert.

$» N$. Saepe mihi cogitanti diligentiusque quantum vires suppetunt inquirenti rerum omni-
»N. So oft ich mir überlege und, soweit die Kräfte reichen, genau untersuche, dass von allen Gegen-

\footnotetext{
${ }^{19}$ Goulven Madec: Jean Scot et ses auteurs, Paris 1988.

${ }^{20}$ G.H. Allard: Indices Generales, Montreal/Paris 1983.

${ }^{21}$ Buch I Zeile I-153 nach der Edition Jeauneaus, Synopsis Versionum, Manuskript R ohne die Einfügungen von $\mathrm{R} i^{2}, \mathrm{~d}$. h. ohne die Zeilen 79-83.

${ }^{22}$ Johannes Scottus Eriugena: Über die Einteilung der Natur, Buch 1-3, übersetzt von Ludwig Noack, Berlin 1870, neu herausgegeben Hamburg 1984.
} 


\section{Einleitung}

um quae vel animo percipi possunt vel intentionem eius superant primam summamque divisionem esse in ea quae sunt et in ea quae non sunt horum omnium generale vocabulum occurrit quod graece $\Phi Y C I C$, latine vero natura vocitatur. An tibi aliter videtur?

A. Immo consentio. Nam et ego, dum ratiocinandi viam ingredior, haec ita fieri reperio.

N. Est igitur natura generale nomen, ut diximus, omnium quae sunt et quae non sunt.

A. Est quidem. Nihil enim cogitationibus nostris potest occurere quod tali vocabulo valeat carere.

N. Quoniam inter nos convenit de hoc vocabulo generale esse, velim dicas divisionis eius per differentias in species rationem; aut, si tibi libet, prius conabor dividere, tuum vero erit recte iudicare.

A. Ingredere quaeso. Impatiens enim sum de hac re veram rationem a te audire volens.

N. Videtur mihi divisio naturae per quattuor differentias quattuor species recipere, quarum prima est in eam quae creat et non creatur, secunda in eam ständen, mögen sie vom Geist erfasst werden können oder dessen Reichweite übersteigen, die erste und höchste Einteilung diejenige ist in die Seienden und Nichtseienden, tritt mir ein allgemeines Wort entgegen, das griechisch physis, lateinisch hingegen natura heißt. Oder scheint es dir anders?

A. Ich stimme zu. Denn auch ich, indem ich mich auf den Weg des Schlussfolgerns begebe, finde das so Vorgebrachte.

N. Es ist also Natur das allgemeine Wort, wie wir sagten, all derer, die sind und die nicht sind.

A. Gewiss ist es so. Nichts nämlich kann unseren Überlegungen begegnen, für das dieses Wort nicht gilt.

N. Da wir uns also einig sind, dass dieses Wort allgemein ist, will ich, dass du den Grund seiner Einteilung durch Differenzen in Arten angibst; oder, wenn es dir beliebt, beginne ich zuerst einzuteilen, dann aber wird es an dir sein, richtig zu urteilen.

A. Ich bitte dich, voranzugehen. Ungeduldig nämlich will ich einen wahren Gedanken über diesen Sachverhalt von dir hören.

N. Mir scheint die Einteilung der Natur durch vier Unterschiede vier Arten anzunehmen, von denen die erste diejenige ist, welche erschafft und nicht erschaffen wird, die zwei- 
quae et creatur et creat, tertia in eam quae creatur et non creat, quarta quae nec creat nec creatur. Harum vero quattuor binae sibi invicem opponuntur. Nam tertia opponitur primae, quarta vero secundae; sed quarta inter impossibilia ponitur, cuius esse est non posse esse. Rectane tibi talis divisio videtur an non?

A. Recte quidem. Sed velim repetas, ut praedictarum formarum oppositio clarius elucescat.

N. Vides, ni fallor, tertiae speciei primae oppositionem. Prima nanque creat et non creatur, cui e contrario opponitur illa quae creatur et non creat; secundae vero quartae, siquidem secunda et creatur et creat, cui universaliter quarta contradicit, quae nec creat neque creatur.

A. Clare video. Sed multum me movet quarta quae a te addita est. Nam de aliis tribus nullo modo haesitare ausim, cum prima, ut arbitror, in causa omnium quae sunt, quae deus est, intelligatur; secunda vero in primordialibus causis; tertia in his te diejenige, welche sowohl erschaffen wird als auch erschafft, die dritte diejenige, welche erschaffen wird und nicht erschafft, die vierte, welche weder erschafft noch erschaffen wird. Von diesen vier aber sind jeweils zwei einander entgegengesetzt. Denn die dritte steht der ersten entgegen, die vierte aber der zweiten; die vierte jedoch, als Unmögliches aufgestellt, hat ein Sein, das nicht sein kann. Scheint dir diese Einteilung richtig oder nicht?

A. Gewiss richtig. Doch will ich, dass du sie wiederholst, damit der Gegensatz der zuvor genannten Arten klar hervortritt.

N. Du siehst, wenn ich nicht irre, die Entgegensetzung der dritten Art zur ersten. Denn die erste schafft und wird nicht erschaffen, welcher konträr diejenige entgegengesetzt ist, die erschaffen ist und nicht erschafft; die (Entgegensetzung) der zweiten aber zur vierten, da die zweite erschaffen wird und erschafft, der allgemein die vierte widerspricht, die weder schafft noch erschaffen wird.

A. Klar sehe ich dies. Aber sehr bewegt mich die vierte Art, die von dir hinzugefügt ist. Denn an den anderen drei wage ich keineswegs $z u$ zweifeln, da die erste, wie ich meine, in der Ursache aller Seienden, welche Gott ist, gedacht wird; die zweite aber in den erstrangigen Ur- 


\section{Einleitung}

quae in generatione temporibusque et locis cognoscuntur. Atque ideo de singulis disputari subtilius necessarium est, ut video.

N. Recte aestimas. Sed quo ordine ratiocinationis via tenenda sit, hoc est de qua specie naturae primo discutiendum, tuo arbitrio committo.

A. Recte mihi videtur ante alias de prima quicquid lux mentium largita fuerit dicere.

N. Ita fiat. Sed prius de summa ac principali omnium, ut diximus, divisione in ea quae sunt et quae non sunt breviter dicedum existimo.

A. Iure existimas. Non enim ex alio primordio ratiocinationem inchoari oportere video, non solum quia prima omnium differentia est, sed quia obscurior caeteris videtur esse et est.

N. Ipsa itaque primordialis omnium discretiva differentia quinque suae interpretationis modos inquirit.

Quorum primus videtur esse ipse per quem ratio suadet omnia quae corporeo sensui vel intelligentiae perceptioni succumbunt sachen; die dritte in denen, die im Werden und zu Zeiten sowie an Orten erkannt werden. Und darum ist es, wie ich sehe, notwendig, sich mit den einzelnen Arten gründlich auseinanderzusetzen.

N. Richtig schätzt du dies ein. Doch in welcher Reihenfolge der Weg des Schlussfolgerns einzuhalten ist, das heißt, über welche Art der Natur zuerst etwas zu erfahren ist, will ich dir überlassen.

A. Richtig scheint mir, vor den anderen über die erste all das zu sagen, was das Licht der Geister gespendet hat.

N. So sei es. Aber zuerst entscheide ich, von der, wie wir sagten, höchsten und allanfänglichen Einteilung in die Seienden und Nichtseienden kurz zu reden.

A. Mit Recht entscheidest du so. Ich sehe nämlich nicht, dass man mit einer anderen vorrangigen Überlegung beginnen darf, nicht allein, weil (diese Einteilung) die erste Differenz aller ist, sondern auch, weil sie undeutlicher als die Übrigen zu sein scheint und ist.

N. Diese vorrangige trennende Unterscheidung aller verlangt fünf Weisen ihrer Auslegung. Deren erste die $\mathrm{zu}$ sein scheint, durch welche der Verstand angibt, alle, die dem körperlichen Sinn oder dem Erfassen des Denkvermögens erliegen, wahr und verständig sseiend< 
vere ac rationabiliter dici esse, ea vero quae per excellentiam suae naturae non solum sensum sed etiam omnem intellectum rationemque fugiunt iure videri non esse, quae non nisi in solo deo et in omnium rerum quae ab eo condita sunt rationibus atque essentiis recte intelliguntur. $\mathrm{Nec}$ immerito. Ipse nanque omnium essentia est, qui solus vere est, ut ait Dionysius Ariopagita: `Esse enim/, inquit, >omnium est super esse divinitas $<$. Gregorius etiam theologus multis rationibus nullam substantiam seu essentiam sive visibilis sive invisibilis creaturae intellectu vel ratione comprehendi posse confirmat.

Nam sicut ipse deus in se ipso ultra omnem creaturam nullo intellectu comprehenditur, ita etiam in secretissimis sinibus creaturae $a b$ eo factae et in eo existentis consideratus incomprehensibilis est. Quicquid autem in omni creatura vel sensu corporeo percipitur seu intellectu consideratur nihil aliud est nisi quoddam accidens incomprehensibili, ut dictum est, unicuique essentiae. Nam aut per qualitatem aut quantitatem aut formam aut materiem aut differentiam quandam aut locum aut tempus cognoscitur non quid zu nennen, jene aber, die durch das Herausragen ihrer Natur nicht allein dem Sinn, sondern auch allem Geist und Verstand entfliehen, zurecht als nichtseiend aufzufassen, die nur in Gott und in den Ideen und essentiae aller von ihm gegründeten Gegenstände rechtmäßig gedacht werden. Und nicht ohne Grund. Denn derjenige ist essentia aller, der allein wahrhaft ist, wie es Dionysius Areopagita sagt: >Das Sein aller nämlich<, sagt er, >ist die überseiende Gottheit<. Und auch Gregor der Theologe bestätigt mit vielen Begründungen, dass keine substantia oder essentia, sei es des sichtbaren oder unsichtbaren Geschöpfes, vom Denken oder Urteilsvermögen begriffen werden kann.

Denn so wie Gott selbst in sich selbst über allem Geschöpf von keinem Geist begriffen wird, so ist er auch in den verborgensten Tiefen des Geschöpfes, das als von ihm gemacht und in ihm existierend betrachtet wird, unbegreiflich. Was auch immer in allem Geschöpf mit dem körperlichen Sinn erfasst oder dem Denken betrachtet wird, ist nichts anderes als ein gewisses Akzidenz jener, wie gesagt wurde, unbegreiflichen einzelnen essentia. Denn durch das Wie und das Wiegroß und die Gestalt und Materie und den Unterschied, wie auch Ort und Zeit, erkennt man nicht, was 


\section{Einleitung}

est, sed quia est. Iste igitur modus primus ac summus est divisionis eorum quae dicuntur esse et non esse, quia ille videtur quodam modo esse, qui in privationibus et substantiarum et accidentium constituitur, nullo modo recipiendus, ut arbitror. Nam quod penitus non est nec esse potest nec prae eminentia suae existentiae intellectum exsuperat, quomodo in rerum divisionibus recipi valeat non video.

Fiat igitur secundus modus, qui in naturarum creatarum ordinibus atque differentiis consideratur. Qui ab excelsissima et circa deum proxime constituta intellectuali virtute inchoans usque ad extremitatem rationalis irrationalisque creaturae descendit, hoc est, ut apertius dicamus, a sublimissimo angelo usque ad extremam rationabilis irrationabilisque animae partem, nutritivam dico et auctivam vitam, quae pars animae ultima est, quoniam corpus nutrit et auget. Ubi mirabili intelligentiae modo unusquisque ordo, cum ipso deorsum versus novissimo, qui est corporum et in quo omnis divisio terminatur, potest dici esse et non esse. Inferioris enim affirmatio superioris est negatio. diese ist, sondern dass sie ist. Diese Weise also ist die erste und höchste der Einteilung derer, die seiend heißen und nichtseiend, da solches, das derart zu sein scheint, dass es in Ermangelung sowohl der Substanz als auch der Akzidenzien besteht, keineswegs aufzunehmen ist, wie ich meine. Denn von dem, was vollständig nicht ist und nicht sein kann und nicht durch Herausragen seines Daseins das Denken übersteigt, sehe ich nicht, auf welche Weise es in die Einteilungen der Gegenstände aufgenommen werden kann.

So wird also die zweite Weise die sein, welche in den Reihen und Differenzen der geschaffenen Naturen betrachtet wird. Sie, die beim herausragendsten und Gott am nächsten gestellten denkenden Vermögen beginnt, steigt bis zum Äußersten des rationalen (und irrationalen) Geschöpfes hinab, das heißt, wie wir klarer sagen, vom erhabensten Engel bis zum äußersten Teil der rationalen (und irrationalen) Seele, dem ernährenden sage ich und wachsenden Leben, welches äußerster Teil der Seele ist, da es den Körper nährt und wachsen lässt. Wo aufgrund einer Weise des wundersamen Denkens jede einzelne Reihe, abwärts gerichtet mitsamt dieser letzten Reihe, die den Körpern zukommt und worin alle Einteilung endet, seiend und nichtseiend hei- 
Itemque inferioris negatio superioris est affirmatio. Eodemque modo superioris affirmatio inferioris est negatio, negatio vero superioris erit affirmatio inferioris. Affirmatio enim hominis negatio est angeli, negatio vero hominis affirmatio est angeli et vicissim. Eademque regula in omnibus caelestibus essentiis usque dum ad supremum omnium perveniatur ordinem observari potest. Ipse vero in suprema sursum negatione terminatur; eius nanque negatio nullam creaturam superiorem se confirmat. Deorsum vero novissimus solummodo superiorem se aut negat aut firmat, quia infra se nil habet quod vel auferat vel constituat, qui ab omnibus superioribus se praeceditur, nullum vero inferiorem se praecedit. Hac item ratione omnis ordo rationalis et intellectualis creaturae esse dicitur et non esse. Est enim, quantum a superioribus vel a se ipso cognoscitur; non est autem, quantum ab inferioribus se comprehendi non sinit.

Tertius modus non incongrue in his quibus huius mundi visibilis plenitudo perficitur et in ßen kann. Die Bejahung nämlich der unteren ist die Verneinung der oberen. Und ebenso ist die Verneinung der unteren die Bejahung der oberen. Auf dieselbe Weise ist die Bejahung der oberen die Verneinung der unteren, die Verneinung der oberen wird die Bejahung der unteren sein. Die Bejahung nämlich des Menschen ist die Verneinung des Engels, die Verneinung aber des Menschen ist die Bejahung des Engels und umgekehrt. Diese Regel kann in allen himmlischen essentiae bis hin zur allerhöchsten aufsteigenden Reihe beobachtet werden. Sie wird aber endet in der höchsten aufwärtigen Verneinung; denn die Verneinung (der höchsten Reihe) bejaht kein Geschöpf mehr über ihr. Abwärts aber bejaht oder verneint die letzte Reihe allein jene über ihr, weil es unter ihr nichts hat, was aufhebt oder bestätigt, da es von allen ihr höheren überragt wird, indes keine niedrigere überragt. Aus diesem Grund sagt man von jeder Reihe des verständigen und denkenden Geschöpfes Sein und Nichtsein aus. Sie ist nämlich, soweit sie von den höheren oder sich selbst erkannt wird; sie ist hingegen nicht, sofern sie der ihr niederen nicht gestattet, sie zu begreifen.

Die dritte Weise wird nicht unpassend in solchen angeschaut, mit denen die Fülle dieser sichtbaren Welt 


\section{Einleitung}

suis causis praecedentibus in secretissimis naturae sinibus. Quicquid enim ipsarum causarum in materia et forma in temporibus et locis per generationem cognoscitur quadam humana consuetudine dicitur esse, quicquid vero adhuc in ipsis naturae sinibus continentur neque in forma vel materia loco vel tempore caeteribus accidentibus apparet eadem praedicta consuetudine dicitur non esse. Huiusmodi exempla late patent et maxime in humana natura. Cum enim deus omnes homines in illo primo atque uno, quem ad imaginem suam fecit, simul constituit, sed non simul in hunc mundum visibilem produxit, certis vero temporibus locisque naturam quam simul condiderat, quadam ut ipse novit serie ad visibilem essentiam adducit, hi qui iam in mundo visibiliter apparuerunt dicuntur esse, qui vero adhuc latent futuri tamen sunt dicuntur non esse. Ad hunc modum pertinet ratio illa quae virtutem seminum considerat sive in animalibus sive arboribus sive in herbis. Virtus enim seminum eo tempore quo in secretis naturae silet, quia nondum apparet, dicitur non esse; dum vero in nascentibus crescentibusque animalibus seu floribus fructibusve li- vollbracht wird und in ihren vorangehenden Ursachen in den Tiefen der verborgensten Natur. Was immer nämlich von den Ursachen (der sichtbaren Fülle) in Materie und Gestalt zu Zeiten und an Orten durch das Werden erkannt wird, nennt man einer menschlichen Gewohnheit folgend seiend, was immer hingegen bis jetzt in den Tiefen ihrer Natur beinhaltet ist und nicht in Gestalt oder Materie, Ort oder Zeit und den übrigen Akzidenzien erscheint, heißt aufgrund der zuvor genannten Gewohnheit nichtseiend. Derartige Beispiele zeigen sich weithin und vor allem in der menschlichen Natur. Da nämlich Gott alle Menschen in jenem ersten und einen, den er nach seinem Bilde schuf, zugleich erstellte, aber nicht gleichzeitig in dieser sichtbaren Welt hervorbrachte, dennoch $\mathrm{zu}$ gewissen Zeiten und an gewissen Orten die Natur [des Menschen] vielmehr zugleich begründete, sie wie in einer ihm bekannten Abfolge in die sichtbare essentia hineinführt, heiBen die, welche schon in der sichtbaren Welt erschienen sind, seiend, welche aber bis jetzt unerkannt in der Zukunft trotzdem sind, heißen nichtseiend. Auf diese Weise bezieht sich der Verstand auf das, was er als Vermögen des Samens betrachtet, sei es in den Lebewesen oder Bäumen oder Pflanzen. Das Vermö- 
gnorum et herbarum apparuerit, dicitur esse.

Quartus modus est qui secundum philosophos non improbabiliter ea solummodo quae solo comprehenduntur intellectu dicit esse; quae vero per generationem materiae distentionibus seu detractionibus locorum quoque spatiis temporumque motibus variantur, colliguntur, solvuntur vere dicuntur non esse, ut sunt omnia corpora quae nasci et corrumpi possunt.

Quintus modus est quem sola in humana natura ratio intuetur, quae cum divinae imaginis dignitatem in qua proprie substetit, peccando deseruit merito esse suum perdidit, et ideo dicitur non esse. Cum vero unigeniti filii dei gratia restaurata ad pristinum suae substantiae statum in qua secundum imaginem dei condita est reducitur, incipit esse, cum in eo qui secundum imaginem dei conditus est, incipit vivere. Ad hunc modum videtur pertinere quod Apostolus dicit: gen des Samens nämlich heißt zu jener Zeit, wo es in der verborgenen Natur ruht, weil es noch nicht erscheint, nichtseiend; wenn es hingegen in den entstehenden und wachsenden Lebewesen oder Blüten und Früchten der Hölzer und Pflanzen erscheinen wird, heißt es seiend.

Eine vierte Weise ist den Philosophen nach nicht unpassend diejenige, in welcher lediglich solche seiend genannt werden, die allein mit dem Denken begriffen werden; was hingegen durch das Werden der Materie in den Ausdehnungen und Zusammenziehungen der Orte wie den Spannen und Bewegungen der Zeiten verändert, zusammengestellt, aufgelöst wird, heißt fürwahr nichtseiend, wie alle Körper, die Entstehen und Vergehen können.

Die fünfte Weise ist eine, die der Verstand lediglich bei der menschlichen Natur erblickt, die, indem sie die Würde des göttlichen Abbilds, in der sie eigentümlich besteht, in der Verfehlung verließ, zurecht auch ihr Sein verlor, und daher nichtseiend heißt. Wenn sie aber durch die wiederherstellende Gnade des eingeborenen göttlichen Sohns in den früheren Stand ihrer substantia, in welcher sie nach dem göttlichen Bilde gegründet ist, zurückgeführt wird, fängt sie an zu sein, da sie in dem, der nach dem göttli- 


\section{Einleitung}

'Et vocat ea quae non sunt tanquam quae sunt $<$, hoc est, eos qui in primo homine perditi sunt et ad quandam non subsistentiam ceciderunt deus pater per fidem in filium suum vocat ut sint, sicut hi qui iam in Christo renati sunt, quanquam et hoc ita intelligi possit et de his quos cotidie deus ex secretis naturae sinibus, in quibus aestimantur non esse, vocat ut appareant visibiliter in forma et materia caeterisque, in quibus occulta apparere possunt, et si quid praeter hos modos indagatior ratio invenire potest. Sed praesentialiter, ut arbitror, de his satis dictum est, si tibi aliter non videtur. chen Bilde gegründet ist, anfängt zu leben. Auf diese Darstellungsweise scheint sich $\mathrm{zu}$ beziehen, was der Apostel sagt: >Und er ruft die Nichtseienden zu sich sowie die Seienden $<$, dies bedeutet, jene, die im ersten Menschen verloren und in ein gewisses Nichtbestehen übergegangen sind, ruft Gott Vater durch den Glauben an seinen Sohn zu sich, damit sie sind, sowie (auch) die, welche schon in Christus wiedergeboren sind; obgleich ich diese Aussage sowohl derart auslegen kann, als auch im Hinblick auf jene, die Gott täglich aus den Tiefen der verborgenen Natur, in denen sie als nichtseiend beurteilt werden, ruft, damit sie sichtbar in Gestalt und Materie und den Übrigen erscheinen, in denen die Verborgenen sich zeigen können, ferner, was außer diesen Weisen aufspürend der Verstand finden kann. Aber zunächst ist, wie ich meine, darüber genug gesagt, wenn es dir nicht anders scheint. 


\section{Interpretation des Periphyseon, ausgehend vom Anfang}

Es handelt sich beim Periphyseon, zu deutsch wörtlich >Über die Naturen $<$ oder >Von Naturen<, der Textgattung nach um einen Dialog 1 Philosophische und Theologische Texte in Dialogform blicken ausgehend von Platon auf eine lange Tradition zurück, die, vor allem durch die Vermittlung Augustins, auch bei den Karolingern verbreitet war. ${ }^{2}$ Jeauneau hat sich ausführlich mit der Frage beschäftigt, wer sich hinter den Buchstaben $\mathrm{N}$ und A verbergen könnte, die sich im Text als Kennzeichnung der Dialogpartner finden. Er geht davon aus, dass die Namen Abkürzugen für die lateinischen Wörter nutritor und alumnus sind, also >Ernährer < und >Zögling < und nennt als wahrscheinliche Vorlage dieser Benennung die Consolationes des Boethius.

Hinsichtlich der Funktion des Dialogs ist beim Periphyseon dreierlei auffällig: erstens gleitet der Dialog in Buch drei und vier in ausufernde Monologe und Quellenzitate N's ab, zweitens ist der Wissensvorsprung von $\mathrm{N}$ gegenüber A unklar, drittens fragt A nicht nach, wo man gerne seiner Nachfrage folgen würde. Stattdessen ist für ihn das von $\mathrm{N}$ Gesagte oft evident und nicht weiter diskussionswürdig. Aus didaktischer Sicht hätte Eriugena sicherlich mehr aus dieser Textgattung machen können. Um das Periphyseon als Versuch ansehen zu können, griechisches Gedankengut in die lateinische Tradition einzuweben, käme es der Interpretation gelegen, wenn A etwa nur die lateinische Tradition kennen würde, die von N erwähnten griechischen Schriften hingegen nicht. Doch dies erfüllt der Dialog nicht.

Aus naheliegenden Gründen sollen im Folgenden die Sprechenden $\mathrm{N}$ und A mit Eriugena gleichgesetzt werden, allerdings im Falle A's

\footnotetext{
${ }^{1}$ Siehe zu diesem griechischen Titel und seinem Ursprung Jeauneaus Einleitung zur Edition von Buch I, p. 4-7.

${ }^{2}$ Prominentester karolingischer Vertreter ist dabei sicherlich Alkuin, dessen dialektische Werke oftmals in Dialogform angelegt sind. Siehe zur Dialogtradition im lateinischen Mittelalter auch Klaus Jacobi: Gespräche lesen - Philosophische Dialoge im Mittelalter, Tübingen 1989, S. 63-99.
} 
nur, wenn N dem Gesagten zustimmt. Dieser eine, darin folgt Eriugena der Dialog-Tradition, weiß mehr, auch wenn unklar bleibt, wieviel mehr, als der andere. Es ist kein Grund ersichtlich, warum die Gleichsetzung von Eriugena mit $\mathrm{N}$ unberechtigt sein sollte, denn weder wird an irgendeiner Stelle eine untragbare Aussage N's von Eriugena kenntlich gemacht, noch eine Frage offen gelassen. Der Dialog hat hier nicht solch eine didaktische und oft schwer durchschaubare Struktur, wie es bei Platon der Fall ist. Er ist denen des Augustinus und Alkuin ähnlicher, weil in ihm wie in diesen ein Dialogpartner stets als der Unwissende und Fragende, der andere als der Belehrende auftritt. Während die Forschung zum Periphyseon zumeist unterschiedslos jede Aussage vorbehaltlos Eriugenas Lehre zuschreibt und so die Dialogebene übergeht, soll dies hier nur im Falle der Aussagen N's geschehen. Es scheint nicht, als habe Eriugena sich als eine dem Dialog übergeordnete Person begriffen, die mehr weiß, als seine stets belehrende Figur $\mathrm{N}^{3}$

Grob zusammengefasst beginnt Eriugena sein Werk mit einer Einteilung: die der Gesamtnatur in vier Arten. Offensichtlich hat er schon von Beginn an für jede der vier Arten ein eigenes Buch geplant, und das fünfte Buch ist wohl die Fortsetzung des vierten Buches, möglicherweise, um dessen geplanten Umfang nicht zu sprengen. Die besagte Natur umfasst dem Anfang zufolge die Gesamtheit aller Gegenstände. Den Umfang aller Gegenstände wiederum sollen die Klassen der Seienden und Nichtseienden ausmachen. Für die Antwort, was die Seienden sind und was die Nichtseienden, gibt der Text fünf Auslegungsmöglichkeiten an. Bevor der Text mit der Untersuchung der ersten Art der Gesamtnatur fortfährt, hat Eriugena einen Einwand A's eingefügt, für dessen Zurückweisung $\mathrm{N}$ einen langen Exkurs über die Theophanie anführt. Der frühere Periphyseon-Editor und -Übersetzer SheldonWilliams hat die These vertreten, dieser Teil des Werkes sei älter als der Rest des Buches. ${ }^{4}$ Doch hält er, dies ist Bedingung für seine These, das Rheimser Manuskript für eine Abschrift des unbekannten Autographen. Jeauneaus Ausweis dieses Manuskriptes als den Autographen kippt somit Sheldon-Williams' These. Wolfgang Gombocz glaubt

\footnotetext{
${ }^{3}$ Siehe zur Dialogstruktur des Periphyseon auch Mischa von Perger: Deliberativa theoria - Eriugenas dialogische Kunst der Erwägung; in: Klaus Jacobi: Gespräche lesen Philosophische Dialoge im Mittelalter, Tübingen 1989, S. 63-99.

${ }^{4}$ Periphyseon I, Dublin 1968, intr., p. 5.
} 
zudem, Buch I sei deutlich früher abgefasst, als die übrigen vier Bücher ${ }^{5}$ Doch auch dafür gibt es weder handschriftliche Hinweise noch zwingende inhaltliche Beweise.

Wie bereits beim ersten Lesen deutlich wird, ist der Text zu Beginn sparsam mit Erläuterungen. So wird der Ausdruck >die Nichtseienden aus dem ersten Satz, der einen Teil der Gesamtnatur bezeichnet, erst einige Seiten später erläutert, so dass zunächst ungewiss bleibt, was damit gemeint sein kann. Ähnlich verhält es sich mit dem Geist (ani$m u s)$, von dem im ersten Satz die Rede ist. Wessen Geist hier gemeint sein muss, wird erst deutlich später ersichtlich ${ }^{6}$

Wenngleich mit der vorliegenden Untersuchung angestrebt werden soll, den Text anhand des jeweils Gegebenen zu erläutern und keine weiteren Prämissen hinzuzunehmen, lassen sich einige Vorgriffe im Text nicht vermeiden, um das Gesagte darzulegen. Manche Fragen indes, die sich bei der Texterläuterung unweigerlich ergeben, sind hintenanzustellen, weil eindeutige Antworten darauf erst später folgen und ein Vorgriff zu ausufernd wäre.

Mögliche Quellenvorlagen werden nur in den folgenden Fällen zur Texterläuterung herangezogen: erstens, wenn die Bedeutung eines Ausdrucks unklar ist, zweitens, wenn Annahmen vorliegen, die im Text nicht zureichend begründet sind, was häufig der Fall sein wird, drittens, um zu klären, ob eine Aussage philosophiegeschichtlich innovativ ist, viertens, wenn Eriugena selbst auf eine Quelle verweist.

Die Untersuchung folgt hinsichtlich der Frage, welche Quellen Eriugena zur Verfügung standen, den Arbeiten Madecs.7/Lediglich in Bezug auf Boethius' Theologische Traktate wird die Position Madecs aus

\footnotetext{
${ }^{5}$ Wolfgang L. Gombocz: Geschichte der Philosophie, Bd. IV, München 1997, S. 373.

${ }^{6}$ Nämlich I, 162-178. Die Interpretation Gangolf Schrimpfs, animus hier als »unseren Geist« aufzufassen, entbehrt nicht nur jeglicher Textgrundlage, sondern wird sich auch als falsch erweisen. Siehe zu Schrimpf: Das Werk des Johannes Scottus Eriugena im Rahmen des Wissenschaftsverständnisses seiner Zeit, Münster 1982, S. 149.

${ }^{7}$ Goulven Madec: Jean Scot et ses auteurs, Paris 1988. Siehe zu Eriugenas Umgang mit den christlichen Autoritäten seiner Zeit auch: J. C. Marler: Use of Authority in the Periphyseon, und Giulio d'Onofri: The Concordia of Augustine and Dionysius: Towards a Hermeneutic of the Disagreement of Patristic Sources in John the Scot's Periphyseon; beide in: Eriugena: East and West-Papers of the Eight International Colloquium of the Society for the Promotion of Eriugenian Studies, Chicago and Notre Dame, 18-20 October 1991, ed. by Bernard Mc Ginn and Willemien Otten, Notre Dame/London 1991, p. 95-113 \& 114-140.
} 
Gründen aufgegeben, die im Zuge der Textinterpretation ersichtlich werden.

\subsection{Der erste Satz: ein metaphysisches Fundament?}

"So oft ich mir überlege und, soweit die Kräfte reichen, genau untersuche, dass von allen Gegenständen, mögen sie vom Geist erfasst werden können oder dessen Reichweite übersteigen, die erste und höchste Einteilung die ist in solche, die sind, und solche, die nicht sind, begegnet mir ein allgemeines Wort, das griechisch physis, lateinisch hingegen natura heißt. Oder scheint es dir anders?«

In diesem Satz sind ein epistemologischer Gesichtspunkt, eine dialektische Grundunterscheidung sowie eine metaphysische Bestimmung auszumachen. Diese drei Dinge sind nacheinander zu untersuchen. Bevor dazu ins Detail gegangen wird, soll der Satz überblickartig dargelegt werden. Zunächst besagt der Hauptsatz, dass jedem Gegenstand (res) die Bezeichnung natura zukommt. Dieser Aussage mangelt es hier noch an Deutlichkeit und sie wird erst im sich daran anschließenden Satz besser ersichtlich: »Es ist also Natur das allgemeine Wort, wie wir sagten, für alle Seienden und Nichtseienden. 48 Nehmen wir den $\mathrm{Ne}-$ bensatz aus dem Anfang hinzu: Weil diese Einteilung in die Seienden und Nichtseienden die höchste aller Gegenstände ist, gibt es keinen Gegenstand, der weder unter die Seienden noch unter die Nichtseienden fällt.

Wie wird `Gegenstand < hier bestimmt? >Gegenstand ‘ ist nicht nur solches, was mit dem Geiste fassbar ist (vel animo percipi potest), sondern auch solches, was das geistige Vermögen übersteigt (intentionem eius superat). Ob dabei vom Geistesvermögen bestimmter Personen oder Personengruppen die Rede ist, oder vom Geistesvermögen allgemein, wird noch zu klären sein. Eines ist dabei klar: Weil hier die vom Geist fassbaren Gegenstände nur einen Teil der Gesamtheit aller Gegenstände ausmachen, wird es in Eriugenas Lehre fassbare und unfassbare Gegenstände geben, und beide werden >Natur $<$ genannt. >Natur $<$ heißt da-

${ }^{8}$ I, 9-10: Est igitur natura generale nomen, ut diximus, omnium quae sunt et quae non sunt. 
her das Fassbare wie auch das Unfassbare, und zwar insofern sie Gegenstände sind. Eine erste Einteilung der Gegenstände ist so eine in fassbare und nicht fassbare.

In welchem Bezug steht dazu die anschließende explizite Einteilung der Gegenstände in die Seienden (ea quae sunt) und die Nichtseienden (ea quae non sunt), die hier im ersten Satz »erste und höchste" genannt wird? Lässt sich der Schluss ziehen, das Fassbare falle unter die Seienden und das Unfassbare unter die Nichtseienden? Aus diesem ersten Satz heraus ergibt sich diese Konsequenz nicht. Nur wenn man im Text weiter blickt, findet sich eine derartige Verbindung in der ersten Auslegung (interpretatio) von Sein und Nichtsein, welche Eriugena erste und höchste Auslegungsweise nennen wird (I,73, iste modus primus ac sum$m u s$ ). Sie lautet: »Deren erste (Auslegung) die zu sein scheint, durch welche der Verstand angibt, alle, die dem körperlichen Sinn oder dem Erfassen des Denkvermögens unterliegen, wahrhaftig und verständig als seiend zu bestimmen, jene aber, die durch das Hervorragen ihrer Natur nicht allein dem Sinn, sondern auch allem Geist und Verstand

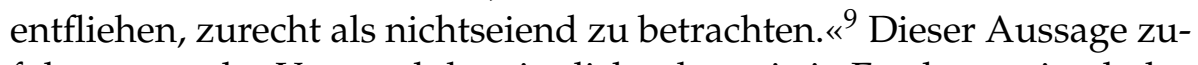
folge nennt der Verstand das sinnlich oder geistig Fassbare seiend, das Unfassbare hingegen nichtseiend. Doch von dieser Zuordnung ist hier noch nicht die Rede.

Lässt sich der Umfang des Untersuchungsgegenstandes näher bestimmen? Wie der erste Satz darlegt, benennt das Wort >Natur < alle Gegenstände, fassbare wie unfassbare. Und der sich daran anschließende, bereits angeführte Satz zeigt, dass ebenso alle seienden wie nichtseienden Gegenstände als >Natur zu bezeichnen sind. Damit ist eine größtmögliche Gesamtheit umfasst. Gibt es etwas, so lässt sich fragen, was nicht mit dem Wort >Natur < benannt wird?

Der erste Satz gibt darüber keine Auskunft. Wieder erst in der eben angeführten ersten Auslegungsweise von Sein und Nichtsein findet sich eine hilfreiche Angabe über den Umfang des Naturbegriffs. Dort heißt es: »Denn von dem, was vollständig nicht ist und nicht sein kann und nicht durch Herausragen seines Daseins den Geist übersteigt, se-

\footnotetext{
${ }^{9}$ I,52-57: Quorum primus videtur esse ipse per quem ratio suadet omnia quae corporeo sensui vel intelligentiae perceptioni succumbunt vere ac rationabiliter dici esse, ea vero quae per excellentiam suae naturae non solum sensum sed etiam omnem intellectum rationemque fugiunt iure videri non esse.
} 
he ich nicht, auf welche Weise es in die Einteilungen der Gegenstände aufgenommen werden soll.< 10

Bezieht man diese Ausssage in die Interpretation des ersten Satzes mit ein, um eine Bestimmung des Untersuchungsgegenstands vorzunehmen, dann ergibt sich folgender Schluss: Wenn das Wort >Natur< für alle Gegenstände gilt, und diesen Gegenständen eine erste Einteilung zukommt, so wird auch nur dasjenige >Natur< zu nennen sein, was »in die Einteilungen der Gegenstände aufzunehmen ist«. Solches, was »vollständig nicht ist « (penitus non est) und »nicht sein kann « (non potest esse) und nicht auf solche Weise existiert, die über das Geistvermögen übersteigt, ist daher nicht >Natur < zu nennen und fällt aus der Untersuchung heraus. Umgekehrt gilt: was >irgendwie ist ` (quoquomodo est) oder >sein kann ( potest esse) oder auf eine den Geist übersteigende Weise existiert, wird in die Untersuchung mitaufgenommen und heißt `Natur`. Dies zum Umfang von `Natur`, sofern man spätere Aussagen auf den ersten Satz hin reflektiert.

Wenn weiter aus dem soeben Gesagten folgt, dass keiner der im ersten Satz genannten Gegenstände vollständig nicht ist, sondern auf irgendeine Weise ist, etwa auf eine, die den Geist übersteigt (intentionem animi superat), so ist jene Frage unzutreffend, die Werner Beierwaltes hinsichtlich des ea quae non sunt aus dem Textanfang stellt: »Wie ist Nicht-Seiendes zu denken und zur Sprache zu bringen? Endet nicht dieser Versuch - nichtssagend - selbst >im Nichts $<?<11$ Sie orientiert sich wohl am platonischen Sophistes, wonach das vollständig Nichtseiende weder fassbar noch aussagbar noch irgendwie denkbar ist: »Siehst du also, wie ganz unmöglich es ist, richtig das Nichtseiende auszusprechen oder etwas davon zu sagen oder es auch nur an und für sich zu denken; sondern wie es etwas Ungedenkliches ist und Unbeschreibliches und Unaussprechliches und Unerklärliches? «12 Da aber im Periphyseon selbst jene Gegenstände, die Eriugena als nichtseiende klassifiziert, irgendwie sind, auf den Geist überragende Weise oder im Sinne

\footnotetext{
${ }^{10}$ I,77-79: Nam quod penitus non est nec esse potest nec prae eminentia suae existentiae intellectum exsuperat, quomodo in rerum divisionibus recipi valeat non video.

${ }^{11}$ Werner Beierwaltes: Denken des Einen, Frankfurt 1985, S. 342.

${ }^{12} 238$ c, Übersetzung nach Schleiermacher. Es bedarf kaum des Hinweises, dass dieses Paradox hinsichtlich des Nichtseienden schon von Parmenides ausgesprochen wird. Wie Platon den eleatischen Fremden im Sophistes berichten lässt, hielt Parmenides es für das Klügste, das Nichtsein aus aller Untersuchung herauszuhalten.
} 
der Möglichkeit, ergibt sich dieses Paradox für den Anfang des Periphyseon nicht. Auf welche Weise Eriugena das Nichtsein verstanden wissen will und inwieweit er es zu einem Gegenstand der Untersuchung macht, ist jetzt zu klären.

\subsubsection{Untersuchung der einzelnen Satzteile}

Das Verfahren Eriugenas

Die Aussagen aus dem ersten Satz werden nicht unmittelbar geäußert, sondern Eriugena lässt $\mathrm{N}$ angeben, auf welchem Weg er zu ihnen gelangt: »So oft ich mir überlege und, soweit die Kräfte reichen, genau untersuche $(. .$.$) « und stellt dann die Folge hinten an: »tritt mir das all-$ gemeine Wort natura entgegen«. Dieses Vorgehen wird A im direkten Anschluss als »Weg des Schlussfolgerns « (via ratiocinandi) bezeichnen, ohne doch genauer zu sagen, wie dieser Weg aussieht. Was hat es damit auf sich?

Die Formulierung »So oft ich mir überlege« (saepe mihi cogitanti) erinnert sprachlich an Ciceros Anfang von De inventione: "Saepe et multum hoc mecum cogitavi, ... 13 Daher nennt Sheldon-Williams den Anfang des Periphyseon "a good classical opening phrase deriving from Cicero $\ll$ und Jeauneau führt alle lateinischen Vertreter vor Eriugena an, die den Anfang aus Ciceros De inventione mehr oder minder übernommen haben 15

Dem Überlegen (cogitare) aus Ciceros Satz ist im Periphyseon das Untersuchen (inquaerere) hinzugefügt. Cogitare und inquaerere sind so die beiden Tätigkeiten, welche die Begegnung mit dem Wort `Natur bedingen.

Auffällig an diesem Textbeginn ist, dass er im Unterschied zur theologischen Tradition keinen göttlichen Beistand anruft, wenngleich es in der Folge vielerlei theologische Fragestellungen behandelt. ${ }^{16}$

\footnotetext{
${ }^{13}$ De inventione I, 1 (ed. C. F. W. Mueller, S. 117).

${ }^{14}$ Periphyseon, edited and translated by Inglis Patrick Sheldon Williams, Book I, p. 222 (notes).

${ }^{15}$ Periphyseon, ed. Edouard Jeauneau; Liber I, p. 3 notes.

${ }^{16}$ So etwa Boethius in Trinitas unus deus ac non tres dii (ed. Stewart \& Rand, London 1918, p. 2): "quantum nostrae mentis igniculum lux divina dignata est«; ähnlich lässt Dionysius Areopagita seine Mystische Theologie mit einem Anruf an das Gött-
} 
Allein das einschränkende quantum in Bezug auf die eigene Kraft (vis) gibt an, dass sich Eriugena über die mangelnde Reichweite des Denk- und Erkenntnisvermögens bewusst ist ${ }^{17}$

Das Fehlen eines Anrufens der göttlichen Macht sowie die verwendete Sprache rücken den Anfang des Periphyseon somit in die Nähe von Ciceros Untersuchungen. Es fällt dem Anfang des Werks nach schwer, in Eriugena jenen Mystiker zu sehen, den einige in ihm erkennen wollen $\sqrt{18}$ Welche Bedeutung dabei dem Nachdenken (cogitatio) und Untersuchen (inquaestio) zukommt, die als bedingende Tätigkeiten für die vorgebrachten Einsichten anzusehen sind, ist jetzt zu zeigen.

\subsubsection{Nachdenken und Erfassen: eine epistemologische Grundunterscheidung}

Wie der erste Satz darlegt, denkt N über alle Gegenstände nach, »mögen sie vom Geist erfasst werden können, oder dessen Reichweite übersteigen«. Wie aber lässt sich ein Nachdenken anstellen über etwas, das die »Reichweite « (intentio) des Geistes übersteigt? Eine solche Form des Nachdenkens und Untersuchens muss es dem Text nach geben. Doch »übersteigen « in welcher Hinsicht? Und was ist mit dieser »Reichweite « gemeint? Es mag Gegenstände geben, von denen der Geist auf keine

liche beginnen: »Übergöttliche Dreiheit, (...) leite uns«, Mystica Theologia, Kap. 1

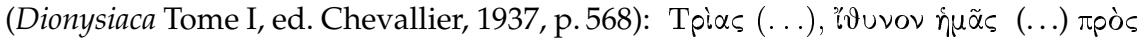

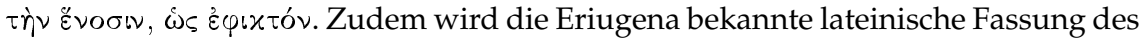
platonischen Timaios mit einem Anruf des Göttlichen eingeleitet: »quanto nos aequius est (...) invocare divinam opem " auf deutsch: "soweit es uns angemessen ist, göttlichen Beistand anzurufen. « Diese lateinische Fassung stammt von Calcidius und ist ediert in: Plato Latinus IV, ed. J.H. Waszink, London und Leiden 1962, p. 20, 8. Zu Eriugenas Kenntnis dieser Übersetzung siehe: Rosamund McKitterick: Knowledge of Plato's Timaeus in the ninth century; in: Haijo Jan Westra: From Athens to Chartres, Leiden 1992, p. 85-95; ebenso G. Madec: Jean Scot et ses auteurs, Paris 1988, p. 32, und Stephen Gersh: Middleplatonism in the latin tradition II, Notre Dame 1986; p. 791-793.

${ }^{17}$ Auch Boethius schränkt später das rationale Vermögen mit solch einem quantum ein, Trinitas unus deus ac non tres dii (ed. Stewart \& Rand, London 1918, p. 2): quantum humanae rationis intuitus ad divinitatis valet celsa conscendere.

${ }^{18}$ Etwa Bernard McGinn: Eriugena Mysticus, in: Giovanni Scoto nel suo tempo, Atti del XXIV Convegno storico internazionale, Todi 11-14 ottobre 1987, S. 235-260. Andererseits halte ich es für überhöht, Eriugena als Aufklärer darzustellen, wie etwa Alfred Gierer: Eriugena, Al-Kindi, Nikolaus von Kues - Protagonisten einer wissenschaftlichen Wende im philosophischen und theologischen Denken, Halle 1999. 
Weise angeben kann, was sie sind, weswegen sie sich so dessen Bestimmungsvermögen entziehen, während sich zugleich das Nachdenken auf sie richtet, indem es feststellt, dass sie zwar existieren, sich aber jeder Bestimmung entziehen. Von solchen Gegenständen wird im Periphyseon viel die Rede sein und daher ist die Annahme naheliegend, auch die vorliegende Aussage beziehe sich darauf.

Wie das Nachdenken zu solchen Gegenständen gelangt, die sich aller Bestimmbarkeit entziehen, jener Bestimmung, was sie sind und wo und wie, legt Eriugena nur an einer einzigen Stelle dar, die sich leider nicht einmal im Periphyseon befindet, sondern im später entstandenen Kommentar zu den himmlischen Hierarchien aus dem Schriftcorpus des Dionysius Areopagita. Da dies der einzige deutliche Hinweis ist, wie wir uns Derartiges zu denken haben, sei diese Passage hier angeführt und auf den Beginn des Periphyseon versuchsweise projiziert.

In diesem Kommentar heißt es in Bezug auf den einzelnen zu betrachtenden Gegenstand, dass der Geist nicht bei der sinnlichen Betrachtung und der Bestimmung desselben stehenbleibe, sondern im Nachdenken weitergehe: »Dieser Stein oder dieses Holz ist für mich Licht; und wenn du fragst, auf welche Weise, so mahnt mich mein Verstand, dir zu antworten, dass mir beim Betrachten dieses oder jenes Steines Vieles begegnet, was meinen Geist erleuchtet. Denn am Betrachteten bemerke ich, dass er als Gutes und Schönes besteht, auf die ihm zuteil werdende eigentümliche Weise, nach Gattung und Art durch den Unterschied von den Gattungen und Arten der übrigen Gegenstände geschieden, seine Einzahl, die ihn zu einem Etwas macht, beinhaltend aus seiner Ordnung nicht heraustritt, und seinen Ort gemäss seiner Eigenschaft der Schwere erstrebt. Sobald ich dieses und dergleichen in diesem Stein wahrnehme, sind sie mein Licht, das heißt, erleuchten mich. Ich fange nämlich an, nachzudenken, von wo ihm dies zukommt, und erkenne, dass es keinem sichtbaren oder unsichtbaren Geschöpf in der Teilhabe auf natürliche Weise gegeben ist, um dann durch den Verstand geleitet über alles hinweg zur Ursache aller zu gelangen, aus welcher heraus der Ort und die Ordnung, Zahl und Art sowie Gattung, das Gute und die Schönheit und das Wesen, sowie das übrige Gegebene und Geschenkte allen zugeteilt werden. $<19$

${ }^{19}$ Expositiones Joannis Scoti super Terarchias sancti Dionysii 1 (PL 122, 129B-C): Lapis iste vel hoc lignum mihi lumen est; et si quaeris, quomodo, ratio me admonet, ut tibi 
Eriugena beschreibt hier zunächst, als was der sinnliche Gegenstand wahrgenommen wird: als ein einzelner, als zu einer Art gehörig, als an einem bestimmten Ort seiend, als zu Boden strebend, als Gutes, Schönes und so fort. Er besteht demnach innerhalb einer festen Ordnung, durch die er als bestimmbarer Gegenstand auftritt. Die Frage nach dem Woher dieser Ordnung regt zum Nachdenken an, jenes cogitare, von dem auch zu Beginn des Periphyseon die Rede ist, und im Zuge dieses Nachdenkens wird, so heißt es hier, der Geist über alles hinweg zur Ursache geleitet. Die Einsicht, dass es eine Verursachung und Aufrechterhaltung dieser allgemeinen Ordnung geben muss, die jenseits der einzelnen Gegenstände anzusiedeln ist, soll dabei der Verstand ( $\mathrm{ra}$ tio) hervorbringen. Und dieser Vorgang ist möglicherweise jener Weg des Nachdenkens (via ratiocinandi), von dem A im Periphyseon im Anschluss sprechen wird. Er leitet das fragende Nachdenken auf die Ursache aller hin, und diese ist für Eriugena Gott.

Der Geist sieht demnach die notwendige Existenz einer Allursache ein, doch zugleich wird er gewahr, dass diese Ursache sich seinem Vermögen des Erfassens und Benennens entzieht. Er kann nicht angeben, was sie ist, noch wo oder wie beschaffen, und hat sich daher auf die Einsicht zu beschränken, dass sie ist. Der notwendigen Einsicht in die

respondeam, hunc vel hunc lapidem consideranti multa mihi occurrunt, quae animum meum illuminant. Eum quippe animadverto subsistere bonum et pulchrum, secundum propriam analogiam esse, genere specieque per differentiam a ceteris rerum generibus et speciebus segregari, numero suo, quo unum aliquid fit, contineri, ordinem suum non excedere, locum suum juxta sui ponderis qualitatem petere. Haec horumque similia dum in hoc lapide cerno, lumina mihi fiunt, hoc est, me illuminant. Cogitare enim incipio, unde ei talia sunt, et intueor, quod nullius creaturae sive visibilis sive invisibilis participatione naturaliter haec insunt, ac mox ratione duce super omnia in causam omnium introducor, ex qua omnibus locus et ordo numerus et species genusque, bonitas et pulchritudo et essentia, ceteraque data et dona distribuuntur. Hervorhebung durch Kapitälchen von mir eingefügt. Dabei ist der Gegenstand nicht das Gute oder Schöne schlechthin, sondern er ist Gutes und Schönes auf die begrenzte, ihm eigentümliche Weise, nämlich indem er daran teilhat, vgl. Periphyseon I,500-502: »Nam sicut nullum bonum naturale est, sed omne quod dicitur bonum esse ex participatione unius summi boni est, (...).«Die Zahl (numerus) fasst Eriugena im Zusammenhang mit Art und Gattung als Anzahl innerhalb einer Art und die Art als Einheit der Anzahlen (numeri): »nil aliud sit species nisi numerorum unitas et nil aliud numerus nisi speciei pluralitas « (I, 1231-1232). Seiner Ansicht nach bedarf der einzelne Gegenstand der Einzahl, um als Einer unter Vielen innerhalb einer Art bestehen zu können. 
Existenz eines solchen Gegenstandes steht demnach das Dilemma gegenüber, nicht angeben zu können, was dieses Existierende ist.

Was hilft das angeführte Zitat aus dem Dionysius-Kommentar für das Verständnis des ersten Satzes? Es zeigt eine Möglichkeit an, wie sich das Nachdenken über solche Gegenstände erklären lässt, welche die Reichweite des Geistes übersteigen. Die Reichweite (intentio) erstreckt sich auf diejenigen Gegenstände, die sich bestimmen lassen hinsichtlich der Frage, was sie sind, wie, wo, in welcher Relation usw. Diejenigen, von denen dies nicht möglich ist, übersteigen folglich die Reichweite des Geistes (animus). Ob es darüberhinaus weitere Erlärungen des im ersten Satz Gesagten gibt, sei dahin gestellt; zumindest findet sich explizit nichts dergleichen im Evre Eriugenas. Hingegen lässt sich die soeben aufgezeigte Interpretation auf das gesamte Periphyseon und nicht nur auf den Anfang anwenden. Etwa, um eine im Text nahe folgende Stelle zu nennen, in der ersten Auslegungsweise von Sein und Nichtsein. Dort heißt es, vom unbegreiflichen Wesen (uncomprehensibilis essentia) werde lediglich erkannt (cognoscitur), dass es ist ${ }^{20}$ Diese Art des Erkennens (cognoscere) fällt daher nicht in den Bereich des Begreifens (comprehendere), sondern mit ihr wird die Existenz desjenigen erkannt, was sich dem Begreifen, und damit der Reichweite des Geistes, entzieht.

Ist dieser Gedanke, man könne in der Schöpfung durch Nachdenken den Schöpfer erkennen, Eriugenas eigene Idee? Nein, denn eine sehr wahrscheinliche Quellenvorlage für die dargestellte Auffassung Eriugenas lässt sich mit Maximus Confessors Ambigua ad Iohannem angeben, wo sie als Leitgedanke auf vielerlei Weise ausgeführt und beleuchtet wird. So etwa in der folgenden prägnanten Aussage:

»Wer in die Größe des Sichtbaren, so diesem Schönheit und Natur zukommt, mit dem Verstand der Sinneswahrnehmung folgend eintritt, ohne die Sinne vollständig ihrem eigenen Lauf zu überlassen, frei vom lenkenden Urteil, und ohne den Verstand von der Einfachheit des Geis-

\footnotetext{
${ }^{20} \mathrm{I}, 68-73$ : Quicquid autem in omni creatura vel sensu corporeo percipitur seu intellectu consideratur nihil aliud est nisi quoddam accidens incomprehensibili, ut dictum est, essentiae. Nam aut per qualitatem aut quantitatem aut formam aut materiem aut differentiam quandam aut locum aut tempus cognoscitur non quid est, sed quia est.

Warum ihm das Wesen als unbegreiflich gilt, wird im Zusammenhang mit der Erläuterung dieser Textstelle noch einmal dargelegt.
} 
tes abzulösen, sodass er einerseits im Sinn die Formen und Gestalten durch die Vermittlung des Verstandesvermögens in vielfältige Begriffe auf natürliche Weise zusammenführt, und andererseits im Verstandesvermögen die aufgrund der Differenz gegebene Verschiedenartigkeit der darin (i.e. Form und Gestalt) vorhandenen mannigfachen Begriffe in einförmiges und einfaches und indifferentes Denken führt, sie gemäß dem zusammenfassend, was man unteilbares und größenloses und einfaches Wissen nennt, der also wird fürwahr durch das Sichtbare und der darin gegebenen Ordnung den Schöpfer desselben und Bewahrer und Begründer, soweit es dem Menschen möglich ist, abbilden und Gott erkennen, nicht einsehend, was er seinem Wesen und seiner Substanz nach ist (denn das ist unmöglich und unerreichbar), sondern dass er an sich das allein Seiende ist. 21

So wie in Eriugenas Kommentar wird hier derjenige, dessen Verstand das Sinnliche mit dem Einungsvermögen des Denkens zusammenführt, zur Einsicht über die notwendige Existenz eines Schöpfers der Ordnung gelangen, ohne doch zu erkennen, was dieser ist. Der Gedanke der Einung der gegebenen sinnlichen Vielfalt, der hierbei eine gewichtige Rolle spielt, war im angeführten Zitat Eriugenas zwar nicht zugegen, doch taucht er spätestens in der Seelenlehre des Iren wieder auf.

Im Grunde ist die bei Maximus angeführte Argumentation bereits den drei kappadokischen Kirchenvätern vertraut, die sie vor allem gegen die stoische Lehre anführen, um zu zeigen, dass die Welt keineswegs mit dem Körperlichen allein erschöpft ist, sondern der Geist zwingend auf das Unkörperliche hingelenkt werde, wenn auch ohne es im selben Maße erkennen zu können, wie das Körperliche. Diese

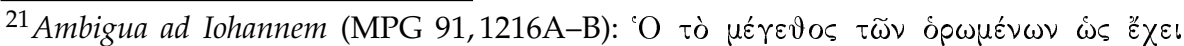

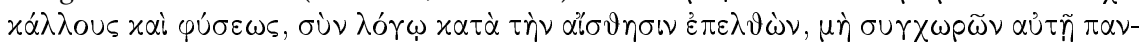

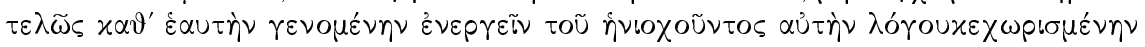

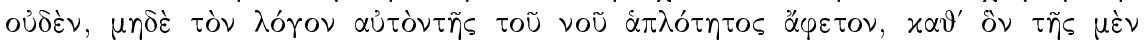

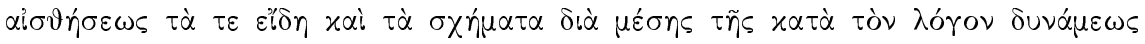

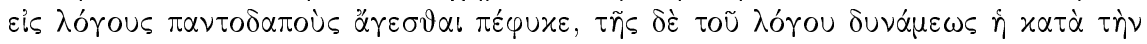

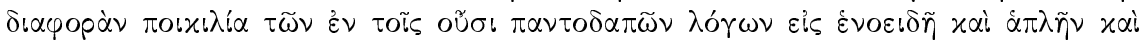

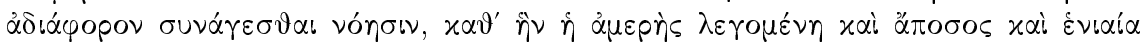

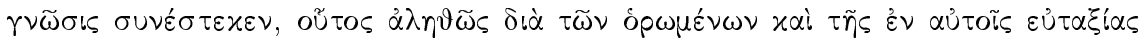

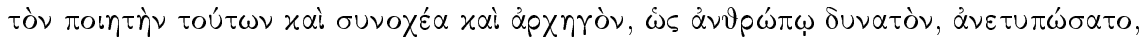

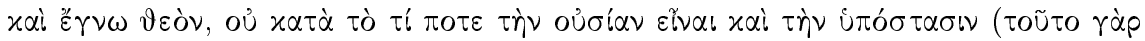

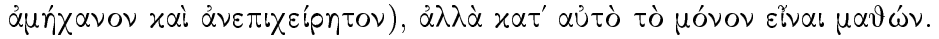


antistoische Begründung wiederum lässt sich zurückverfolgen bis zu Plotin, indes nicht in Verbindung mit dem Argumentationszweck, den die Kirchenväter beabsichtigen: dem Erweis eines Schöpfers und Bewahrers der sinnlichen Welt.22 Basilius von Cäsarea, um einen Kirchvater anzuführen, verweist am Anfang seiner ersten Homilie zum Hexaemeron auf die Notwendigkeit eines Anfangs und einer verborgenen Ordnung dieser sichtbaren Welt. Und diese Argumentation zieht sich durch die gesamte Homilie hindurch ${ }^{23}$ Zwei Gedanken sind es, die Eriugena aus seinen Quellenschriften der griechischen Theologen, allen voran Maximus Confessor, für den vorliegenden Zusammenhang übernimmt:

1. Das Sinnliche hat seine Ordnung nicht aus sich selbst heraus.

2. Dasjenige, was die Ordnung des Sinnlichen bedingt, ist nicht im selben Maße erkennbar, wie das Sinnliche, und auch nicht wie das geistig Fassbare. Dieses die Ordnung Verleihende ist auf eine Weise unbegreiflich (incomprehensibilis), die weder vom sinnlich noch vom geistig Fassbaren gilt. Allein die Erkenntnis, dass es ist, dass es existiert, ist für den Geist möglich, und nicht nur das; sie ist, wie Maximus Confessor Eriugena lehrt, eine notwendige Einsicht der ratio, bei Maximus des logos.

Vor diesem Hintergrund werden jene Gegenstände, die »die Reichweite des Geistes übersteigen ", solches sein, was die Ordnung des Sinnlichen bewirkt, und von denen lediglich einsichtig ist, dass sie sind. Von dieser Einsicht gelenkt, kommt es dem Nachdenken (cogitatio) zu, alle Gegenstände in dem ihm möglichen Maße zu untersuchen (quantum vires suppetunt inquirenti), die fassbaren wie die unfassbaren, die seienden wie die nichtseienden.

Auffälligerweise spricht Figur A im Anschluss von Weg des Schlussfolgerns (ratiocinandi via), auf dem sich sowohl das Fassbare als auch das Unfassbare als Natur ausweist. Dieses Wort ratiocinando taucht in Eriugenas Übersetzung jener Passage auf, aus der das oben genannte Maximus-Zitat stammt. Maximus führt dabei eine Aussage von Gregor von Nazianz an und beginnt seine Erläuterung derselben mit dem

\footnotetext{
${ }^{22}$ Enneaden II, 4; III, 2; V, 9 (1-3).

${ }^{23}$ Sources Chrétiennes 26, p. 86-137.
} 
angeführten Satz. Gregor sagt in diesem Zitat, die Notwendigkeit eines Schöpfers lasse sich erschließen (syllogizomenos). Wahrscheinlich hatte Eriugena bei Abfassung des ersten Satzes auch oder vor allem diese Quellenaussage im Sinn.

Stimmt diese Auslegung, dann ergibt sich für den sich daran anschließenden Satzteil, der die erste Einteilung der Gegenstände angibt, eine weitreichende Konsequenz.

»dass (...) die erste und höchste Einteilung diejenige ist in die Seienden und die Nichtseienden, «

Wenn von jenen Gegenständen, die das Erfassen übersteigen, gewiss ist, dass sie existieren, wie zuvor angeführt, dann kann ihre Bestimmung als $>$ Nichtseiende $<$ nicht deren Existenz verneinen. Entweder also ist die Bestimmung als >die Nichtseienden $<$ keine Verneinung der Existenz, oder es sind mit den Nichtseienden jene Gegenstände gemeint, die mit dem Geist erfasst werden können; denn von diesen wurde noch nicht behauptet, dass sie gewiss existieren. Es könnte demnach sein, dass sie zwar fassbar sind, aber dennoch nicht wirklich existieren. Solch eine platonisierende Auffassung, die vielleicht nicht einmal Plato selbst vertreten hätte, liegt Eriugena indes fern. Zwar hält er die sinnlichen Dinge nicht im selben Maße für seiend wie das wahrhaft seiende göttliche Wesen, doch die Teilhabe derselben an diesem, welche er lehrt, ist mit einer gänzlichen Verneinung der Existenz des Sinnlichen nicht vereinbar. Zudem wäre der Versuch merkwürdig, aus dem gar nicht existierenden Sinnlichen die Existenz eines ihm die Ordnung Verleihenden zu erweisen. Es bleibt demnach nur die erstgenannte Möglichkeit: die Bestimmung >die Nichtseienden bezieht sich auf die unfassbaren Gegenstände und verneint nicht deren Existenz.

Aber was verneint sie stattdessen? Da Eriugena dies nicht für unmittelbar einleuchtend hält, führt er in der Folge, nachdem die Einteilung der Natur dargelegt ist, fünf Weisen (modi) an, auf welche die Bestimmung eines Gegenstandes als ein nichtseiender verstanden werden kann. Doch er sagt nicht, welcher der Aussagemodi jener aus dem ersten Satz ist. Merkwürdigerweise lässt er zudem N diesen Vorschlag der Erläuterung unterbreiten und nicht etwa den Schüler A. Es will scheinen, als habe A mit dem Ausdruck »ea quae non sunt « keinerlei Schwierigkeiten. Für uns aber bleibt seine Bedeutung allein aufgrund 


\subsection{Der erste Satz: ein metaphysisches Fundament?}

des ersten Satzes unklar. Lediglich eine sprachliche Untersuchung des Ausdrucks »ea quae non sunt « kann Einiges erhellen.

\subsubsection{Die Bedeutung des Ausdrucks ea quae sunt}

Dabei ist zunächst auf eine grammatikalische Auffälligkeit hinzuweisen. Das Demonstrativpronomen ea, das in ea quae sunt et ea quae non sunt auftritt, kann sich nicht auf die zuvorgenannten Gegenstände beziehen, denn das lateinische res (Gegenstand) ist feminin, weswegen das dazu passende Pronomen im Akkusativ Plural eas heißen müsste. Hier hingegen steht $e a$, was auf ein Neutrum als Bezugsobjekt hinweist ${ }^{24}$ Dem philologisch geschulten Eriugena ist solch ein Grammatikfehler höchst unwahrscheinlich unterlaufen. Warum ist diese Beobachtung wichtig? Es scheint, als wären ea quae sunt und ea quae non sunt feststehende Ausdrücke, die Eriugena in den Satz einfügt. Das ea wäre dann nicht als Pronomen auf Vorangehendes zu beziehen (was sich als grammatikalisch unmöglich erweist), sondern bestünde als Teil eines Gesamtausdrucks.

Wie ein Blick auf Eriugenas Übersetzungsarbeit zeigt, verwendet er ea quae sunt anstelle eines ganz bestimmten griechischen Ausdrucks, der sich im Lateinischen ungleich schwerer wiedergeben lässt: ta onta. Boethius hat dafür das Wort ens verwendet, allerdings nicht zur Übersetzung von tôn ontôn in der aristotelischen Kategorienschrift herangezogen ${ }^{25}$ Dieses ens ist Eriugena bekannt und er wählt es, wohl auch in Anlehnung zur vorangehenden Übersetzung von Hilduin, zur Übertragung von ta onta im Corpus Dionysiacum. In seiner später angefertigten Übersetzung der Ambigua ad Iohannem des Maximus taucht es hingegen nicht mehr auf; an seine Stelle ist ea quae sunt getreten ${ }^{26}$ Dieser latei-

${ }^{24}$ Zum besseren Verständnis sei der lateinische Satz noch einmal angeführt: Saepe mihi cogitanti diligentiusque quantum vires suppetunt inquirenti rerum omnium quae vel animo percipi possunt vel intentionem eius superant primam summamque divisionem esse in ea quae sunt et in ea quae non sunt (...). Auch divisio ist feminin, weswegen sich das Pronomen ea auch nicht darauf beziehen kann.

${ }^{25}$ Erst Wilhelm von Moerbeke wird für $\tau \widetilde{\omega} \nu$ ǒ $\tau \omega \nu$ in der Kategorienschrift das lateinische entium verwenden. Siehe dazu Aristoteles latinus I, 1-5, ed. Laurentius Minio-Paluello, Bruege/Paris 1961, p. 5 und p. 85. Siehe zum ersten Auftreten von ens auch: Forcellini Tom. II, p. 281.

${ }^{26}$ Siehe etwa CCSG 18, VI 605/606 oder VI 1450; zur griechischen Vorlage entsprechend MPG 91, 1137A und 1180D. 
nische Ausdruck ist ihm dabei aus mindestens einer Quelle geläufig, der Schrift De categoriis Aristotelis, und hat dort eine grundlegende Bedeutung: er bezeichnet die Menge der Seienden aus der aristotelischen Kategorienschrift, eben das ta onta ${ }^{27}$ Somit liegt der Schluss nahe, dass bei ea quae sunt aus dem ersten Satz des Periphyseon an jene Gesamtheit zu denken ist, die der Autor von De categoriis Aristotelis als Aussagebereich der Kategorien auffasst. Er ist zwar nicht zwingend, aber dennoch naheliegend und ohne bessere Alternative. In seinen späteren Übersetzungen verwendet Eriugena den Ausdruck ea quae sunt als Ausdruck für die Klasse aller Seienden, welche die Griechen ta onta nennen. Gerade Maximus Confessor bezeichnet mit diesem Ausdruck häufig die Gesamtheit der von Gott geschaffenen Dinge 28

Der griechische Ausdruck ouk onta, dem auf dieselbe Weise die Verneinung ea quae non sunt entsprechen wird, liegt für Eriugena im Corpus Dionysiacum vor ${ }^{29}$ Daher sind beide Ausdrücke, ea quae sunt und ea quae non sunt, mit grosser Wahrscheinlichkeit an die griechischen Quellen anknüpfende Klassenbegriffe.

Dazu gibt es Weiteres zu sagen. In der ersten Auslegungsweise wird Eriugena essentia, griechisch ousia, den quae non sunt zuweisen. Er weiß aber durch die lateinische Tradition, dass Aristoteles die ousia den Seienden (ea quae sunt) zuorndet ${ }^{30}$ Dabei taucht der lateinische Ausdruck ea quae sunt für das griechische tôn ontôn tatsächlich in der entscheidenden Vermittlerschrift auf, in De categoriis Aristotelis ${ }^{31}$ Eriugena ist sich demnach sicherlich der Abweichung von Aristoteles bewusst. Die Darstellung Martianus Capellas in De nuptiis philologiae et mercurii ist in dieser Hinsicht wenig brauchbar, da dieser nicht von »denen, die sind « spricht, sondern von Aussagen: »Was immer wir benennen, ist entweder $(. .$.$) oder (..) \ll 32$

\footnotetext{
${ }^{27}$ Paraphrasis Themistiana, in: Aristoteles latinus I, 1-5, ed. Minio-Paluello; p. 140, 11.

${ }^{28}$ Siehe etwa MPG 91, 1180B-1181A, wo der Ausdruck $\tau \grave{\alpha}$ ő $\nu \tau \alpha$ genannt wird.

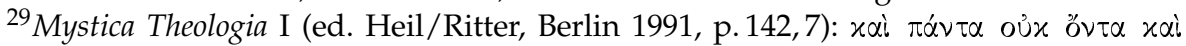
״ $\nu \tau \alpha$, damit ist das angezeigt, was der `Empfänger Timotheus hinter sich lassen soll, um zur göttlichen Einheit zu gelangen.

${ }^{30}$ Kategorien, $2 \mathrm{a} 10$.

${ }^{31}$ Paraphrasis Themistiana, in: Aristoteles latinus I, 1-5, ed. Minio-Paluello; p. 140, 11.

${ }^{32}$ De nuptiis philologiae et mercurii IV, (ed. Willis, 361; p. 117,5-6): Omne quicquid dicimus, aut (...) aut (...).
} 
Es gibt in den bisherigen deutschen Übersetzungen des ersten Satzes die Tendenz, den Ausdruck in ea quae sunt et ea quae non sunt mit: "in das, was ist und das, was nicht ist « wiederzugeben 33 Doch es ist treffender, ea quae sunt als >die Seienden $\mathrm{zu}$ übersetzen, und ea quae non sunt als >die Nichtseienden $<$. Wie sich gegen Ende des ersten Buches zeigt, unterscheidet Eriugena sehr wohl zwischen dem Plural ea quae sunt und dem Singular id quod est ${ }^{34}$ Die passende deutsche Übersetzung von id quod est ist dabei sicherlich >das, was ist<, während für ea quae sunt dann >die Seienden< zu übersetzen ist.

\subsubsection{Zwei Gegenstandsklassen}

Unter diese beiden Klassen der Seienden und der Nichtseienden fällt die zuvor genannte Gesamtheit der Gegenstände. Gleich also, ob ein Gegenstand mit dem Geist fassbar ist oder nicht, er lässt sich einer der beiden Klassen zuordnen. Wie die fünf darauffolgenden Auslegungsweisen von esse und non esse überraschenderweise zeigen werden, ist die Zuordnung veränderlich: ein und derselbe Gegenstand wird je nach Standpunkt einmal unter die Klasse der Seienden fallen, ein anderes Mal unter die der Nichtseienden. Doch davon ist hier noch nicht die Rede 35

${ }^{33}$ Gangolf Schrimpf: Das Werk des Johannes Scottus Eriugena im Rahmen des Wissenschaftsverständnisses seiner Zeit, Münster 1982, S. 149; ders.: Die systematische Bedeutung der beiden logischen Einteilungen (divisiones) zu Beginn von Periphyseon, in: Giovanni Scoto nel suo tempo - Atti del XXIV Convegne storico internazionale Todi, 11-14 ottobre 1987; (publiziert: Spoleto 1989), S.113-151, insbes. S. 125; er greift hier zurück auf die Übersetzung von Ludwig Noack: Über die Einteilung der Natur, Buch 1-3, Berlin 1870, S. 3 (neu herausgegeben Hamburg 1984); von Schrimpf übernimmt dies Dirk Ansorge: Johannes Scottus Eriugena: Wahrheit als Prozess - eine theologische Interpretation von Periphyseon, Innsbruck/Wien 1996, S. 42.

${ }^{34} \mathrm{I}, 2943$ \& 2946.

${ }^{35}$ Ohne Not und Beweisgrundlage interpretiert Schrimpf das esse und non esse als »etwas Bestimmtes zu sein « und »etwas Bestimmtes nicht zu sein«. Nach I, 2941-2943 aber sind sowohl die Seienden wie auch die Nichtseienden etwas, hoc und illum. Zudem hieße dies aufgrund des noch Folgenden, essentia und die rationes dei seien etwas Unbestimmtes. Sie sind lediglich für unseren und den Geist der Engel unbestimmbar, aber darum nicht auch schlechthin Unbestimmtes, und wenn Schrimpf angibt, esse müsse als »etwas zu sein « verstanden werden, wird gerade essentia zu einem nicht-etwas-Seiendem, weil sie in der Folge als non esse klassifiziert ist. Siehe 
Einige haben zu dieser Einteilung Untersuchungen hinsichtlich des Ursprungs angestellt. Gangolf Schrimpf und mit ihm Dirk Ansorge glauben die Vorlage in der Dialektik der Artes-liberales Tradition gefunden zu haben, ausgehend von der Vermutung, es handele sich um die Einteilung einer Gattung in Arten. Gattung wäre dabei das allgemeine Wort >Natur<, die zugehörigen Arten >das, was ist< und >das, was nicht ist $<$, wie es Schrimpf übersetzt. ${ }^{36}$ Giulio d'Onofri stellt zu diesem Ansinnen kritisch fest: »Weil die Begriffe res quae sunt und res quae non sunt keinem gemeinsamen Gattungsgrund entsprechen können, ist es tatsächlich nicht deutlich zu erkennen, welche logischen Unterschiede (differentiae) den zwei Kategorien esse und non-esse entsprechen: So ist es in diesem Fall unmöglich, das Wort natura als logische Gattung zu behandeln, obwohl Eriugena gerade hinsichtlich der esse-non esse Einteilung (...) zweimal behauptet, dass es ein generale nomen ist. ${ }^{37}$

Dem ist Folgendes hinzuzufügen: Noch auf der selben Seite im Text zeigt sich, dass Eriugena von Arten (species) spricht, wenn er eine Differenzierung des Wortes >Natur $<$ als artbildend auffasst ${ }^{38}$ Weshalb er darum im ersten Satz mit der Unterscheidung der Seienden und der Nichtseienden eine artbildende Differenz von >Natur $<$ im Sinn gehabt haben soll, ohne dies kenntlich zu machen, lässt sich nicht schlüssig beantworten. Zwar wird natura in der Tat eine Gattung sein, aber nicht für die Klassen der seienden und nichtseienden Dinge, sondern für die vier Arten der Natur. Sein und Nichtsein sind für Eriugena, dies wird sich noch zeigen, keine Arten, sondern Aussageweisen.

zu Schrimpf: Das Werk des Johannes Scottus Eriugena im Rahmen des Wissenschaftsverständnisses seiner Zeit, Münster 1982, S. 150.

${ }^{36}$ Gangolf Schrimpf: Die systematische Bedeutung der beiden logischen Einteilungen (divisiones) zu Beginn von Periphyseon, in: Giovanni Scoto nel suo tempo - Atti del XXIV Convegne storico internazionale Todi, 11-14 ottobre 1987; (publ.: Spoleto 1989), S. 113-151, insbes. S. 122ff; ebenso Dirk Ansorge: Johannes Scottus Eriugena: Wahrheit als Prozess - eine theologische Interpretation von Periphyseon, Innsbruck/Wien 1996, bes. S. 42-75.

${ }^{37}$ Giulio d'Onofri: Über die Natur der Einteilung. Die dialektische Entfaltung von Eriugenas Denken, in: Begriff und Metapher - Sprachform des Denkens bei Eriugena, Vorträge des VII. internationalen Eriugena-Colloquiums Bad Homburg 26.-29. Juli 1989, herausgegeben von Werner Beierwaltes, Heidelberg 1990, S. 17-38, Zitat S. 27.

${ }^{38} \mathrm{I}, 13-15$ : Quoniam inter nos convenit de hoc vocabulo generale esse, velim dicas divisionis eius per differentias in species rationem. 
Was aus dem ersten Satz folgt, ist lediglich, dass sich das Wort >Natur nicht allein auf alles Seiende erstreckt, sondern auch auf alles Nichtseiende, was immer mit letzterem Ausdruck verneint wird. >Natur heißen demnach alle Gegenstände, seien sie jeweils als Seiendes klassifiziert, oder als Nichtseiendes, seien sie fassbar oder jenseits des Erfassens. Der Naturbegriff ist somit allgemein gebraucht, da er alle Gegenstände bezeichnet, aber die Natur ist nicht Gattung aller Gegenstände, weil die für eine Gattung erforderlichen Arten nicht gegeben sind.

Wenn >Gegenstand ( (res) im ersten Satz aufgrund zweier kontradiktorischer Einteilungen derart allgemein gefasst ist, dass es offensichtlich nichts gibt, was nicht darunter fällt, wird die Frage erlaubt sein, ob auch Gott als ein Gegenstand in diese Einteilung mitaufgenommen wird. So etwa als ein Gegenstand, der das Fassungsvermögen des Geistes übersteigt, denn von Gott ist offensichtlich die Rede, wenn Eriugena im angegebenen Zitat aus dem Dionysius-Kommentar von der Ursache aller spricht, deren notwendige Existenz es einzusehen gilt. Zudem wird, wie sich noch zeigt, die erste und umfassendste Auslegungsweise von esse und non esse Gott unter jene Gegenstände miteinbeziehen, die vom Verstand nichtseiend genannt werden. Dennoch sträubt sich Eriugena gegen die konsequente Auffassung Gottes als eines Gegenstandes, wie eine Aussage gegen Ende des ersten Buches zeigt: »Wenn du fürwahr verkünden wirst: >Jener (i. e. Gott) ist nicht dieses und nicht jenes und nicht irgendetwas<, so wird es dir richtig erscheinen, da er nichts von den Seienden und den Nichtseienden ist. 39 Weil Gott kein Gegenstand ist, fällt er dem zur Folge auch nicht unter die Gesamtheit der Gegenstände, die im ersten Satz >Natur genannt werden, wenngleich im Beginn des Werkes das Gegenteil nahe zu liegen scheint. Die Frage, inwiefern Gott irgendwie als Natur zu fassen ist, und sie zugleich gänzlich überragt, wird im weiteren Textverlauf noch beantwortet und gehört nicht zur Erläuterung des ersten Satzes.

Darüberhinaus ließe sich noch viel über den Wert und theologischen Sinn der Einteilung in die Seienden und Nichtseienden spekulieren, die Eriugena als erste und höchste angibt, doch ist von solchem hier nicht die Rede, und da es keine späteren Aussagen zu dieser Einteilung im

${ }^{39}$ I,2941-2943: Si vero pronuntiaveris: >Nec hoc nec illum nec ullum ille est‘, verax esse videberis, quia nihil horum quae sunt et quae non sunt est. 
Periphyseon gibt, abgesehen von den darauffolgenden fünf Auslegungsweisen von Sein und Nichtsein, ist nicht ersichtlich, warum Eriugena mit dieser Einteilung mehr benannt und bewirkt haben will, als es dem Text nach ersichtlich ist 40

\subsubsection{Exkurs: Ein Vergleich mit Boethius' Naturbestimmung}

Aus philosophiegeschichtlicher Sicht drängt sich ein Vergleich mit jener Naturbestimmung auf, die Boethius zu Beginn seiner Schrift Contra Eutychen angibt. Da dieser Vergleich indes nur begrenzt das Verständnis des ersten Satzes vom Periphyseon fördert, sei er lediglich als Exkurs aufgefasst. Es ist dabei zunächst nicht einmal klar, ob Eriugena diese Abhandlung kannte. Die Forschung hält dies für gewiss, weil sich im fünften Buch des Periphyseon ein Zitat aus demselben findet ${ }^{41}$ Doch lässt sich einerseits, wie dargelegt, für das fünfte Buch nicht angeben, was daraus ein Zusatz einer späteren Hand ist, und sollte dieses angefügte Zitat von Eriugena selbst stammen, so ist andererseits damit nicht geklärt, ob er die Schrift schon bei Abfassung des ersten Buches kannte. Hingegen legt ein Vergleich beider Textanfänge den Schluss nahe, dass ihm die betreffende Schrift des Boethius unbekannt war. Der Anfang von Contra Eutychen lautet wie folgt:

\footnotetext{
${ }^{40}$ So ließe sich etwa eine Parallelstelle aus der Vorrede zur Dionysius-Übersetzung anführen, auf die auch Giulio d'Onofri verweist, und die esse und non esse als höchste Teile der logischen Disziplinen angibt, PL 122, 1036 (Die Aussage bezieht sich dabei auf den Inhalt des Buches zur mystischen Theologie): »Unde et in duas maximas logicae disciplinae dividitur partes, cataphaticam plane et apophaticam, id est esse et non esse. « Doch ein Bezug dieser Aussage auf den ersten Satz fördert das Textverständnis in keiner Weise. Siehe zum Verweis Giulio d'Onofri: Über die Natur der Einteilung. Die dialektische Entfaltung von Eriugenas Denken, in: Begriff und Metapher - Sprachform des Denkens bei Eriugena, Vorträge des VII. internationalen Eriugena-Colloquiums Bad Homburg 26.-29. Juli 1989, herausgegeben von Werner Beierwaltes, Heidelberg 1990, S. 17-38, dort S. 17.

${ }^{41}$ Siehe zu dieser Behauptung etwa Georgi Kapriev: Eodem sensu utentes? - Die Energienlehre der >Griechen $<$ und die causae primordiales Eriugenas, in: Göttinger Theologische Quartalsschrift, Jg. 2000, S. 289-307, bes. S. 304-305; ebenso Giulio d'Onofri: A proposito del »magnificus Boethius «: un' indagine sulla presenza degli »Opuscula sacra « e della »Consolatio« nell' opera eriugeniana, in: Eriugena Studien zu seinen Quellen, Vorträge des III. internationalen Eriugena-Kolloquiums Freiburg 27.-30. August 1979, herausgegeben von Werner Beierwaltes, Heidelberg 1980, S. 189-200; sowie Goulven Madec: Jean Scot et ses auteurs, Paris 1988, p. 31.
} 
»Natur kann man entweder von Körpern allein aussagen oder von Substanzen allein, d.h. von körperlichen und unkörperlichen, oder von allen Dingen, die auf irgendeine Weise seiend heißen. Da man also auf dreierlei Weisen Natur aussagen kann, ist sie zweifellos (auch) auf dreierlei Weisen zu definieren. Wenn es nämlich angeht, von allen Dingen Natur auszusagen, wird man ihr eine solche Definition geben, welche alle Dinge, die sind, einschließen kann. Folglich wird sie von dieser Art sein: >[Natur sind solche Dinge,] die, weil es sie gibt, auf gewisse Weise von der Vernunft erfasst werden können<. In dieser Definition werden sowohl Akzidenzien als auch Substanzen definiert, denn diese können alle von der Vernunft erfasst werden. Es ist jedoch hinzugefügt >auf gewisse Weise<, weil Gott und die Materie nicht in unverminderter und vollkommener Einsicht erkannt werden können, sondern auf irgendeine Weise durch Wegnahme der übrigen Dinge erfasst werden. >Weil sie sind`, fügen wir aber aus dem Grunde hinzu, weil selbst das (Wort) Nichts ein Etwas bezeichnet, jedoch nicht die Natur. Denn es bezeichnet nicht, was etwas ist, sondern vielmehr ein Nicht-sein. Jede Natur aber ist. Wenn es nun angeht, von allen Dingen Natur auszusagen, ist dies die Definition der Natur, die wir oben vorgelegt haben. 42

Zunächst zur Übersetzung. Elsässer gibt das natura est earum rerum so wieder, dass natura zu einem intrinsischen Prädikat wird, zu einer Natur von etwas, während zuvor natura eindeutig als Umfangsbegriff oder, vorsichtig gesagt, als Klasse, als Bezeichnung für eine Gesamtheit

${ }^{42}$ Contra Eutychen I, 1-21 (ed. Stewart/Rand, London 1967, p. 76-78): Natura igitur aut de solis corporibus dici potest aut de solis substantiis, id est corporeis atque incorporeis, aut de omnibus rebus quae quocumque modo esse dicuntur. Cum igitur tribus modis natura dici possit, tribus modis sine dubio definienda est. Nam si de omnibus rebus naturam dici placet, talis definitio dabitur quae res omnes quae sunt possit includere. Erit ergo huiusmodi: `natura est earum rerum, quae cum sint, quoquo modo intellectu capi possunt. $<$ In hac igitur definitione et accidentia et substantia definiuntur; haec enim omnia intellectu capi possunt. Additum vero est >quoquo modo<, quoniam deus et materia integro perfectoque intellectu intellegi non possunt, sed aliquo tamen modo ceterarum rerum privatione capiuntur. Idcirco vero adiunximus >quae cum sint, < quoniam etiam ipsum nihil significat aliquid sed non naturam. Neque enim quod sit aliquid sed potius non esse significat; omnis vero natura est. Et si de omnibus quidem rebus naturam dici placet, haec sit naturae definitio quam superius proposuimus. Übersetzung nach Michael Elsässer: A.M.S. Boethius - Die theologischen Traktate, Hamburg 1988, S.69, der Übersetzungstext innerhalb der eckigen Klammer wurde von mir verändert. 
auftritt. Aus diesem Grund habe ich mich zu einem korrigierenden Eingriff in seine Übersetzung entschieden.

Die Auffassung, »von allen Dingen Natur auszusagen«, die Boethius als erste Möglichkeit angibt, entspricht dabei wohl der aus dem Anfang des Periphyseon.

Nun bezieht sich diese umfassendste von Boethius angegebene Möglichkeit auf alles Seiende, weswegen man Eriugenas Naturbegriff als weiter auffassen könnte, weil er auch das Nichtseiende benennt. Doch hier ist genauer zu vergleichen. Boethius fügt ein quocumque modo ein, also irgendeine Weise, auf die etwas seiend genannt wird. Es wurde für das Periphyseon schon angemerkt, dass auch das Nichtseiende nicht vollständig nicht ist (non penitus non est), sondern irgendwie (quoquomodo est). Boethius, und dies ist der entscheidende Unterschied, verwendet das Wort intellectus auf andere Weise, woraus ein weiterer Umfang des Seienden folgt, als bei Eriugena. Zunächst nämlich gibt Boethius das Seiende als solches an, was mit dem Geist (intellectus) fassbar ist.

Wie Eriugenas bereits angeführte erste Auslegungsweise von Sein und Nichtsein darlegt, nennt auch er nur dasjenige Seiendes, was der Intellekt fassen kann. Boethius fügt dem Erfassen des Intellekts ein quoquo modo an, welches ihn das intellektuelle Begreifen weitreichender auffassen lässt, als es Eriugena tut. Er sagt: »Es ist jedoch hinzuzufügen sauf gewisse Weise`, weil Gott und die Materie nicht in unverminderter und vollkommener Einsicht erkannt werden können, sondern auf irgendeine Weise durch Wegnahme der übrigen Dinge erfasst werden.« Dieses Erfassen mittels der Privation, das sich selbst auf Unbegreifliches wie etwa Gott erstreckt, gilt Eriugena nicht mehr als ein Erfassen des Geistes, wie Aussagen im ersten Buch immer wieder belegen 43 Die intellektuelle Leistung, die Boethius im Sinn hat, entspricht dabei dem, was Eriugena als cogitare und inquaerere an den Anfang des ersten Satzes stellt. Die Auffassung von intellectus und dessen Leistung ist zwischen Boethius und Eriugena also deutlich verschieden. Eriugena

\footnotetext{
${ }^{43}$ Etwa I, 55-57: (...) ea vero quae per excellentiam suae naturae non solum sensum sed etiam omnem intellectum rationemque fugiunt (...) I, 171-173: Causa igitur omnium rerum, quae omnem intellectum exsuperat nulli creatae naturae secundum Apostulum cognitam fieri ratio sinit. Und selbst das Wesen der Dinge entflieht dem Intellekt: I, 61-64: Gregorius etiam theologus multis rationibus nullam substantiam seu essentiam sive visibilis sive invisibilis creaturae intellectu vel ratione comprehendi posse confirmat.
} 
tendiert dazu, das intellektuelle Erfassen auf das einzuschränken, was benannt werden kann, eine Auffassung, die er wohl aus der Schrift De categoriis Aristotelis gewinnt ${ }^{44}$ An eine Benennung ex negativo, wie sie Boethius anführt, denkt er dabei nicht.

Hätte Eriugena diese Passage des Boethius gekannt, wäre es sehr merkwürdig von ihm, die Bestimmung eines Gegenstandes als ein Seiendes von dessen intellektueller Fassbarkeit abhängen zu lassen, ohne das intellektuelle Vermögen in Hinblick auf die abweichende Auffassung des Boethius näher zu bestimmen. Immerhin galt ihm Boethius als bedeutende Autorität. Da sich eine derartige Bestimmung im Periphyseon nicht findet, liegt der Umkehrschluss nahe, Eriugena habe diese Darstellung nicht gekannt.

Festzuhalten ist, dass der Umfang von Boethius' erster Definitionsweise von natura nicht hinter dem Eriugenas zurückbleibt, sondern beide übereinstimmen. Doch da es keine weiteren Übereinstimmungen gibt, hilft Boethius' Naturbegriff bei der Interpretation des Periphyseon nicht weiter.

\subsection{Die Einteilung der Natur}

$» N$. Oder scheint es dir anders?

A. Ich stimme zu. Denn auch ich, indem ich mich auf den Weg des Schlussfolgerns begebe, finde das so Vorgebrachte. $\mathrm{N}$. Es ist also Natur das allgemeine Wort, wie wir sagten, all derer, die sind und die nicht sind.

A. Gewiss ist es so. Nichts nämlich kann unseren Überlegungen begegnen, für das dieses Wort nicht gilt.«

Die dem ersten Satz angefügte Frage ist im Grunde nur von formaler Bedeutung. Die Zustimmung A's ist notwendig für den weiteren Verlauf des Dialogs. Natürlich lässt sich anmerken, N wolle sein Urteil auf eine allgemeine Grundlage stellen und sucht A's Bestätigung. Doch ist dies eben nur in Bezug auf den Dialog und dessen Figuren von Belang, während es zur Darlegung von Eriugenas Lehre nichts beiträgt. Vielmehr würde man sich wünschen, A würde nachfragen, wie genau

${ }^{44}$ Hierauf wird bei der Besprechung der ersten Auslegungsweise von esse noch ausführlich eingegangen, siehe Abschnitt 2.3. 
N zur Einsicht kommt. Doch ihm scheint dieser »Weg des Schlussfolgerns « schon bekannt zu sein 45

A's Antwort ist eine Zustimmung, und zwar ohne jegliche Einschränkung oder Nachfrage. Offensichtlich hält Eriugena das Vorgebrachte für so evident, dass er keine weitere Erläuterung anfügt. Es ist der »Weg des Schlussfolgerns « (ratiocinandi viam), auf dem A vorgibt, das von $\mathrm{N}$ Gesagte wiederzufinden. Wie er genau aussieht, erfahren wir nicht. Da A sagt "auch « (etiam) nimmt er wohl an, denselben Weg einzuschlagen, wie vor ihm N. Und er hält das zuvor Gesagte offensichtlich für eine notwendige Einsicht, die allen zuteil wird, die der ratio folgen. Der Ausdruck ratiocinatio legt dabei die Vermutung nahe, es handle sich um syllogistisches Schließen, wie es die Dialektik der Artes liberales lehrt. Bei Martianus Capella heißt es dazu: »Dies alles, was aus zwei Annahmen und einer Folgerung besteht, heißt bei uns rationcinatio, bei den Griechen syllogismos. Es ist also ratiocinatio das notwendige Hingelangen ausgehend von zwei oder mehr zugestandenen Aussagen zu dem, was (noch) nicht zugestanden wird. 446

Da indes ratiocinatio im Periphyseon weitläufig und allgemein das verstandesmäßige Vorgehen bezeichnet, welches mehr umfasst als das syllogistische Schließen, ist es wenig sinnvoll, aufgrund dieses Ausdrucks das im ersten Satz Gesagte unbedingt als einen Syllogismus auffassen zu wollen. Oftmals steht ratiocinatio im Periphyseon schlicht für >Gedankengang $4{ }^{47}$ Dennoch ist klar, dass das Wort >Natur $<$ dem Geist nicht unmittelbar, sondern über den Weg des Nachdenkens begegnet.

»N. Es ist also Natur das allgemeine Wort, wie wir sagten, aller, die sind und die nicht sind.«

Wenngleich der Ausdruck »wie wir sagten« (ut diximus) es so darstellt, als würde die Aussage des ersten Satzes wiederholt, ist dies nicht ganz zutreffend. Der erste Satz besagt, dass `Natur ein gültiges Wort für alle Gegenstände ist, und dass sich alle Gegenstände in die Klassen der

\footnotetext{
${ }^{45}$ Darauf ist später noch einzugehen, siehe Abschnitt 2.9.

${ }^{46}$ De nuptiis philologiae et mercurii (ed. James Willis), S. 138, 20-23: Hoc totum, quod constat ex duobus sumptis et illatione, ratiocinatio a nobis, a Graecis $\sigma 0 \lambda \lambda o \gamma\llcorner\sigma \mu o ́ \varsigma$ appellatur. Est ergo ratiocinatio ex duobus pluribusve concessis ad id, quod non conceditur, necessaria perventio.

${ }^{47}$ Etwa I, 40 und I, 48.
} 
Seienden und Nichtseienden einteilen lassen. Dieser Satz ist die notwendige Folge daraus: weil sich die Einteilung in die Seienden und Nichtseinden auf alle Gegenstände erstreckt, heißen seiende wie nichtseiende >Natur . Auf diese Aussage will Eriugena offensichtlich mit dem ersten Satz hinaus. Damit umfasst $>$ Natur $<$ die höchste nur mögliche Einteilung der Gegenstände; ein allgemeineres Wort lässt sich nicht mehr denken.

»A. Gewiss ist es so. Nichts nämlich kann unseren Gedanken begegnen, für das dieses Wort nicht gilt.«

Auch hier belässt es A mit einer Zustimmung, anstatt eine Erklärung zu verlangen. Ihm scheint diese Ansicht nicht ungewöhnlich zu sein.

Zumindest dient dieser Satz noch einmal als Bestimmung des Umfangs von >Natur<. Alles nämlich, was den Überlegungen begegnet, fällt unter dieses Wort (mit ,Überlegungen< ist hier der Plural cogitationes von cogitatio, >Überlegung< wiedergegeben). Umgekehrt gibt es nichts, was in das Nachdenken gelangt, für das die Benennung 'Natur< nicht zutreffen würde. Damit heißt >Natur< all das, worüber nachgedacht werden kann. Die Selbstverständlichkeit, mit der Eriugena dies hier vorträgt, mag uns überraschen, aber einen karolingischen Leser vielleicht nicht. Selbst wenn Eriugena die Naturbestimmung des Boethius nicht kannte, war ihm wohl ein derartiger Begriffsumfang irgendwie vertraut. So heißt es etwa bei Alkuin mit derselben Geläufigkeit wie bei Eriugena: »Daher gibt es schließlich unter den Gegenständen der Natur zweierlei, Schöpfer und Geschöpf.<48 Es leuchtet sofort ein, dass auch hier Natur als Gesamtheit aller Gegenstände aufgefasst wird, und zwar unter Einschluss des göttlichen Schöpfers. Dies ist umso bemerkenswerter, als das Wort >Natur ', wenn es zur Umfassung eines Gegenstandsbereichs verwendet wird, in der Antike zumeist nur die Gesamtheit des Werdenden oder Gewordenen bezeichnet. Im Periphyseon, zumindest im ersten Buch, heißt nicht solches >Naturı, was geworden oder im Werden begriffen ist, sondern was dem Überlegen begegnet.

Eine für Eriugena wichtige griechische Quelle, Maximus Confessor, benennt dabei zwar auch die größtmögliche Gesamtheit aller Dinge mit

${ }^{48}$ De fide trinitatis, PL 101,28C: Ideo in rerum naturis haec duo tantum sunt, id est creator, et creaturae. 
Natur, bezieht dieses Wort aber zugleich nur auf die Wirklichkeit alles Gewordenen, griechisch tôn pantôn gegonontôn hypostasin ${ }^{49}$ Zwar hat es aufgrund der ersten, darauffolgenden Einteilung in Schöpfernatur und Geschöpfnatur den Anschein, als benenne Maximus mit >Natur in der Tat alle Gegenstände, auch den Schöpfergott, so wie eben Alkuin und Eriugena, doch steht dieser Annahme die zuvor gemachte Einschränkung »der gewordenen Gegenstände« (tôn gegonontôn) entgegen. (Möglicherweise liegt der Darstellung bei Maximus folgende scharfsinnige Überlegung zu Grunde: Gott ist nicht Schöpfer, denn das widerspräche seiner Unendlichkeit und Vollkommenheit, sondern er wird für die Schöpfung zum Schöpfer. Diese Dualität tritt erst mit der Schöpfung zutage und berührt den anfanglosen und vollkommenen Gott nicht. Daher wird der Schöpfer erst in der Schöpfung und durch sie gedacht und gilt als Substanz, die, indem sie in der Schöpfung offenbart wird, geworden ist.) Und auch der Naturbegriff, wie ihn Beda in De natura rerum (PL 90, 187ff) einsetzt, bezeichnet nur das Gewordene, falls Eriugena diese Schrift gekannt hat.

Indes verliert der außergewöhnliche Naturbegriff, den Eriugena hier im Ansatz vorstellt und der selbst die unbegreifliche Ursache der Dinge zu umfassen scheint, seine Tragweite durch die theologische Einschränkung, die ihm im weiteren Verlauf widerfährt. Da es den theologischen Quellenaussagen zufolge keine Benennung von Gott gibt, wird für Eriugena auch >Natur keine Bezeichnung Gottes sein, mag dieser auch dem Nachdenken als der notwendige Schöpfer des Alls oder als etwas Allüberragendes begegnen. Und so kommt es, dass er die Allursache »übernatürlich« (supernaturalis) nennt, wenngleich die Ursache dem Denken sehr wohl und sogar als Notwendigkeit entgegentritt $[50$ Damit wird der Naturbegriff, wie er zu Anfang des Werkes dargelegt ist, deutlich eingeschränkt. Eine philosophische Bestimmung beugt sich, so könnte man meinen, einem theologischen Grundsatz. Doch dies ist zunächst noch eine vage Behauptung.

${ }^{49}$ MPG 91, 1304.

${ }^{50}$ III, $112-122$. 
2.2.1 Von Natur als generale vocabulum zur Einteilung derselben

»N. Da wir uns also einig sind, dass dieses Wort allgemein ist, will ich, dass du den Gedanken seiner Einteilung durch Differenzen in Arten angibst; oder, wenn es dir beliebt, beginne ich zuerst einzuteilen, dann aber wird es an dir sein, richtig zu urteilen.

A. Ich bitte dich, voranzugehen. Voll Ungeduld nämlich will ich einen wahren Gedanken über diesen Sachverhalt von dir hören.

N. Mir scheint die Einteilung der Natur durch vier Unterschiede vier Arten anzunehmen, deren erste die ist, welche erschafft und nicht erschaffen wird, die zweite die, welche sowohl erschaffen wird, als auch erschafft, die dritte die, welche erschaffen wird und nicht erschafft, die vierte die, welche weder erschafft, noch erschaffen wird. Von diesen vier aber sind jeweils zwei einander entgegengesetzt. Denn die dritte steht der ersten entgegen, die vierte aber der zweiten; jedoch ist die vierte als Unmögliches aufgestellt, da es ihr Sein ist, nicht sein zu können. Scheint dir diese Einteilung richtig oder nicht?

A. Gewiss richtig. Doch will ich, dass du sie wiederholst, damit der Gegensatz der zuvor genannten Arten klar hervortritt.

N. Du siehst, wenn ich nicht irre, die Entgegensetzung der dritten Art zur ersten. Denn die erste schafft und wird nicht erschaffen, welcher konträr diejenige entgegengesetzt ist, die erschaffen ist und nicht erschafft; die (Entgegensetzung) der zweiten aber zur vierten, da die zweite erschaffen wird und erschafft, der allgemein die vierte widerspricht, die weder schafft noch erschaffen wird.

A. Klar sehe ich dies. Aber sehr bewegt mich die vierte Art, die von dir hinzugefügt ist. Denn an den anderen drei wage ich in keiner Weise zu zweifeln, da die erste, wie ich meine, in der Ursache aller Seienden, welche Gott ist, gedacht wird; die zweite aber in den vorrangigen Ursachen; die dritte in denen, die im Werden und zu Zeiten sowie an Orten er- 
kannt werden. Und darum ist es, wie ich sehe, notwendig, sich mit den einzelnen Arten gründlich auseinanderzusetzen.«

Nachdem zwischen $\mathrm{N}$ und A Einigkeit über den Benennungsumfang des Wortes >Natur herrscht (»da wir also übereinkommen«), geht $N$ zur Einteilung desselben über.

Die Formulierung »seiner Einteilung (divisionis eius)« bezieht sich dabei zweifelsfrei auf das Wort >Natur<, wie auch bereits zuvor >Natur mehrfach als Wort (vocabulum) bezeichnet wurde. Doch wie hat man sich die Einteilung eines Wortes in Arten zu denken? Man sollte annehmen, ein Wort lasse sich, wenn überhaupt, nur in Buchstaben oder Silben einteilen oder trennen. Doch Derartiges hat Eriugena offensichtlich nicht im Sinn. Hinzu kommt, dass zumindest nach den Regeln der Dialektik, wie sie Eriugena aus den Artes liberales vertraut sind, jeder Art und artbildenden Differenz notwendig eine Gattung vorangeht. Die Bezeichnung >Gattung (genus) für das Wort >Natur findet sich jedoch weder hier, noch irgendwo sonst im Periphyseon. Lediglich als generale vocabulum ist es im ersten Satz bezeichnet, wonach 'Natur', so scheint es, Name einer Gattung ist. Daher liegt vorerst der Schluss nahe, es gebe eine allgemeinste Gattung, deren Name >Natur ist, welche in der Folge in vier Arten eingeteilt wird. A entscheidet sich für die zweite von $\mathrm{N}$ angegebene Möglichkeit und zieht es vor, ihn mit der Einteilung beginnen zu lassen.

Die Formulierung mihi videtur, welche die Einteilung hier einleitet, kann als klassisches rhetorisches Stilmittel angesehen werden, um für die Untersuchung Grundlegendes einzuleiten. Sie findet sich für Eriugena vermehrt in Ciceros Werken wie De inventione und Topica ${ }^{51}$ und auch Calcidius übersetzt den Beginn der Timaios-Rede auf solche Weise 52

Ebenso klassisch ist die Form der verwendeten Vierteilung. Als Vorlage begegnet sie dem lateinischen Westen etwa in der aristotelischen Kategorienschrift und damit Eriugena über deren Vermittlerquellen 53

\footnotetext{
${ }^{51}$ Siehe De inventione I, II 3; I, IV 5 Topica II, II 6.

${ }^{52} 20,15-16$ (ed. Waszink): Est igitur, ut mihi quidem videtur, in primis dividendum, quid sit quod semper est, carens generatione, quid item quod gignitur nec semper est (...).

${ }^{53}$ Bei Aristoteles 1a19-22.
} 
Auch dort beinhaltet die vierfache Struktur ein >Weder-noch $<$ und ein 'Sowohl-als auch<, wie es im Periphyseon auftritt. Dass diese Struktur im karolingischen Denken einen hohen Stellenwert einnahm, weist Giulio d'Onofri nach ${ }^{54}$ Daraus lässt sich ersehen, dass die viergliedrige Einteilung, die sich hier zu Beginn des Periphyseon findet, bereits in Eriugenas Quellen verbreitetet ist 55

Es wird bei der Aufzählung der einzelnen Arten im Text zunächst nicht erklärt, als was man sich solches zu denken habe, was schafft und nicht erschaffen wird und solches, was sowohl schafft als auch erschaffen wird usw. Klar ist nur, dass alle Möglichkeiten der Verbindung von Bejahung und Verneinung zugegen sind; eine weitere, fünfte Natur ist bereits logisch unmöglich.

Eine Besonderheit ergibt sich für die erste und vierte Art, wenn man sie auf die Kategorienlehre hin reflektiert, wie Eriugena sie darstellen wird. In diesem Fall schließt er die beiden Arten von dem aus, was die aristotelischen Kategorien umfassen: »Aristoteles, der genaueste bei den Griechen, wie sie sagen, Erfinder der Unterscheidung der natürlichen Gegenstände, fasste die unzähligen Verschiedenheiten aller Gegenstände, die nach Gott und von ihm sind in zehn allgemeine Gattungen zusammen, die er zehn Kategorien (das sind Aussageweisen) nannte. Nichts nämlich lässt sich in der Vielheit der erschaffenen

\footnotetext{
${ }^{54}$ Siehe Giulio d'Onofri: Über die Natur der Einteilung. Die dialektische Entfaltung von Eriugenas Denken, in: Begriff und Metapher - Sprachform des Denkens bei Eriugena, Vorträge des VII. internationalen Eriugena-Colloquiums Bad Homburg 26.-29. Juli 1989, herausgegeben von Werner Beierwaltes, Heidelberg 1990, S.1738, insbes. S.34; Eine vierfache Einteilung in Bezug auf die Schöpfung findet sich auch bei dem zeitlich etwas früheren lateinischen Gelehrten Beda eingangs seiner Naturabhandlung De rerum natura (PL 90,187-189). Wie grundlegend für ihn die Vier als Einteilungszahl ist, zeigt der Fortlauf der Abhandlung, wo die vier Elemente sowie die vier Klimazonen der Erde erläutert sind (195A ff).

${ }^{55}$ Manche, so etwa Willemien Otten, machen den Einfluss von Origenes' Vierteilung seines Werks Peri archon auf Eriugena geltend, siehe dies.: The Dialectic of Return in Eriugena's Periphyseon, The Harvard Theological Review 84, 4 (1991), p.399-421, dort p. 400. Doch ist bereits die Einteilung von Peri archon in vier Bücher sowohl eine unpassende als auch nachträgliche, und zwar vor allem darum, weil es keine inhaltliche Viergliederung in diesem Werk gibt. Siehe hierzu vor allem Origène traité des principes, texte établi par M. Harl, G. Doviral, A. Le Boulluec, Paris 1976, intr. p.9.
} 
Dinge und in den verschiedenen Bewegungen der beseelten Wesen auffinden, was nicht in einer dieser Gattungen enthalten sein kann. 466

Wenn also die Kategorien nur enthalten, was »sich in der Vielheit der erschaffenen Dinge« auffinden lässt, dann bleibt solches, was nicht erschaffen ist, also die erste und vierte Art der Natur, außen vor. Damit geht Eriugenas Naturbegriff über die zehn allgemeinsten Gattungen hinaus. Jedem mit dem christlichen Weltbild Vertrauten, in dessen Rahmen es einen Schöpfer und Geschaffenes gibt, ist auch die Ansicht geläufig, es gebe etwas unerschaffenes Schaffendes und etwas unschöpferisches Geschaffenes. Dass beide >Natur zu nennen sind, wirkt zwar ungewöhnlich, ist aber mit Blick auf Alkuin wohl eher opinio communis bei den Karolingern 57

Ungewöhnlicher ist sicher die zweite Art, die sowohl schafft als auch erschaffen wird und eine vierte, die weder schafft noch erschaffen wird. Dabei ist anzugeben, was Eriugena überhaupt unter creare und facere versteht. Den Menschen wird er nicht als >schaffend ‘ auffassen, weil ihm creare das bedeutet, was Gott im Sechstagewerk vollbracht hat oder darüberhinaus noch vollbringt. Alles Hervorbringen von Menschenhand, sei es Geistiges oder Körperliches, oder auch das Werk der Engel, gilt ihm nicht als creare oder facere.

Weiterhin fällt bezüglich der zweiten und dritten der im Periphyseon genannten Arten die Bezeichnung creatur (es wird erschaffen) auf, anstatt creata est (es ist erschaffen) oder creabatur (es wurde erschaffen). Während das Sechstagewerk der biblischen Genesis eine vollendete und abgeschlossene Weltschöpfung lehrt, legt Eriugenas creatur einen noch immer andauernden Prozess nahe. Dies hängt offensichtlich mit der später von ihm geäußerten und noch zu untersuchenden Untrenn-

${ }^{56}$ I, 887-893: Aristoteles, acutissimus apud graecos, ut aiunt, naturalium rerum discretionis repertor, omnium rerum quae post deum sunt et ab eo creata innumerabilis varietates in decem universalibus generibus conclusit, quae decem kategorias (id est praedicamenta) vocavit. Nihil enim in multitudine creatarum rerum variisque animorum motibus inveniri potest quod in aliquo praedictorum generum includi non possit.

Die ungenaue Trennung zwischen Kategorie als Gattung der Gegenstände und Kategorie als Aussagenklasse findet sich oft in der frühmittelalterlichen Philosophie. Erst der Universalienstreit sucht hier Klärung.

${ }^{57}$ Siehe hierzu die ohne nähere Erläuterung vorgebrachte, schon erwähnte Aussage Alkuins in De fide trinitatis, PL 101,28C: Ideo in rerum naturis haec duo tantum sunt, id est creator, et creaturae. 
barkeit von Schaffen und Sein des Schöpfergottes zusammen, wonach es weder ein Sein des Schöpfers gibt, in dem er noch nicht schuf, noch eines geben wird, in welchem er nicht mehr schafft.

»Von diesen vier aber sind jeweils zwei einander entgegengesetzt. Denn die dritte steht der ersten entgegen, die vierte aber der zweiten; jedoch ist die vierte als Unmögliches aufgestellt, da es ihr Sein ist, nicht sein zu können. Scheint dir diese Einteilung richtig oder nicht?«

Da Eriugena hier von einer oppositio spricht, und erst weiter unten von contradictio, übersetze ich hier mit `Gegensatz< und unten mit >Widerspruch $<$, um den sprachlichen Unterschied zu erhalten. Diese einsichtige Gegenüberstellung der vier Arten ist formal betrachtet eigentlich nicht der Erläuterung bedürftig, doch fügt Eriugena die Gegensätze in noch deutlicherer Form an. Merkwürdig ist die Anmerkung zur vierten Art: sie sei »als Unmögliches aufgestellt«, da ihr ein solches Sein zukomme, das nicht sein könne. Näheres zu dieser Unmöglichkeit sagt Eriugena weder hier noch anderswo. Sie ergäbe sich dann zwingend, wenn die Natur als ewig fortdauernder Schöpfungsprozess aufgefasst wird; damit ist solches, was weder schafft noch erschaffen wird, in keiner Weise Teil eines solchen Prozesses. Umgekehrt will man das, worin es keine Schöpfung mehr gibt und kein Geschöpf mehr, unweigerlich als Ende der Welt auffassen, als ruhenden Endpunkt. Doch Eriugena lässt seinen Leser mit dieser Aussage merkwürdig allein und es wird im gesamten Periphyseon keinen Hinweis geben, warum das Sein dieser Art von Natur ein unmögliches ist, oder genauer, wie es hier heißt, »als Unmögliches aufgestellt« ist. Man würde eine Nachfrage von A sehr begrüßen, doch ihm, und damit Eriugena, scheint auch diese Aussage nicht der Erklärung bedürftig.

Hingegen stimmt A der Einteilung N's zu, wenngleich er eine deutlichere Darstellung der Gegensätze verlangt, also gerade desjenigen, was dem heutigen Leser am meisten einleuchtet. Eriugena verwendet hier wie manchesmal im Periphyseon forma gleichbedeutend mit species ${ }^{58}$ Ich übersetze forma, wenn damit offensichtlich >Art ‘, und nicht >Gestalt< bezeichnet ist, daher wie species mit demselben deutschen Wort >Art‘.

${ }^{58}$ Etwa I, 2511; 2519; 2522; II, (33-34), III, 3. 
Es lässt sich für die zwei Gegensätze noch eine Aufstellung aus dem Anfang des zweiten Buchs anfügen, wo die Differenzen und Gleichheiten zwischen den Arten noch einmal angeführt sind: "Die zweite Art ist der ersten gleich, darin, dass sie erschafft, unterscheidet sich von ihr hingegen darin, dass sie erschaffen wird. Denn die erste erschafft und ist nicht erschaffen, die zweite aber erschafft und ist erschaffen. Die dritte bezieht die Gleichheit zur zweiten darin, dass sie erschaffen wird, unterscheidet sich jedoch von ihr darin, dass sie nichts erschafft. Denn die zweite wird erschaffen und schafft, die dritte aber wird erschaffen und schafft nicht. Die dritte ist der vierten darin gleich, dass sie nicht schafft, ungleich aber darin, dass sie erschaffen wird. Die dritte nämlich wird erschaffen und erschafft nicht, die vierte aber ist weder erschaffen noch schafft sie. So ist die vierte der ersten gleich, weil sie nicht erschaffen wird, unterscheidet sich aber von ihr, weil sie nicht schafft. Denn die erste erschafft und wird nicht erschaffen, die vierte aber schafft weder, noch wird sie erschaffen. 459

Diese Aussagenkette ist evident und bedarf keiner weiteren Erklärung. Die vorliegende Aussage aus dem Anfang des Periphyseon indes enthält einen logischen Fehler: Der ersten Art ist sicherlich die dritte konträr entgegengesetzt (e contrario opponitur), doch die Aussage, die zweite Art sei der vierten kontradiktorisch (contradictio) entgegengesetzt, ist unsinnig. Denn in einem kontradiktorischen Gegensatz gibt es kein Drittes, hier aber gibt es ein Drittes und Viertes. Was Eriugena zu dieser Aussage veranlasst, ist nicht ersichtlich. Verstärkt wird der befremdende Eindruck noch durch das Adverb universaliter, wonach die Kontradiktion allumfassend ist (was sie im Grunde ohnehin ist). Dass sich also eins und drei nur konträr entgegenstehen sollen, zwei und vier aber kontradiktorisch, ist nicht nur merkwürdig, sondern logisch unmöglich. Dies ist zudem ein Fehler, den Eriugena ohne ersichtliche Argumentationsnot begeht.

${ }^{59} \mathrm{II},(85-101)$ : Secunda forma primae similis est in eo quod creat, ab ea vero distat in eo quod creatur. Nam prima creat et non creatur, secunda vero et creat et creatur. Tertia secundae similitudinem attrahit eo quod creatur, ab ea tamen differt eo quod nil creat. Nam secunda et creatur et creat, tertia vero creatur et non creat. Tertia quartae similis est in eo quod non creat, dissimilis vero in eo quod creatur. Tertia enim creatur et non creat, quarta vero neque creatur neque creat. Item quarta similis est primae quia non creatur, ab eo vero distat quia non creat. Prima siquidem creat et non creatur, quarta vero neque creat neque creatur. 


\section{Daraufhin sagt A:}

»A. Klar sehe ich dies. Aber sehr bewegt mich die vierte Art, die von dir hinzugefügt ist."

Das ist der erste Einwand, den Eriugena die Figur A vorbringen lässt und durch den diese Dialogfigur die aus antiken Dialogen bekannte Rolle des Fragenden einnimmt. A sieht die Notwendigkeit einer vierten Art nicht ein.

Doch zunächst zur Darstellung der ersten drei Arten, die A ohne Schwierigkeiten bestimmen kann. Eine formal ähnliche Darstellung Augustins diente möglicherweise als Vorlage für diese Zuordnung. Dem Inhalt nach sind bei diesem allerdings Ursachen unterteilt, und nicht die Gesamtnatur. So sagt Augustinus, indem er eine Ordnung der Ursachen (ordo causarum) vorgibt: »Daher ist die Ursache der Dinge, die macht und nicht wird, Gott, anderes hingegen sind die Ursachen, die sowohl machen, als auch (gemacht) werden, wie etwa alle geschaffenen, am meisten rationalen Geister. Die körperlichen Ursachen aber, die mehr (gemacht) werden als machen, sind nicht unter die Wirkursachen zu zählen. ${ }^{60}$ Dies deckt sich mit dem, was im Periphyseon ganz selbstverständlich (nullo modo haesitare ausim, I, 35) den ersten beiden Arten zugewiesen wird: die Allursache, welche Gott ist, und jene rationes, die im Anschluss an Augustins serstrangige Ursachen< (causae primordiales) genannt werden. Und so wie Augustinus die körperlichen Ursachen nicht mehr als causa auffasst, so tritt auch die dritte Art der Natur im Periphyseon als effectus auf. ${ }^{61}$ Gleich ist dabei auch die Differenzierung der Arten mittels Bejahung und Verneinung von Tun und Erleiden des Schaffens, wenngleich die gleichzeitige Verneinung beider bei Augustinus fehlt. Vielleicht sagt A im Hinblick auf diese Vorlage, ihn verwundere die vierte von $\mathrm{N}$ hinzugefügte Art (quae addita est).

${ }^{60}$ De civitate dei V,9, 4 (CCSL XLVII, p. 139, 138-142): Causa itaque rerum, quae facit nec fit, deus est. Aliae vero causae et faciunt et fiunt, sicut sunt omnes creati spiritus, maxime rationales. Corporales autem causae, quae magis fiunt quam faciunt, non sunt inter causas efficientes adnumeranda. Ich habe bei der Übersetzung bewusst den Unterschied von creare bei Eriugena zu facere bei Augustinus kenntlich gemacht. Siehe zu dieser Quellenvorlage Goulven Madec: Jean Scot et ses auteurs, Paris 1988, p. 74 .

${ }^{61}$ Effectus zur Bezeichnung der dritten Art als Gegenpart zu den causae der zweiten tritt im Periphyseon etwa auf III, 227-236. 
Neben der genannten dreigliedrigen Einteilung findet sich bei Augustinus auch eine viergliedrige. So heißt es in dessen Genesis-Kommentar, mit dem Eriugena vertraut war: »Diese Seienden sind auf eine Weise im Wort Gottes, wo sie nicht gemacht, sondern ewig sind; auf eine andere in den Elementen der Welt, wo alle als zugleich gemachte zukünftig sind, wieder anders in den Gegenständen, die durch die zugleich geschaffenen Ursachen nicht schon zugleich, sondern zu ihrer jeweiligen Zeit erschaffen werden (...), und anders in den Samen, in denen gleichsam von Neuem die erstrangigen Ursachen wiederholt werden (...). $\times{ }^{62}$ Diese Darstellung des Augustinus und seine mögliche Vorlage für das Periphyseon könnten die Vermutung nahelegen, als seien erste und vierte Natur bei Eriugena den göttlichen Personen zuzuordnen, die erste Natur, welche schafft und nicht erschaffen wird, als das Wort Gottes (verbum dei), die vierte Natur hingegen als der Vater. Doch solch eine Auslegung führt vielleicht für Eriugena in die Annahme verschiedener göttlicher Naturen, die er als Verfechter der homoousion-Lehre unbedingt vermeiden will 63

Als Ergebnis für alles Weitere bleibt festzuhalten, dass Eriugena den Schöpfer als höchste unerschaffene Ursache, die causae primordiales in-

${ }^{62}$ De genesi ad litteram VI, 10,17 (PL 34, p. 346; der Abschnitt trägt die Überschrift: res variis modis existentes): Sed haec aliter in verbo dei, ubi ista non facta, sed aeterna sunt; aliter in elementis mundi, ubi omnia simul facta futura sunt; aliter in rebus quae secundum causas simul creatas, non iam simul sed suo quaeque tempore creantur (...), aliter in seminibus, in quibus rursus quasi primordiales causae repetuntur (...).

Bei Beda findet sich eine daran offensichtlich angelehnte viergliedrige Einteilung des göttlichen Wirkens (operatio divina), De natura rerum (PL 90,187A-188A): Operatio divina, quae saecula creavit et gubernat, quadriformi ratione distinguitur: primo, quod haec in verbi dei dispensatione non facta, sed aeterna sunt (...); secundo, quod in materia informi pariter elementa mundi facta sint (...); tertio, quod eadem materia, secundum causas simul creatas non iam simul, sed distinctione sex primorum dierum in coelestem terrestemque creaturam formatur; quarto, quod ex euisdem creaturae seminibus et primordialibus causis totius saeculi tempus naturali cursu peragitur.

Doch es deutet nichts darauf hin, dass Eriugena diesen Text Bedas gekannt hat. Auch Goulven Madecs Quellenverzeichnis schweigt dazu, siehe ders.: Jean Scot et ses auteurs, Paris 1988.

${ }^{63}$ Siehe dazu etwa I,621-638, wo die Behauptung verschiedener göttlicher Naturen (diversae naturae) als häretisch zurückgewiesen wird. 
des als die ihm nachfolgenden und geschaffenen Ursachen bestimmt. Der Schöpfer also ist die erste Ursache in der Reihe aller Ursachen.

\subsubsection{Die Gegenstände der einzelnen Naturarten}

Die erste Art der Natur werde in Gott gedacht, so sagt es A, genauer in der Ursache aller. Eine nähere Angabe hierüber erfolgt etwas später im Text: »Die erste Differenz also der zuvor genannten Einteilungen der Natur erscheint uns in jener (Natur), die schafft und nicht erschaffen wird. Und zurecht, weil diese Art der Natur allein von Gott zutreffend ausgesagt wird, der allein allschaffend als anarchos (das heißt ohne Anfang) zu denken ist, weil nur er die höchste Ursache all derer ist, die aus ihm und durch ihn gemacht sind. $\sqrt{64}$

Die Aussage soll offensichtlich eine Begründung für die Spezifizierung der ersten Art angeben, wie das zweimalige quia sprachlich aufzeigt. Nur von Gott gilt die differenzierende Bestimmung sschaffend und nicht erschaffend`, weil er allein als solches rechtmäßig zu denken ist (intelligitur). Und da solch ein Schöpfer Eriugena zufolge notwendiger Teil einer denkbaren Gesamtnatur ist, wird es eine erste Art der Natur geben, die >schafft und nicht erschaffen wird<, ließe sich die Begründung fortsetzten, wenngleich er sie nicht vorbringt. Sie ist insofern zwingend, als es einer Erklärung bedarf, warum das unerschaffene Schaffende als Art der Natur aufzufassen ist; es könnte ja auch über der Natur stehen. Doch eine Antwort auf genau diese Frage liefert uns weder Eriugena, noch, wie schon aufgezeigt, vor ihm Alkuin. Eines ist es, Gott als Schöpfer zu denken, ein anderes hingegen, diesen Schöpfer der Gesamtnatur gedanklich unterzuordnen. Wie wenig geneigt Eriugena letztlich ist, den Schöpfer konsequent als eine Art der Natur aufzufassen, wird sich im zweiten Buch zeigen. Für evident hält er indes die Bestimmung des Schöpfers als unerschaffenes Schaffendes, wie folgende Aussage aus dem ersten Buch zeigt: »N: Du zweifelst nicht, dass

\footnotetext{
${ }^{64}$ I, 402-407: Praedictarum itaque naturae divisionum prima differentia nobis visa est in eam quae creat et non creatur. Nec immerito, quia talis naturae species de deo solo recte praedicatur, qui solus omnia creans ANAPXOC (hoc est sine principio) intelligitur esse, quia principalis causa omnium quae ex ipso et per ipsum facta sunt solus est.

Das solus heißt dabei nicht, dass Gott lediglich dies und nichts anderes ist, sondern dass nur er allein dieses ist.
} 
die göttliche Natur Begründer der Gesamtheit ist? - A: Gehe zum Übrigen. Denn hier zu zögern, ist unrecht. - N: Ebenso als durch nichts erschaffen erfasst du sie durch den Glauben und die verstandesmäßige Einsicht? - A: Nichts sicherer als das. 65 Denn, so ließe sich vielleicht auch hier erläuternd anfügen, was Ursache aller ist, kann nicht selbst wiederum verursacht sein 66

Was die zweite Art betrifft, so geht der Ausdruck für dessen Bezugsgegenstand, causae primordiales (erstrangige Ursachen), anders als es Sheldon-Williams behauptet, auf Augustinus zurück ${ }^{67}$ Dort ist er im Zusammenhang mit der vierten Form der Seienden angeführt: »(...) auf andere Weise in den Samen, in denen gleichsam von Neuem die erstrangigen Ursachen wiederholt werden, durch Dinge geleitet, die von den Ursachen her, die er zuerst gründete, existieren, wie etwa die Pflanze aus der Erde und der Samen aus der Pflanze. 468 Zwar ist damit gesagt, dass die Samenkraft gleichsam eine Wiederholung der erstran-

65I,545-549: Divinam naturam universitatis conditricem esse non dubitas? - Perge ad caetera. Hinc enim haesitare nefas est. - Similiter a nullo creari fide atque intellectu percipis? - Nil eo firmius.

${ }^{66}$ Eriugena trennt nicht immer sorgfältig zwischen anarchos und anaitios, lateinisch sine principio und sine causa, also zwischen anfanglos und ursachenlos (etwa I, 3103), was bei den griechischen Kirchenvätern durchaus differenziert wird. So benennt bei Gregor von Nazianz das Anfanglose den Vater, der Anfang hingegen den Sohn. Der Sohn hat so einen Anfang, ist aber ursachenlos, siehe Oratio 42, 16 (Sources

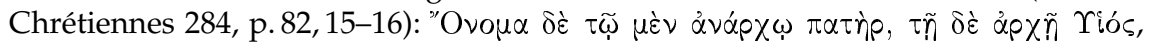
wenngleich der Sohn ursachenlos ist, Oratio 30, 11 (SC 250, p. 246,12-13): $\alpha \lambda \lambda^{\prime}$ '

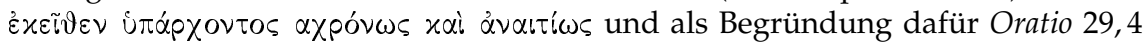

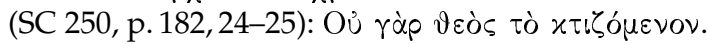

${ }^{67}$ Siehe Goulven Madec: Jean Scot et ses auteurs, Paris 1988, p. 74; er führt als Textstelle bei Augustinus an: De genesi ad litteram VI, 10, 17 (PL 34, 346), Zur Aussage Inglis Patrick Sheldon-Williams' siehe ders.: Periphyseon Book I, Dublin 1968, notes p. 223, Eine Aufstellung zur Begriffsgenese findet sich bei: Robert D. Crouse: Primordiales Causae in Eriugena's Interpretation of Genesis: Sources and Significance; in: Iohannes Scottus Eriugena-the Bible and Hermeneutics, Proceedings of the Ninth International Colloquium of the Society for the Promotion of Eriugenian Studies, held at Leuven and Louvain-la-Neuve, June 7-10, 1995; ed. by Gerd van Riel, Carlos Steel and James McEvoy, Leuven 1996, p. 209-220.

${ }^{68}$ De genesi ad litteram VI, 10, 17 (PL 34, p. 346): aliter in seminibus, in quibus rursus quasi primordiales causae repetuntur, de rebus ductae quae secundum causas, quas primum condidit, existerunt, velut herba ex terra, semen ex herba. Auch Beda gebraucht den Ausdruck causa primordialis zu Beginn von De natura rerum (PL 90,188A). 
gigen Ursachen ist, doch was diese selbst sind und in welcher der vier Formen sie sich wiederfinden (wenn sie sich überhaupt wiederfinden), ist nicht angegeben. Indes sind sie wohl in De civitate dei innerhalb der Ursachenordung als zweites angeführt, weshalb es wahrscheinlich für Eriugena von Anfang an offensichtlich ist, sie als solches denken zu müssen, was sschafft und erschaffen wird 69 Sheldon-Williams hat mit dem Verweis auf Dionysius Areopagita als Quelle für die causae primordiales insofern recht, als die einzelnen Benennungen dieser Ursachen, wie sie sich im Periphyseon finden, auf diesen Theologen zurückgehen. Eriugena macht die göttlichen Namen des Dionysius zu erschaffenen ersten Ursachen (causae primordiales), benennt diese Ursachen aber erst im zweiten Buch: bonum - essentia - vita - ratio - intelligentia - sapientia - virtus - beatitudo - veritas - aeternitas - magnitudo - amor - pax unitas - perfectio ${ }^{70}$ Zur Bestimmung von causa primordialis lassen sich zudem verschiedene Ausdrücke anführen, die im Laufe des Periphyseon gleichbedeutend verwendet werden: etwa principale exemplum, bei den Griechen ПРОТОТУПОСІС genannt, ${ }^{71}$ sowie rationes omnium rerum ${ }^{72}$ principii rerum und divinae voluntates ${ }^{73}$ zudem das griechische $\mathrm{I} \triangle \mathrm{EA} \mathrm{I}^{74}$ Die erstrangigen Ursachen sind demnach Urbilder, göttlicher Wille sowie Gedanken Gottes.

${ }^{69}$ De civitate dei V, 9, 4 (CCSL XLVII, p. 139,138-142): Aliae vero causae et faciunt et fiunt, sicut sunt omnes creati spiritus, maxime rationales.

${ }^{70}$ II, (6475-6485) und III, 133-191, auf Deutsch sinngemäß: das Gute - das Wesen - das Leben - der Verstand - das Denkende - die Weisheit - das Vermögen - die Schönheit - die Wahrheit - die Ewigkeit - die Größe - die Liebe - der Frieden - die Einheit - die Vollendung. In diesem Zusammenhang wirft Georgi Kapriev in: Eodem sensus utentes? - Die Energienlehre der >Griechen` und Eriugenas causae primordiales; in: Göttinger Theologische Quartalsschrift Jg. 2000, S. 289-307, Eriugena vor, er mache aus den Namen Gottes Ursachen und verdingliche sie so. Indes macht Eriugena aus dieser Umformung keinen Hehl (III, 133-135).

${ }^{71}$ I,147-159; Siehe zur Genese dieses Begriffs auch: Robert D. Crouse: Primordiales Causae in Eriugena's Interpretation of Genesis: Sources and Significance; in: Iohannes Scottus Eriugena - the Bible and Hermeneutics, Proceedings of the Ninth International Colloquium of the Society for the Promotion of Eriugenian Studies, held at Leuven and Louvain-la-Neuve, June 7-10, 1995; ed. by Gerd van Riel, Carlos Steel and James McEvoy, Leuven 1996, p. 209-220.

${ }^{72}$ Etwa I, 174-178.

${ }^{73}$ III, 9/17.

${ }^{74}$ II, (342-366); die Vorlage für I $\Delta \mathrm{EA}$ in der Verwendung von exemplum lieferte wohl Calcidius in seinem Kommentar zum platonischen Timaios, siehe Calcidii Commen- 
Eriugena hält den Ausdruck causa primordialis offensichtlich für so geläufig oder selbsterklärend, dass er ihn bei seiner ersten Nennung nicht näher erläutert und es als zweifelsfrei ansieht, die zweite Natur darauf beziehen zu können (nullo modo haesitare ausim). Jegliche nähere Deutung sowie die angeführten Synonyme folgen erst im weiteren Verlauf des Textes. Eine der Erläuterungen verdient dabei eine nähere Betrachtung: Die erstrangigen Ursachen, so sage es die höchste Autorität Paulus, seien »nichts anderes, als was Gott selbst ist « ${ }^{75}$ In Bezug auf die hier dargelegte Einteilung der Natur lässt sich so fragen: weshalb ist eine Art der Natur die göttliche Allursache, während die erstrangigen Ursachen, wenngleich sie doch nichts anderes sind, »außerhalb dessen, was er selbst ist «, einer anderen, zweiten Art zugewiesen werden? Diese Frage ist unbedingt noch zu beantworten.

Die dritte Art schließlich soll sich auf solches beziehen, was »im Werden zu Zeiten und an Orten « erkannt wird (cognoscuntur). Dies ist für Eriugena gleichbedeutend mit der geschaffenen Welt, wie seine spätere Abhandlung über Ort und Zeit offenlegt: »Ort und Zeit nämlich sind zu allem Geschaffenen hinzuzuzählen. Denn in diesen beiden besteht die gesamte jetzige Welt und kann ohne sie nicht sein, weswegen sie bei den Griechen hôn aneu to pan (das heißt ohne die das Gesamte nicht sein kann) heißen. 476

tarius, ed. Waszink, p.306,4-7: (...) porro ideae sunt exempla naturalium rerum. Eine weitere Quelle dafür ist Macrobius, In somnium scipionis I, 2, 14.

${ }^{75}$ I, 164-167: Apostolo resistere videbimur, qui super omne quod dicitur et intelligitur ipsum deum et causas omnium in eo, quae non aliud sunt praeter quod ipse est, affirmat esse. Das praeter wird in der Regel auf eine Verneinung folgend mit sals`(also >nichts anderes als`) übersetzt, siehe Georges Handwörterbuch, Bd. II, Hannover 1962, S.1891. Ungeachtet dessen möchte man es möglicherweise auch als >außerhalb< auffassen. Und auch diese Lesart ist zulässig, denn insofern etwas wahrhaft ist, ist es nur in Gott, nicht aber außerhalb von ihm. Eriugena bezieht sich mit dieser Aussage auf Rom. 11,34: »Quis enim intellectum domini cognovit? - Pax Christi quae exsuperat omnem intellectum «, und fasst unter den intellectus domini auch die causae primordiales, siehe dazu I, 162-178.

${ }^{76}$ I, 1131-1135: Locus siquidem et tempus inter omnia quae creata sunt computantur. In his nanque duobus totus mundus qui nunc est consistit et sine quibus esse non potest, ideoque a graecis dicuntur $\Omega N$ ANEY TO ПAN (id est sine universitas esse non valet). Das geschaffene All ist dabei nicht unbedingt mit der körperlichen Gesamtheit gleichzusetzen. So weist Eriugena etwa auch aller Wissenschaft einen Ort zu, nämlich die Seele (I, 1396-1419). 
Mit diesen Erläuterungen ist zunächst alles Wichtige zum Verständnis der ersten drei Arten gesagt. Der Zuweisung A's wird N zustimmen und sie fortan als Grundlage voraussetzen. Für die vierte Art vermag A keinen Gegenstand anzugeben, weswegen ihm auch deren Notwendigkeit nicht einleuchtet. Eigentlich ist mit dem Schöpfer und der Gesamtheit der Schöpfung alles Denkbare angegeben. Welcher Gegenstand der vierten Art der Natur zuzuordnen ist, jene, die weder schafft noch erschaffen wird, bleibt hier ungeklärt. Wie die späteren Bücher zeigen, wird auch sie auf Gott bezogen, und zwar als Ziel und Ende der Schöpfung ${ }^{77}$ Dabei ist es verlockend, in Anlehnung an die Kirchenväter Christus als den Anfang zu denken und somit als unerschaffenes Schaffendes, das nichtschaffende Unerschaffene hingegen als den Vater, der in sich selbst ruht ${ }^{78}$ Doch diese Auffassung lässt sich nirgendwo im Periphyseon ausmachen. Vielmehr sind erste und vierte Natur insofern ein und dasselbe, als Anfangs- und Zielursache nicht Verschiedenes, sondern eines sind. Diesen Gedanken übernimmt Eriugena von Maximus Confessor, bei dem es heißt:

»Alles durch eine Ursache Seiende und durch eine Ursache Bewegte hat einerseits vollständig eine Anfangsursache seines Seins, wodurch es ist und woraus es ins Sein geführt wurde, und andererseits eine Zielursache für seine Bewegung, durch die es bewegt wird und zu der es hinstrebt. (...) Wenn so das Ziel des Bewegten die Ursache ist, durch die es bewegt wird, dann ist sie vollständig dasselbe wie die Ursache, durch die dieses ensteht und ist. Eine Ursache also ist von allem irgendwie Seienden und Bewegten der Natur nach Anfang und Ziel, durch die alles Sein und Bewegte bewegt wird. ${ }^{79}$ Eriugena führt diese Lehre

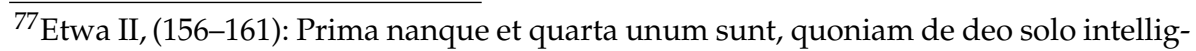
untur. Est enim principium omnium quae a se condita sunt et finis omnium quae eum appetunt ut in eo aeternaliter immutabiliterque quiescant.

${ }^{78}$ Siehe stellvertretend für die Patristiker Gregor von Nazianz, wo das Anfanglose den Vater, der Anfang hingegen den Sohn bezeichnet, Oratio 42, 16 (Sources Chrétiennes

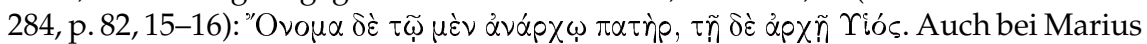
Victorinus findet sich diese Zuordnung in Ad Candidum 13-20 (Sources Chrétiennes 68, p. 148-158).

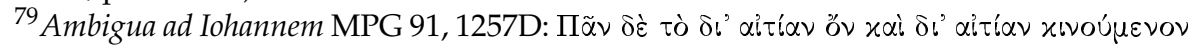

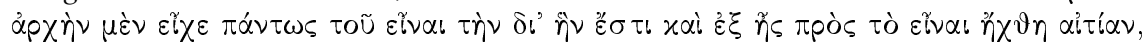

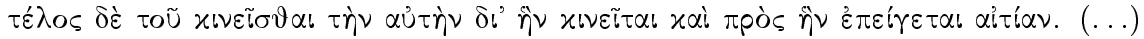

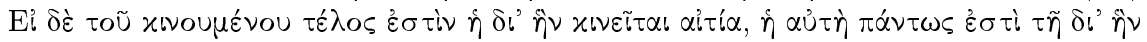

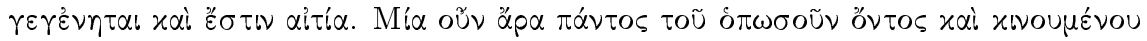


des Maximus gegen Ende des ersten Buches an und fügt hinzu: »(...) denn von allem natürlich Bewegten ist Anfang und Ziel eines; dieses nämlich ist Gott, von dem aus und durch den und zu dem hin alles bewegt wird. ${ }^{80}$ In einem Schöpfungsprozess sind beide unterscheidbar, weil die Schöpfung notwendig einen Anfang und ein Ziel hat. Und daher heißt es im selben Zusammenhang: »Aber weil eines der Geist des Anfangs ist und eines der Geist des Ziels, so heißt gleichsam von diesen beiden eines wie das andere >Geist`, wenn sie auf ein Anfang und Ziel von allem hin gedacht werden, so etwa, wenn jemand sagte >vom Geist des Anfangs hin zum Geist des Ziels in Gott<..81 Nicht also allein das schöpferische Wort Gottes (verbum dei) ist Geist, sondern auch das Ende, in dem alles zur Ruhe kommt. Eine Differenzierung zwischen Vater und Sohn ist demnach hier nicht auszumachen, und sie käme wohl auch, dies wurde bereits gesagt, für Eriugena einem häretischen Denken gleich, das verschiedene Naturen in Gott behauptet. Wie aber ist es überhaupt möglich, von zwei Naturen zu sprechen, einer ersten und vierten, wenn beide Gott zuzuordnen sind und dieser doch nur als eine Natur besteht: ${ }^{82}$ Die Differenzierung geschieht, so lässt sich antworten, nur in Hinblick auf die Schöpfung, nicht aber in Hinblick auf Gott selbst, da Gott nur für die Schöpfung als Anfang und Ziel auftritt, während er gleichbleibend als derselbe ohne Anfang und Ende besteht. Doch diese Antwort ist noch Spekulation und muss erst erwiesen werden.

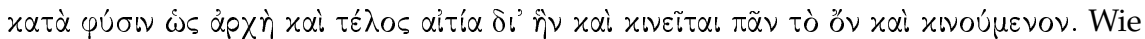
Jeauneau aufzeigt, ist die Nähe der Aussagen zu Formulierungen aus der aristotelischen Physik unübersehbar, Edouard Jeauneau: Jean l'Erigène et les Ambigua ad Iohannem de Maxime le Confesseur, in: Maximus Confessor, Actes du Symposium sur Maxime le Confesseur, Fribourg, 2-5 septembre 1980, édités par Felix Heinzer et Christoph Schönborn 1982, p. 343-364.

${ }^{80}$ I, 3159-3161: (...) dum omnium quae naturaliter moventur principium et finis unum sit; est enim deus, a quo et per quem et ad quem moventur omnia.

${ }^{81}$ I, 3161-3165: Sed quia alius intellectus est principii et alius intellectus finis, ideoque quasi alterum et alterum ipsi duo intellectus dicuntur, dum circa unum omnium principium et finem versantur; verbi gratia, veluti si quis dixerit ab intellectu principii ad intellectum finis in deo. Was dabei der Ausdruck in deo eigentlich genau meint, ist noch zu untersuchen.

${ }^{82}$ Siehe zu Eriugenas Auffassung des homoousion als una natura I, 621-634. 
Dies ist alles, was im ersten Buch über die Einteilung der Natur gesagt wird. Ihr Sinn und Zweck für die weitere Abhandlung bleiben damit zunächst unklar.

\subsubsection{Der Untersuchungsplan des Werks}

»N. Richtig schätzt du dies ein. Doch in welcher Reihenfolge der Weg des Schließens einzuhalten ist, das heißt, über welche Art der Natur zuerst etwas zu erfahren ist, will ich dir überlassen.

A. Richtig scheint mir, vor den anderen über die erste all das zu sagen, was das Licht der Geister gespendet hat.

N. So sei es. Aber zuerst entscheide ich, von der, wie wir sagten, höchsten und allanfänglichen Einteilung in die Seienden und Nichtseienden kurz zu reden.

A. Mit Recht entscheidest du so. Ich sehe nämlich nicht, dass man aus einer anderen vorrangigen Überlegung heraus beginnen darf, nicht allein, weil (diese Einteilung) die erste Differenz aller ist, sondern auch, weil sie undeutlicher als die Übrigen zu sein scheint und ist.«

Dieser Abschnitt lässt sich recht zügig erläutern. Er bestimmt, mit welcher Art der Natur die Untersuchung beginnen soll und weist auf die Notwendigkeit hin, Näheres über die Einteilung aus dem ersten Satz vorauszuschicken; dies ist die zu Anfang genannte Einteilung aller Gegenstände in Seiendes und Nichtseiendes (divisione in ea quae sunt et quae non sunt). Hilfreich wäre es in diesem Zusammenhang, etwas über das Verhältnis dieser Einteilung zur anschließenden viergliedrigen Einteilung der Natur zu erfahren, doch Eriugena unternimmt nichts dergleichen, wenngleich er hier vorgibt, die Einteilung in die Seienden und Nichtseienden sei die »höchste und allanfängliche« (summa ac principali omnium). Diese Behauptung wird später ebenso von der Zweiteilung der Natur ausgesagt, wenn es von dieser heißt: »Die erste also und vorzüglichste Einteilung ist die der gesamten Natur in das die gegründete 
Gesamtheit Schaffende und in diese gegründetete Gesamtheit.<83 Welches also die erste und höchste Einteilung ist, bleibt unklar.

\section{Das Licht der Geister als Bedingung für Erkenntnis}

Eine weitere Bemerkung verlangt dieser Abschnitt noch. A entscheidet sich dafür, die Untersuchung mit der ersten Art der Natur zu beginnen, und zwar im Hinblick auf das, "was das Licht der Geister gespendet hat«. Was bezeichnet der Ausdruck »Licht der Geister« (lux mentium)? Wie die Indizes von G.H. Allard zum Periphyseon zeigen, tritt er im gesamten Werk fünfmal auf 84 Im zweiten Buch heißt es, man könne von der vierten wie der ersten Natur nur in dem Masse sprechen, »insoweit es das Licht der Geister schenken wird « ${ }^{85}$ Selbst das Schlussfolgern ( $r a-$ tiocinatio) vermöge dabei nicht zu leisten, was dieses Licht ermöglicht: "(...) und bis nicht dieses Licht der Geister sich uns enthüllen wird, reicht das Bestreben unseres Schlussfolgerns nicht aus, um es zu enthüllen. 86 Dieses Licht eröffnet dem menschlichen Erkennen einen $\mathrm{Zu}$ gang zum Verborgenen: »Es wird das Licht der Geister da sein, welches das Verborgene der Dunkelheiten erleuchtet, das Verschlossene öffnet, das Unbekannte enthüllt, das Entflohene zurückruft, das Unbeschreibliche beschreibt, das Unbestimmte bestimmt, den Zweifel zu einer Art gesichertem Satz hinführt. 87 Es liegt daher nahe, dass Eriugena mit dem Ausdruck »Licht der Geister « das Wort Gottes bezeichnet, welches allein diese Wirkungsmächtigkeit der Offenbarung innehat. Etwas verkürzt ist daher die schlichte Interpretation von Sheldon-Williams des lux mentium als Gott 88

\footnotetext{
${ }^{83}$ III,79-81: Prima siquidem et maxima divisio est universalis naturae in creatricem universitatis conditae et creatam in ipsa condita universitate.

${ }^{84}$ G. H. Allard: Periphyseon, Indices Generales, Montreal 1983, p. 316; der Ausdruck mentium findet sich sechsmal im Periphyseon, allerdings nur fünfmal in Verbindung mit lux.

${ }^{85}$ II, (190-191): quantum lux mentium donaverit.

${ }^{86} \mathrm{II},(5388-5391):(.$.$) et nisi ipsa lux mentium nobis revelaverit, nostrae ratiocinationis$ studium ad eam revelandam nil proficiet.

${ }^{87}$ V, 2894-2897: Aderit lux mentium, quae illuminat abscondita tenebrarum, aperit obstrusa, incognita revelat, fugitiva revocat, incircumscripta circumscribit, indiffinita diffinit, ambigua ad certam quodammodo sententiam adducit.

${ }^{88}$ Periphyseon I, Dublin 1968, p. 223, note 12.
} 
Wenn das »Licht der Geister « für die Untersuchung der ersten Art notwendig ist, dann folgt aus den übrigen Erwähnungen dieses Lichts im Periphyseon dreierlei: Erstens, das dialektische Vorgehen des Schlussfolgerns allein reicht zur Untersuchung der ersten (und vierten) Natur nicht aus. Zweitens, der rechte Gang der angestrebten Untersuchung beginnt bei dem, was das »Licht der Geister « hervorbringt und endet wahrscheinlich ebenso dort, denn was für die erste Natur gilt, wird wohl auch für die vierte Gültigkeit haben. Drittens, da N von einer vernünftigen Ordnung spricht, die den Fortgang der Untersuchung bestimmt, soll augenscheinlich der Weg der ratio dennoch auch dort als Richtschnur gelten, wo der Verstand allein nichts zu bewirken vermag und auf das gnadenvolle »Licht der Geister « angewiesen ist.

\subsection{Die erste Auslegung von Sein und Nichtsein: eine negative Ontologie 89}

$» N$. Diese vorrangig alles trennende Unterscheidung verlangt fünf Weisen ihrer Auslegung.«

Ganz gleich, wie diese Auslegungsweisen aussehen mögen, eines ist schon hier festzuhalten: die erste und höchste Einteilung aller Dinge sagt nichts über deren tatsächliches Sein. Es wird, wie sich unmittelbar im Anschluss zeigt, nicht darum gehen, was Seiendes und was Nichtseiendes ist, sondern welche Gegenstände so bezeichnet werden, unabhängig davon, wie es sich ihrer Natur nach verhält.

\subsubsection{Sein und die Aussage >zu sein}

Die erste Auslegungsweise enthält Vieles von dem, was für das Periphyseon grundlegend sein wird. Im Vergleich mit den übrigen vier Auslegungweisen ist sie die allgemeinste, die fünfte hingegen die speziellste. Über die erste Weise heißt es: »Diese Weise also ist die erste und höchste

\footnotetext{
${ }^{89}$ Der Ausdruck >negative Ontologie $<$ ist an der gängigen Formel >negative Theologie ausgerichtet, da Eriugena das Verfahren, einen Gegenstand mittels verneinter Prädikate zu bestimmen, von der Theologie auf die Ontologie herunterbricht. Beide Ausdrücke indes sind bei ihm nicht zugegen.
} 
der Einteilung derer, die seiend heißen und nicht seiend, (...). ${ }^{90}$ Über die fünfte und letzte Weise sagt er, sie gelte allein in Hinblick auf die menschliche Natur: „Die fünfte Weise ist eine, die der Verstand allein in der menschlichen Natur betrachtet. $<11$

Man würde erwarten, dass Eriugena hier angibt, was solches ist, das ist, und solches, das nicht ist, eben jenes ea quae sunt und ea quae non sunt aus dem Anfang. Doch bei genauem Hinsehen wird dies nicht dargelegt. Er erklärt lediglich, welche Gegenstände verstandesgemäß

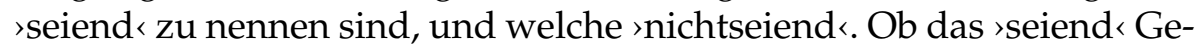
nannte auch tatsächlich ein Seiendes ist, lässt sich daraus nicht schließen. Und die Folge wird genau das Gegenteil aufzeigen: das sseiend Genannte ist in Wahrheit gar nicht.

Um hier dem möglichen Vorwurf eines Anachronismus vorzubeugen, ist eine Anmerkung vorzubringen. Auch ein mittelalterlichen Denker wie Eriugena wird Folgendes zu unterscheiden wissen:

1. quid sit id, quod est (was ist das Seiende)?

2. quorum sunt ea quae sunt (welche Gegenstände sind diejenigen, die sind)?

3. quorum sunt ea quae esse dicuntur (welches sind die Gegenstände, die seiend genannt werden)?

Es geht dabei nicht um die Frage, ob das frühe Mittelalter streng die Logik von der Ontologie trennt. Sondern wir müssen für das Textverständnis wissen, wovon im Anfang die Rede ist: vom Seienden und Nichtseienden, oder vom seiend und nichtseiend Genannten. Dass Eriugena zwischen beidem unterscheidet, zeigt er im Hinblick auf Gott, der wahrhaft ist (qui vere est), aber >nichtseiend < genannt wird (non esse dicitur). Nun ließe sich dies mit der Sonderstellung des göttlichen Seins und der negativen Theologie erklären. Doch spätestens wenn Eriugena auch alle essentia und substantia als >nichtseiend < bestimmt, lässt er sich auf obige Unterscheidung ein.

Dabei behandelt die erste Auslegungsweise im Periphyseon die dritte Frage, sie ist also eine Untersuchung der Seinsprädikation. Weil dem

\footnotetext{
${ }^{90}$ I, 73-77: Iste igitur modus primus ac summus est divisionis eorum quae dicuntur esse et non esse (...).

${ }^{91} \mathrm{I}, 137$ : Quintus modus est quem in sola humana natura ratio intuetur (...).
} 
am meisten Seienden, der essentia, dieses Prädikat in der Folge abgesprochen wird, unterscheidet Eriugena folglich zwischen Frage 2 und 3. Untersucht werden soll aber, so seine eigene Vorgabe in I, 46, die Unterscheidung zwischen quae sunt et quae non sunt und nicht etwa quae esse dicuntur et non esse. Inwiefern klärt die Unterscheidung in quae esse dicuntur et non esse das quae sunt et quae non sunt? Im ersten Satz war die höchste Einteilung aller Gegenstände nicht die in ea quae esse dicuntur et non esse, sondern in ea quae sunt et quae non sunt. Wenn die folgenden Auslegungsweisen (modi interpretationes) irgendetwas im Hinblick auf die vorangehende Unterscheidung erklären sollen, dann ist das nur möglich, wenn quae sunt und quae esse dicuntur dasselbe meint. Doch gerade dies verneint die erste Auslegungsweise, etwa hinsichtlich der essentia.

Eine eindeutige Antwort, um welche Frage es hier geht, ist daher nicht möglich, so enttäuschend dies auch sein mag. Es geht teils um Logik, teils um Erkenntnistheorie und teils um Ontologie, ohne klare Abgrenzung. Wie sich bei der vierten Auslegungsweise zeigen wird, tendiert Eriugena einerseits dazu, esse und esse dicuntur als dasselbe aufzufassen. Und selbige Tendenz zeigt sein Vorhaben, mittels fünf Aussageweisen die höchste Einteilung in esse und non esse zu erläutern. Dann bleibt zu fragen, wie der in der ersten Auslegungsweise formulierte Unterschied, ja Gegensatz zwischen vere esse bzw. existentia und esse dicitur zu denken ist.

Nehmen wir einmal an, Eriugenas Darstellung sei gerade eine Kritik an der Auffassung, nur dasjenige, was `seiend ‘ heißt, existiere auch. Das hieße dann zugleich, dass er die höchste Einteilung aller Gegenstände in die Klasse der Seienden und die Nichtseienden als eine bloß durch die ratio und deren Prädikationsweise hervorgebrachte Einteilung relativieren muss. Doch mit dieser Deutlichkeit sagt er das nirgendwo. Und warum stellt er dann beide, das esse und das esse dicitur, nicht klar gegenüber, sondern vermischt sie im Text so miteinander, dass eine nachträgliche Trennung die Argumentation zum Kippen bringt?

Gleich, ob es eine befriedigende Antwort darauf gibt oder nicht, diese gegebene Schwierigkeit ist in der Folge unbedingt zu berücksichtigen, wenn die Ontologie Eriugenas untersucht wird.

Wenn esse und esse dicitur nicht dasselbe meinen, und dies legt die 
erste Auslegungsweise nahe, ist zugleich die oben angeführte Erklärung des ersten Satzes zu relativieren. Solches, was Sinne oder Geist erfassen können, nennt zwar die ratio >Seiendes<, aber ob es auch ein Seiendes ist, fragt man dann vergeblich. >Seiend ‘ und snichtseiend ‘ wird offenbar nur als Klassifizierung der ratio verstanden und ist damit zunächst ohne ontologische Bedeutung. >Seiend < heißt, knapp gesagt, was sinnlich oder geistig fassbar ist, und >nichtseiend dementsprechend, was nicht fassbar ist, aber doch existiert. Dabei ist noch unklar, was unter dem Begriff `Existenz` zu verstehen ist, der auch das Dasein von solchem beschreibt, das sich »durch Herausragen seiner Natur « (per excellentiam suae naturae, I, 55/56) der Fassbarkeit entzieht. Es wird zumindest keine Existenzform sein, durch die der Gegenstand von der ratio das Prädikat sseiend c erhält, sondern umgekehrt vielleicht gerade eine solche, welche die ratio veranlasst, den existierenden Gegenstand >nichtseiend zu nennen.

Diesem Unfassbaren und als >nichtseiend Klassifiziertem kommt zumindest eine Natur zu (sua natura), und zwar eine das Fassungsvermögen von Sinn und Geist überragende. Hier ist sich zu vergegenwärtigen, dass in dieser Aussage das Wort >Natur die Natur von etwas bezeichnet. Damit unterscheidet es sich von der Verwendung, die im Anfang >Natur als allgemeinen Namen (generale vocabulum) für die Gesamtheit der Gegenstände verwendet. Eriugena schweigt hier wie auch im übrigen Werk zur doppelten Verwendung des Wortes >Natur<.

$\mathrm{Ma}$ der Seinsbestimmung ist, ob die Gegenstände auf irgendeine Weise fassbar sind. Ist dies der Fall, nennt der Verstand sie >seiend<, ist dies nicht der Fall, nennt er sie >nichtseiend «. Es drängt sich auch hier die Frage auf, wie solches, das in keiner Weise erfasst wird, überhaupt als snichtseiend < bestimmt werden kann. Denn das gar nicht Fassbare kann dem Denken nicht als ein Gegenstand entgegentreten und ein Prädikat erhalten. Doch die Möglichkeit einer solchen >Negativprädikation > des Unfassbaren und Unbenennbaren behauptet bereits die negative Theologie. Und es wurde gezeigt, inwieweit Eriugena den Bereich des cogitare über den des capere hinaus ausdehnt.

Eine Aussage in dieser ersten Auslegungsweise wird darlegen, was schon im Zusammenhang mit dem ersten Satz angeführt wurde: ’nicht fassbar sein $<$ heißt für Eriugena, von etwas nicht sagen zu können, was es ist und wo und wie. Die Einsicht hingegen, dass es ist, gilt ihm nicht 
als ein Erfassen desselben. Fassbar sind jene Gegenstände, die dem Fassungsvermögen von Sinn und Geist unterliegen (succumbunt), unfassbar diejenigen, die beidem entfliehen (fugiunt).

Wie gelangt Eriugena zur Auffassung einer Abhängigkeit des Prädikats >seiend ‘ von der Fassbarkeit eines Gegenstandes? In seinen lateinischen Quellen ist sie am ehesten in der pseudo-augustinischen Schrift De categoriis Aristotelis greifbar. Dort heißt es: »Erstens: Es sind alle Dinge, welche die Natur hervorbrachte; zweitens: erfasst werden die Dinge, deren Bilder wir durch das Sehen des Geistes formen und gründen; drittens, gesagt werden jene Dinge, mit denen wir das, was dem Geist eingedrückt ist, aussprechen. $\left\langle{ }^{92}\right.$ Und als Schlussfolgerung heißt es hinsichtlich der Seienden (ea quae sunt): "Es sind also die, welche wir entweder mit den Sinnen wahrnehmen oder mit dem Geist und Denken erfassen. $4{ }^{93}$ Bis auf die lateinischen Wörter mens und cogitatio (im Periphyseon heißt es intellectus und ratio), gleicht diese Aussage der ersten Bestimmung des Seienden im Periphyseon ${ }^{94}$ So scheint es zumindest. Doch was ist mit dem gegebenen Unterschied zwischen esse und esse dicitur? Der pseudo-augustinische Text gibt an, welche Dinge Seiendes sind, und nicht etwa, welche Dinge sseiend < genannt werden. $\mathrm{Ob}$ beides dasselbe ist, bliebe zu klären. Wenngleich damit eine wahrscheinliche gedankliche Vorlage für Eriugenas Auffassung hinsichtlich des Seienden gegeben ist, sollte diese Abweichung zugestanden werden.

${ }^{92}$ Paraphrasis Themistiana, in: Aristoteles Latinus I, 1-5 (ed. Minio-Paluello), p. 137, 16-19 [19]: Primo: sunt, res omnes quas natura peperit; secundo: percipiuntur, ea quorum imagines animo videndo formamus et condimus; tertio: dicuntur, illa quibus ea quae sunt impressa animis efferuntur.

Wenn man das esse zu Satzanfang mit ses existieren oder >es gibt< übersetzt, was legitim wäre, weicht dies deutlich von der Auffassung im Periphyseon ab, da darin von Existierendem die Rede ist, das die Natur nicht hervorbringt, das nicht fassbar ist und von dem es keine Aussage gibt.

${ }^{93}$ Ebenda, S. 139, 10-11: Sunt, igitur, illa quae aut percipimus sensibus aut mente et cogitatione colligimus.

${ }^{94}$ Dieses Verhältnis zwischen De categoriis Aristotelis und dem Beginn des Periphyseon findet in John Marenbons Untersuchung: JJohn Scottus and the Categoriae decem keine Berücksichtigung, in: Eriugena - Studien zu seinen Quellen, Vorträge des III. internationalen Eriugena-Kolloquiums Freiburg 27.-30. August 1979, herausgegeben von Werner Beierwaltes, Heidelberg 1980, S. 117-134. 
»die nur in Gott allein und in den Ideen und Wesen aller von ihm gegründeten Gegenstände rechtmässig gedacht werden.«

Gott als >nichtseiend < zu benennen, ist theologische Tradition. Die Benennung Gottes als >Nichtseiender $<$ oder > Überseiender ist in den Texten der lateinischen und griechischen Kirchenväter allgegenwärtig.

Auch, dass Gott sich der geschöpflichen Fassbarkeit entzieht, ist ein Gedanke, den Eriugena in allen theologischen Quellen findet. Der Zusatz hinsichtlich der Nichtseienden, wie er hier auftritt, ist indes ungewöhnlich und Eriugenas entscheidender Schritt zu einer negativen Ontologie: Auch die »Ideen und Wesen aller von ihm gegründeten Gegenstände « >nichtseiend < zu nennen, setzt nach vorangehender Regel voraus, dass auch sie weder sinnlich, noch irgendwie geistig fassbar sind ${ }^{95}$ Was solche rationes oder essentiae der Gegenstände sind, ist hier noch nicht näher beschrieben. Zumindest besteht zwischen >gegründet (condita) und >geschaffen< (creata) ein Unterschied. `Geschaffen sind auch die rationes und essentiae der Gegenstände, aber nicht >gegründet‘. Daher ist in der Übersetzung eine sprachliche Unterscheidung angebracht, wo etwa Sheldon-Williams condita und creata unterschiedslos mit >created < übersetzt 96

Bei der Entlehnung des Ausdrucks >negativ< von der Theologie ist folgende Einschränkung zu machen: Die negative Theologie verneint alle denkbaren Prädikate im Hinblick auf Gott. Eriugena wird der essentia des Einzelnen hingegen zugestehen, dass sie ihrem Ort, ihrer Zeit und ihrer Beschaffenheit nach bestimmbar sei. Dies sind bejahende Prädikate, welche sich auf die neun Akzidenzien beziehen ${ }^{97}$ Doch in Bezug auf die Frage, was essentia ist, wird es nur verneinende Prädikate geben. Und darin gleicht seine Ontologie der negativen Theologie, die auf die Frage, was Gott ist, antwortet, er sei unerschaffen, unendlich,

\footnotetext{
${ }^{95}$ Ratio sei hier mit >Idee< übersetzt, da ratio offensichtlich der zuvor genannten causa primordialis entspricht, was später auch principale exemplum, idea und divina ratio genannnt wird.

${ }^{96}$ De divisione naturae, liber I, p. 39.

${ }^{97}$ Als Akzidenz wird hier das anzusehen sein, was in der aristotelischen Kategorienschrift als Kategorie 2-9 genannt ist und von dem es heißt, es sei in einem $\mathrm{Zu}$ grundeliegenden. Aristoteles selbst nennt das besagte an keinem Ort symbêbêkos, vielmehr stellt er manchesmal dem Akzidenziellen die zehn Aussageweise, d. h. Kategorien zur Seite, etwa Metaphysik VI, 1026a34-b1.
} 
nichtseiend, nicht Lebendiges usw. So wie von Gott all das verneint wird, was um ihn herum besteht, also gesagt wird, er sei nicht dies oder jenes, so bilden nach Eriugena die Akzidenzien nur die Peripherie der essentia, ohne etwas von deren eigentlicher Natur zu verraten. Die essentia wird sich nicht als dieses oder jenes bestimmen lassen, sondern zeigt sich allemal an einem bestimmten Ort, zu einer Zeit und in einer Gestalt. Die Analogie von negativer Theologie hin zu einer negativen Ontologie ist also nur stimmig im Hinblick auf die >Was-ist-das-Frage der ersten Kategorie. Fragt man nach der Prädizierbarkeit der übrigen Kategorien, ist die essentia, sofern von essentia des Einzeldings die Rede ist, von Gott verschieden.

»Und nicht ohne Grund. Denn derjenige ist das Wesen aller, der allein wahrhaft ist, wie es Dionysius Areopagita sagt: >Das Sein aller nämlich<, legt er dar, >ist die überseiende Gottheit «.«

Es ist hier das erste Mal im Text, dass Eriugena seiner Aussage eine Begründung folgen lässt. Wir müssen annehmen, dass er das Gesagte nicht ohne weiteres für evident hält. Aber was genau soll begründet werden? Die Aussage, dass Fassbares >seiend < heißt und Unfassbares >nichtseiend', oder jene Auffassung, dass Gott und die rationes und essentiae des von ihm Gegründeten unfassbar sind und daher zurecht >Nichtseiendes ' genannt werden? Das im Text Folgende sollte eine Antwort auf mindestens eines von beidem geben, doch in dieser Hinsicht überrascht es: »Denn derjenige ist das Wesen aller, der allein wahrhaft ist «, heißt es. Damit ist weder begründet, warum nur das Fassbare >seiend genannt wird, noch, dass Gott und die erwähnten rationes und essentiae unfassbar sind. Dennoch ist das nanque ein eindeutiger Hinweis auf eine Begründung. Aber eine Begründung wofür?

\subsubsection{Essentia und vere esse}

Lassen wir einmal alles theologische Vorwissen beiseite. Es gibt diesem Begründungssatz zufolge jemanden, der das Wesen (essentia) von allem ist, dies zeigt das ipse. Bis zu diesem Zeitpunkt hat das Periphyseon noch keine Erklärung abgegeben, was essentia ist, und zwar essentia von etwas. Es liegt nahe, das ipse als Gott zu lesen. Doch soweit soll noch nicht 
gegangen werden. Der Satz liefert eine Bestimmung, wer oder was als essentia von allem zu gelten hat: nämlich derjenige, der "wahrhaft ist « (qui vere est). Was aber ist wahrhaftes Sein? Darauf gibt es hier keine Antwort. Wenn wir aber nicht wissen, was wahrhaftes Sein ist, so können wir auch nicht nachvollziehen, wer wahrhaft ist und ebensowenig, wer essentia von allem ist. Ohne theologisches Vorwissen ist der Text hier nicht evident.

Nun soll die Passage eine Aussage eines Anderen wiedergeben, nämlich des Dionysius Areopagita. Und so fügt Eriugena seiner eigenen Aussage dessen Zitat an: »Das Sein aller nämlich ist die überseiende Gottheit.«Es findet sich in der Schrift von den himmlischen Hierarchien, Kapitel IV ${ }^{98}$ Das Sein von allem ist bestimmt als dasjenige, was über dem Sein ist. Ob diese Aussage paradox ist, hängt davon ab, wie man das >Sein-von-etwas-zu-sein auffasst. Wenn dieses Sein ein UrsacheSein des Seienden ist, ergibt sich nichts Paradoxes. Nur wenn es ein und dieselbe ontologische Kategorie ist, die auf beides angewendet wird, ergibt sich ein Widerspruch.

Angenommen, die Aussage ist nicht widersprüchlich, dann erfahren wir, dass die Gottheit das Sein von allem ist. Doch wie passt dies zum vorangehenden Satztteil? So, wie es Eriugena darstellt, erläutert der erste Satzteil lediglich das Zitat des Dionysius. Doch der erste Satzteil sagt, der wahrhaft Seiende sei essentia von allem, bei Dionysius heißt es hingegen, Gott sei das esse von allem. Ist esse zwangsläufig dasselbe wie essentia? Mit esse gibt Eriugena hier das griechische to einai wieder und, wie seine Übersetzung dieser Textpassage des Corpus Dionysiacum zeigt, einen Satz zuvor das griechische ousia mit essentia ${ }^{99}$ Zumindest sprachlich unterscheidet er so zwischen esse und essentia, doch an dieser Stelle im Periphyseon sieht es so aus, als wolle er inhaltlich zwischen beiden nicht unterscheiden. Denn ansonsten wäre seine dem Zitat vorangestellte Aussage schlicht eine schiefe Wiedergabe des von Dionysius Gesagten. Interessanterweise hält es schon der spätantike Scholienverfasser zu dieser Schrift, Johannes Scythopolis, für angemessen, ousia

\footnotetext{
${ }^{98}$ Dieses Zitat des Dionysius ist gegen Ende des ersten Buches noch einmal angeführt

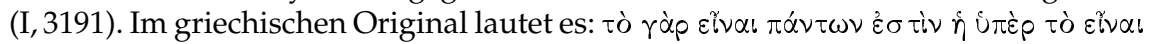
$\vartheta \varepsilon o ́$ †ns, ediert in: De caelesti hierarchia IV (ed. Heil/Ritter, Berlin 1991, p. 20,16-17).

${ }^{99}$ De caelesti hierarchia IV, iuxta Eriugenam interpretationem (ed. in Dionysiaca Tome II, ed. Chevalier, Paris 1937, p. 20,801).
} 
hier nicht nur sprachlich, sondern auch sinngemäß von einai abzuleiten, und das göttliche Sein des biblischen >ich bin, der ich bin < als ousia aufzufassen 100

Für das Periphyseon ist festzuhalten, dass an dieser Stelle esse mit essentia gleichgesetzt werden muss „, da sonst die Begründung scheitert. Damit ist essentia keineswegs näher bestimmt, denn auch was esse ist, wurde noch nicht angegeben. Immerhin kann dieses esse nicht als jene Aussageweise gelten, die zuvor das Fassbare benennt; denn Gott wurde dort als non esse bezeichnet. Eher ist wohl dieses esse Gottes als das genannte vere esse aufzufassen.

Vere esse bildet dabei augenscheinlich den Gegenbegriff zu esse dicitur, also zum sseiend (Genannten. Das wird zwar an keiner Stelle explizit gesagt, ist aber die einzige Möglichkeit, das hier Gesagte zu verstehen. Demnach ist Gott wahrhaft seiend, wird jedoch vom Verstand aufgrund seiner Unfassbarkeit `nichtseiend ‘ genannt. Erst viel später, im dritten Buch, findet sich eine Begründung für die Annahme, Gott sei wahrhaft seiend (Die eingefügte kursive Hervorhebung markiert dabei die entscheidenden Passagen):

»Denn die Bewegung der höchsten und dreifaltigen und allein wahren Güte, die in sich selbst unbeweglich ist, und die Vervielfältigung ihrer Einfachheit und ihre unauslöschliche Verbreitung, ausgehend von sich selbst in sich selbst zu sich selbst zurück, sind die Ursache von allem, ja sind sogar alles. Wenn nämlich das Denken von allem all dieses Gedachte ist und diese Bewegung allein alles denkt, dann ist sie allein all diese Dinge, denn sie allein ist das Erkenntnisvermögen, das alle Dinge kennt, noch bevor sie sind. Und nicht außerhalb ihrer selbst kennt sie alle Dinge, weil außerhalb von ihr nichts ist, sondern nur in ihr. Sie umläuft alles und nichts ist in ihr, insofern es wahrhaft ist, was nicht sie selbst ist, weil sie allein wahrhaft ist. Denn die übrigen Dinge, von denen man sagt, dass sie sind, sind ihre Theophanien, die ebenso wahrhaft in ihr selbst bestehen. Gott ist daher alles, was wahrhaft ist, weil er alles hervorbringt und in allem wird, wie der heilige Dionysius Areopagita sagt. 401

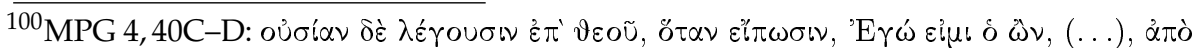

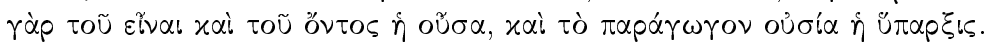

${ }^{101} \mathrm{III}, 577-588$ : Summae siquidem ac trinae soliusque verae bonitatis in se ipsa immutabilis motus et simplex multiplicatio et inexhausta a se ipsa in se ipsa ad se ipsam diffusio causa omnium, immo omnia sunt. Si enim intellectus omnium est omnia et ipsa sola intelligit omnia, ipsa igitur sola est omnia, quoniam sola gnostica virtus 


\section{Interpretation des Periphyseon, ausgehend vom Anfang}

Auch hier beruft sich Eriugena auf Dionysius. Gott sei alles, was wahrhaft ist, weil er Schöpfer von allem sei und in allem wird. Doch diese Passage ist mitsamt ihrer Begründung so gehalt- und voraussetzungsvoll, dass sie für die vorliegende Textstelle zunächst nicht viel erklären kann. Festzuhalten bleibt allein, dass es für Eriugena ein wahrhaftes Sein gibt und das davon unterschiedene Prädikat sseiend`, und diese beiden tauchen in dem angeführten Zitat aus dem dritten Buch wieder auf. Warum die sseiend ' genannten Dinge nicht wahrhaft sind, ließe sich mit einer Aussage aus dem ersten Buch erklären, wenn vere esse gleich universaliter esse bedeutet: "Hingegen haben die Seienden ihr Sein auf eine gewisse Weise, aber nicht schlechthin, so sind sie irgendwo sind aufgrund ihrer Lage und aufgrund der Grenze der ihnen naturgemässen Bestimmungen sowie sie auch in vollem Maße irgendwann sind, weil sie einen Anfang nehmen. $\times \sqrt{102}$ Demzufolge wären die

est ipsa quae, priusquam essent omnia, cognovit omnia. Et extra se non cognovit omnia, quia extra eam nihil est, sed intra se. Ambit enim omnia et nihil intra se est, in quantum vere est, nisi ipsa, quia sola vere est. Caetera enim, quae dicuntur esse, ipsius theophaniae sunt, quae etiam in ipsa vere subsistunt. Deus est itaque omne quod vere est, quoniam ipse facit omnia, et fit in omnibus, ut ait sanctus Dionysius Ariopagita. Sheldon-Williams übersetzt intellectus als Tätigkeit, >understanding ‘ (hier auf Deutsch >Denken`), was in Bezug auf die zuvor genannte Bewegung und die nachfolgenden Aussagen in der Tat eine sinnvollere Lesart ist, als `Geist<, englisch >intellect< (Periphyseon Book III, p. 58).

${ }^{102}$ I, 1702-1706: Si autem aliquo modo sed non universaliter ea quae sunt habent esse, quemadmodum sub loco esse per positionem et finem rationum in quibus secundum naturam sunt, et sub tempore esse omnino per principium [non] ostendentur. Sheldon-Williams weiß in seiner englischen Übersetzung mit dem Satz wenig anzufangen, wohl auch, weil ihm entgeht, dass Eriugena hier ein Zitat aus seiner Ambigua-Übersetzung mit einer Abänderung übernimmt. So taucht im Autograph des Periphyseon ein non auf, das sich seiner lateinischen Ambigua-Fassung nicht findet. Zudem übersetzt Eriugena in der ersten Fassung (d. h. seiner Ambigua-

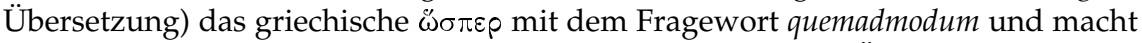
so aus dem Satz im Grunde eine Frage. Vielleicht hat er bei Übernahme des Satzes in das Periphyseon das non sogar absichtlich hinzugefügt, weil ihm das fragende quemadmodum sonst nicht mehr schlüssig schien. Jeauneau übernimmt für die Hauptedition das Zitat aus der Ambigua ohne das non, während es in der anschließenden synoptischen Fassung der Kolummne I angeführt ist (p. 282, Zeile 2905). Da der Satz, wie er im Autographen Eriugenas steht (Kolummne I der Paralleledition), keinen Sinn ergibt, ist die angeführte deutsche Übersetzung am griechischen

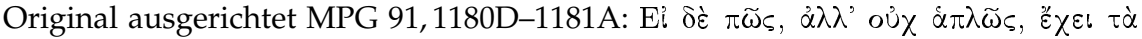

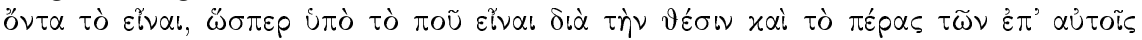

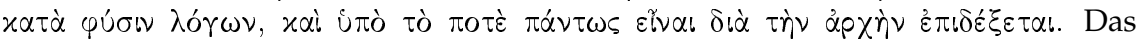


Seienden nur an einem begrenzten Ort und zu einer begrenzten Zeit und das universale Sein ein unbegrenztes und ewiges. Möglicherweise denkt Eriugena beim vere esse in der Tat an solch eine universale Seinsform, doch darüber ist hier nichts gesagt.

Im Hinblick auf den Textverlauf war die Fragestellung, was von den vorangehenden Aussagen begründet wird. Als Ergebnis lässt sich zusammenfassen:

Wenn Gott die essentia von allem ist, dann wird für sie gelten, was für ihn gilt. Ist er unfassbar und daher >nichtseiend $<$ zu nennen, dann auch sie. Es wäre so erklärt, warum auch die essentia omnium rerum >nichtseiend $\mathrm{zu}$ nennen ist. Doch was ist mit den zugleich genannten rationes? Es scheint, als würde auf sie zutreffen, was auch auf die essentia zutrifft, ja es lässt sich sogar vermuten, dass beide Wörter dieselbe Sache bezeichnen. Wenn zudem die Ausdrücke esse omnium und essentia omnium dasselbe benennen, ergeben sich drei Ausdrücke für eine Sache: esse omnium, essentia omnium und ratio omnium. Diese Sache ist

1. etwas, das nicht gegründet ist (I,58-59),

2. etwas, das Gott ist.

Die Benennung Gottes als essentia ist dabei schon bei Augustinus bezeugt ${ }^{103}$ Doch Augustinus geht es dabei um etwas anderes als Eriugena. Er rechtfertigt, angelehnt an die Seinsformel aus Exodus 33, 13 (»ich bin, der ich bin«) die Benennung substantia für Gott, nach dem selben argumentativen Aufbau wie ihn Marius Victorinus (Ad Candidum 1-14) im Zusammenhang mit dem homoousion vollführt. Gott ist daher substantia, aber nicht substantia omnium, also Substanz für andere, sondern eher substantia sua, seine eigentümliche göttliche Substanz.

Indem Eriugena Gott essentia von allem sein lässt, wird für die essentia zutreffen, was zuvor für die Theologen nur von Gott gilt: dass man

عỉ ò̀ leitet dabei keinen Bedingungssatz ein, sondern kontrastiert die nachfolgende Aussage zum Vorangehenden. Gott wird metaphorisch >irgendwie und einfach Seiender «genannt; hingegen sind die geschaffenen Dinge zwar auch irgendwie, aber nicht einfach.

${ }^{103}$ De trinitate VII, 5, 10: Unde manifestum est Deum abusive substantiam vocari, ut nomine usitatione intelligatur essentia, quod vere ad proprie dicitur; ita ut fortasse solum deum dici oporteat essentiam. Est enim vere solus, quia incommutabilis est. Siehe zu Eriugenas Kenntnis dieser Schrift Goulven Madec: Jean Scot et ses auteurs, Paris 1988, p. 74 . 
zwar sagen könne, dass er sei, aber zugleich jede Prädikation auf ihn hin nicht zutreffe. Man kann nur sagen, was er nicht ist, also negative Prädikate saussagen . Und selbiges wird nach Eriugena für dasjenige gelten, was er essentia nennt.

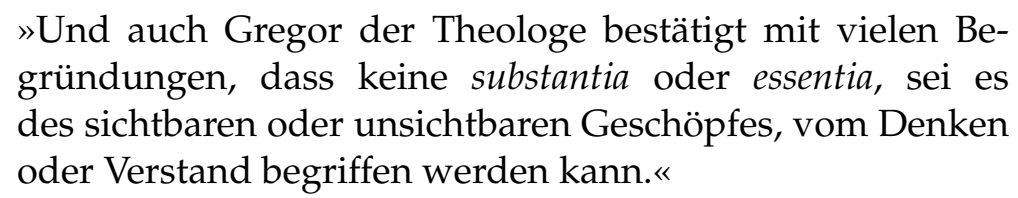

Als würde das bislang Gesagte als Begründung nicht genügen, fügt Eriugena eine weitere christliche Autorität an, und zum zweiten Mal ist es eine griechische. Dem etiam nach soll Gregor von Nazianz dasselbe behaupten wie zuvor Dionysius. Anders als im Hinblick auf diesen führt Eriugena hier kein Zitat an, und das nicht ohne Grund: er verfügt über keine unmittelbare Kenntnis der Schriften Gregors ${ }^{104}$ Was er von ihm kennt, sind lediglich einzelne Sätze oder manchmal gar nur Satzteile, nämlich jene, die Maximus Confessor seiner Erläuterung von ausgesuchten Textpassagen aus den Reden Gregors jeweils voranschickt. Wenn Eriugena daher von Gregor spricht, so spricht er vorangig von dem, was Maximus Confessor in der Ambigua ad Iohannem über dessen Lehre sagt. Daher verweist auch Jeauneau in der Edition des Periphyseon auf die Ambigua des Maximus als Quelle für den dargelegten Gedanken 105

Zunächst ist zu prüfen, was hier im Periphyseon behauptet wird, bevor eine mögliche Quelle anzuführen ist. Gregor lege mit vielen Begründungen (multis rationibus) dar, dass etwas Bestimmtes nicht vom Intellekt oder der ratio begriffen werden könne. Von solch einer Un-

${ }^{104}$ Es wird innerhalb der Forschung kontrovers diskutiert, ob Eriugena Gregor von Nazianz und Gregor von Nyssa für zwei Personen oder ein und dieselbe hielt. Meines Erachtens glaubte Eriugena, es habe einen Gregor gegeben, welcher den Beinamen >der Theologe trägt, Verfasser der von Maximus kommentierten Reden, und einen, der Gregor von Nyssa oder auch >von Nazianz genannt wird, Verfasser der ihm bekannten Schrift De imagine. Die Textstelle, auf die sich die Verfechter der These der Ineinssetzung beider stützen, findet sich prekärerweise im fünften Buch und damit ist nicht klar, ob $\mathrm{R} i^{1}$ oder $\mathrm{R} i^{2}$ hier beide Gregors nicht auseinanderhalten. Doch diesen Fragen im Einzelnen nachzugehen, wäre zu ausufernd und für das hier Darzulegende nicht förderlich.

${ }^{105}$ Nämlich auf CCSG 18, XI, 80-148 (p. 126-128), siehe in seiner Edition, p. 5, unten. 
begreiflichkeit war schon oben die Rede, nämlich in Bezug auf die essentiae und rationes omnium rerum. Hier nun heißt es, keine substantia oder essentia eines Geschöpfes, sei dieses sichtbar oder unsichtbar, könne begriffen werden. Nach obiger Aussage ist also die substantia von etwas ein weiterer Kandidat für solches, das >nichtseiend ‘ genannt wird. Doch während die oben zu essentia gesellte ratio eine schöpfungstheologische Auffassung von essentia nahelegt, deutet hier die oderVerbindung (seu) zwischen essentia und substantia auf die Substanz des Einzeldings hin.

Eriugena behauptet also, die Substanz, um bei diesem gängigen Wort zu bleiben, der geschaffenen Individuen sei unbegreiflich. Da er sich dabei auf Gregor von Nazianz beruft, ist diese Berufung zu prüfen.

\subsection{Die Unbegreiflichkeit der Substanz: der Kern der negativen Ontologie}

Jeauneaus Angabe der entsprechenden Stelle in Maximus' Ambigua wurde bereits angeführt. Doch ein alleiniger Verweis auf diese Textstelle hilft nicht weiter, da dort nichts über die Substanz des Geschöpfes gesagt wird. Um Eriugenas Quelleninterpretation zu verstehen, bedarf es zunächst der Anführung einer anderen Passage aus der Ambigua, dem Beginn des 30. Abschnitts, wo folgende Aussage aus Gregors Rede No. 38, Absatz 7 erläutert ist: »Nicht aus dem, was er (d.h. Gott) selbst ist, sondern aus dem, was um ihn ist, fügt man aus dieser und jener Erscheiung ein bestimmtes Abbild der Wahrheit zusammen. «106

Bereits diese deutsche Übersetzung verzerrt die Aussage in die Richtung, in der sie Eriugena lesen wird. Der Ausdruck kath' auton ergibt zunächst wohl am meisten Sinn, wenn er der aristotelischen Verwendung folgt, als Bezeichnung des san-sich $<107$ Eriugena hingegen über-

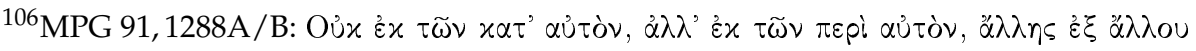

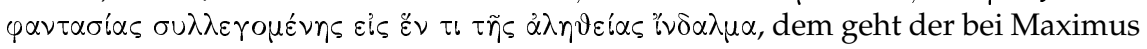
nicht angeführte Satzteil voran: "O

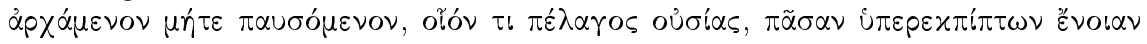

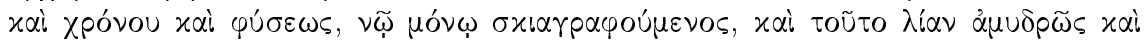

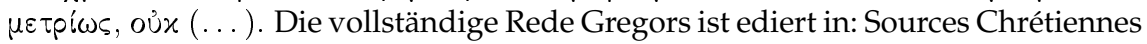
358, p. 103-149.

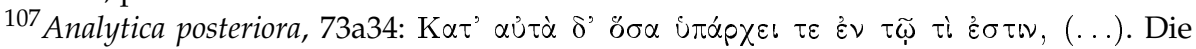
m. E. treffendste Übersetzung liefert Jonathan Barnes im Englischen: »One thing 
setzt: »Non ex his quae secundum ipsum sed his quae circa ipsum, alia ex alio phantasia collecta in unam quandam veritatis imaginem. 108

Entscheidend ist dabei, dass Eriugena das griechische peri mit cir$c a$ übersetzt, was in aller Regel eine räumliche Präposition bezeichnet. Man sollte ihn aber nicht vorschnell dieser Lesart bezichtigen. Gregor denkt sehr wahrscheinlich bei peri an etwas Bestimmendes, so wie etwa Sokrates im Menon fragt, wie sich die Tugend peri ousian bestimmen lässt (72a9). Und die Ausführungen des Maximus bestärken diese Vermutung. Auch hier könnte man zunächst auf eine räumliche, und damit vielleicht Eriugenas Interpretationsrichtung hin übersetzen: „Gemäss dem Wesentlichen, das heißt gemäss dem Wesen selbst, wird Gott hinsichtlich dessen, als was er besteht, auf keine Weise erkannt. Denn unmöglich und völlig unzugänglich ist für jedes Geschöpf, sichtbares wie unsichtbares gleichermassen, der Begriff dessen, was er ist, hingegen ist aus denen, die um sein Wesen sind, allein deutlich, dass er ist. « ${ }^{109}$ Maximus sagt über dieses peri ousian bei Gregor, so man auch bei dieser Erläuterung mit Eriugenas Lesart herangeht: »Alles (um) das Wesen Herumseiende offenbart nicht, was dieses ist, sondern was es nicht ist, wie etwa das Ungewordene, das Anfanglose, das Unendliche, das Unkörperliche (...).«110 Eriugena liest dieses peri wiederum als circa (um) und übersetzt: »Omnia vero quae circa essentiam sunt non quid est, sed quid non est subdeclarant, verbi gratia quod ingenitum (...).«

Entscheidend ist nun die Frage, ob man die akzidenziellen Bestimmungen wie `das Ungewordene` und `das Anfanglose` nur prädikativ,

belongs to another in itself (both) if it belongs to it in what it is, (...).", in ders.: The complete works of Aristotle, Vol. I, Princeton 1984, p. 118,34. Siehe zu dieser Aristoteles-Stelle auch den Kommentar von Wolfgang Detel: Aristoteles - Analytica posteriora, 2. Halbband, Berlin 1993, S. 100. Maximus interpretiert den Ausdruck Gregors auf genau diese Weise, wie sich unten zeigen wird.

${ }^{108}$ CCSG 18, XXX (p. 167).

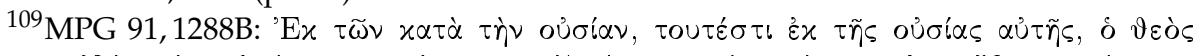

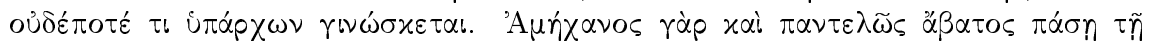

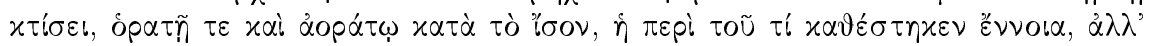

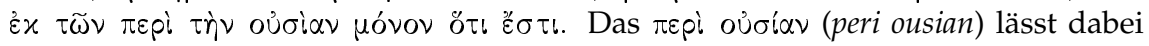
abermals auch als »aus alledem, was sich darüber vorbringen lässt« auffassen, was den Text von Eriugenas Interpretation des peri als circa entfernt, wenn er dabei an etwas Räumliches denkt.

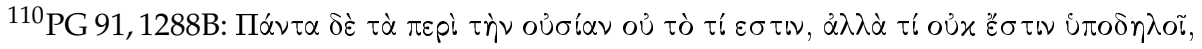

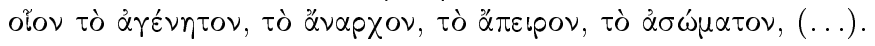


oder ontologisch fassen will. Bei Eriugena werden die Akzidenzien eindeutig auch res, Dinge sein, die als Peripherie um die ousia herum bestehen. Liest man das griechische peri lediglich als Anzeige einer Prädikation, als >über<, dann heißt der Satz bei Maximus: »Alles über das Wesen Gesagte offenbart nicht, was dieses ist, sondern was es nicht ist, wie etwa das Ungewordene (...).«

Diese Betrachtung hat für das Periphyseon folgende Bedeutung: Wenn Eriugena von den unbegreiflichen essentiae und substantiae spricht, von denen nur das angebbar ist, was an Akzidenzien umliegend angeordnet ist, und zudem Gregor als Quelle für diese Unbegreiflichkeit angibt, so hat er dies in den Text des Maximus hineingelesen, insofern es dort nicht einmal in Bezug auf Gott gesagt wird. Den Anfang des Hineinlesens bildet dabei das circa. Eriugena wird das secundum ipsum als Kennzeichen der essentia auffassen und das circa als das der Akzidenzien. Und damit gelangt er von der negativen Theologie Gregors zu seiner negativen Ontologie. Von der essentia ist so nur prädizierbar, was als Akzidenz um es herum gegeben ist. Da sich, wie er sagen wird, durch die Prädikation eines Akzidenz aber nicht angeben lässt, was die einen Mittelpunkt bildende essentia selbst ist, bleibe sie letztlich unbestimmbar.

Damit kommt eine weitere Interpretationshürde ins Spiel: Maximus spricht hier nur von der Unbegreiflichkeit des Wesens (ousia) Gottes, und meint damit die Bestimmung dessen, was dieser sals er selbst $<$ oder san sich ( $k a t h '$ auton, wie es bei Gregor heißt) ist. Wenngleich hier also von ousia die Rede ist, was Eriugena zumeist mit essentia übersetzt, steht diese Aussage in keinem unmittelbaren Bezug zur Behauptung des Periphyseon, essentia und substantia aller Geschöpfe seien unbegreiflich, denn bei Maximus ist nicht von der ousia der Geschöpfe die Rede, sondern von der ousia Gottes.

Für sich genommen hilft also auch diese Textangabe für das Verständnis der Aussage im Periphyseon wenig. Es ist dafür eine von Eriugenas Randbemerkungen zu seiner Ambigua-Übersetzung hinzuzuziehen, wo er mit Bezug auf eine andere Stelle das Folgende angibt: »Phantasia bedeutet an dieser Stelle, wie ich meine, eine im Geist gefasste Vorstellung einer gedachten substantia, sei es von Sichtbarem, sei es von Unsichtbarem, wie etwa vom Menschen oder vom Pferd oder vom Rind, von deren jeweiliger substantia ich, indem ich im Geist über 
sie eine bestimmte Kenntnis sammle, eine bestimmte phantasia besitze, das heißt eine Oberfläche oder Erscheinung (...). Während ich über diese phantasiai wiederum nachdenke, finde ich, dass ihnen ein bestimmtes Subjekt zugrunde liegt, in welchem sie sind und ohne das sie nicht sein können; nicht dass ich dieses Subjekt (aufs Klare nämlich lässt sich nicht erkennen, was es ist) in geistiger Einsicht erfasst hätte, sondern dass die aus ihm gesammelten Erscheinungen ein bestimmtes Bild der Wahrheit bewirken, das heißt, sie teilen mit, dass ihnen wahrhaftig ein Subjekt zugrunde liegt, auch wenn sie nicht klar eröffnen, was es ist, so wie vom göttlichen Wesen aus dem, was um es herum eingesehen wird, nur herausgelesen wird, dass es ist, aber nicht, was es ist. « ${ }^{111}$ Das scheint das Prinzip zu sein, wie sich Eriugena das cogitare einer Substanz denkt: via fassbarer Abbilder (phantasiai) gelangt der Geist zur Einsicht in die Existenz einer zugrunde liegenden Substanz. Und damit kommt nicht nur jene substantia des Geschöpfes ins Spiel, von der in der gesamten Ambigua nirgendwo expressis verbis die Rede ist, sondern wieder ist auch das cogitare zugegen, auf das schon hinsichtlich des ersten Satzes verwiesen wurde.

Bedeutsam ist an dieser Aussage weiterhin der Ausdruck »so wie« (sicut), der eine Analogie aufzeigt zwischen dem göttlichen Wesen und dem Subjekt (subiectum) der einzelnen Gegenstände. So wie vom Wesen Gottes nur erkennbar ist, dass es ist, so soll dies auch für das subiectum und damit für die substantia des Geschöpfes gelten. Von Ersterem spricht in der Folge auch Maximus, von Letzterem hingegen nicht. Die Unterscheidung von >selbst< (ipse) und >umliegend < oder >über< (circa) in Bezug auf das Göttliche dehnt Eriugena nun auf alles Seiende aus: Das subiectum aller Dinge ist an sich selbst verborgen und offenbart sei-

${ }^{111}$ Ediert in Ambigua ad Iohannem, Marg. ad. XXX (CCSG 18, p. 281): ФANTACIA in hoc loco significat, ut arbitror, conceptam in animo notionem de intellecta sive visibilium sive invisibilium substantia, verbi gratia hominis vel equi vel bovis, de quorum substantia dum notionem quandam in mente colligo, ФANTACIAN quandam, hoc est superficiem seu apparitionem, (...), habeo. Ipsas ФANTIACIAC dum cogito, invenio unum quoddam subiectum subesse eis in quo sunt et sine quo esse non possunt, non quod illud videlicet subiectum (ad purum nanque intelligi quid sit non potest) mentis intellectu perceperim, sed quod fantasiae ex ipso collectae unam quandam imaginem veritatis efficiunt, hoc est vere subesse eis subiectum insinuant, etsi quid sit illud clare non aperiant, sicut divina essentia ex his quae circa eam intelliguntur solummodo esse, non autem quid sit colligitur. 
ne Existenz lediglich durch die akzidenzielle Peripherie. Man erhält so eine Oberfläche der jeweiligen Substanz oder eben eine phantasia.

Das Herausgreifen gerade dieser Anmerkung zur Ambigua mag zunächst willkürlich erscheinen, doch findet sich beim näheren Hinsehen hier die Grundlage jener negativen Ontologie, die Eriugena Gregor und Maximus unterstellt und sich bei ihnen doch nicht findet. Erst im Zusammenspiel mit dieser Randemerkung Eriugenas erahnt man, in welche Richtung hin Eriugena den Text des Maximus interpretiert. Die entsprechende Passage der Ambigua, wo sich die Randbemerkung findet, behandelt einen Satz aus der 28. Rede Gregors, welcher die Unbegreiflichkeit und Unbenennbarkeit Gottes gegen alle erdenklichen Einwände hin verteidigt. So heißt es, zur vollständigen Bestimmung eines Gegenstandes reiche es nicht, wenn man sage, er sei körperlich, sondern man müsse zugleich angeben, was dieses Verkörperte sei: Mensch, Pferd oder Rind. Man fragt also nach der entsprechenden Art, und ebendiese Bestimmung sei in Hinsicht auf Gott nicht möglich. ${ }^{112}$ In seinen Erläuterungen dazu bestimmt Maximus die jeweilige Art, die dem Körperhaften zukommt, als das ihm Zugrundeliegende:

»Da es für ein vollständiges Erkennen der Dinge nicht reicht, die Fülle dessen anzugeben, was darüber erfahrbar ist, Körper sage ich, und das es entsteht und vergeht, und was sonst noch solcherart in Betreff auf das Zugrundeliegende vorliegt, sondern wenn wir das mit dem Geiste Erfasste vollkommen und vollständig darlegen wollen, muss man gänzlich aufzeigen, was das Zugrundeliegende von all diesem ist, als eine Art Fundament, auf dem jene stehen: Wir müssen sagen, ob wir einen Menschen vor uns haben oder ein Rind oder ein Pferd, da diese nicht di eser Körper, sondern Verkörpertes sind, und nicht dieses Entstehen und Vergehen selbst, sondern Gewordenes und Vergängliches. $\ll 113$

\footnotetext{
${ }^{112}$ Die vollständige Rede Gregors ist ediert in: Sources Chrétiennes 250, p. 101-175.

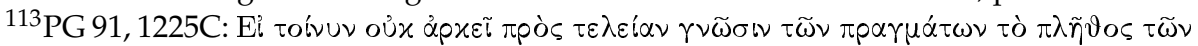

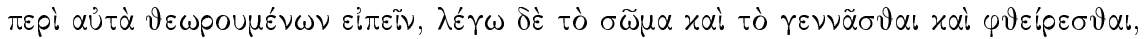

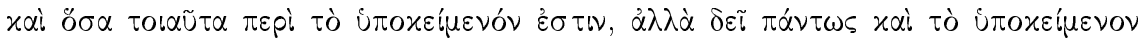

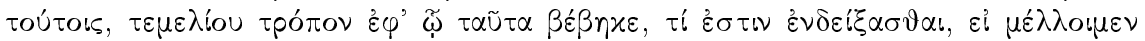

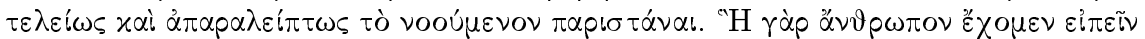

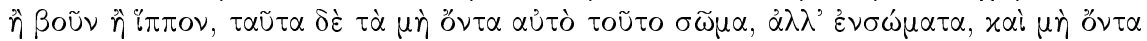

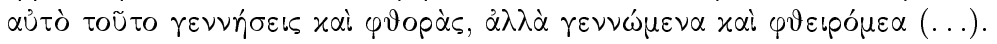


Hier kommt der Text der Auffassung Eriugenas recht nahe. Zwar ist von eipein, also vom Sagen im Zusammenhang mit dem peri die Rede, was die obige Interpretation des lediglichen Prädizierens stützt; doch weil Maximus vom Körper und dessen hypokeimenon spricht, erlangt die Aussage jene ontologische Dimension, die in der vorangehenden nicht gegeben war, aber von Eriugena offensichtlich auch dort hineingelesen wurde. Beide Textstellen für sich genommen belegen recht wenig. Erst die Verbindung beider ermöglicht einen Quellenverweis hinsichtlich der negativen Ontologie, die im Periphyseon dargelegt ist. So, wie es die Theologen von der Gottesprädikation lehren, verhält es sich auch für alle Substanzen.

Dies soll zunächst für die Texterläuterung genügen. In der Tat müssen wir viel Nachsicht aufbringen, um diese Quelleninterpretation Eriugenas als multae rationes, also als »viele Begründungen« gelten zu lassen. Die gewagte Interpretation seiner Quelle zeigt sich im Grunde schon darin, dass er keine Aussage aus der Ambigua anführt, die seine Behauptung prägnant belegt; es gibt keine solche. Und die Suche danach hat mehr Wahrscheinliches als wirklich Zwingendes zu Tage gebracht. Festzuhalten bleibt, dass Eriugena die gewaltige Behauptung, alle Substanz sei unbegreiflich, hier nicht als seine eigene ausweist, sondern als die einer griechischen Autorität.

Nun sollte ja auch diese Textpassage die anfängliche Behauptung stützen, Gott und die essentiae und rationes omnium rerum seien erstens unbegreiflich und zweitens daher snichtseiend zu nennen. In der Tat bekräftigt sie diese Behauptung, doch sie beweist ebensowenig irgendetwas, wie das vorangehende Zitat des Dionysius. Denn ein Verweis auf die Autorität Gregor und dessen Begründungen ist an sich keine Erklärung. Sie steht also noch aus. Indes bringt sie einen wesentlichen Aspekt in die Untersuchung ein.

Man könnte die essentiae und rationes omnium rerum zunächst als die göttlichen Ursachen fassen wollen, mit welchen er die Vielfalt der Dinge hervorbringt, also jene schon genannten causae primordiales. Doch die substantia und essentia des einzelnen Geschöpfes will als etwas anderes erscheinen, nicht als schöpferische Ursache, sondern entweder, aristotelisch gesprochen, als hypokeimenon (Zugrundeliegendes), oder als ti ên einai (>das, was es für etwas heißt, zu sein< oder >das Sein von 
etwas $<{ }^{114}$ Wie der Ausdruck etiam bei der Nennung von Gregors angeblicher Begründung zeigt, glaubt Eriugena, hier nichts anderes zu erweisen, als es schon mit dem Zitat des Dionysius der Fall war. Die essentia omnium ist für ihn demnach in dieser Hinsicht identisch mit der substantia des einzelnen Geschöpfes. Genau dies gilt es noch näher zu hinterfragen.

Man mag innehalten wollen: hiess es nicht einen Satz zuvor, essentia aller Dinge sei Gott? Plausibel schien es doch, dies so zu verstehen, als sei Gott die seinsverursachende essentia, das esse omnium, von dem Dionysius spricht. Doch wenn hier im Anschluss essentia zusammen mit substantia als Prädikat für die einzelnen Geschöpfe auftritt, als einzelne essentia des einzelnen Geschöpfes, so möchte man zumindest erfahren, wovon hier die Rede ist, von der einen göttlichen und schöpferischen essentia, oder von genau so vielen essentiae, wie es Geschöpfe gibt. Und wenn beides dasselbe ist, hieße das nicht, dass Gott auch diese vielen essentiae der einzelnen Geschöpfe ist? In der Tat; gleich wie befremdlich dieser Gedanke zunächst auch sein mag, genau davon ist im Anschluss die Rede.

»Denn so wie Gott selbst in sich selbst über allem Geschöpf von keinem Geist begriffen wird, so ist er auch in den verborgensten Tiefen des Geschöpfes, das als von ihm gemacht und in ihm existierend anzusehen ist, unbegreiflich."

Nachdem Eriugena zwei Autoritätsverweise präsentiert hat, folgt nun von Zeile 65-73 seine eigene Begründung für die Behauptung, auch die rationes und essentiae omnium rerum seien unbegreiflich. Sprachlich zeigt sich dies am einleitenden nam (`denn`). In dieser Begründung ist Gott ein Doppeltes: er ist über allem Geschöpf und zugleich in allem Geschöpf. Diese theologisch wie metaphysisch weitreichende Aussage kommt ziemlich unvermittelt. Vorbereitet wurde sie durch den Hinweis, dass niemand denken solle, man könne die substantia oder essentia der Geschöpfe irgendwie begreifen. Theologisch gesehen darf dies

${ }^{114}$ Siehe zur Diskussion über Übersetzungsweise und Bestimmung dieses aristotelischen Begriffes Hermann Weidemann: Zum Begriff des ti ên einai und zum Verständnis von Metaphysik Zeta 4 1029b22-1030a6, in Christof Rapp: Metaphysik Die Substanzbücher, Berlin 1996, S. 75-103. 
gar nicht möglich sein, wenn Gott diese substantia ist; denn er ist unbegreiflich.

Dass Gott an sich unbegreiflich ist und über allen seinen Geschöpf erhaben, ist aus christlich-theologischer Sicht so selbstverständlich, dass es hier nicht der Erläuterung bedarf. Überraschender sind die verborgenen geschöpflichen Tiefen (sinus), in denen Gott zugegen sein soll. Die Doppelrolle Gottes setzt sich fort, wenn Eriugena die Geschöpfe näher bestimmt: als "von ihm gemacht und in ihm existierend « sind sie anzusehen. Ersteres ist vertraut, zweiteres nicht. Dass die Geschöpfe in Gott existieren, bedarf der Erklärung, die aber hier nicht folgt.

Von existentia gibt es im gesamten Periphyseon keine nähere Bestimmung. Blicken wir auf die Quellenschriften, so hilft auch das kaum weiter. In Eriugenas wohl später entstandenen Übersetzung der Quaestiones ad Thalassium von Maximus übersetzt er mit existentia das griechische öv $\tau \alpha$ (onta), wenngleich er in seinen vorangehenden Übersetzungen für $\tau \alpha$ ö $\nu \tau \alpha$ (ta onta) wie gezeigt ea quae sunt wählte ${ }^{115}$ Doch weil Maximus an dieser Stelle das to on vom to einai abgrenzt (esse bei Eriugena), hält es Eriugena wohl für angebracht, das on des Maximus als existentia zu interpretieren. Erklärt ist damit die Bedeutung von existentia freilich noch nicht.

Es liegt nahe, die geschöpflichen Tiefen als dasjenige aufzufassen, was zuvor substantia und essentia genannt wurde. Zwar wird dies nicht explizit gesagt, aber nur so ergibt die Argumentation des Textes einen Sinn. Gott ist demnach die jeweilige substantia und essentia des Geschöpfes, und zwar insofern, so zeigt es der Text, als das Geschöpf in ihm existiert. Wie dies im Einzelnen zu verstehen ist, bleibt noch zu untersuchen.

»Was auch immer in allem Geschöpf mit dem körperlichen Sinn erfasst oder dem Denken betrachtet wird, ist nichts anderes als ein gewisses Akzidenz jedes, wie gesagt wurde, einzelnen und unbegreiflichen Wesens."

Aus zweierlei besteht hier jedes Geschöpf: aus seiner essentia und den Akzidenzien. Dass die essentia eine dem einzelnen Geschöpf eigene ist, zeigt das unicuique. Sie, dies wird noch einmal wiederholt, ist unbegreiflich. Erst damit ist klar gesagt, dass tatsächlich nicht nur jene

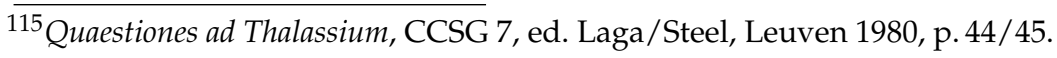


göttliche, das Sein verursachende essentia unbegreiflich ist (dies sagten auch Gregor und Maximus), sondern auch die, vorsichtig gesagt, individuelle Substanz des Geschöpfes. Klar ist ebenso, dass essentia hier als Zugrundeliegendes der Akzidenzien auftritt, also in einer Verwendung aus der aristotelischen Kategorienschrift, die über die lateinische Dialektik zu Eriugena gelangt. Damit lässt sich hinsichtlich essentia Folgendes festhalten:

1. essentia von allem ist Gott $(\mathrm{I}, 60)$

2. essentia ist das Sein von allem (esse omnium, I, 61)

3. essentia ist gleichzusetzen mit substantia (I, 61/62)

4. essentia ist das Zugrundeliegende der Akzidenzien (I, 70)

Nun ist es nicht so, als präsentiere Eriugena ähnlich wie Aristoteles in Metaphysik VII hier verschiedene Kandidaten, die als Substanz (ousia) in Frage kommen. Vielmehr tut er so, als rede er stets von derselben Sache. Daher könnte ihm die hier gemachte vierfache Aufstellung durchaus unangebracht erscheinen. Doch wir müssen uns wenigstens darüber klar werden, dass Eriugena dabei von etwas spricht, das für uns mindestens zwei verschiedene Dinge sind: erstens essentia als die eine Seinsursache und zweitens essentia als jeweils Zugrundeliegendes für die Akzidenzien. Wenn man dann noch die Gleichsetzung von essentia mit ratio dei hinzunimmt, gibt es noch ein Drittes: essentia als Idee oder Urbild Gottes. Und viertens ergibt sich vielleicht sogar noch der Gedanke, essentia sei genau dasjenige, das wahrhaft ist (vere est). Umgekehrt lässt sich das Ganze auch zusammenfassend lesen:

Gott ist essentia aller und mit dieser essentia Ursache von allem Sein. Er allein ist wahrhaft. Weil er allein wahrhaft ist, existiert auch nur in ihm alles Geschaffene. Und alles existiert in ihm, insofern er in den geschöpflichen Tiefen zugegen ist: als seinsspendende Substanz und als Zugrundeliegendes der Akzidenzien.

Erst durch solch eine Synopsis erhält Eriugenas Argumentation die Form eines Arguments. Der Text ist weit davon entfernt, das Gesagte mit dieser Deutlichkeit offen zu legen. Doch wenn die gegebenen Sätze nicht in argumentativ unverbundener Abfolge bestehen bleiben sollen, ist dies die einzig auffindbare Lösung. 
Sehen wir uns an, wie Eriugena erläutert, dass vom Geschöpf nur dessen Akzidenzien, nicht aber dessen essentia erkennbar sei.

\subsubsection{Dass-Sein und Was-Sein}

»Denn durch das Wie und das Wiegroß und die Gestalt und Materie und den Unterschied, wie auch Ort und Zeit, erkennt man nicht, was dieses ist, sondern dass es ist."

Auffällig ist zunächst die Unterscheidung zwischen der Bestimmung, dass etwas ist und was etwas ist, die philosophiegeschichtlich wohl auf Aristoteles zurückgeht ${ }^{116}$ Sie bildet die logische Basis für Eriugenas negative Ontologie. So, wie eine negative Theologie nur unter der Annahme sinnvoll ist, Gott existiere, d. h. dass er ist, so wird Eriugenas negative Ontologie auf der Annahme aufbauen, das Vorhandensein einer je zugrunde liegenden Substanz sei evident. Diese Evidenz ergibt sich aus dem, was von der Substanz wahrnehmbar und fassbar ist, ohne dass sich dadurch die Substanz selbst bestimmen ließe. Man erfasst demnach, dass sie ist, aber nicht, was sie ist. Diese Unterscheidung findet Eriugena in seinen Quellen vor allem in Maximus' Ambigua ad Iohannem, der sie in Bezug auf die göttliche Substanz mehrfach anführt, etwa: »Ich sage nicht, dass diese Natur unfassbar ist in Bezug auf die Rede, dass sie ist, sondern was sie ist. «117 Und weiter: »Sehr unterscheidet sich, gewiss zu sein, dass etwas ist, von der Erkenntnis, was dieses ist ‘, das heißt, groß ist der Unterschied vom Überzeugtsein, dass etwas besteht, hin zum genauen Erfassen von der ousia des Erkannten.« worin der erste Satzteil ein Zitat Gregors ist 118

\footnotetext{
116 Analytica posteriora, 89b34-90a7.

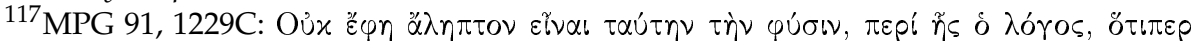

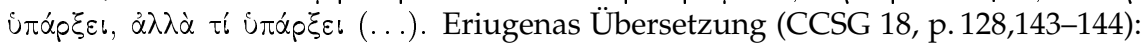
Non dixi inacceptibilem esse hanc naturam, de qua sermo est, quia subsistit, sed quid subsistit.

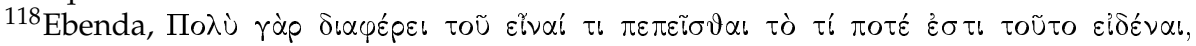

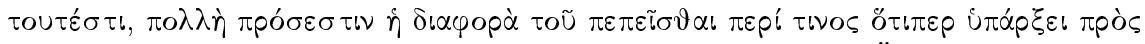

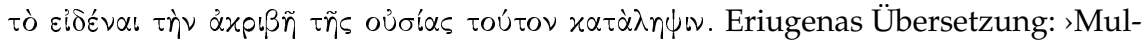
tum enim differt esse quid credere et quid est ipsum nosse<, hoc est, multa adest distantia inter credere de aliquo quia subsistit et scire diligentem essentiae ipsius comprehensionem.

Für die Unterscheidung von quia est und quid est verweist Sheldon-Williams auf Au-
} 


\subsection{Der Kern der negativen Ontologie}

Die dringliche Frage im Hinblick auf diese Aussage im Periphyseon ist, wovon lediglich erkannt wird, dass es ist, aber nicht was es ist, vom Geschöpf oder von der essentia des Geschöpfes? Grammatikalisch lässt der Satz beides zu. Da im vorangehenden Satz vom Geschöpf die Rede ist, von dem sich nur die Akzidenzien erkennen lassen, nicht aber die essentia, liegt es nahe, das Gesagte auf das Geschöpf zu beziehen. Dann bestimmte die essentia das Was eines Geschöpfes, die Akzidenzien hingegen die Qualität, Quantität, die Differenzen usw. Doch vorher hieß es mit Bezug auf Gregor, alle essentia und substantia des Geschaffenen sei unbegreifbar. Und man könnte den Folgesatz durchaus in diesem Lichte lesen, wonach sich von der verborgenen göttlichen essentia im Geschöpf nur das offenbare, was ihm an Akzidenzien zukomme und letztlich das wahrnehmbare Geschöpf ausmache. Je nachdem, für welche Interpretation man sich entscheidet, weist man der essentia eine bestimmte Auffassung zu: der ersten Interpretation nach bestimmt sie das Was einer Sache, der zweiten Interpretation nach ist sie das den Akzidenzien Zugrundeliegende. Beides schließt sich nicht aus, doch wenn Eriugena hier nur an eine der beiden Bedeutungen von essentia denkt, sollte man dies für alles Weitere berücksichtigen.

In jedem Fall weitet Eriugena die angeführte theologische Unterscheidung des Maximus auf die Erkenntnis des Geschöpflichen aus. Was man von diesem oder von seiner essentia erkenne, sei das Akzidenzielle wie Ort, Zeit, Größe oder Wiebeschaffenheit. Nun behauptet keiner der antiken Autoren, durch Ort oder Größe erkenne man von einem Ding, was es ist, sondern nur, wo und wiegroß und vielleicht dadurch auch, dass es ist. So sagt Aristoteles etwa in der Metaphysik: »Wenn wir nämlich angeben wollen, wie beschaffen dies sei, dann sagen wir gut oder schlecht, nicht aber, es sei drei Ellen lang oder ein Mensch. Wenn wir aber das >Was etwas ist< von etwas angeben wollen, sagen wir nicht, es sei weiß oder heiß oder drei Ellen lang, sondern ein Mensch oder ein Gott. «119 Abwegig ist daher die Annahme, mittels

gustinus (Periphyseon Book I, p. 223, note 20), doch Madec zeigt auf, dass sowohl die Formulierung als auch der Kontext bei Augustinus eine andere ist, in ders.: Jean Scot et ses auteurs, Paris 1988, p. 75.

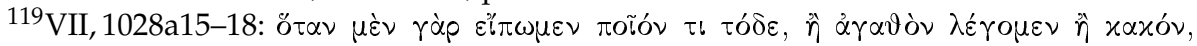

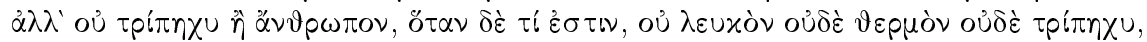

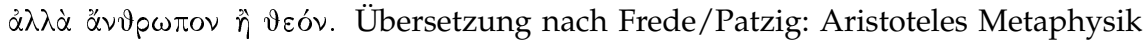
Zeta, Bd. 1, München 1988, S. 61. 
der genannten Akzidenzien lasse sich das Was der essentia erkennen. Welche Auffassung also kritisiert Eriugena hier?

Seine Kritik ist zumindest von größerer Tragweite. Denn nicht nur die Akzidenzien bestimmten nicht das Besagte, sei es Geschöpf oder dessen essentia, sondern auch weder die spezifische Form (forma), noch die Materie oder die Differenz. Entscheidend ist hier die Interpretation der forma. Wird sie nur als Gestalt verstanden, zielt die Kritik vielleicht in die Richtung einer Auffassung, die in der äußerlichen Gestalt die essentia des Dings zu erkennen glaubt. Fasst man sie hingegen als species auf, dann erhält die Aussage in Verbindung mit der genannten Differenz eine gewaltige Konsequenz: die klassische Definition einer Sache mittels Angabe der artbildenden Differenz und Gattung bzw. Art würde dann hinfällig. Genau zu diesem Schluss ist Eriugena letztendlich bereit, zieht ihn hier aber nicht. All dies ist abschließend noch einmal eingehend $\mathrm{zu}$ diskutieren 120

\subsubsection{Das unbestimmbare subiectum}

Theologen wollen jetzt vielleicht auf die Lehren Augustins und Gregors von Nyssa verweisen, wonach der menschliche Geist unbegreiflich ist, doch Eriugena spricht hier nicht nur vom beseelten oder vernünftigen Geschöpf, sondern von schlichtweg allem Geschaffenen und substanziell Seienden. Seine Aussage von der Unbegreiflichkeit des Geschöpfes oder der geschöpflichen essentia lässt sich auch nicht auf die pseudoaugustinischen Schrift De categoriis Aristotelis zurückführen: »Denn von der ousia, da man sie der gültigen Lehre nach nicht bestimmen konnte - weil diese vorschreibt, dass die Bestimmung, damit sie sich weiter ausdehnt, von der Gattung her ihren Anfang nehmen soll, ousia selbst aber keine Gattung hat, da sie selbst alles enthält (...). $\left\langle{ }^{121}\right.$ Denn hier ist von ousia als höchster Gattung die Rede, aber nicht von der jeweiligen Substanz des Individuellen. Insofern Eriugena die substantia des Ein-

${ }^{120}$ Siehe Abschnitt 3.4.6.

${ }^{121}$ Paraphrasis Themistiana, in: Aristoteles Latinus I, 1-5 (ed. Minio-Paluello), p. 145, 2528: Sed usian, quoniam secundum artem difiniri non poterat - quae praecepit ut definitio, quo possit tendi latius, a genere sumat exordium, ipsa autem usia genus non habet cum omnia ipsa sustineat (...). Hier liegt der Gedanke zugrunde, eine Definition umfasse das zu Bestimmende, indem sie die Grenze des Gegenstandes angibt. Diese Auffassung findet sich auch im Periphyseon wieder I, 1819-1839. 
zelnen mit ins Spiel bringt, vertritt er einen noch nicht da gewesenen Gedanken. Doch dazu später mehr.

Die Frage, ob Eriugena bei essentia das definitorische ti ên einai des Aristoteles im Blick hatte, erübrigt sich insofern, als er um dieses nicht wusste. Es liegt die Vermutung nahe, seiner Auffassung zufolge beantworte das subiectum die Frage nach dem Was eines Dings. Doch ist dies eine aristotelisierte Lesart, die so nicht zutrifft. Wenn angebbar wäre, was die essentia eines Geschöpfes ist, dann wäre damit nach Eriugena viel weniger das Geschöpf zureichend definiert, als dass der verborgene Schöpfer, der diese essentia ist, erkannt wäre. Es geht ihm nicht darum, ob die essentia das Was einer Sache verrät, sondern darum, dass die essentia ein Gegenstand ist, der sich dem Erfassen stets entzieht. Das Geschöpf ist weniger eine mit Form verbundene Materie, der aufgrund seiner Form ein ti ên einai zukommt, sondern das Resultat der Zusammenkunft der Akzidenzien an einer essentia, kurz gesagt, die Sichtbarwerdung der an sich unfassbaren essentia.

Nicht das Geschöpf ist unbestimmbar, sondern dessen essentia, wie es der behandelte Textabschnitt zeigt. Der in I, 71 beginnende Satz soll das Vorangehende begründen, und dieses Vorangehende bezieht sich, wie das argumentative nam zeigt, wiederum auf Gregors Aussage. Gregor lege dar, die substantia bzw. essentia sei unbegreiflich. Dazu passt die Begründung, wonach es Gott sei, der sich als dieses Unbegreifliche im Geschöpf verberge (I, 65-68). Darauf folgt die Aussage, von einem Geschöpf sei, »wie dargelegt « (ut dictum est), die essentia unbegreiflich. Die Aussage bezieht sich demnach eindeutig auf das schon Angeführte. Da in I, 71 der Satz mit einem begründenden nam beginnt, kann er sich allein auf das schon Gesagte beziehen. Sinnvoll ist daher eine Lesart, die diese Begründung an das Bisherige anknüpft, und demzufolge ist von der essentia die Rede, die sich nicht mittels Akzidenzien, Differenz usw. bestimmen lasse, und nicht vom Geschöpf.

Abschließend bleibt zu fragen, in welche Richtung Eriugenas Argument eigentlich verläuft, von der Theologie zur Dialektik oder umgekehrt. Kommt er zuerst zu der Einsicht, dass Gott die jeweilige essentia der Geschöpfe ist und glaubt im Anschluss daran, dessen dialektische Unbestimmbarkeit tatsächlich darlegen zu können, oder erkennt er zunächst diese Unbestimmbarkeit und erhält dann aus seinen griechischen Quellen die entscheidende theologische Erklärung, warum die 
essentia gar nicht bestimmbar sein kann, weil sie nämlich göttlich ist? Der Text gibt uns hierauf keine Antwort.

An dieser Textstelle endet Eriugenas Argument. Was bleibt als Fazit? Es sollte erwiesen sein, so ließe sich der Text zusammenfassen, dass auch die essentiae und rationes omnium rerum unbegreiflich sind, weil sich die substantia und essentia von jedem Geschöpf nicht fassen lässt. Und weiter: sie lässt sich darum nicht fassen, weil sie nichts anderes ist, als der im Geschöpf verborgene Schöpfer, der sich aller Fassbarkeit entzieht. Das Argument funktioniert aber nur dann, wenn essentia als causa omnium und die vielen essentiae bzw. subiecta dasselbe sind, ein Sprung, dem es noch nachzugehen gilt ${ }^{122}$

»Diese Auslegungsweise also ist die erste und höchste von der Einteilung jener Dinge, die seiend heißen und nichtseiend, da solches, das derart zu sein scheint, dass es in Ermangelung sowohl der Substanz als auch der Akzidenzien aufgestellt ist, auf keine Weise aufnehmbar ist, wie ich meine.«

Man sollte meinen, dass sich dieser Satz ohne Schwierigkeiten als $\mathrm{Zu}$ sammenfassung von I, 53-73 verstehen lasse und speziell von 53-59. Doch er steht dem entgegen, was oben als Einteilungsgrund angegeben wurde, und zwar im Zusammenhang mit der Aussage in I, 53-55. Es lag die Vermutung nahe, die ratio teile die Gesamtheit der Dinge ein, eben weil sie Einiges davon erfassen kann und Einiges nicht. Doch warum sollten dann noch vier weitere Auslegungsweisen folgen? Und warum nennt Eriugena dies überhaupt modus interpretationis? Sinnvoll interpretieren lässt sich nur, was vorgefunden wird, nicht aber, was man selbst hervorbringt. Wenn also die ratio gemäss ihres Ordnungsvermögens die Einteilung von seiend und nichtseiend selbst hervorbringt, kann sie diese zwar näher beschreiben, aber nicht interpretieren. Zudem, dass die ratio eine bereits gegebene Differenz interpretiert, legt der hier vorliegende Satz in I,73-74 dar. Eriugena sagt nicht iste modus primus ac summus est divisio in ea quae esse et non esse dicuntur, sondern iste modus primus ac summus est divisionis eorum quae dicuntur esse et non esse. Im ersten Fall könnte man sagen, die ratio nenne auf ei-

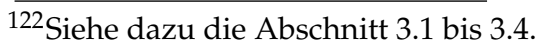




\subsection{Der Kern der negativen Ontologie}

ne solche Weise die Dinge seiend und nichtseiend, im zweiten Fall hingegen muss man aufgrund des Genitivs divisionis hinnehmen, dass die ratio etwas bereits Gegebenes auf eine von fünf möglichen Weisen (modi) auslegt. Demnach handelt es sich beim zuvor Erläuterten um den ersten Modus der (gegebenen) Einteilung derer, die seiend und nichtseiend heißen.

Das klingt so, als wären Sein und Nichtsein gegebene Kategorien oder Klassen, unter denen die ratio die Gegenstände zwangsläufig vorfinde und nun hinsichtlich ihres Sinns interpretieren müsse. Der Anschluss »da solches, das derart zu sein scheint, dass es (...) aufgestellt ist, auf keine Weise aufnehmbar ist « wäre dann so zu verstehen, dass die ratio in ihrer Erklärung der gegebenen Klassen nur solche Gegenstände miteinbeziehen sollte, die sich innerhalb eines sinnvollen Erklärungsrahmens befinden. Solches, dem sowohl substantia als auch jegliches Akzidenz ermangelt, scheint nach Eriugena kein für die Untersuchung sinnvoller Gegenstand zu sein.

Wir müssen nach Eriugena augenscheinlich entweder eine Natur annehmen, die unterteilt ist in Seiendes und Nichtseiendes, oder eine Natur, die der Alltagssprache nach so eingeteilt ist. In beiden Fällen obliegt unserer ratio die Interpretation, wie dieses >zu sein ‘ und >nicht zu sein<, zu erklären ist. Das anwesende dicitur legt nahe, sseiend ‘ und >nichtseiend < als Aussageweisen aufzufassen. Aber wie gelangt man zu diesen Aussageweisen, die nicht einmal den ontologischen Tatsachen entsprechen? Erst aufgrund einer späteren Aussagen aus dem dritten Buch wird dies deutlich:

"Alles nämlich, was begriffen oder sinnlich wahrgenommen wird, ist nichts anderes als die Erscheinung des nicht Erscheinenden, die Offenbarung des Verborgenen, die Bejahung des Verneinten, das Verstehen des Unverständlichen, der Ausspruch des Unaussprechlichen, die Annäherung an das Unnahbare, der Begriff des Unbegreiflichen, der Körper des Unkörperlichen, das Wesen des Überwesenhaften, die Gestalt des Gestaltlosen, das Maß des Unermesslichen, (...) die Örtlichkeit des Ortlosen, die Zeitlichkeit des Zeitlosen, die Bestimmung des Unendlichen, die Eingrenzung des Grenzenlosen (...).423 Demnach wäre

${ }^{123} \mathrm{III}, 589-597$ : Omne enim quod intelligitur et sentitur nihil aliud est nisi non apparentis apparitio, occulti manifestatio, negati affirmatio, incomprehensibilis comprehensio, ineffabilis fatus, inaccessibilis accessus, inintelligibilis intellectus, incorporalis 
das non esse das, was im Verborgenen wahrhaft ist, das esse die bloße Erscheinung desselben. Diese Darstellung fügt sich passend an das an, was in der ersten Auslegungsweise angegeben ist. Somit kehrt der Sprachgebrauch die ontologischen Tatsachen um: dasjenige, was ontologisch als non esse zu bestimmen ist, weil es gar nicht wahrhaft ist, nennt man gewöhnlich esse, dasjenige hingegen, das wahrhaft ist, non esse. Der Grund dafür ist folgender: Wie das Zitat zeigt, geht die Sichtbarwerdung immer mit der Bejahung einher, das Verborgensein mit der Verneinung. Folglich wird die Erscheinung des wahrhaft Seienden esse genannt, anstatt dieses selbst so zu benennen.

Diese erste der fünf Auslegungsweisen des Periphyseon, in I, 53-77 dargelegt, scheint die von Eriugena favorisierte zu sein, da er wenig später sagt: »Zurecht also heißen die seiend, welche mit dem Verstand oder Denken begriffen werden können, die aber allen Verstand und alles Denken überragen, heißen gleichermaßen zurecht nichtseiend ", und selbiges zeigt sich im dritten Buch ${ }^{124}$ Diese erste Auslegungsweise bezieht er dabei auf die Unterscheidung zwischen substantia und Akzidenz, wie nicht nur I,75-76 zeigt, sondern auch eine spätere Aussage aus dem ersten Buch: »Die erste Einteilung aller Gegenstände freilich ist die in essentiae und Akzidenzien. 125 Die Akzidenzien werden dabei, da sie nach Eriugena für das Sichtbare stehen, dem esse zugeordnet, die essentia, weil sie unbegreiflich ist, dem non esse. Man sieht deutlich, wie Eriugena hier den Sprachgebrauch relativiert: die essentia unter die Nichtseienden zu klassifizieren, kann nicht den ontologischen Tatsa-

corpus, superessentialis essentia, informis forma, immensurabilis mensura, (...) illocalis localitas, carentis tempore temporalitas, infiniti diffinitio, incircumscripti circumscriptio (...). Man kontrastiere dagegen Aristoteles, De generatione et corruptione, 318b19-27 (angeführte englische Übersetzung nach C.J.F. Williams, Clarendon Aristotle Series, 1982; aufgenommen in J.L. Ackrill: A new Aristotle reader, Oxford 1987, p. 146): »The common view is rather that the difference is in terms of the perceptible and the imperceptible (...). They distinguish what is and what is not by their perceiving and not perceiving it, in the same way as the knowable is what is and the unknowable what is not, for perception has the force of knowledge. (...) In a sense they are on to something true, though what they actually say is untrue."

${ }^{124}$ I, 200-203: Recte igitur dicuntur esse quae ratione atque intellectu comprehendi possunt, quae vero omnem rationem ac intellectum exsuperant recte similiter dicuntur non esse. Sowie III, 404-411.

${ }^{125}$ I, 2827-2829: Prima siquidem rerum omnium divisio est in essentias et accidentia. 
chen entsprechen, sondern ist unseren Sprachgewohnheiten geschuldet, die nur Sichtbares und Fassbares mit >Seiendes< benennen.

Jene Grundunterscheidung von Substanz und Akzidenz gelangt bereits mit Porphyrios' Kategorieninterpretation in den lateinischen Westen und wird in einer Marius Victorinus zugeschriebenen Abhandlung wie folgt angeführt: »Man sieht also, dass die ganze Verschiedenheit aller in ein zweigliedriges Haupt der Gegenstände unterteilt ist; in Substanz und Akzidenz, weil weder das Akzidenz ohne Substanz, noch ohne Akzidenz die Substanz sein könnte. ${ }^{126} \mathrm{Ob}$ diese Unterscheidung über diese oder andere Quellen zu Eriguena gelangte, ist ungewiss, doch sie ist ihm offensichtlich so geläufig, dass er auf eine Rechtfertigung derselben verzichtet.

In I, 74-76 des Periphyseon ist dieser zweigliedrigen Unterscheidung der spekulative Gedanke angefügt, es könne etwas geben, das in Ermangelung sowohl der Substanz als auch der Akzidenzien bestehe (in privationibus constituitur). Ungeachtet der Frage, ob und wie solch ein Dasein vorstellbar ist, wird es von vorn herein von der Unterteilung ausgeschlossen. Jedem sseiend ‘ oder snichtseiend ' genannten Gegenstand kommt also eine Substanz oder Akzidenzielles zu, und auch nur solches wird daher >Natur $<$ zu nennen sein. Und als Begründung heißt es in der Folge:

»Denn von dem, was vollständig nicht ist und nicht sein kann und nicht durch Hervorragen seines Daseins den Geist übersteigt, sehe ich nicht, auf welche Weise es in die Einteilungen der Gegenstände aufgenommen werden soll.«

Hier sind zwei interessante Ausdrücke zugegen. Zum einen das schon angesprochene penitus non esse, das vollständige Nichtsein, zum anderen wiederholt die Existenz (existentia). Existenz bezeichnet demnach eine Daseinsform, die nicht etwa sseiend / genannt wird, sondern viel-

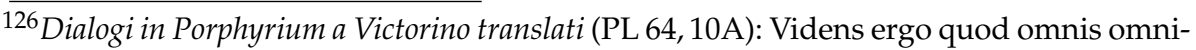
um disparilitas in gemina rerum principia secaretur. in substantia atque accidens, ita ut neque accidens sine substantia, neque sine accidenti substantia esse possit. Siehe zur Unterscheidung bei Porphyrios: Commentarius in Categoriis Aristotelis, in: Commentaria in Aristotelem Graeca (CAG) IV.1, ed. Adolf Busse, Berlin 1887, 71, 2829; eine englische Übersetzung liegt vor als: Porphyry - On Aristotle's Categories, translated by Steven K. Strange, London 1992, dort p. 53. 
mehr >nichtseiend $<$. Demnach setzt Eriugena zwar existentia mit vere esse gleich, nicht aber mit esse dicitur.

Wie ein Gegenstand aussehen könnte, der gar nicht ist oder nicht existiert, ist hier nicht dargelegt und vielleicht auch nicht erklärbar. Die Anfügung durch $\mathrm{R}^{2}$, wonach selbst die Abwesenheit (absentia) und der Mangel (privatio) nicht nichts sind, bezieht sich wahrscheinlich auf die Abhandlung des Alkuin-Schülers Fridugisus, wonach selbst dem nihil, aus dem Gott die Welt erschafft, eine substantia zukommen muss ${ }^{127}$

\subsection{Die übrigen vier Auslegungsweisen und ihre Funktion}

Im Unterschied zur ersten Auslegungsweise lassen sich die übrigen vier deutlich zügiger behandeln. Man wünscht sich dabei vom Text eine Erklärung, wie sich die fünf Auslegungsarten zueinander verhalten und ob sie irgendeiner Ordnung entspringen, doch es finden sich dazu keinerlei Angaben. Die dritte bezieht sich wohl auf Aussagen Augustins, die vierte steht in Verbindung zum platonischen Timaios, die fünfte zu einem Bibelzitat.

Zusammenfassend lassen sich die fünf Weisen folgendermaßen bestimmen: die erste Weise, >Sein < auszusagen, orientiert sich an der Fassbarkeit des Gegenstandes, die zweite ebenso. Die dritte Weise nennt sseiend`, was nicht bloß der Möglichkeit nach, sondern aktuell und wirklich ist, die vierte Weise das, was unveränderlich und ewig ist und die fünfte schließlich das, was in Christus das ewige Leben wiedergefunden hat.

\subsubsection{Die zweite Auslegungsweise}

Die zweite Aussageweise ist dabei die unklarste von allen. Liest man sie unter Auslassung von I,94-106, bleibt wenigstens die größte Schwierigkeit außen vor. Ein Versuch der Ordnung: Die Wesensheiten (essentiae) einer Reihe (ordo) erkennen sich selbst und die Wesenheiten niederen Ranges, nicht aber diejenigen von höherem Rang. Doch was heißt hier cognoscere? Erkennen, dass etwas ist oder was es ist, um die Unterscheidung aus dem vorangehenden Abschnitt anzuführen?

$\overline{{ }^{127} \text { De substantia nihili et tenebrarum, }}$ PL 105, 751-756. 
Wenn essentia aus I, 99 dasselbe meint wie zuvor, dann ist ausgeschlossen, dass dessen Was erkannt wird, selbst auch bei den essentiae der niedersten Reihe. Doch tritt essentia tritt hier nicht als Substanz von etwas auf oder als Wesensdefinition, sondern als Klassenbegriff bestimmter, nämlich geistiger, Gegenstände. Essentia bezeichnet ein himmlisches Wesen, das mit anderen in einer Rangstufe steht. Damit wird das cognoscere noch undeutlicher, denn nicht die essentia von etwas soll ja für das Rangniedere unerkennbar sein, sondern die essentia als solche, ja nicht einmal diese, wie ein Blick auf die Grammatik des Satzes zeigt: »Aus diesem Grund sagt man von jeder Reihe des verständigen und denkenden Geschöpfes Sein und Nichtsein aus. Sie ist nämlich, soweit sie von den höheren oder sich selbst erkannt wird; sie ist hingegen nicht, sofern sie den niederen nicht gestattet, sie zu begreifen.« Das nachfolgende $a$ se ipso kann sich nicht auf das zuvor genannte Geschöpf oder die essentia beziehen, da es ein maskulines bzw. neutrales Pronomen ist, creatura und essentia hingegen feminin sind 128 Es bleibt daher nur der Bezug auf ordo. Demzufolge ist es der gesamte ordo, der erkennt und erkannt wird, also die gesamte Reihe an essentiae. Das ist wenig befriedigend auch im Hinblick auf die Frage, was cognoscere hier meint.

Nimmt man I, 94-106 hinzu, ergibt sich eine weitere Schwierigkeit: Die Bejahung des Niederen und die Verneinung des Höheren stehen wohl in einem wechselseitigen Verhältnis. Auf welche Weise jedoch geschieht die Verneinung des Niederen infolge der Bejahung des Höheren, wie sie der Text behauptet? In welcher Hinsicht lässt sich, um bei dem gegebenen Beispiel zu bleiben, aufgrund der Bejahung des Engels der Mensch verneinen? Was ist mit der Bejahung des Engels (affirmatio angeli) überhaupt gemeint, d.h. welche Aussage wird bejaht und folglich dann vom Menschen negiert? Es findet sich dafür keine Erläuterung im Text.

Anders als in der ersten Auslegungsweise, wo Eriugena seine vermeintlichen Quellen nennt, ist hier nicht klar, wie er zu seiner Darstellung gelangt. Keiner seiner Quellentexte behauptet Derartiges. Dabei liegt die Vermutung nahe, der Abschnitt orientiere sich an der Hierarchien-Lehre des Dionysius Areopagita, doch ist in dessen Schriften

\footnotetext{
${ }^{128} \mathrm{Hac}$ item ratione omnis ordo rationalis et intellectualis creaturae esse dicitur et non esse. Est enim, quantum a superioribus vel a se ipso cognoscitur.
} 
kein Bezug der Hierarchien auf >Sein « und >Nichtsein ‘ auffindbar, und auch die Ambigua des Maximus Confessor gibt nichts Dergleichen an.

Im Buch von den himmlischen Hierarchien, das als Gedankenquelle für das hier Gesagte naheliegend scheint, findet sich im fünften Kapitel nur der auch hier angeführte Verweis auf das abnehmende geistige Vermögen im Abstieg der Rangordnung; mehr gedankliche Parallelen gibt es nicht. Und auch in der mystischen Theologie des Dionysius heißt es lediglich, dass im Aufsteigen zum Göttlichen hin die Bejahungen der geeigneten Benennungen Gottes zunehmen, die Verneinungen der ungeeigneten Benennungen hingegen abnehmen, und dass umgekehrt im Abstieg die geeigneten göttlichen Benennungen zusehends zu verneinen sind 129

Der Quellenapparat in Jeauneaus Edition, sonst umfangreich und zuverlässig hinsichtlich möglicher Vorlagen, führt hierzu nichts an. Daher ist einzig verbleibender Anhaltspunkt zur Erläuterung der Aussagen eine Randbemerkung im Autographen, die Jeauneau als eine Anfügung von $\mathrm{R}^{2}$ identifiziert hat, also der Hand eines irischen Schreibers, der den Text redigierte ${ }^{130}$ Darin wird das Beispiel aus dem Text von Engel und Mensch weiter ausgeführt. Zur Bejahung des Menschen heißt es da: >Der Mensch ist ein rationales sterbliches Lebewesen. 131 Demnach ist die Bejahung nichts anderes als eine affirmative Bestimmung. Daraus leite sich die Verneinung ab: >Ein rationales unsterbliches Lebewesen ist der Mensch nicht. ${ }^{132}$ Diese >Verneinung ist eine verneinende Bestimmung, eine definitio ex negativo. Dieselbe Bestimmung komme dem Engel in bejahender Form zu: >Der Engel ist ein rationales unsterbliches Lebewesen. ${ }^{133}$ Dies ist soweit einsichtig, doch erklärt es nicht, warum die Verneinung schlechthin (und nicht nur irgendeine bestimmte) in Bezug auf den Menschen die Bejahung des Engels ergibt. Man könnte etwa statt >sterblich < das >rational< verneinen, dann ergäbe sich: `Ein irrationales sterbliches Lebewesen ist der Mensch nicht‘,

\footnotetext{
${ }^{129}$ Mystica theologia II \& III (ed. Heil/Ritter, Berlin 1991, p. 145-147). Geeignet zur Benennung des Göttlichen seien dabei etwa >Güteく, >Schönheit< und >Vollkommenheit<, ungeeignet >Schlechtigkeit<, >Hässlichkeit< und >Mangel<.

${ }^{130}$ Jeauneau hat die Randglosse unterhalb des Textes ediert, p. 6.

${ }^{131}$ Affirmatio hominis: animal rationale mortale homo est.

${ }^{132}$ Negatio hominis: animal rationale immortale non est homo.

${ }^{133}$ Affirmatio angeli: Animal rationale immortale angelus est.
} 
woraus die unzutreffende Bejahung folgt: >Der Engel ist ein irrationales sterbliches Lebewesen $<134$

Zudem erstreckt sich dieses Beispiel nur auf das Paar Mensch-Engel. Wie der Text behauptet, soll es aber für alle Rangstufen (omnis ordo) aufsteigend bis zur höchsten gelten. Die Verneinung des niedersten Engels soll so die Bejahung des nächsthöheren ergeben und so fort bis zum höchsten Engel. Von welcher Form sollen solche Verneinungen und Bejahungen sein?

Es scheint, als sei die Glosse dem Umstand geschuldet, dass sich auch $\mathrm{Ri}^{2}$ keinen Reim aus dieser Passage machen konnte und es mit einer dialektischen Erklärung versuchte. Sie scheitert und muss scheitern, wenn Eriugena Bejahung und Verneinung nicht nur als dialektisches, sondern als dialektisch-ontologisches Prinzip auffasst, das die Gesamtheit aller Geschöpfe bedingt und ordnet. Dann ist die Verneinung des Engels als ontologisches Prinzip überhaupt erst dafür verantwortlich, dass er über dem Menschen steht.

\subsubsection{Die dritte Auslegungsweise}

Auch die dritte Auslegungsweise lässt sich nicht erschöpfend erklären. Fragt man nach dem Gegenstand, der sseiend ‘ oder snichtseiend ‘ genannt wird, so könnte man einerseits die Ursachen aus Zeile 112/113 nennen, andererseits das Sichtbare nebst seiner verborgenen Natur aus Zeile 115. Es hängt dabei viel davon ab, worauf man das Demonstrativpronomen ipsis in Zeile 115 bezieht. Um das Problem hervorzuheben: heißen die Ursachen snichtseiend', insofern man ihre Existenz nicht erkennt, weil sie noch nichts hervorgebracht haben, und dann sseiend<, insofern man aufgrund des Sichtbaren auf sie schließt, oder heißen die Wirkungen, insofern sie noch nicht sind und nur der Möglichkeit nach sind, snichtseiend<, sseiend < hingegen, wenn sie in die Aktualität treten? Das Beispiel in I, 125-130 von der Samenkraft deutet auf die erste

${ }^{134}$ Möglicherweise hatte der Glossenschreiber $\mathrm{R} i^{2}$ dabei den >Baum des Porphyrios< als Vorlage im Sinn, wie er sich im Kommentar des Boethius findet (PL 64, 103A). Dort wird das animal rationale in mortale und immortale eingeteilt. Mortale sei der Mensch, immortale Gott. Und später heißt es (104A): Animal vero rationalis genus est, et rationale genus est mortalis. Doch ist keinerlei Zusammenhang zwischen den Darstellungen des Boethius und der zweiten Auslegungsweise im Periphyseon ersichtlich, wo von Gattung und Art nicht die Rede ist und auch nicht sein kann. 
Variante hin und 112-113 verweist zudem ausdrücklich auf die Ursachen, die sseiend ‘ und snichtseiend ‘ heißen. Aber das ipsis will nicht $\mathrm{zu}$ den zuvor genannten causae passen, da diese sicherlich keine Tiefen ihrer Natur (ipsis naturae sinibus) besitzen, sondern vielmehr selbst diese Tiefen ausmachen. I, 127 zeigt, dass gerade virtus und causa in einer verborgenen Natur liegen. Dann wäre ipsis auf die Wirkung zu beziehen und dieses damit der Gegenstand, der >seiend ‘ und >nichtseiend ‘ genannt wird. Diese Zuordnung der Bestimmungen >seiend ‘ und >nichtseiend ‘ auf die Wirkung hin konnte Eriugena zudem bei Calcidius vorfinden 135

Was also wird sseiend $<$ und >nichtseiend < genannt, die Ursache oder die Wirkung? Oder ist die Ursache stets das Nichtseiende und die Wirkung das Seiende, wie es das Beispiel von der menschlichen Natur in I, 117-125 nahelegt? Die humanae substantia wäre die verborgene Ursache und die sichtbare Substanz (visibilis essentia) die Wirkung, und genau diese Interpretation legt auch I, 110-112 nahe.

Es soll nicht darauf eingegangen werden, mit welcher Leichtfertigkeit Eriugena hier von so etwas wie visibilis essentia spricht, nach alledem was er in I, 53-73 gesagt hat. Zu wenig klar ist ohnehin der gesamte Absatz. Zwar erinnert das Beispiel aus I, 117-125 über die menschliche Natur stark an die spätantiken Genesis-Exegeten, wonach Gott im Sechstagewerk bereits alles erschaffen hat, und so alles danach Werdende nicht als neue Substanz auftritt, die zuvor nicht war, sondern als eine Sichtbarwerdung des im Sechstagewerk bereits Geschaffenen ${ }^{136}$ Doch erklärt dieser Umstand nicht den Abschnitt hinsichtlich der Frage, was hier Gegenstand der Unterscheidung ist:

1. die Ursachen untereinander,

2. die Wirkungen untereinander,

3. oder die Ursachen von den Wirkungen?

${ }^{135}$ Commentarius in Timaeum Platonii, in: Plato latinus IV, ed. J.H. Waszink, p. 288, 20289, 2: alia vero ratione esse et non esse dicitur quid, quotiens nondum adhibito effectu esse dicitur, quod procul dubio futurum erit, si adhibeatur effectus.

${ }^{136}$ Die dritte Auslegungsweise orientiert sich sprachlich wie auch inhaltlich stark an den exegetischen Darstellungen des Augustinus, siehe dazu die Textverweise Jeauneaus in der Edition Periphyseon I, p. 7 und Goulven Madec: Jean Scot et ses auteurs, Paris 1988, p. 77. 
Wenigstens lässt sich im Beispiel von der menschlichen Natur die Verbindung zur ersten Einteilungsweise erkennen (I,65-68), da dem Erkennbaren wiederum die unergründlichen Tiefen der geschöpflichen Natur gegegnüberstehen (secretissimis naturae sinibus) ${ }^{137}$

Interpretiert man den gesamten Abschnitt aus I, 117-125 heraus, so ist der Einteilungsgrund von Sein und Nichtsein aufgrund der Zeit gegeben: Dasjenige, wovon bereits etwas sichtbar geworden ist, heißt seiend, dasjenige, was noch im Verborgenen liegt und erst in Zukunft in Erscheinung tritt, heißt nichtseiend. Diese Auffassung stützt eine Aussage aus dem ersten Buch über die Zeit: "Nichts anderes ist die Zeit als der Beginn der Gegenstände im Werden der Bewegung aus dem Nichtsein ins Sein. $<138$ Die essentia ist eine einzige, von Gott geschaffene, zeigt sich aber an verschiedenen Körpern: »Alle ousia ist aber einfach; ousia also ist kein aus Form und Materie zusammgesetzter Körper. Daher ist die ousia aller Menschen ein und dieselbe: alle nämlich haben an einer ousia teil und darum, weil sie allem gemein ist, ist ihr nichts eigen. Der Körper hingegen ist nicht ein gemeinsamer aller Menschen, denn ein jeder von ihnen besitzt seinen eigenen Körper. ${ }^{139}$ Es soll hier noch nicht auf Eriugenas eigentümliche Körperlehre eingegangen werden. Allein, was hier gesagt wurde, stützt die Interpretation ausgehend von I, 117125. Doch aus den schon genannten Gründen passt der Rest des Abschnittes mehr oder minder nicht dazu. Welche Gegenstände sseiend und `nichtseiend < zu nennen sind, muss daher unentschieden bleiben.

${ }^{137} \mathrm{Ob}$ mit diesem Verborgenen die substantiae und essentiae aus dem ersten Auslegungsmodus gemeint sind, sei dahin gestellt; es ist zumindest wahrscheinlich, da zuvor schon Selbiges »in den verborgensten Tiefen des Geschöpfes « verortet wurde. Siehe zu dieser Annahme Edouard Jeauneau: Quatre thémes érigéniens, Le caché et l' obscure; in: Etudes érigéniennes, Paris 1987, p. 25-46. Der Ausdruck secretis naturae sinibus tritt auch schon bei Augustinus mehrmals auf, siehe Goulven Madec: Jean Scot et ses auteurs, Paris 1987, p.74; an Textstellen bei Augustinus führt er an: De trinitate III, 9 (PL 42, 878) und Epist. 190, 5, 16 (PL 33, 862). Zudem nennt Jeauneau noch weitere Stellen im Apparat der Edition, p. 7.

${ }^{138}$ I, 1753-1754: nil aliud est tempus nisi rerum per generationem motionis ex non esse in esse inchoationem (...).

${ }^{139}$ I, 2087-2092: Omnis autem OYCIA simplex est; nullum igitur corpus forma materiaque compositum OYCIA est. Item omnium hominum una eademque OYCIA est; omnes enim unam participant essentiam ac per hoc, quia omnibus communis est, nullius proprie est. Corpus autem commune omnium hominum non est, nam unusquisque suum proprium possidet corpus. 


\subsubsection{Die vierte Auslegungsweise}

Um einem Missverständnis vorzubeugen: vere esse meint hier nicht das vere esse Gottes aus I, 60, was ganz merkwürdig wäre, sondern meint das rechtmäßige Benennen mit esse, wie das vere non esse zwei Zeilen später zeigt. Denn für die Annahme eines wahrhaft Nichtseienden gab es bislang keinen Grund.

Jeauneau spricht Naheliegendes aus, wenn er in seinen Editions-Anmerkungen den platonischen Timaios als Vorlage für das Gesagte anführt. Doch es ergeben sich zwei Schwierigkeiten.

Erstens wäre die Darstellung dann eine falsche Wiedergabe des von Platon Gesagten. Nun müssen wir davon ausgehen, dass Eriugena Platons Timaios nicht im Original, sondern in der Übersetzung des Calcidius kannte. Es ist also auf dessen lateinische Fassung zu schauen, die oftmals, und auch hier, sehr frei mit dem griechischen Text verfährt: »Es ist ja, wie mir scheint, zuerst einzuteilen, dasjenige, das immer ist, frei vom Werden, und ebenso dasjenige, das wird und nicht immer ist (...).« 140 Im Vergleich mit dieser Übersetzung ergibt sich ein deutlicher Unterschied zu Eriugenas Auffassung. Wie er behauptet, ist die vierte Art »den Philosophen nach nicht unpassend diejenige, in welcher lediglich jene wahrhaft seiend heißen (...)«. Es geht also nicht um eine Feststellung (wie bei Platon), dass es Seiendes und Nichtseiendes gibt und um eine Definition derselben, sondern darum, dass es eine Weise gibt, auf die Manches sseiend < genannt wird und Manches >nichtseiend

Zweitens ist in Bezug auf Jeauneaus Quellenangabe fraglich, ob Eriugena hier an den Timaios dachte, denn er sagt nicht »secundum Platonem « oder »secundum philosophum «, sondern »secundum philosophos", womit Mehrere bezeichnet sind. In Boethius' Arithmetik findet er die Bestimmung des Unveränderlichen und geistig Fassbaren als >Seiendes aus dem Timaios wieder, nebst der Behauptung, nur dieses Seiende sei Gegenstand der Philosophie ${ }^{141}$ Dahingehend wohl spricht Eriugena von >den Philosophen<, statt nur von einem, nämlich Platon.

Wieder stellt sich die Frage, welche Gegenstände es sind, die `seiend

\footnotetext{
${ }^{140}$ Timaios 27a; Bei Calcidius heißt $t$ es wie folgt (Plato latinus IV, ed. J.H. Waszink, p.20,15-17): Est igitur, ut mihi quidem videtur, in primis dividendum, quid sit quod semper est, carens generatione, quid item quod gignitur nec est semper (...).

${ }^{141}$ Institutio Arithmetica I, I, 1-4 (ed. Jean-Yves Guillaumin, 1995, p. 6-8). Eriugena nennt und zitiert diese Schrift des Boethius etwa in I, 2401-2415.
} 
und >nichtseiend < genannt werden. >Nichtseiendes < ist wohl eindeutig der Körper, aber welches sind die >Seienden`, die "nur mit dem Geist begriffen werden «? Der Text gibt hierzu keine Auskunft und daher ist wiederholt ein Blick auf die Quellen angebracht. Boethius führt zu Beginn der Arithmetik solche Dinge als seiend an, die ihrer Natur nach keine Veränderung erleiden: »die Qualitäten, die Mengen, die Formen, die Größen, die Kleinheiten, die Gleichheiten, die Zustände, die Antriebe, die Anordnungen, Orte, Zeiten und was immer auf solche Weise vereint in den Körpern vorliegt. $<{ }^{142}$ Über sie sagt er: »Denn diese Dinge, die ihrer Natur nach unkörperlich sind und in einer unveränderlichen Substanz Kraft des Geistes bestehen, werden durch die Teilnahme des Körpers verändert und gehen durch Berührung mit dem veränderlichen Ding in wandelbare Unbeständigkeit über. Diese also, denen ihrer Natur nach eine unwandelbare Substanz und Kraft eigen ist, heißen fürwahr und eigentümlich seiend. $\ll 143$

Wohl im Anschluss an diese Darstellung des Boethius lässt Eriugena später im Periphyseon den Akzidenzien ein vom Körper unabhängiges Sein im Geistigen zukommen, wo sie ihrer Natur nach unveränder-

${ }^{142}$ Institutio Arithmetica I,I 1-4 (ed. Jean-Yves Guillaumin, 1995, p. 6-8): Haec autem sunt qualitates, quantitates, formae, magnitudines, parvitates, aequalitates, habitudines, actus, dispositiones, loca, tempora, et quicquid adunatum quodam modo corporibus invenitur.

Michael Masi merkt in diesem Zusammenhang an, dass es sich hier um die Ideen der Kategorien handelt, unterschieden von deren einzelnem Auftreten am Körper, in ders.: Boethian Number Theory, A translation of the De institutione Arithmetica, Amsterdam 1983, p.71, adn. Guillaumin indes weist darauf hin, dass hier 11 seiende Dinge aufgezählt werden, und nicht 10 Gattungen, wie in den Kategorien, p. 182, adn. 11.

${ }^{143}$ Ebenda: quae ipsa quidem natura incorporea sunt et immutabilis substantiae ratione vigentia, participatione vero corporis permutantur et tactu variabilis rei in vertibilem inconstantiam transeunt. Haec igitur quoniam, ut dictum est, natura immutabilem substantiam vimque sortita sunt, vere proprieque esse dicuntur.

Beide Übersetzungen, die französische von Guillaumin wie die englische von Masi, geben das lateinische vigentia nicht wörtlich wieder und es ist in der Tat schwer $\mathrm{zu}$ fassen, was mit diesem in der lateinischen Sprache nicht gängigen Wort hier gemeint ist. Guillaumin übersetzt zudem participatione corporis als »Teilnahme der Dinge am Körper (»en participants aux corps«), und führt in einer Anmerkung aus, dass dies der herkömmlichen Teilhabehierarchie entgegenstehe (p. 182, adn. 12). Warum er diesen Passus nicht schlicht als `durch Teilhabe des Körpers` lesen will, bleibt unbegründet. 
lich bestehen ${ }^{144}$ Der Körper sei, so führt er später unter Berufung auf Gregor von Nyssa aus, lediglich ein »Zusammenfall der Akzidenzien« (accidentium concursum) ${ }^{145}$ Er entspräche genau jener res variabilis, von der bei Boethius die Rede sei, und wäre aus dem entstanden, was dieser >quae vere sunt nenne ${ }^{146}$ Wenn sich dies rückbeziehen lässt, dann sind es in der vierten Auslegungsweise die Akzidenzien, die sseiend und snichtseiend < heißen: für sich selbst genommen und im Geistigen unveränderlich bestehend werden sie sseiend ' genannt, in ihrem den Körper bedingenden Zusammenfall nennt man sie hingegen snichtseiend .

\subsubsection{Die fünfte Auslegungsweise}

Die fünfte und letzte Auslegungsart bezieht sich auf ein Bibelzitat, in dem von Sein und Nichtsein die Rede ist: Gott ruft die Seienden wie die Nichtseienden zu sich ${ }^{147}$ Es sind dabei zwei Möglichkeiten angegeben, dies zu verstehen. Die als zweites genannte greift im Grunde das Beispiel der menschlichen Natur aus der dritten Aussageweise wieder auf und nennt solches nichtseiend, was von Gott noch nicht ins Sein gerufen wurde, das heißt, was noch nicht sichtbar hervorgetreten ist. Das vocare entspricht dann dem zuvor genanten adducere. Zudem lasse sich das Apostelwort der ersten Möglichkeit nach auch allein auf die menschliche Natur beziehen, und damit ist der kleinste Umfang aller Auslegungsweisen von Sein und Nichtsein angegeben. Die menschliche Natur, heißt es, habe ihr Sein verloren, in welchem sie dem Ursprung nach bestehe. Dies sei geschehen durch die Sünde, die den Menschen vom göttlichen Ebenbild habe abfallen lassen, und in diesem $\mathrm{Zu}$ stand heiße die menschliche Natur >nichtseiend $<$. Aus diesem Nichtsein könne sie durch den Sohn zurück ins Sein gelangen, indem sie, zurückgekehrt in ihre eigentümliche Substanz (suae substantiae status), anfange, zu leben ${ }^{148}$ Im jetzigen, sündigen Zustand hieße die menschliche

\footnotetext{
${ }^{144} \mathrm{I}, 1555-1262$.

${ }^{145} \mathrm{I}, 1583-1586 ;$ 2618-2620.

${ }^{146} \mathrm{I}, 2620-2625$.

${ }^{147}$ Römer 4, 17.

${ }^{148}$ Wie bereits im Zusammenhang mit der ersten Auslegungsweise dargelegt, ist für Eriugena die Natur des Menschen mit der Erschaffung Adams bereits vollständig gegeben.
} 
Natur hingegen >nichtseiend ‘. Auffälligerweise nennt Eriugena dieses menschliche Sein non subsistentia (I, 146), ohne dass klar ist, was subsistentia meint und ob es mit substantia identisch ist.

Einem biblischen Ausspruch des Apostels folgend könnte man meinen, mit dem, worin die menschliche Natur anfängt zu leben, sei Christus gemeint, da es heißt: "Sind wir aber mit Christus gestorben, so glauben wir, dass wir auch mit ihm leben werden. 149 Doch kann sich die Bestimmung »der nach dem göttlichen Bilde gegründet ist « nur auf Adam beziehen, und nicht auf Christus.

Außer den beiden angeführten Auslegungweisen des Bibelwortes könne es, wie es am Ende des Abschnitts heißt, auch noch weitere Möglichkeiten geben. Mit hos modos sind dabei wohl die beiden unmittelbar zuvor genannten Auslegungsarten gemeint. Es bestünde auch die Möglichkeit, dass hier an weitere Auslegungen von Sein und Nichtsein gedacht ist, die sich nicht auf das Bibelwort beziehen (also die fünfte Auslegungsweise), sondern zu den bisherigen fünf Weisen hinzutreten. Dies wäre eine nicht unwichtige Interpretation. Sheldon-Williams' Textedition kommt der letzteren Möglichkeit entgegen, da er vor dem et si (»ferner«) einen Punkt setzt und so die Aussage formal wie inhaltlich vom Vorangehenden trennt ${ }^{150}$ Jeauneau hingegen liest statt dem Punkt ein Komma und schließt die Aussage damit an das Vorangehende an. Ich halte es für wahrscheinlich, dass Eriugena nicht an gänzlich andere, weiterführende Auslegungsweisen von Sein und Nichtsein denkt, sondern schlicht an weitere Varianten der Bibelexegese. Doch beweisen lässt sich dies anhand dieser Textstelle nicht.

Wie schon zweimal zuvor, fragt $\mathrm{N}$ abschließend, ob A seinen Ausführungen zustimme. Wir hätten zwar viele Fragen, doch A beschränkt sich lediglich auf einen Einwand, der zunächst eher fern liegt. Alles Übrige wird nicht geklärt.

\subsection{Ergebnisse dieser ersten Textuntersuchung}

Als gewichtiges Ergebnis ist eine Auffassung Eriugenas hervorgetreten, die sich nicht nur in seinen Quellen so nicht findet, sondern wahrscheinlich in keiner philosophischen oder theologischen Abhandlung

${ }^{149}$ Röm. 6, 8; Übersetzung nach Luther.

${ }^{150}$ Periphyseon Book I, p. 44, 25-26. 
aus der Antike: die Auffassung, die substantia, das subiectum der Akzidenzien sei unbegreiflich, und zwar darum, weil es göttlich sei. Die Aussage, Gott sei das Sein von allem, findet sich auch in Eriugenas Quellen, doch dass sich dieses göttliche Sein als substantia des Individuums manifestiere, davon ist nirgendwo die Rede. Dies ist die noch näher zu untersuchende Innovation Eriugenas, welche er selbst nicht als eine solche ansieht. Und wie sich zeigen wird, zieht sie sich als Grundbehauptung durch das gesamte Periphyseon.

Wie die Untersuchung zudem gezeigt hat, bleiben einige Fragen:

1. Wir wissen nicht eindeutig, wie die Einteilung in die Seienden und Nichtseienden aufzufassen ist, ob ontologisch oder nur prädikativ.

2. Hinsichtlich der zweiten Auslegungsweise war nicht klar, worauf das Erkennen (cognoscere) abzielt. Zudem ließ sich die Gegenüberstellung von Bejahung und Verneinung nicht plausibel darlegen.

3. Bei der dritten Weise bleibt offen, was Gegenstand der Einteilung in seiend und nichtseiend ist.

4. Bezüglich der ersten Einteilung war nicht klar, was vere esse im Gegensatz zum esse dicitur bedeutet und was die rationes und essentiae omnium rerum sind. Gleiches gilt für den Begriff existentia. Klar wurde hingegen, das Eriugena hier essentia mit zwei eigentlich verschiedenen Begriffen gleichsetzt: erstens mit dem göttlichen esse omnium und zweitens mit der substantia des Geschöpfes. Drittens findet sich zudem in der zweiten Auslegungsweise essentia als Bezeichnung für geistige Wesen wie etwa Engel. Ob und inwiefern alle drei als dasselbe aufzufassen sind, legt der Text nicht dar.

5. Wir wissen nicht, wie sich die Einteilung in sseiend $<$ und snichtseind ` zur viergliedrigen Einteilung der Natur verhält.

6. Ebensowenig wissen wir, wie man sich die Einteilung eines generale vocabulum wie natura in species zu denken hat.

7. Auch der Einteilungszweck der Natur ist noch unbekannt. 
Diese Fragen sollen im Hinblick auf den noch ausstehenden Text festgehalten werden.

\subsection{Die Ontologie im ersten Buch}

Wie die Literatur zum Periphyseon aufzeigt, enthält das erste Buch in großen Teilen eine Abhandlung über die zehn Kategorien ${ }^{151}$ Dieser richtig interpretierte Umstand überrascht, da der Ankündigung nach (I, 43-45; I, 402-403) das erste Buch von der ersten species der Natur handeln soll, jene, die schafft und nicht erschaffen wird. Der Zusammenhang zu den Kategorien ergibt sich dadurch, dass Eriugena die Anwendbarkeit der Kategorien auf Gott hin prüfen will. Doch wenngleich er dabei N sagen lässt, die Antwort darauf sei eine ausführliche (I, 674675), macht er sogleich unmissverständlich klar, dass gewiss keine der Kategorien von Gott ausgesagt werden könne. Die Sache ist daher eigentlich schon in I,911-915 erschöpfend behandelt und man darf sich fragen, warum sie dennoch hinsichtlich jeder einzelnen Kategorie noch einmal durchgegangen wird.

Im weiteren Verlauf kann man sich nicht des Eindrucks erwehren, als ginge es Eriugena gar nicht vorrangig um die Anwendbarkeit der Kategorien auf Gott hin, sondern um eine Untersuchung der Kategorien selbst. Diese Untersuchung wiederum verläuft nicht geradlinig geizt mit Überleitungen, die den Zusammenhang erhellen. Daher erscheint das erste Buch leicht als jenes »Konglomerat von Ideen, Zitaten und Interpretationen «, von dem Flasch spricht ${ }^{152}$ Um der Frage, worum es Eriugena bei alledem eigentlich geht, irgendwie näherzukommen, ist der Text in der Folge in Abschnitte gegliedert, die nacheinander zu untersuchen sind. Vorwegnehmend ist die Stellung der Kategorien in Eriugenas Lehre von der Wirklichkeit hervorzuheben. Was sich weder als Substanz noch als Akzidenz fassen lässt, ist gar nicht Gegenstand. Umgekehrt hat Eriugena bei seiner Konstitution der Wirklichkeit nur diese beiden Elemente zur Verfügung, die Substanz und die neun Akzidenzien. Dabei wird man fragen wollen, ob er die Substanz lediglich als

\footnotetext{
${ }^{151}$ Siehe etwa Schrimpfs Gliederung des ersten Buches in ders.: Das Werk des Johannes Scottus Eriugena im Rahmen des Wissenschaftsverständnisses seiner Zeit, Münster 1982, S. 236-237.

${ }^{152}$ Kurt Flasch: Das philosophische Denken im Mittelalter, Stuttgart ${ }^{2} 2000$, S. 183.
} 
eine individuierte auffasst oder auch als Art und Gattung. Als Abkehr von der Dialektik wird er genau diese Differenz zwischen dem Subjekt und dem Subjektprädikat, also Art und Gattung, aufheben. Die Substanz wird von der obersten Gattung ausgehend bis in das Einzelne hinabreichen und wird somit weder nur Gattung noch nur Individuiertes sein, sondern ein beides Umfassendes. Wie sie als Individuiertes auftritt, und zwar mittels der Akzidenzien, legt das erste Buch dar. Erinnern wir uns der gewaltigen Aussage, Gott sei substantia aller Dinge. Das restliche erste Buch wird klären, wie die göttliche substantia im Individuum zugegen sein kann.

\subsubsection{Zur Unbegreiflichkeit der rationes dei und zur Theophanie} (154-401)

I, 154-401 behandelt einen Einwand A's hinsichtlich des zuvor von N Gesagten. In der ausführlichen Antwort N's bringt Eriugena dabei die Theophanie-Lehre vor, wie er sie von Maximus Confessor glaubt erhalten zu haben. Der Einwand A's ist der folgende (I, 154-166): Augustinus lehre in De genesi ad litteram, die Engel könnten sehr wohl ihre Ursachen erkennen. Diese Ursachen nennt Eriugena hier causae primordiales, principalia exempla oder griechisch prototypa.

Da A mit keinem Wort angibt, auf welche Aussage N's er sich mit diesem Einwand bezieht, ist zunächst gar nicht klar, worauf er abzielt. Ein wenig mehr Klarheit ergibt sich durch A's Nachfrage in I, 204-222, wo A angibt, dass es sich bei den fraglichen Ursachen, hier auch rationes genannt, um die divina essentia handelt. Der Einwand muss sich also auf die Aussage aus I, 57-59 beziehen, wonach nicht nur Gott selbst unbegreiflich ist, und zwar für jeden Intellekt, sondern es auch die rationes und essentiae omnium rerum sind. Damit erweitert sich sogleich die Anzahl von Namen, mit der Eriugena jene im Geschöpf verborgene göttliche Ursache benennt: essentia, ratio, causa primordiales, principalia exempla, prototypos. Substantia soll dabei nur vorsichtig angefügt werden, weil dieser Begriff möglicherweise eine Sonderrolle einnimmt.

Dabei muss A die Aussage N's so auffassen, dass die essentiae und rationes omnium rerum für keinen Intellekt, auch nicht für den der Engel, fassbar sind. Darum wohl heißt es in I, 55-57 quae omnem intellectum fugiunt. Dann ist es in der Tat angebracht, hier Augustins Aussage ent- 
gegenzuhalten, wonach die Engel die causae primordiales, also die vorrangigen Ursachen der Dinge, erkennen. Aus theologischer Sicht widerspricht Eriugenas Behauptung derjenigen der höchsten lateinischen Autorität, und daher schickt er sich an, diesen Widerspruch aufzulösen.

Ohne zunächst auf die Worte Augustins näher einzugehen, verweist $\mathrm{N}$ auf die Notwendigkeit einer anderen Interpretation von Augustins Aussage, als es durch A geschehen ist. Und als Begründung führt er, durchaus geschickt, die letztgültige Autorität an: die Bibel. Das Argument verläuft dabei etwas unklar.

Eriugena zitiert zunächst die Aussage aus Römer 11,34 an, wo es heißt: »Wer hat den Geist des Herrn erkannt? - Der Friede Christi, der allen Intellekt überragt. « $\sqrt{153}$ Doch das allein reicht noch nicht als Begründung aus. Wie er darum in I, 175-178 anführt, sei der intellectus domini die causa omnium. Und ohne allen Zweifel (absque ulla dubitatio$n e$ ) bestünden die rationes omnium rerum in dieser höchsten causa. Daher seien diese rationes ebenso unbegreiflich, wie die höchste göttliche Ursache selbst. Festzuhalten bleibt für diese Untersuchung, dass so die essentiae und rationes omnium rerum in dieser ersten Ursache bestehen (quae aeternaliter atque incommutabiliter in ea sunt).

Nun lässt sich berechtigt fragen, was diese Ineinssetzung überhaupt soll. Aus dem Anfang des Periphyseon lernt man, dass es eine Art der Natur gibt, welche schaffe und nicht erschaffen werde, und eine zweite, die schafft und erschaffen wird. Ersteres wird als causa omnium bestimmt, Zweiteres als die causae primordiales (I,35-37). Aus welchem Grund wird daher behauptet, die causae primordiales bestünden ewig und unveränderlich in der ersten Ursache, wo sie von verschiedener Natur sind, nämlich einer geschaffenen? Die Frage sei trotz ihrer Dringlichkeit zunächst hinten angestellt.

Da nun die Engel, wie Eriugena mit dem Apostelwort darzulegen glaubt, mit ihrem Intellekt nicht ihre eigenen Ursachen, also die causae primordiales, einsehen können, so muss die Stelle bei Augustinus auf eine andere Weise interpretiert werden, als es zuvor von A geschah. Eriugena stellt nicht in Abrede, dass die Engel irgendetwas erkennen, was dem menschlichen Geist (noch) nicht zuteil wird, doch

${ }^{153}$ Quis enim intellectum domini cognovit? - Pax Christi quae exsuperat omnem intellectum. 
ist dieses Erkannte keine der Ursachen selbst, sondern eine Theophanie. Und somit erklärt sich der anschließende Exkurs über Letzteres. Zur Theophanie-Lehre Eriugenas sei hier nur soviel gesagt, dass diese Theophanie genau dasjenige ist, was dem Menschen im Zustand der zukünftigen Glückseligkeit versprochen ist. Was immer ein Geschöpf von Gott, sei es er selbst, oder die in ihm bestehende vorrangige Ursache, je erkennen kann, ist nur dessen Erscheinung als Theophanie. Und auch diese Theophanie, um sie in einen noch an Bedeutung gewinnenden Gedanken einzuordnen, besteht nicht außerhalb von Gott (extra se), sondern in ihm (in se, I, 322-323).

\subsubsection{Gott als Geschöpf (402-557)}

Nach dem Exkurs über die Theophanie kehrt der Text zu dem geplanten Vorhaben zurück, über die erste der vier Naturen zu sprechen, über jene, die schafft und nicht erschaffen wird. Und er beginnt mit einer interessanten Feststellung. Es gebe einen guten Grund, eine species der Natur anzunehmen, die als differentia specifica das sschaffend >unerschaffen-sein > innehat. Denn diese Spezifizierung lasse sich rechtmässig (recte) von Gott, und nur von Gott aussagen. Dieser Umstand zeigt, was Eriugena mit seiner Einteilung der Natur überhaupt im Sinn hatte: spezifische Differenzen anzugeben, welche die Gesamtnatur unterteilen. Dabei fasst Eriugena das Differenzpaar creat und creatur nicht nur als artbildende Differenzen, sondern benennt auch die species selbst mit ihnen, so als fehlte ihm ein Name für die Art.

Gott allein sei anarchos, also als ohne Anfang zu denken (intelligitur) und als erste Ursache aller Dinge. Und weil er der Anfang von allem sei, sei er auch die Mitte und das Ende von allem. Zwar bringt Eriugena dies ohne nähere Begründung vor, doch kann er sich sicher sein, damit unter den karolingischen Gelehrten nichts Ungewöhnliches zu sagen.

Dieser Darlegung durch $\mathrm{N}$ folgt einer der interessantesten Abschnitte des gesamten Werks. A wendet ein, in den Büchern der heiligen Väter finde sich die Behauptung, Gott sei nicht nur schaffend, sondern auch erschaffen: »A. Nicht wenig nämlich bewegt mich, wenn ich häufigst in den Büchern der heiligen Väter, die den Versuch unternehmen, von der göttlichen Natur zu sprechen, lese, dass diese Natur nicht allein alles 
Seiende erschafft, sondern auch erschaffen ist. Weil sie ja, wie sie sagen, macht und gemacht ist, sowohl schafft als auch erschaffen wird. $\$ 154$

Dieser Einwand zeigt, dass Eriugena die Figur A mit dem Werk des Dionysius Areopagita vertraut sein lässt, wo sich diese Aussage vorgeblich finden wird. Für wie gewichtig und interpretationsbedürftig Eriugena diese Aussage des Dionysius hält, zeigt die Wiederholung des Einwandes im dritten Buch, wo A sagt: »Und unvergleichlich höher und verwunderlicher als all dies scheint mir das zu sein, was du der Autorität des heiligen Dionysius Areopagita zuerkennst, dass nämlich Gott selbst sowohl der Macher von allem ist als auch in allem gemacht ist; dies nämlich ist nicht nur von mir bis jetzt unvernommen und mir unbekannt, sondern vielen und fast allen. Denn wenn dies so ist, wer wird dann nicht unverzüglich in diese Worte ausbrechen und verkünden: Gott ist so alles und alles ist Gott! «155

Wenngleich der letzte Satz in einen Pantheismus zu münden scheint, ist dies hier im ersten Buch noch gar nicht die entscheidende Schwierigkeit. Paradox ist vielmehr, wie Dionysius Gott auch als Geschöpf bezeichnen kann, wenn es doch die differentia specifica Gottes ist, unerschaffen zu sein. Wie ist dieses creari $(\mathrm{I}, 420) \mathrm{zu}$ verstehen? Auffallenderweise spricht Eriugena hier von den heiligen Vätern (sanctorum patrum) und nicht im Singular von einem heiligen Vater, ganz so, als hätte er weitere Quellen, was durch das saepissimus noch verstärkt wird. Doch weder führt er solche an, noch findet sich für uns eine weitere neben Dionysius Areopagita ${ }^{156}$

Das Problem ist klar ausgesprochen: Wie und auf welche Weise gilt von Gott, dass er erschaffen ist?

Sehen wir uns Eriugenas Erklärung an. Sie soll, so heißt es in I, 425429, den schon im Anfang genannten Weg des Verstandes (I, 429, ra-

\footnotetext{
${ }^{154}$ I, 417-421: Non enim me parvum movet dum saepissime in libris sanctorum patrum qui de divina natura disputare conati sunt invenio eam non solum omnia quae sunt creare, sed etiam creari. Ea siquidem, ut aiunt, facit et fit, et creat et creatur.

${ }^{155}$ III, 1328-1334: Et his omnibus incomparabiliter altius et mirabilius mihi videtur quod sancti Dionysii Ariopagitae auctoritate utens asseris, ipsum videlicet deum et omnium factorem esse et in omnibus factum; hoc enim adhuc inauditum et incognitum non solum mihi, sed et multis ac paene omnibus. Nam si sic est, quis non confestim erumpat in hanc vocem et proclamet: Deus itaque omnia est et omnia deus!

${ }^{156}$ Siehe hierzu auch den Quellenapparat Jeauneaus.
} 
tiocinandi via) gehen. Das Problem wird ausgeweitet mit dem Hinweis, schon das griechische Wort theos bestimme Gott etymologisch als einen Laufenden (von griechisch theô, ich laufe) und einen Sehenden (von griechisch theorô, ich sehe). Wie aber sei Gott als ein Laufender zu aufzufassen, wo er sich doch in unveränderlicher Ruhe befindet, und wie als ein Sehender?

Beide Antworten bauen auf demselben Gedanken auf, welcher zugleich erklärt, inwiefern Gott sgeschaffen ‘ genannt werden darf. Zum Laufen oder auch Umlaufen Gottes heißt es:

»Er bewegt sich selbst aber durch alles hindurch, damit jene sind, die aufgrund von ihm essentialiter bestehen. Durch seine Bewegung nämlich wird alles (erschaffen). «157 Und später: »Gott heißt also darum >laufend $(. .$.$) , weil er alles in Umlauf setzt aus den Nichtexistierenden her-$ aus in die Existenz. 458 Dabei ist besonders das erste Argument interessant. Dort heißt es nicht nur, wie im zweiten Argument, Gott umlaufe alles, indem er erschaffe, sondern auch, dass er selbst sich durch alles hindurchbewege. Dieser Gedanke ist festzuhalten mit Blick auf das Argument hinsichtlich des Sehens Gottes. Dazu wird gesagt: »Er selbst nämlich sieht die Seienden in sich selbst, denn er betrachtet nichts außerhalb seiner selbst, weil nichts außerhalb von ihm ist. « 159 Das Sehen Gottes ist so eine Selbstbetrachtung und zwar darum, weil nicht außerhalb von Gott ist. Anders gesagt, alles ist entweder in Gott oder ist Gott.

Damit gibt Eriugena schwer Verständliches als Begründung an. Noch ungeklärt, warum die zweite Natur, die causae primordiales, dasselbe sind, wie Gott, begegnet uns nun die Behauptung, es gebe gar nichts außerhalb von Gott. Um noch mehr an Material zur Diskussion hinzuzufügen, sei noch das Argument angeführt hinsichtlich der Rechtfertigung, Gott sei auch >Geschaffenes < zu nennen: »Er schafft also alle, die er aus dem Nichts herausführt, damit sie sind, aus dem Nichtsein ins

\footnotetext{
157 I,448-450: (...) movet autem se ipsum per omnia ut sint ea quae a se essentialiter subsistunt. Motu enim ipsius omnia fiunt.

${ }^{158}$ I, 475-478: Deus ergo currens dicitur (...), quia omnia currere facit ex non existentibus in existentia.

${ }^{159}$ I, 440-441: Ipse enim omnia quae sunt in se ipso videt, dum nihil extra se ipsum aspiciat quia nihil extra ipsum est.
} 
Sein, erschaffen aber ist er, weil nichts essentialiter außer ihm selbst ist, denn er ist essentia von allem. 160

Hier taucht wieder die schon diskutierte Aussage auf, Gott sei essentia omnium rerum. Und weil er diese essentia ist, so sei auch nichts außerhalb von ihm, zumindest nicht essentialiter. Es ist in einem anschließenden Kapitel noch zu untersuchen, was dieses essentialiter esse meint und ob es seinen Gegensatz im tantum esse hat. Gott heißt hier darum >geschaffen<, weil seine Schöpfung, insofern sie essentialiter ist, nicht außerhalb von ihm, sondern in ihm besteht. Und so fügt Eriugena als naheliegende Folge an, dass Gott sich in der Schöpfung selbst erschafft: »Denn wenn er >sich selbst schaffend < genannt wird, so ist an nichts anderes zu denken, als an das Begründen der gegenständlichen Naturen. Denn seine Schöpfung, das heißt seine Erscheinung in etwas, ist fürwahr das Bestehen alles Existierenden. «161

Das ist viel an Inhalt.

Schauen wir uns an, was in allen vier genannten Argumenten auftritt: Gott sieht sich selbst, bewegt sich innerhalb seiner selbst, weil dasjenige, was er sieht, worin er sich bewegt und was er erschafft, nicht außerhalb von ihm besteht. Dieses >nur in Gott Sein erfährt im vorletzten genannten Argument die Einschränkung essentialiter; alles ist in Gott, insofern man dessen wesenhaftes Sein betrachtet (oder wie immer essentialiter sinnvoll zu übersetzen ist). Wie das letzte Argument angibt, sei es richtig, die gesamte sichtbare Schöpfung als eben das aufzufassen, was Gott in sich selbst erschafft. Was aber ist dann überhaupt noch außerhalb von ihm? Diese Frage stellt sich hier für Eriugena offenbar nicht. 'Schöpfung < ist dabei näher bestimmt als 'Erscheinung in etwas<, doch wie soll Gott in etwas erscheinen, da doch nichts außerhalb von ihm existiert?

Man muss darauf wohl antworten, dass es schon etwas gibt, das außerhalb von Gott ist, nämlich alle geschaffenen Dinge, doch dass sie, nach ihrem wesenhaften Sein befragt, nur in Gott bestehen. Der entscheidende Punkt in diesem Zusammenhang ist zweifelsohne jenes

\footnotetext{
${ }^{160}$ I,498-500: Creat igitur omnia quae de nihilo adducit ut sint ex non esse in esse, creatur autem quia nihil essentialiter est praeter ipsam, est enim omnium essentia.

${ }^{161}$ I,554-555: Nam cum dicitur se ipsam creare, nil aliud recte intelligitur nisi naturas rerum condere. Ipsius nanque creatio, hoc est in aliquo manifestatio, omnium existentium profecto es subsistutio.
} 
von Eriugena essentia und vere esse genannte. In Eriugenas Substanzund Seinslehre liegt der Grund für die Annahme, alles bestehe in Gott und Gott erschaffe so sich selbst.

Seine Aussagen erinnern dabei an die neuplatonische Trias des Hervorgangs, der Rückkehr und des Verharrens, was bei Eriugena, wohl auch mit Blick auf Paulus, als a se ipso in se ipso ad se ipsum auftaucht, etwa I, 458-459 ${ }^{162}$ Zudem taucht bei seiner Argumentation auch der Teilhabegedanke auf: »(...) daher existiert alles, was existierend genannt wird, nicht in sich selbst, sondern existiert durch Teilhabe an der wahrhaft existierenden Natur. «163 Auch hier ist wieder das vere zugegen, und zwar als Kennzeichen für jenes an sich Seiende, an dem alles übrige Sein teilhat. Doch bei allem naheliegenden Verweis auf den Neuplatonismus darf man nicht übersehen, dass Eriugena hier von essentia spricht, also vom Sein oder Wesen oder von der Substanz, und nicht vom Einen. Es ist die göttliche essentia, welche den >Kosmos` des Periphyseon durchdringt und zusammenhält. $\mathrm{Ob}$ es sich dabei um einen Pantheismus handelt, wird noch zu klären sein. Doch diese Frage ist nur die halbe Konsequenz. Wenn das Sein aller Dinge nur in Gott besteht, dann sagt dies mehr aus als die Behauptung, Gott sei in allen Dingen zugegen. Die sichtbare Natur wird damit zu einem in Wahrheit gar nicht Seienden, zu einer bloßen Sichtbarwerdung des Göttlichen, Theophanie, wie Eriugena sagen wird, bar einer eigenständigen Substanz. Was Eriugena in Frage stellt, ist schlicht die eigenständige Existenz der Dinge.

Weil er wenig Eindeutiges dazu sagt und auch den Begriff der Existenz nicht näher diskutiert, bleiben nur Vermutungen, in welchem Ausmaß und mit welcher Konsequenz er alles Sein auf den göttlichen Bereich beschränkt. Ob er die gesamte Körperwelt nur als `Schatten` auf-

${ }^{162}$ Siehe zu Paulus, Kolosser 1,16: »Denn in ihm ist alles geschaffen, was im Himmel und auf Erden ist, das Sichtbare und das Unsichtbare, es seien Throne oder Herrschaften oder Mächte oder Gewalten; es ist alles durch ihn und zu ihm hin geschaffen« (Kol. 1,16; Übersetzung nach Luther). Interessanterweise aber bezieht sich Paulus hier nicht auf den Schöpfergott, sondern auf den Sohn, und Marius Victorinus etwa nennt daraufhin den Sohn, nicht aber den Vater das vollkommene Sein aller. Christus wird hingegen bei Eriugena nicht als derjenige angeführt, der das wahrhafte Sein aller ist.

${ }^{163}$ I, 502-503: (...) ita omne quod dicitur existere non in se ipso existit, sed participatione vere existentis naturae existit. 
fasst, aufgrund derer sich der göttliche Glanz erahnen lässt, jenes angesprochene allein wahrhaft Seiende, ist nicht eindeutig beantwortbar.

\subsection{3 creari als se ipsum creare}

Gleich, ob diese Aussagen Eriugenas überzeugen mögen oder nicht, sie sind zunächst kontraproduktiv im Hinblick auf die Einteilung der Natur. Wenn Gott auch serschaffen< genannt werden darf, welcher Sinn kommt dann noch der differentia specifica >nicht erschaffen< zu? Glücklicherweise lässt Eriugena A genau diese Frage stellen (I, 536-539) und $\mathrm{N}$ darauf antworten: Wenn man höre, Gott sei geschaffen, dürfe man nicht denken, Gott sei von etwas anderem geschaffen, sondern er sei durch sich selbst erschaffen. Damit dieses Argument funktioniert, müssen wir uns, auch wenn Eriugena dies nicht sagt, das non creatur als ein non ab alia (natura) creatur (I, 550-551) denken. Dennoch bleibt ein Unbehagen: Hebt diese Selbsterschaffung Gottes, die nichts anderes sei als das Gründen der natürlichen Dinge (I, 555, naturas rerum condere) nicht die so wichtige Differenz zwischen Schöpfer und Geschöpf auf? An dieser Stelle erfährt man dazu nichts. Erst zu Beginn des zweiten Buches spricht Eriugena diese Konsequenz aus, wie die anschließende Untersuchung zeigen wird ${ }^{164}$

\subsubsection{Der Name trinitas (558-665)}

Der Abschnitt beginnt mit einer Frage A's, wie oder ob überhaupt die Theologie die alles erschaffende Natur bestimme (diffinit). Die explizite Nennung der Theologie legt den Verdacht nahe, die bisherige Untersuchung wäre gerade keine theologische gewesen. Dies hieße dann, der von Eriugena zuvor beschrittene Weg der ratio (ratiocinandi via) sei kein theologischer, sondern vielleicht ein dialektischer. Doch es fehlen Textbelege, um diesen Verdacht, Eriugena unterscheide zwischen einem dialektischen und einem theologischen Weg, wirklich zu erhärten. Vielmehr zeigt der Abschnitt, dass die Theologie für Eriugena vor allem eine bestimmte Thematik umfasst, nämlich die göttliche Trinität. Diese

${ }^{164}$ Abschnitt 2.9 . 
Bestimmung der Theologie findet sich bereits bei Alkuin und war wohl opinio communis bei den Karolingern 165

Was Eriugena zur Trinität sagt, entnimmt er seiner griechischen Premium-Quelle, der Ambigua ad Iohannem des Maximus Confessor ${ }^{166}$ Der Umstand, dass er im Text dennoch Gregor und nicht Maximus als Quelle nennt (I,622), zeigt einmal mehr, wie sehr er sich via Maximus berechtigt sieht, auf Gregors Aussagen zu verweisen. Was Eriugena hier von Maximus anführt, ist der Gedanke, dass die unterschiedlichen Namen >Vater und >Sohn ' die Wesenseinheit Gottes, das honoousion, nicht unterlaufen, da sie nicht die göttliche essentia oder natura benennen, sondern eine, wie Eriugena es ausdrückt, habitudo. Was ist damit gemeint? Habitudo steht in Eriugenas Übersetzung der Ambigua für das griechische schesis, das eigentlich zunächst >Anhalten< oder >Hemmung heißt ${ }^{167}$ Er weiß um die Abstammung dieses Nomens von schein / echô, und übersetzt es darum, um der Aussage einen Sinn zu geben, mit habitudo. Anders als der Übersetzer in der Patrologia Graeca, der schesis mit relatio übersetzt (PG 91,1266D), wohl mit einem unpassenden Bezug auf schêma hin, gibt es bei Eriugena den sprachlichen Bezug zum Haben, schein. Echein gibt intransitivisch auch ein ssich-verhalten an, und auf genau diese Weise ist wohl die habitudo bei Eriugena zu verstehen. Christus verhält sich zum Vater als Sohn, der Vater wiederum zu ihm als Vater. Die Namen der göttlichen Person >Vater < oder `Sohn< sind also dem ssich-zueinander-verhalten ' geschuldet und benennen nicht die göttliche Natur ${ }^{168}$

Daraus lässt sich nach Eriugena nicht folgern, dass die Kategorien shabitudo und srelatio< von der göttlichen Trinität ausgesagt werden können, denn, so legt er später dar, die Verhältnisausdrücke wie >Va-

\footnotetext{
165 Alkuin: De fide trinitatis, PL 101 und De dialectica, PL 101,952C.

${ }^{166}$ Siehe zu der Textvorlage des Maximus Confessor Jeauneaus Quellenapparat, p. 24, unten.

${ }^{167}$ Ambigua ad Iohannem CCSG 18, XXII, p. 153, 14.

${ }^{168}$ Kurt Flasch diskutiert ausführlich die außergewöhnliche Stellung der habitudo bei Eriugena, wonach diese bei allen übrigen Kategorien zugegen ist, doch unterscheidet er dabei nicht zwischen den Kategorien relatio und habitudo, sondern nennt beides unterschiedlos »Relation « , was die Darstellung Eriugenas etwas verzerrt; siehe ders.: Zur Rehabilitierung der Relation, Die Theorie der Beziehung bei Johannes Eriugena, in: Philosophie als Beziehungswissenschaft, Festschrift für Julius Schaaf, Hg. von W. F. Niebel und D. Leisegang, Frankfurt 1974, S. I/5-I/25.
} 
ter oder >Sohn « würden doch nur im übertragenen Sinne (translative, I, 959-968) von Gott ausgesagt.

$\mathrm{Zu}$ fragen bleibt, was diese Passage zur Abhandlung beiträgt. Eriugena sucht offensichtlich nach Alternativen, die Schöpfernatur passend $\mathrm{zu}$ benennen. Seiner eigenen Bestimmung nach ist es ja nur das non $a b$ alia creari, das eigentümlich (proprie) von ihr ausgesagt werden kann. Man kann also den Abschnitt der Trinität dahingehend lesen, dass auch die Namen für die göttlichen Personen die Schöpfernatur nicht zutreffend benennen. Der Text selbst sagt nichts zur Funktion dieses Exkurses über die Trinität, doch wenn man ihn in einen systematischen Zusammenhang setzen will, dann ist diese Interpretation die einzig sinnvolle.

\subsubsection{Die erstrangigen Ursachen als göttliche Namen (666-886)}

Bereits in I, 669-671 fordert A sein Gegenüber N auf, die aristotelischen Kategorien hinsichtlich der Frage zu prüfen, ob eine von ihnen von der göttlichen Natur (hier verwirrenderweise divina bonitatis genannt) ausgesagt werden kann. Doch $\mathrm{N}$ gibt zunächst keine Antwort, sondern geht ohne Angabe eines Grundes zu der Darstellung der beiden Theologieformen über, der affirmativen und der negativen. Die affirmative übertrage dabei die geschöpflichen Namen auf den Schöpfer, die negative verneine jegliche Benennung. All dies ist bei Dionysius Areopagita ausführlich darlegt und von dort her wohl ins Periphyseon eingeflossen.

Die Namen `Güte`, >Wahrheit<, >Weisheit<, die Eriugena im dritten Buch als causae primordiales, also als erstrangige Ursachen bestimmt, werden in der affirmativen Theologie von Gott übertragen ausgesagt, in der verneinenden ihm abgesprochen. Aufgrund dieser translatio ergibt sich ein Problem. So hieß es eingangs, die causae primordiales seien nur in Gott zugegen und daher ebensowenig zu erkennen, wie er selbst. Sie waren die Rechtfertigung dafür, Gott auch serschaffen $\mathrm{zu}$ nennen, weil er essentia von allem ist und alle essentia nur in ihm besteht. Jetzt heißt es dazu: »Gott also heißt essentia, aber er ist nicht eigentümlich essentia. Er ist demnach hyperousios, das heißt überwesenhaft. «169

Dies erscheint im Hinblick auf das Vorangehende als, bildlich gesprochen, Rolle rückwärts. Welche Aussage hat Gültigkeit: ist Gott es-

\footnotetext{
${ }^{169}$ I, 748-750: Essentia igitur dicitur deus, sed proprie essentia non est. Esse enim opponitur non esse. YПЕРОYCIOC igitur est, id est superessentialis.
} 
sentia von allem, da allein er wahrhaft ist (vere est), oder ist er über aller essentia, also superessentialis? Dasselbe Paradox findet sich schon bei Dionysius Areopagita klar ausgesprochen. Sehen wir uns daher dessen Erläuterung an, um Klarheit für das Periphyseon zu erlangen, auch darum, weil Eriugena selbst dazu nichts Näheres sagt:

"Zunächst ist es, um tausendmal Gesagtes auch jetzt wiederaufzunehmen, kein Widerspruch, Gott Kraft an sich oder Leben an sich und zugleich Schöpfer des Lebens an sich oder des Friedens und der Kraft zu nennen. Das eine nämlich nennt man ihn aufgrund des Seienden und insbesondere aufgrund des erstrangig Seienden, weil er der Urheber von allem Seienden ist, das andere hingegen insofern, als er alles und auch das erstrangig Seiende überwesentlich überragt. (...) Wir sagen vielmehr, dass Sein an sich, Leben an sich und Gottheit an sich ursprünglich, göttlich und ursächlich der eine einzige übergrundhafte und überwesentliche Urgrund und Urheber des Universums ist, dass ferner die von Gott, dem Unmittelbaren, verteilten fürsorglichen Kräfte auf dem Weg der Mitteilung die Wesensschaffung an sich, die Lebensschaffung an sich und die Vergottung an sich bedeuten, woran das Seiende auf charakteristische Weise Anteil nimmt und infolgedessen als Existierendes, Lebendes und Gottbegeistertes vorhanden ist und bezeichnet wird. $\sqrt{170}$

Bei Dionysius ist also Gott darum `Sein an sich zu nennen, weil er Ursache alles Seins ist. Dies war im Grunde schon im Zusammenhang mit dem von Eriugena angeführten Zitat in I, 60 in begrenztem Maße ersichtlich. Doch im Anschluss daran hieß es, Gott sei substantia jedes einzelnen Geschöpfes, und davon ist bei Dionysius weder hier noch sonstwo die Rede. Dieser Umstand macht das Paradox prekärer, als es

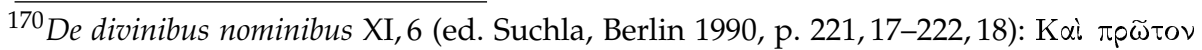

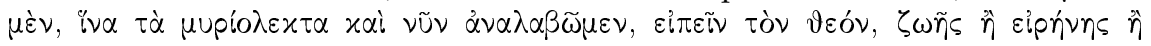

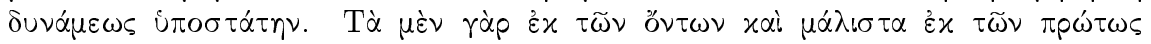

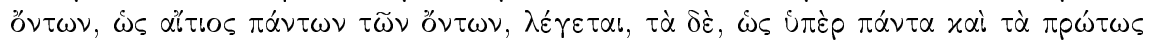

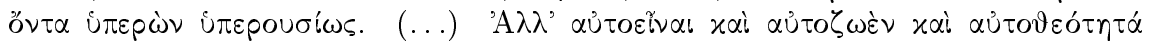

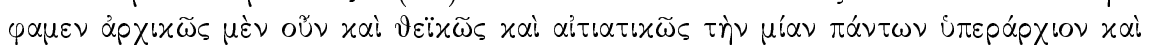

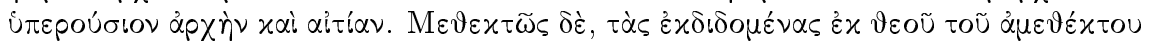

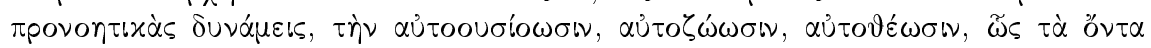

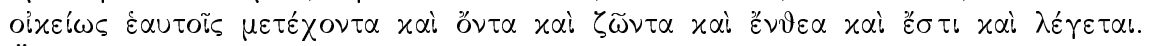
Übersetzung nach Beate Regina Suchla: Pseudo-Dionysius Areopagita - Die Namen Gottes, Stuttgart 1988, S. 97. 
dies bei Dionysius ist: »Dem Sein steht das Nichtsein entgegen « ${ }^{171}$, so lautet Eriugenas Begründung. Da Gott alle Gegensätze umfassen soll, so ist er auch nicht essentia oder esse, weil das esse verneinbar ist, sondern superessentialis.

Das mag zwar eine zutreffende Bestimmung Gottes sein, doch dürfen wir Eriugena damit noch nicht aus der Beweißchuld entlassen. Zumindest in der ersten Auslegungsweise ging das esse nicht mit der essentia einher, sondern war die Prädikation für das Nicht-Substanzielle. Eriugena muss hier also mit esse das schon genannte vere esse meinen, damit die Zuordnung stimmt.

Zudem, einmal angenommen, Gott sei superessentialis und essentia werde nur übertragen von ihm ausgesagt. Was geschieht dann mit der ontologischen Bestimmung, Gott sei essentia und substantia jedes einzelnen Geschöpfes? Ist dies auch nur eine übertragene Aussage, den wahren Sachverhalt nicht wiedergebend? Wenn essentia ein nomen divinis ist, weil Gott Ursache aller essentia ist, und genau so legt es Dionysius Areopagita ja dar, was geschieht dann mit der Bestimmung der geschöpflichen essentia als etwas Göttliches, als der verborgene Schöpfer im Geschöpf?

Die negative Ontologie Eriugenas, die auf dem Gedanken aufbaut, Gott sei die Substanz der Dinge, gerät so unvermittelt ins Wanken. Das dionysische Argument, Gott sei darum essentia omnium zu nennen, weil er Ursache aller essentia ist, taucht hier nicht auf. Es wäre wohl zu einschränkend, weil Eriugena Gott nicht allein darum essentia omnium nennt, insofern dieser alles Seiende verursacht, sondern auch, insofern er allem Seienden als Substanz zugrunde liegt. Auf die präsentierte Weise kollidiert diese Passage mit dem in der ersten Auslegungsweise Gesagten. Eine Lösung wäre es, Gott sowohl essentia als auch superessentialis zu nennen, je nach Betrachtungsstandpunkt. Doch scheint es, als wage Eriugena nicht, seine Substanzlehre auf solche Weise der negativen Theologie und ihrer Prädikationsweise zur Seite zu stellen.

\subsubsection{Eriugenas Kategorieninterpretation (887-2009)}

Es finden sich zwei eindeutige Hinweise im Periphyseon, und zwar vor Abhandlung der einzelnen Kategorien, dass die Aussagbarkeit der Ka-

${ }^{171}$ I, 749: Esse opponitur non esse. 
tegorien von Gott gar nicht möglich sein kann. In I, 903-915 verweist Eriugena auf Augustinus, wonach das Aussagevermögen der Kategorien im Hinblick auf Gott erlösche. Zudem nennt er es in I, 921-935 eine Absurdität, Kategorien proprie von Gott aussagen zu wollen, da dies doch nicht einmal mit den causae primordialis (also bonitas, virtus, veritas etc.) möglich ist.

Daher behandelt die Folge zwar die Kategorien, aber nur begrenzt die schon geklärte Anwendbarkeit auf Gott. Schon in I, 886 macht Eriugena klar, nicht nur die Prädizierbarkeit der Kategorien untersuchen zu wollen, sondern auch die Natur der Kategorien selbst: »(...) und nun ist, wie es scheint, die Natur der Kategorien zu betrachten. $4{ }^{172}$ Es sind, wie schon angemerkt, die zehn Kategorien, aus denen Eriugena die Wirklichkeit bestehen lässt. Und darum misst er ihrer Untersuchung solch eine Bedeutung bei.

Das erste Buch endet mit der Darlegung, dass auch die beiden letzten Kategorien >Tun $<$ und >Leiden ` von Gott ausgesagt werden können. Es kehrt also zur ursprünglichen Fragestellung zurück. Die Abweichung von dieser setzt ein in I, 1149 und wird bedingt durch eine Klassifizierung der Kategorien. Was gibt Anlass zu dieser? A scheint sie zu ahnen, denn er will die aktuelle Diskussion darum abschließen, um zu einer anderen jetzt notwendigen Untersuchung (quae ad praesens negotium necessario) übergehen zu können. Dann setzt die Klassifizierung und damit der lange Kategorien-Exkurs recht abrupt ein. Es gibt keinen weiteren Hinweis oder eine Hinleitung dazu. Der Exkurs beginnt mit dem Ende der Abhandlung der Kategorien >Ort $<$ und `Zeit $<$ hinsichtlich ihrer Prädizierbarkeit von Gott.

Die dann einsetzende Klassifizierung ist ein Versuch, der schon seit Beginn der Kategorienrezeption angedacht wird, nämlich, die zehn Kategorien, die für Eriugena zunächst die höchsten Gattungen sowohl der Gegenstände als auch der Prädikate darstellen (I, 887-893), einer noch höheren Gattung zu unterstellen ${ }^{173}$ Bei Eriugena sind die beiden obers-

\footnotetext{
${ }^{172} \mathrm{I}, 885-886$ : (...) et nunc, si videtur, kategoriarum natura consideranda est.

${ }^{173}$ Ich teile nicht die euphorische Ansicht Kurt Flaschs, Eriugena lege hier eine bemerkenswerte Kritik an den Kategorien vor, siehe ders.: Die Metaphysik des Einen bei Nikolaus von Kues, Leiden 1973, S. 9-10. Seinen Ursprung hat diese Zuteilung Eriugenas wohl in De categoriis Aristotelis, wo, was Eriugena übernimmt, die Akzidenzien als jeweils außerhalb oder in der ousia liegend bestimmt werden (Aristoteles latinus, I, 1-5, ed. Minio-Paluello, p. 144, 21-28). Siehe zu antiken Versuchen der Ka-
} 
te Gattungen die Ruhe und die Bewegung und letzte allumfassende Einheit die universitas. Unter die Ruhe fallen, was A überraschen wird, die Kategorien ousia, quantitas, situs und locus. Überraschend ist dies für A darum, da dies seiner Ansicht nach die Konsequenz mit sich brächte, dass diese an sich bestehen würden (I, 1223, An per se subsistentiae?), was von einem Akzidenz doch gerade nicht gilt.

Von ousia, und nicht mehr von essentia, spricht Eriugena von nun an, insofern er damit die erste der Kategorien meint. Wenngleich er ousia auch dann wiederholt, in Klammern eingefügt, mit essentia übersetzt (I, 896, 1885, 2039), meint er damit von jetzt an dasjenige, was dem Einzelding zugrunde liegt und in der lateinischen Tradition substantia heißt.

\subsubsection{Die Verwerfung einer dialektischen Unterscheidung}

Die Antwort N's auf die Frage von A bezüglich der Zuordnung einiger Akzidenzien zur Klasse status beginnt mit einer Umwerfung der traditionellen, auf die aristotelischen Kategorienschrift zurückgehende Unterscheidung zwischen de subiecto und subiectum. Subiectum meint das, was Aristoteles erste ousia nennt, was also im Unterschied zum de subiecto gerade nicht von einem Zugrundeliegenden ausgesagt werden kann. >Dieser Mensch<, um bei Aristoteles' Beispiel zu bleiben, lässt sich nicht von einem Zugrundeliegenden aussagen, wohl aber >Mensch ‘ oder >Lebewesen<. Dieses Aussagbare, was aber dennoch wie die erste ousia nicht in einem Zugrundeliegenden (lateinisch: in subiecto) ist, nennt Aristoteles zweite ousia. Gemeint sind damit Art und Gattung.

Eriugena legt hier wenig Wert auf die Unterscheidung zwischen einem Prädikat und einem prädizierten Gegenstand. Während, wie es sowohl Aristoteles als auch Porphyr in seiner Isagoge darlegen, Art und Gattung als beides auftreten können, als Prädikat wie auch als das, wovon etwas prädiziert wird, ist die erste ousia stets nur Letzteres. Sie ist also von irgendeiner anderen Natur als Art oder Gattung. Für Eriugena indes sind beide gerade ihrer Natur nach (iuxta naturam) dasselbe

tegorienaufteilung etwa Dexippus, Commentarius Categoriae, ed. Busse, CAG IV, 2, p. 31, 11-15. 
(I,1230-1235). Aus welchem Grund glaubt er, diese traditionsreiche Unterscheidung verwerfen zu müssen?

Die Art, sagt er als Begründung, sei im Individuum als Einheit enthalten und das Individuum umgekehrt auch in der Art (I, 1232-1234). Er sehe daher keinen Grund, beide nicht als dasselbe anzusehen. Man ahnt die Problematik, die hier im Hintergrund und schon in der Antike im Raume steht, doch führt Eriugena sie nicht weiter aus, nämlich die Universalienfrage. Offensichtlich lässt er nicht nur das Inviduum an der Art teilhaben, sondern umgekehrt die Art auch im Individuum bestehen. Um anzugeben, wie Eriugena zu dieser Ansicht gelangt, ist ein Blick auf die Vorrede seiner Ambigua-Übersetzung lehrreich. Dort zeigt sich, dass er die Wirklichkeit als eine dialektische Entfaltung Gottes ansieht, als eine Vervielfältigung der göttlichen Güte, die doch in allem als Eines zugegen ist. Maximus zeige, dass »die göttliche Güte durch alles Seiende hindurch vom Höchsten abwärts, zuerst durch die allem allgemeine essentia, dann durch die allgemeinsten Gattungen, dann durch die allgemeinen Gattungen, schließlich durch die speziellen Arten bis hin zur speziellsten Art durch die Differenzen und Eigentümlichkeiten hinabsteigt. $<174$

Wir haben hier das ganze Begriffsarsenal der antiken Dialektik vor uns liegen, wie es über die lateinische artes liberales-Tradition auch zu Eriugena gelangte. Ein byzantinischer Theologe, Maximus Confessor, zeigt ihm, dass diese Dialektik die Ordnung des Seienden ist ${ }^{175}$ Was aber hat diese Darstellung mit der Aufhebung der Differenz zwischen subiectum und de subiecto zu tun?

Wie sich wenig später zeigt (I, 1295-1305), soll die ousia in dieser dialektischen Vervielfältigung als Ganzes erhalten bleiben. Sie sei, so heißt es, in der höchsten Gattung ebenso wie im Individuum vollständig und eigentümlich (universaliter proprieque) enthalten. Eine Erklärung, wie der ousia die beiden Eigenschaften universaliter und proprie zugleich zugesprochen werden können, würde sicherlich nicht nur den Aristo-

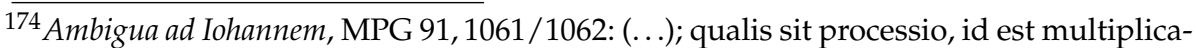
tio divinae bonitatis per omnia quae sunt, a summo usque deorsum, per generalem omnium essentiam primo, deinceps per genera generalissima, deinde per genera generaliora, inde per species specialiores usque ad species specialissimas per differentias proprietasque descendens.

${ }^{175}$ Zum Ursprung dieser Auffassung ist später noch mehr zu sagen. Es ist ein stoischer.
} 
teliker im Hinblick auf Metaphysik Zeta interessieren ${ }^{176}$ Doch das Periphyseon gibt darauf keine Antwort. Wenn allerdings, um zur Fragestellung zurückzukehren, dieselbe ousia auf dieselbe Weise in Gattung, Art und Individuum zugegen ist, dann sind wohl in der Tat diese drei ihrer Natur nach dasselbe, einmal ungeachtet, was >der Natur nach< (iuxta naturam) eigentlich meint. Damit hält es Eriugena für berechtigt, die Differenz zwischen subiectum und de subiecto aufzuheben. Doch es fallen nicht beide ineinander, sondern das de subiecto löst sich im subiectum auf.

Auf der anderen Seite der Vierteilung steht in der Dialektiktradition das, was Porphyrios allgemeines und einzelnes Akzidenz nennt ${ }^{177}$ Auch hier verfährt Eriugena in selbiger Weise. Das allgemeine Akzidenz, was in subiecto sein und auch de subiecto ausgesagt werden könne, unterscheide sich nicht von dem individuellen Akzidenz, dass lediglich in subiecto sei. Die Begründung dafür ist die folgende: es gebe nicht eine allgemeine Wissenschaft (disciplina) an sich, die von anderem ausgesagt werden könne und eine solche individuelle, die in subiecto auftrete, sondern im Gesamten (in toto) wie auch in Art und Individuum sei es dieselbe. Was ist vor dem Hintergrund der aristotelischen Kategorienschrift von dieser Aussage zu halten?

Aristoteles sagt nichts zu der Frage, ob das Akzidenz als Teil oder im Gesamten im Zugrundeliegenden zugegen sei, sondern lediglich, dass es keinen Teil desselben ausmache. Vielleicht hätte er es auch befremdlich gefunden, auf seine Aussage hin, etwas werde von einem $\mathrm{Zu}$ grundeliegenden ausgesagt, $\mathrm{zu}$ fragen, ob dieses Ausgesagte dasselbe sei, als was es im Zugrundeliegenden auftreten könne. Man kann hier Eriugena zunächst nicht der Fehlinterpretation bezichtigen, da er die Kategorienschrift selbst nicht kannte und auf Vermittlerquellen wie die pseudo-augustinische De categoriis Aristotelis angewiesen war. Und der Vorwurf, Logik und Ontologie nicht klar voneinander zu trennen, träfe auch schon Aristoteles und seine neuplatonischen Kommentatoren. Diese Diskussion fortführen, hieße zunächst ausführlich auf Aristoteles einzugehen, was hier nicht von Nutzen ist. Festzuhalten bleibt, dass nach Eriugena aus der ursprünglichen Viergliederung der Seienden ei-

\footnotetext{
${ }^{176}$ Insbesondere Michael Frede/Günther Patzig diskutieren diese Frage hinsichtlich Zeta ausführlich in dies.: Aristoteles Metaphysik Zeta, Bd. 2, München 1988.

${ }^{177}$ Porphyrios, Commentaria Categoriarum, ed. Busse, CAG IV, 1 , p. 73, 36-74,1.
} 
ne Zweigliederung verbleibt, die in subiectum und in subiecto (I, 12441245, Ac per hoc relinquitur subiectum et in subiecto).

Die Verwerfung dieser Differenz ist die konsequente Folge aus der Annahme, die ousia als Allgemeinstes entfalte sich dialektisch vom Universalsten bis zum Individuum. Dabei sind nach Eriugena in der einen menschlichen Natur alle Menschen erschaffen, doch es gibt nicht das Universale >Mensch < oder >Lebewesen<, und zwar vor allem deshalb nicht, weil es in seiner Lehre zwischen der fassbaren Erscheinung und der Existenz Gottes keinen Raum für Derartiges gibt. Essentia, einzelne wie allgemeine, ist Gott. Das Intelligible, im Platonismus allgegenwärtig, verschwindet im Periphyseon bis zur Unkenntlichkeit, und Eriugena wird große Mühe haben, die suniversalen Akzidenzien`, wie er sie bei Boethius vorfindet, gedanklich einzuordnen.

Der Ausdruck in subiecto dicitur (I, 1236/1237) $\sqrt{178}$ muss dabei wohl als in subiecto esse dicitur aufgefasst werden, da in I, 1242/1243 von in subiecto subsistens die Rede ist. Subiectum bezeichnet dabei prima substantia (I, 1242), und wenn wir konsequent sind, so wissen wir aus I, 6570 um die gewaltige Behauptung, diese prima substantia sei der verborgene Schöpfer im Geschöpf. Wenn essentia in Art und Gattung dasselbe ist, wie im Individuum, wenn also de subiecto gleich dem subiectum ist, dann gilt für jene dasselbe wie für dieses: sie sind unbegreiflich hinsichtlich der Frage, was sie sind. An solche sich ergebenden Konsequenzen denkt Eriugena vielleicht gar nicht. Dennoch sollten wir sie uns vor Augen halten, wenn wir den weiteren Textverlauf betrachten.

\subsubsection{Die circumstantiae locus und tempus}

Die eigentliche von A gestellte Frage war, ob die Akzidenzien quantitas, situs und locus wirklich der Gattung Ruhe zuzuordnen sind, was heiBen könnte, sie bestünden an sich (per se subsistentiae) neben der ousia. In der Folge werden diese drei Akzidenzien nebst der Zeit (tempus) als circumstantiae der ousia bestimmt und von den übrigen Akzidenzien, die ihren Namen behalten, unterschieden. Diese circumstantiae seien, wie es die Bezeichnung schon angibt, um die ousia herum angesiedelt und nicht wie die übrigen Akzidenzien in ihr (in subiecto). Sie bilden

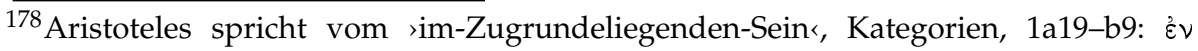

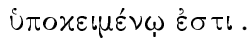


so eine neue Gegenstandsklasse, sind nicht subiectum, nicht in subiecto, sondern circa subiectum. Diese Unterscheidung ist der lateinischen Dialektik nicht fremd 179

Wir sollten uns nach der Funktion umsehen, welche die circumstantiae in Eriugenas Erklärung der Wirklichkeit einnehmen. Was bewirken diese? Wie der Text anführt, umrollen (volvunt) sie die ousia, ohne die sie nicht sein können (I, 1251-1256). Sie bilden also die Peripherie einer zentralen ousia.

Dabei nehmen insbesondere Ort und Zeit zwei besondere Funktionen ein:

1. Sie sind die Bedingungen für die Individuation der ousia. Nichts auf der Welt kann ohne sie zu einem bestimmten Etwas werden (I, 1995-1998).

2. Mit ihrer Hilfe lässt sich die individuelle ousia erkennen, zwar nicht, was sie ist, aber dass sie ist, weil erkennbar ist, wo die ousia ist und wann: »(...) so wirst du finden, dass die ousia vollständig in allen Seienden an sich unbegreiflich ist, nicht nur für den Sinn, sondern auch für den Geist, und daher aus solchen, die wie ihre Begleitumstände sind, als existierend begriffen wird, aus dem Ort sage ich, der Größe, der Lage; und diesen ist die Zeit hinzuzufügen. $<180$ Und jede ousia, so heißt es zuvor, ist irgendwann und irgendwo (I,1911-1920). Gemeint ist dabei wohl die individuelle Substanz.

Die Auffassung von Ort und Zeit als Bedingung alles Seienden ist nicht Eriugenas eigene Idee. Er übernimmt sie von Maximus Confessor, der sie für ein gegen die Platoniker gerichtetes Argument verwendet. In der Ambigua ad Iohannem legt Maximus dar, dass nichts außer dem Schöpfer selbst unendlich sei, und mit unendlich meint er der Zeit und der Ausdehnung nach. Alles Übrige sei an einem fest umgrenzten Ort (gemeint ist die Ausdehnung) und in der Zeit. Es sei in der Zeit, weil es anders

\footnotetext{
${ }^{179}$ Paraphrasis Themistiana (bei Eriugena angeführt als: De categoriis Aristotelis, in: Aristoteles latinus, I, 1-5, ed. Minio-Paluello, p. 144, 21-28.

${ }^{180}$ I,1247-1251: (...) invenies OYCIAN omnino in omnibus quae sunt per se ipsam incomprehensibilem non solum sensui sed etiam intellectui esse, atque ideo ex his veluti circumstantiis suis intelligitur existere, loco dico, quantitate, situ; additur etiam his tempus.
} 
als die erste Ursache nicht unveränderlich sei. Was wiederum veränderlich ist, das sei auch nicht ohne Zeit. Die Nähe dieses Arguments zur aristotelischen Physik hat bereits Jeauneau aufgezeigt ${ }^{181}$

Um die Veränderlichkeit der ousia darzulegen, verweist Maximus auf ihre Bewegung durch den denkenden logos in der Dialektik, beginnend bei der höchsten Gattung bis hinab zum Individuum. ${ }^{182}$ Zurecht fühlt man sich hierbei sofort an die dialektische Entfaltung der Wirklichkeit erinnert, wie sie zuvor im Periphyseon beschrieben wurde, und in der Tat hat diese hier ihren Ursprung. Selbige Bewegung widerfahre, so Maximus weiter, auch der Quantität und der Qualität. Demzufolge spricht er allem, was als unveränderliches Intelligibles gelten könnte, die Unveränderlichkeit ab. Die Ruhe komme, ganz aristotelische Physik, nur der ersten Ursache zu.

Doch was macht Eriugena aus dieser Vorlage? Bei ihm ist ja nicht nur die ousia in Ruhe befindlich, sondern auch die Kategorien locus, quantitas und situs. Wie passt das mit Maximus zusammen? Und zudem, wenn sich die ousia in Ruhe befindet, wie geht dies mit der Aussage einher, alles Geschaffene, und damit auch ousia, sei zeitlich, etwa: »Die essentia alles Existierenden ist daher räumlich und zeitlich (...).«?183

\subsubsection{Eriugenas Lehre von der geschaffenen Wirklichkeit}

Diese Untersuchung hat sich in Anlehnung an den Textverlauf von der Kategorienbetrachtung weg hin zu einer Konstitution der Wirklichkeit bewegt. Was im ersten Buch bis I, 2645 noch folgen wird, geht auf diese Wirklichkeitskonstitution näher ein. Unbedingt zu berücksichtigen ist die Tatsache, dass Eriugena, bei aller platonischer Färbung hier und da, seine Kosmologie auf der aristotelischen Kategorienlehre aufbaut. Die Elemente der gegebenen Wirklichkeit, und für ihn als Christen heißt diese Wirklichkeit `Schöpfung`, sind ousia und die neun Akzidenzien. Da in seine Erklärung dieses Wirklichen dennoch einiges an Platonismus einfließt und er um die Begriffe der Materie und Form nicht um-

\footnotetext{
${ }^{181}$ Edouard Jeauneau: Jean l'Erigène et les Ambigua ad Iohannem de Maxime le Confesseur, in: Maximus Confessor, Actes du Symposium sur Maxime le Confesseur, Fribourg, 2-5 septembre 1980, édités par Felix Heinzer et Christoph Schönborn 1982, p. 343-364.

${ }^{182}$ MPG 91,1177C-D.

${ }^{183} \mathrm{I}, 1677-1678$ : Omnium itaque existentium essentia localis atque temporalis est (...).
} 
hinkommt, verkompliziert sich die Sache, auch weil das, was Aristoteles als Kategorien anführt, bei Platon einen anderen ontologischen Stellenwert einnimmt.

Vorrangig zu klären ist die Aussage, wonach alle ousia orts- und zeitgebunden ist. Denn dies klingt nach allem, was über ousia bislang gesagt wurde, merkwürdig. Es heißt in I, 1205-1206: "Alles befindet sich in Bewegung, außer der ousia, der allein die Bewegung fehlt«. Einmal abgesehen von der Frage, wie es um die zuvor behauptete Ruhe von quantitas, locus und situs bestellt ist, die hier offensichtlich doch negiert wird, da sich nur die ousia in Ruhe befinden soll, fragt es sich, wie ousia außerhalb von Bewegung gedacht werden kann, wenn sie durch Ort und Zeit bedingt ist. Wie ein Zitat dazu zeigt, unterscheidet Eriugena hier kaum merklich zwischen der ousia als solcher und der ousia, die an einem Ort und zu einer Zeit erscheint:

»Denn, wenn eigentümlich Ort und Zeit benannt würden, schiene es da, dass sie nicht außerhalb von allem durch das Hervorragen der essentia sind, sondern in der Anzahl all derer, die sind, beinhaltet sind? Ort sicherlich und Zeit sind unter all das zu zählen, was geschaffen ist. Denn in diesen beiden besteht die gesamte Welt, die jetzt ist, und ohne diese beiden nicht sein kann, weshalb sie von den Griechen hôn aneu to pan genannt werden (das heißt, ohne das die Gesamtheit nicht sein kann). Alles nämlich, was sich in der Welt befindet, ist notwendig durch die Zeit bewegt und durch den Ort bestimmt. \&184

Wenn die ousia so als einzelne oder am Einzelnen auftritt, an sich, wie wir gesehen haben, allgemein und unteilbar, so geschieht dies durch eine räumliche und zeitliche Umgrenzung, die ihr widerfährt oder umgekehrt, der sie zugrunde liegt. Anders gesagt, sofern die unveränderliche und ewige ousia zur Substanz des Individuellen wird, so ist dieses Werden in Raum und Zeit begriffen: »Denn jegliche aus dem Nichts geschaffene ousia ist örtlich und zeitlich, örtlich, weil sie auf eine Weise ist,

\footnotetext{
${ }^{184}$ I, 1129-1135: Num, si proprie locus diceretur et tempus, videretur non extra omnia per excellentiam essentiae sed in numero omnium quae sunt includi? Locus siquidem et tempus inter omnia quae creata sunt computantur. In his nanque duobus totus mundus qui nunc est consistit et sine quibus esse non potest, ideoque a graecis dicuntur $\Omega N$ ANEY TO ПAN (id est sine universitas esse non valet). Omne enim quod in mundo est moveri tempore, loco diffiniri necesse est.
} 
die nicht unendlich ist, und zeitlich, weil sie als etwas zu sein anfängt, das zuvor nicht war. 185

Damit werden Ort und Zeit zur Bedingung für Entstehung: »Siehst $\mathrm{du}$ also, dass Ort und Zeit vor allen Seienden zu denken sind? Die Zahl nämlich der Orte und Zeiten, wie der heilige Augustinus im sechsten Buch über die Musik sagt, geht allen, die in ihnen sind, voraus. «186

Zugegebenermaßen erklärt dies nicht ausreichend, wie man sich die Entstehung des Einzeldings, dem ja die ousia zugrunde liegen soll, genau zu denken hat. Und die gemessen am Textverlauf hier sprunghaft angeführten Zitate sind als Sammlung der wichtigsten Aussagen zu verstehen, um die Sache klarer darlegen zu können. Der Dialogpartner A fragt nicht nach, wo wir gerne eindringlich nachfragen würden, und so fordert Eriugena von seinem Leser, diese doch gewaltige Theorie fürs Erste so hinzunehmen. Es handelt sich dabei um eine durchaus elegante Lösung, die Schöpfung sowie deren Ende zu erklären. Denn wenn allein Ort und Zeit das sinnlich wahrnehmbare Geschöpf bedingen, dann ist mit Aufhebung dieser beiden auch alles Sinnliche aufgehoben. Die theologische Fragestellung, was eigentlich mit dem Körper nach der Auferstehung passiert, erfährt so eine überraschend einfache Antwort: In der Ewigkeit und Grenzenlosigkeit Gottes gibt es weder Ort und Zeit, und damit weder Einzelnes noch Sinnliches. Und so heißt es denn auch:

»Allen freilich, die zur Ewigkeit ihrer Ideen, die weder einen zeitlichen Anfang durch das Enstehen in Ort und Zeit noch ein Ende durch die Auflösung haben noch durch eine örtliche Lage bestimmt werden, auf solche Weise zurückgekehrt sind, dass sie nur in diesen Ideen und nichts anderes sind, fehlt dann jegliches örtliche und zeitliche Ende.< 187 Das versprochene ewige Leben besteht demnach in der ewigen Idee ou-

185I, 1913-1916: Omnis enim OYCIA de nihilo creata localis temporalisque est, localis quidem quia aliquo modo est quoniam infinita non est, temporalis vero quoniam inchoat esse quod non erat.

${ }^{186}$ I, 1706-1709: Videsne igitur locum tempusque ante omnia quae sunt intelligi? Numerus enim locorum et temporum, ut ait sanctus Augustinus in sexto de musica, praecedit omnia quae in eis sunt.

${ }^{187}$ I, 1732-1737: Omnes siquidem, qui ad aeternas suas rationes quae neque initium temporis per generationem in loco temporeve neque finem per resolutionem habent neque ulla locali positione circumscribuntur reversuri sunt ut solae in eis et nil aliud sint, profecto omni locali temporalique termino carebunt. 
sia, jener causa primordialis, die in Gott ist, und ist darum ewig, weil es die Kategorien Ort und Zeit, die alles Sinnliche begrenzen, überstiegen hat.

Solange aber noch nicht geklärt ist, wie sich Eriugena die Individuation der ousia denkt und in welchen Zustand die Akzidenzien im Zuge der Loslösung der ousia übergehen, ist dies nicht befriedigend zu verstehen.

\subsubsection{Von der Differenz zwischen ousia und Körper (1606-2394)}

Bei der Bestimmung der Wirklichkeit, wie Eriugena sie uns präsentiert, darf man fragen, ob sie nur für uns ungewöhnlich ist, oder auch für seine Zeit. Aufgrund zweier Aussagen im Periphyseon können wir davon ausgehen, dass sein damaliges Umfeld zumindest in Teilen eine andere Sicht vertrat. In I,1607-1611 lässt er A sagen: »Aber sehr wundere ich mich, warum es zum gemeinen Gebrauch des menschlichen Lebens gehört, sich daran gewöhnt zu haben, all diese Körper, seien sie himmlische oder luftige oder wässrige oder irdische, Orte innerhalb der kleinsten Körper zu nennen, auf welche Weise ousia nichts anderes zu sein scheint als dieser sichtbare und berührbare Körper. $<{ }^{188}$ Es war demnach bei den Karolingern die Ansicht zugegen, ousia bezeichne den Körper. Ihre Eriugena unliebsame Popularität zeigt sich in der Aussage: »Aber gegen jene, denke ich, die den Körper und die essentia des Körpers für dasselbe halten, und damit so weit abirren, dass sie nicht daran zweifeln, dass diese eine körperliche Substanz sei sowie sichtbar und anfassbar, ist kurz etwas zu sagen. ${ }^{189}$ Man denkt bei dieser Darstellung unweigerlich an die Stoa, von der wir wissen, dass sie eine in diese Richtung verlaufende Ansicht vertrat. Doch wie gelangt stoische Lehre zu den Karolingern? Bei Calcidius und seinem Timaios-Kommentar ist die Darstellung dieser Lehre so knapp dargestellt, dass sie als alleinige

188 I, 1610-1611: Sed valde miror cur in cummunem usum humanae vitae pervenit ut omnia haec corpora, sive caelestia, sive aeria, sive aquatica, sive terrena, minorum intra se corporum loca esse dicere consuescat, quamadmodum nil aliud esse aestimat OYCIAN praeter hoc corpus visibile atque tangibile.

${ }^{189}$ I, 2010-2013: Sed adversos eos qui non aliud esse corpus et aliud corporis essentiam putant, in tantum seducti ut ipsam substantiam corpoream esse visibilemque atque tractabilem non dubitent, quaedam breviter dicenda esse arbitror. 
Quelle entfällt ${ }^{190}$ Seneca und Cicero verbleiben als mögliche Quellen, doch sagen sie wenig zu dieser Frage, und ein solch gewaltiger Einfluss der Stoiker auf die Kosmologie der Karolinger sollte überraschen und wurde in der Forschung bislang nicht nachgewiesen.

Wenn ousia tatsächlich nichts anders sein sollte, als der Körper, dann kippt dieser Umstand Eriugenas Lehre an zwei entscheidenden Punkten:

1. Die Unbegreiflichkeit der ousia wäre nicht mehr gegeben. Somit wäre auch die Behauptung hinfällig, essentia oder substantia des Einzeldings sei Gott.

2. Ousia wäre nicht mehr ewig und unvergänglich und erst recht keine causa primordialis mehr, sondern verginge zusammen mit dem Untergang des Körpers.

Eine Lehre, wonach ousia mit dem Körper identisch ist, passt demnach so gar nicht in die Wirklichkeitslehre des Periphyseon. Dabei hat der Text bereits grob umrissen, was als ousia aufzufassen ist, aber nicht dargelegt, was Körper ist und wie sich ousia dazu verhält. Dies geschieht nun in I, 1606-2394.

Wie dargelegt, verwendet Eriugena zur Konstitution der Wirklichkeit das Begriffsarsenal aus der aristotelischen Kategorienschrift. Nicht Materie und Form oder die Elemente sind daher vorrangig dasjenige, was das Sichtbare hervorbringt, sondern die ousia nebst den Akzidenzien.

Wenn Gerold Prauss mit seiner Plato-Interpretation Recht hat, dann ist die Bündeltheorie, die Eriugena hierzu verwendet, ein platonisches Modell ${ }^{191}$ So entsteht der konkrete sinnliche Gegenstand aus einer Bündelung der einzelnen Eigenschaften. Eriugena nennt dies einen $\mathrm{Zu}$ sammenfall oder ein Aufeinandertreffen der Akzidenzien (I, 2347 und 2605-2606, accidentium concursus). Er macht keinen Hehl daraus, diese Lehre von dem griechischen Theologen Gregor von Nyssa erhalten zu

${ }^{190}$ Calcidius Commentarius, ed. Waszink, Plato Latinus IV, p. 295, 15-16: Ergo corpus universum iuxta stoicos determinatum est et unum et essentia.

${ }^{191}$ Gerold Prauss: Auf der Flucht vor individuellen Eigenschaften oder Der verkannte Platon, in: Rainer Enskat: Amicus Plato magis amica veritas, Berlin 1998, S. 171-193. 
haben ${ }^{192}$ Was sich dabei in Gregors Lehre nicht findet, von Eriugena aber dort hineingetragen wird, ist die ousia. Sie bildet das Fundament, das subiectum, an dem die Akzidenzien aufeinandertreffen. Ohne ousia also kein Körper. Weil diese Lehre bei Eriugena ziemlich vielgestaltig und undurchsichtig ist, soll hier die Anführung der wesentlichen Merkmale genügen.

Die Ansicht, die ousia sei im Gegensatz zum Körper unvergänglich, will Eriugena von Dionysius Areopagita erhalten haben (I,2038-2044). Sie werde zwar in Gattung und Arten unterteilt (dividitur), sei aber nicht wie der Körper zertrennbar (separabile), und daher, anders als der Körper, in ihren Teilen als Ganzes zugegen (I, 2122-2124). Körper ist daher nichts anderes als die quantitas der ousia, oder, wie er korrigierend sagt, deren quantum, also das Wiegroß der ousia. Hierbei greift er einen Gedanken aus der pseudo-augustinischen Schrift De categoriis Aristotelis auf 193

Wir müssen uns natürlich fragen, was mit den Akzidenzien ist, bevor und nachdem sie zu einem Körper zusammengefasst sind. Denn eigentlich sollten sie ja ohne ousia gar nicht bestehen können. Für Eriugena sind sie an sich unkörperlich und bilden lediglich im gemeinsamen Zusammenschluss einen Körper. Aber wie kann, um eine Frage aufzuwerfen, die schon das antike Denken beschäftige, aus etwas Unkörperlichem Körperliches entstehen? Zwei Fragen sind daher zu beantworten:

1. Was sind die Akzidenzien jede für sich genommen?

2. Wie entsteht aus den unkörperlichen Akzidenzien und der unkörperlichen ousia ein Körper?

Genau diese Fragen lässt Eriugena A stellen. Dabei beruft sich A auf Boethius' Arithmetik, um die Frage soweit als möglich selbst zu beantworten (I, 2395-2432). Die Akzidenzien (bei Boethius wohl eher das Intelligible) bestehen für sich selbst frei von Veränderung und gehen erst zusammen mit der Materie eine veränderliche Verbindung ein. Interessanterweise unterrichtet uns Eriugena darüber, wie heikel die zweite

${ }^{192}$ I, 2604-2606, Dessen Werk De imaginis, in PG 45 unter dem Namen De opificio hominis ediert, wurde sehr wahrscheinlich von Eriugena übersetzt.

${ }^{193}$ Siehe Näheres hierzu in Abschnitt 3.4.1 sowie in Jeauneaus Quellenapparat, Periphyseon I, p. 71. 
Frage sei. $\mathrm{N}$ warnt A eindringlich davor, sie an die falschen Personen zu stellen, um nicht einem Scheinargument aufzusitzen (I, 2433-2435). Autorität und ratio seien von Nöten, um die Frage zu beantworten. Wie dieses Argument aussieht, wird die Folge zeigen.

\subsubsection{Von der Materie (2395-2635)}

Die Lösung der Frage, wie aus Unkörperlichem etwas Körperliches entstehen kann, beantwortet Eriugena mit der Materie. Damit wird deutlicher, worauf seine Warnung abzielen könnte: Eine manichäistische Antwort ist nicht fern, wonach die Materie als das Böse mit Gott koexistiert. Zugleich will er nicht abstreiten, dass die Materie eine merkwürdige Ähnlichkeit zu Gott aufweist: Beide sind, so sagt er, unbestimmbar und ohne konkrete Gestalt (I,2464-2469). Dies aber sei bei Gott durch das Überragen (excellentia) aller Form bedingt, bei der Materie hingegen durch den Mangel (privatio) an aller Form (I, 2480-2489).

Nach Plato und Augustinus sei die Materie das Gefäß (capacitas, capax) für alle Formen, Dionysius Areopagita zufolge sei sie die Teilhabe (participatio) an den Formen (I, 2499-2517). Beide, Form wie auch Materie, sind im Periphyseon unkörperlich, schließt N daran an: »Gestehst du daher ein, dass die Körper aus einer Verbindung des Unkörperlichen gemacht sein können? ${ }^{194}$ Und A pflichtet bei, die ratio zwinge ihn dazu. Sehen wir uns die gegebene srationale Erklärung näher an.

Eriugena erklärt den Sachverhalt mittels einer Analogie. So wie ein Schatten aus Körper und Licht entstehe und verschwinde, ohne dass dessen Ursachen, nämlich Körper und Licht verschwänden, so entstehe auch der Körper aus unkörperlichen Ursachen. Dieses Beispiel erhält besonderen Nachdruck, wenn wir uns der bereits angeführten Aussage erinnern, wonach das Sinnliche nur eine Manifestation der verborgenen Ursachen ist ${ }^{195}$ Aber so schön diese Analogie auch klingen mag, sie klärt nicht die Frage. Dass der Schatten etwas ist (I, 2543, aliquid), mögen wir zugestehen. Wenn er etwas Körperliches ist, so entsteht er aus mindestens einem Körperlichem, dem Körper, für den Fall, dass Eriugena das Licht als etwas Geistiges ansieht. Denn dass nicht beide, Körper und Licht, unkörperlich sind, ist offensichtlich. Das Bei-

\footnotetext{
${ }^{194}$ I, 2429: Concedis itaque ex incorporalium coitu corpora posse fieri?
} ${ }^{195}$ III, 589-597. 
spiel zeigt also nicht, wie aus Unkörperlichem Körperliches entstehen kann. Vielleicht geht es Eriugena vielmehr darum, dass etwas vergehen kann, ohne dass dessen Ursachen davon irgendwie berührt werden. Dies reicht ihm möglicherweise, um Unkörperliches als Ursache der Körper anzunehmen. Für die antike Philosophie wäre dies sicherlich unzureichend, da Gleiches aus Gleichem zu entstehen hat, und die Natur des Körpers von der Natur des Unkörperlichen verschieden ist. Aber wir müssen sehen, dass für Eriugena der Körper wohl etwas Schattenhaftes ist, ein Abbild dessen, was wahrhaftig ist, und dem daher eine eigene Natur gar nicht zukommt. Rätselhaft bleibt dabei wieder die Rolle und Stellung der ousia.

\subsubsection{Das Akzidenz}

Es bleibt noch die Frage, was die Akzidenzien als solche sind, bevor sie eine Verbindung eingehen, die den Körper bedingt. Hier steht Eriugena unter Boethius' Einfluss. Dessen Ausführungen zu Beginn der Institutio Arithmetica zugrundegelegt, die in großen Teilen lediglich die Übersetzung der Arithmetik des Nicomachos von Gerasa darstellen, sind die Akzidenzien, oder hier besser das Intelligible zu nennen, an sich selbst und im Geiste betrachtet unveränderlich und nehmen Veränderlichkeit nur insofern an, als sie mit dem Körper verbunden sind ${ }^{196}$ Natürlich ist es zweierlei, ob die Akzidenzien einen Körper selbst hervorbringen oder sich mit ihm verbinden, doch diese Auseinandersetzung wird im Periphyseon nicht geführt. Eriugena glaubt, die Akzidenzien seien für sich genommen und im Geiste betrachtet von unveränderlicher Natur, insofern sie hingegen gemeinsam einen Körper bilden, sind sie veränderlich (I, 2620-2630).

\subsubsection{Der Name >Schöpferく (2636-3496)}

Kaum merklich findet der Text in diesem Abschnitt zu seiner Ausgangsfragestellung zurück. Und das nicht nur, weil er die beiden noch

\footnotetext{
${ }^{196}$ Siehe zur griechischen Vorlage der Institutio John Caldwell: The De institutione arithmetica and the De institutione musica, in: Boethius-his life, thougt and influence, ed. by Margaret Gibson, Oxford 1981, p. 135-161; sowie zur Natur der Akzidenzien in dieser Schrift die Einleitung von Michael Masi: Boethian Number Theory, A translation of the De institutione Arithmetica, Amsterdam 1983.
} 
ausstehenden Kategorien >Tun $<$ und >Leiden $<$ hinsichtlich ihrer Aussagbarkeit auf Gott hin untersucht. Er kehrt auch zurück zu der Frage, ob sschaffend und sunerschaffen die rechtmäßigen differentiae specificae der ersten Natur sind. Das Prädikat >unerschaffen < erfuhr bereits die Interpretation als non ab alio creari, vor dem Hintergrund der Behauptung, Gott erschaffe sich selbst. Jetzt scheint nicht das creari, sondern das creat (er schafft) mit einer theologischen Grundwahrheit zu kollidieren.

Denn Schaffen ist ein Tun, und Tun eine Kategorie. Wenn dieses Tun eigentümlich von Gott ausgesagt werden kann, hieße dies nach Eriugenas Auffassung, die Kategorie >Tun lasse sich von Gott aussagen.

Doch mehr noch als auf dieses weist er auf ein anderes Problem hin: Schafft Gott die Welt oder hat er sie erschaffen, so ist oder war er tätig. Dieses Dilemma führt der Dialog im Periphyseon wie folgt an:

»N. Dass ein Schaffen ohne die Bewegung des Schaffens nicht sein kann, dies hast du bereits zugestanden.

A. Das habe ich.

N. Auch Gott also gibst du eine Bewegung, ohne die er nicht als schaffend gedacht werden kann, und zugleich nimmst du Bewegung und Schaffen von ihm weg. (...)

A. Ich kann Gott keine Bewegung geben, da er allein unver-
änderlich ist und auch nichts hat, worin oder wohin er sich
bewegt, da alle in ihm sind, ja er selbst vielmehr alles ist;
das Schaffen aber kann ich von ihm nicht verneinen, da er
der Schöpfer von allem ist. 197

Schaffen ist demnach eine Bewegung. Hinzu kommt, dass A annimmt, Gott war bereits, bevor er zu schaffen begann: »N. War denn Gott schon, bevor er alles erschuf? - A. Mir scheint, dass er war.<198 Dann käme ihm das Schaffen akzidenziell zu, da es einen Zustand gab,

${ }^{197}$ I,3198-3207: N. Facere sine motu facientis esse non posse iam dedisti. A. Dedi. N. Aut igitur motum deo dabis, sine quo facere non intelligitur, aut simul et motum et facere ab eo auferes. (...) A. Motum deo dare non possum, qui solus immutabilis est nec habet quo vel ad quid se moveat, cum in ipso omnia sint, immo cum sit ipse omnia; facere vero ab eo auferre non possum, cum sit factor omnium.

${ }^{198}$ I, 3213-3215: N. Num deus erat, priusquam omnia faceret? - A. Videtur mihi fuisse. 
in dem er noch nicht schuf. Es ließe sich dabei auf die Differenz von Potenz und Akt verweisen, und diese aristotelische Lösung hat Eriugena hier dem Namen nach parat, legt sie aber dem Argument nach nicht dar.

So nennt er als Lösung die neuplatonische Trias essentia - virtus operatio. Ohne näher zu erklären, was es mit dieser Trias auf sich hat, behauptete er bereits zuvor die Einheit dieser drei innerhalb einer jeden Natur (I,2727-2734). Wahrscheinlich spielt auch Augustinus mit seiner Seelenlehre hier eine wesentliche Rolle. In der Natur Gottes, so Eriugena, bestehe eine Einheit zwischen der göttlichen Substanz, deren Vermögen und deren Wirken:

N. »Gott ist also gleichewig mit seinem Schaffen und gleichwesenhaft? - A. Das glaube und denke ich. N. Ebenso sind Gott und sein Schaffen (das heißt sein Tun) nicht zwei, sondern einfach und unteilbar? A. Ich sehe, dass es eins ist. 4199 Und im Anschluss: »N. Also ist nicht eines das Sein Gottes und ein anderes sein Machen, sondern sein Sein und Machen ist er selbst. «200

Diese Antwort nimmt der theologischen Frage den Raum, warum Gott die Welt erschuf. Wenn das Schaffen unabtrennbar zum Wesen Gottes gehört, dann ist Gott weder ohne ein Schaffen zu denken noch ist die Frage sinnvoll, warum er schuf. Denn das Schaffen ist er selbst seiner Natur nach. Mit dieser Antwort erklärt sich auch die in der Texterläuterung bereits aufgezeigte Eigenheit, wonach die Schöpfernatur schafft (creat) und nicht etwa geschaffen hat (creavit) oder schuf (creabat).

Anders kann es sich Eriugena nach gar nicht verhalten: »Denn wenn etwas anderes bei ihm gedacht wird, was er selbst nicht ist und ihm ja irgendwie zukommt, ist er fürwahr weder unendlich noch einfach.<201 Dies könnte zugleich zu der Annahme führen, Gott sei der Schöpfung bedürftig. Denn wenn er nicht schafft, ist er gar nicht, ist umgekehrt also nur, insofern er auch schafft. Daher wohl glaubt Eriugena, dieses

${ }^{199}$ I, 3248-3252: N. Coaeternum igitur est deo suum facere et coessentiale? A. Ita credo et intelligo. N. Duone quaedam sunt deus et suum facere (hoc est sua actio), an unum simplex atque individuum? A. Unum esse video.

${ }^{200}$ I, 3255-3256: Non ergo aliud est deo esse et aliud facere, sed ei esse id ipsum est et facere.

${ }^{201}$ I, 3221-3223: Nam si aliud cum ipso intelligitur quod ipse non est aut se quippiam ei accidit, profecto neque infinitus est neque simplex. 
Schaffen näher bestimmen zu müssen: »N. Wenn wir also vernehmen, Gott schaffe alles, so dürfen wir an nichts anderes denken, als dass Gott in allem ist, das heißt, dass er als essentia allem zugrunde liegt. Denn er allein ist an sich wahrhaft seiend, und alles, was in den Seienden wahrhaft seiend heißt, ist nur er selbst. Keines nämlich der Seienden ist an sich wahrhaft; was immer aber in ihm als wahrhaft seiend gedacht wird, erfährt dies durch Teilhabe an diesem einen, der allein an sich selbst wahrhaft ist. «202

Diese Aussage fasst Vieles von dem zusammen, was schon gesagt wurde. Wir erinnern uns: "Denn wenn er ssich selbst schaffend nannt wird, so ist an nichts anderes zu denken, als an das Begründen der gegenständlichen Naturen. Denn seine Schöpfung, das heißt seine Erscheinung in etwas, ist fürwahr das Bestehen alles Existierenden.<203 Und zudem: »(...), daher existiert alles, was existierend genannt wird, nicht in sich selbst, sondern existiert durch Teilhabe an der wahrhaft existierenden Natur. 204

Und dennoch ist hier inne zu halten: In der erstgenannten Textstelle wird das creare als esse und subsistere bestimmt. Welch eine gewaltige Behauptung! Das Erschaffen der Welt, der Genesis nach in sechs Tagen vollendet, interpretiert Eriugena als das göttliche Sein und $\mathrm{Zu}-$ grundeliegen in den Dingen. Gott ist nicht, wie bislang in der Theologie, Schöpfer und zudem Bewahrer der Schöpfung, sondern sein Schaffen ist nichts anderes als dieses bewahrende Sein. Damit wird auch deutlich, inwiefern Eriugena Gott als creari, als erschaffen denken kann: Weil das allem zugrunde liegende Sein, diese subsistentia, Gott ist, und das creare nur ein subsistere bedeutet, so hat sich Gott als Sein im Seienden selbst erschaffen. Offensichtlich will Eriugena Gott nicht mehr als Schöpfer von etwas Anderem, ihm Verschiedenen denken, sondern

202I, 3258-3264: Cum ergo audimus deum omnia facere, nil aliud debemus intelligere quam deum in omnibus esse, hoc est essentiam omnium subsistere. Ipse enim solus per se vere est, et omne quod vere in his quae sunt dicitur esse ipse solus est. Nihil enim eorum quae sunt per se ipsum vere est; quodcunque autem in eo vere intelligitur participatione ipsius unius qui solus per se ipsum vere est accipit.

${ }^{203}$ I, 554-555: Nam cum dicitur se ipsam creare, nil aliud recte intelligitur nisi naturas rerum condere. Ipsius nanque creatio, hoc est in aliquo manifestatio, omnium existentium profecto es subsistutio.

${ }^{204}$ I, 502-503: (...), ita omne quod dicitur existere non in se ipso existit, sed participatione vere existentis naturae existit. 
vorrangig als den, der alles Seiende, indem er ihm das Sein verleiht, in sich trägt. Dies ruft unweigerlich den Verdacht des Pantheismus hervor, der in einem abschließenden Kapitel zu behandeln ist.

Im Hippias maior (297a) skizziert Platon den eigentlich naheliegenden Gedanken, die Ursache könne nicht dasselbe sein, wie deren Wirkung. Wie also, so lässt sich mit Blick auf das Periphyseon fragen, kann der Verursacher dem Verursachten subsistieren? Und worin liegt die Differenz zwischen Schöpfer und Geschöpf, wenn sie substanziell dasselbe sind? Man ist geneigt, als Lösung auf Eriugenas Einheitsmetaphysik, seine All-in-eins-Lehre zu verweisen, und dies ist sicherlich richtig. Dabei ist allerdings seine Auffassung lediglich eine Nachahmung der neuplatonischen Einheitslehre. Bei den Neuplatonikern ist das eine Sein in allem auf gleiche Weise zugegen, dass aber die Substanz der ersten Ursache identisch ist mit der Substanz der Wirkungen, lehren sie nicht.

Der Grund für die bemerkenswerte Aussage im Periphyseon, sowohl die theologische Bestimmung >schaffend ‘ als auch die Bestimmung serschaffen < könne Gott zugesprochen werden, liegt damit in dem Gedanken, dass Gott essentia von allem ist.

1. Indem Gott essentia ist, hat er sich selbst geschaffen, da diese geschaffen ist.

2. Indem Gott essentia von allem ist, ist nichts wahrhaft (vere) außerhalb von ihm, existiert nichts außerhalb von ihm, sondern was außerhalb von ihm ist, wird nur seiend genannt (dicitur), weil es fassbar ist.

3. Indem Gott sich als essentia in sich selbst erschafft, ist sein Sein mit der Tätigkeit des Schaffens gleichewig (coeaeternus).

Vor diesem Hintergrund drängt sich die Frage auf, in welcher Hinsicht Gott überhaupt noch von seinem Geschöpf verschieden ist. Doch darauf geht Eriugena erst im zweiten Buch ein.

Ein letztes Zitat aus dem Ende des ersten Buch sei angeführt, um zu der anfänglichen Behauptung zurückzukehren, Gott sei substantia aller Geschöpfe: »Als geschaffen freilich wird er allgemein in seinen Geschöpfen angesehen, nicht nur, weil er in ihnen als seiend gedacht 
wird, insofern sie ohne ihn nicht sein können, sondern auch, weil er deren essentia ist. «205

Darin weist das sine quo esse non possunt in die folgende Richtung: Gott ist nicht nur seinsverursachende essentia, sondern tritt auch als Bewahrer auf. Wie zuvor gezeigt, wird ohnehin die Anfangsursache vom Seinsgrund her interpretiert. In Gott ist alles Seiende zu denken, weil es ohne dessen Sein aufhört, zu existieren. Er ist substantia omnium und subiectum omnium. Und darum, so meint Eriugena, ist er als Schöpfungsursache zu begreifen, und nicht umgekehrt.

\subsubsection{Ergebnisse der Untersuchung}

Zwei wichtige Fragen wurde geklärt, die nach Untersuchung des Anfangs noch offen waren. Erstens ist jetzt klar, aus welchem Grund Eriugena die Gesamtnatur in vier Arten einteilt. Er sucht, so hat sich gezeigt, spezifische Differenzen etwa für den Schöpfer. Die eigentümlichste Differenz bildet das non ab alio creatur. Alle übrigen Prädikate werden entweder nur vom Geschöpf auf den Schöpfer übertragen oder stellen den göttlichen Selbstbezug dar, wie das creari, das von theos abgeleitete videre und currere sowie das facere und damit das movere. Gott schafft sich selbst, sieht nichts anderes als sich selbst und umläuft sich selbst, weil, so Eriugenas durchgängige Begründung, Gott die essentia von allem ist. Es wird daher in der Folge darum gehen, diese Begründung noch einmal eingehend zu prüfen.

In diesem Zusammenhang ist dann auch zu klären, worin sich die vorrangigen Ursachen von der Erstursache unterscheiden, wenn sie, wie es der Text sagt, in dieser ersten Ursache ewig und unveränderlich sind (I, 176-177, aeternaliter et incommutabiliter in ea sunt).

Eine Schwierigkeit blieb in I,731-776, da in der Aufzählung all dessen, was Gott genannt werden kann, auch das superessentialis genannt ist (I,748-750). Das allein wäre schon der Erklärung wert, da es zuvor hieß, Gott sei essentia omnium. Noch schwerer wiegt die Aussage, Gott sei darum superessentialis, weil er sowohl esse als auch non esse umfasse. Essentialis entspricht demnach dem esse. In I,55-61 wurde essentia

${ }^{205} \mathrm{I}, 3187-3190$ : Fieri siquidem aestimatur in creaturis suis universaliter, dum in eis non solum intelligitur esse, sine quo esse non possunt, sed etiam eorum essentia sit. 
nun gerade als non esse bestimmt, als ein unfassbares vere esse, dem das Prädikat non esse zukomme.

Als grundlegende Fragen lassen sich daher die folgenden formulieren:

1. Was genau meint der Ausdruck, Gott sei essentia omnium?

2. Was heißt vere esse und was ist sein Kennzeichen?

3. Wie ist die Aussage zu verstehen, die Schöpfung sei eine manifestatio Gottes? Ist die Schöpfung nur eine Erscheinung dessen, was allein wahrhaft (vere) ist?

4. Was ist die Substanz (ousia) des Körpers und ist sie individuell?

5. Was sind Akzidenzien, insofern sie an sich bestehen?

Die übrigen vier Bücher sollten zur Klärung dieser Fragen beitragen.

\subsection{Zur Ontologie in den übrigen vier Büchern}

"Setze das Ende dieses Buchs. Denn sein Umfang ist ausreichend.<206 Mit diesen Worten A's schließt Eriugena das erste Buch. Was ist damit gemeint? Ist der Umfang so groß, dass alles Weitere in einem nächsten Buch zu besprechen ist? Oder ist der Umfang ausreichend, weil alles darin zur Frage Stehende geklärt wurde?

Wie Eriugena es zu Beginn der Bücher angibt, soll jeweils eines eine der vier Naturen behandeln, also jener Untersuchungsordnung folgen, die in I,40-44 vorgegeben ist. Doch in keinem der Bücher hält er sein Versprechen wirklich ein. Bereits das erste handelt nicht nur von der Anwendbarkeit der Kategorien auf den Schöpfer hin, sondern, wie dargelegt, vor allem von der Natur der Kategorien selbst sowie der Individuation der Substanz. Das das zweite Buch wird nur spärlich auf die zweite Natur, die erstrangigen Ursachen, zu sprechen kommen, und das dritte Buch, der Vorgabe nach eine Abhandlung über die bloß erschaffene Natur, beginnt mit dem, was eigentlich im vorangehenden Buch hätte behandelt werden sollen, eben den erstrangigen Ursachen.

${ }^{206}$ I, 3496: Fige limitem libri. Sat enim est in eo complexum. 
Eine Begründung hierfür findet sich im Text nicht. Das vierte Buch, erwartungsgemäss die letzte Natur behandelnd, jene, welche weder schafft noch erschaffen wird, sollte vorrangig vom Ende der Welt und der Rückkehr zu Gott sprechen, kommt dieser Vorgabe aber nur beschränkt nach. Warum es überhaupt ein fünftes Buch gibt, wenngleich nur vier Naturen zu behandeln sind, ist nicht zufriedenstellend zu klären. Die immer wieder geäußerte Erklärung, der Umfang des vierten Buches sei ansonsten über die Maßen angewachsen, ist zwar naheliegend, aber mit keinem Textbeleg nachweisbar. Eriugena schweigt hier$\mathrm{zu}$. Von seiner eigenen formalen Vorgabe schweift das Werk demnach in allen Büchern ohne Angabe von Gründen ab.

Hinzu kommt ein Wechsel der Untersuchungs- und Darstellungsmethode. Im ersten Buch übernimmt der Dialogpartner A nicht nur die Rolle des kritisch Nachfragenden, er bestimmt auch die zu behandelnde Thematik und Vorgehensweise, und sei es teils durch bloße Zustimmung. Diese Funktion nimmt vom zweiten Buch an merklich ab. Die Monologe N's werden zunehmend länger, was auch damit zusammenhängt, dass er ganze Kapitel aus den Schriften des Dionysius Areopagita und Gregor von Nyssa zitiert. Warum Eriugena hier so ausführlich Texte zitiert, von denen seine eigenen Übersetzungen vorliegen und die damit für andere zugänglich sind, bleibt in der Forschung unbeantwortet. Ebensowenig ist geklärt, warum die didaktisch sinnvolle Dialogform zunehmend aufgeweicht wird.

Am auffälligsten indes ist der Wechsel der Methode. Im ersten Buch war es die Dialektik, mit der Fragen beantwortet wurden, ein Vorgehen, das Eriugena den Weg der ratio (via rationis) nennt. Wer diesem dialektischen Weg in den übrigen Büchern weiter folgen will, sieht sich spätestens im vierten Buch einer Genesisexegese ausgesetzt, die sich um dialektische Argumente nicht mehr bemüht. Das liegt nicht an der zu behandelnden Thematik, dem Schöpfungsbericht, denn auch dieser ließe sich dialektisch untersuchen, sondern an Eriugenas Herangehensweise, die mit einem Mal Autoritätsverweise und metaphorische Erläuterungen als ausreichend betrachtet.

Der Grundsatz aus dem ersten Buch, wonach die ratio aller Autorität vorangehe und ihr allein in der Untersuchung zu folgen sei, wird damit aufgegeben. Die Gründe für diese Abweichung vom vorgegebenen Untersuchungsgegenstand und ursprünglicher Methode sind bislang 
kaum untersucht worden. Jeauneau spricht in seiner Edition des vierten Buches die Entwicklung des Textes hin zu einer Genesis-Exegese an, doch will er kein näheres Urteil hierzu abgeben, damit der Leser unvoreingenommen zu Werke gehe ${ }^{207}$

Mit viel Wohlwollen und Nachsicht versucht Gangolf Schrimpf, wenigstens einen thematischen Überblick für die Bücher zwei bis fünf zu geben ${ }^{208}$ Ein Blick auf diese Gliederung reicht, um zu sehen, dass sich in der Abfolge der behandelten Themen und Fragestellungen keine wirkliche Systematik erkennen lässt. Alain de Libera fällt wohl aus diesem Grund das aus philosophischer Sicht ernüchternde Urteil, Bücher zwei bis fünf seien lediglich eine ausführliche Exegese des biblischen Schöpfungsberichts. ${ }^{209}$ Jemandem, der aufgrund des ersten Buches weiterhin systematisch die Ontologie Eriugenas untersuchen will, entgleitet in den übrigen vier Büchern der Boden. Die bisherige Untersuchungsmethode greift nicht mehr. Allein der Beginn des dritten Buches, auf die Metaphysik des Dionysius Areopagita rekurrierend, liefert noch einmal Stoff und Argumente.

Autoritätsverweise mögen angebracht oder unangebracht sein, aber sie lassen nicht als schlüssig oder unschlüssig klassifizieren, sondern nur die Autoritätsaussagen als solche. Wenn $\mathrm{N}$ auf die Frage A's, wie man dieses oder jenes zu verstehen oder zu beantworten habe, ohne Umschweife oder weitere Erläuterungen einfach ganze Kapitel des Dionysius oder Gregor von Nyssa zitiert, eben als Antwort auf die gestellte Frage, so ist das für den Leser nicht nur unbefriedigend, sondern hinterlässt auch Zweifel an Eriugenas geistiger Eigenständigkeit. Dies wiegt darum so schlimm, weil er uns gerade im ersten Buch diese Eigenständigkeit im Argumentieren und Auffinden von Lösungen so begeisternd vorlegt.

Die Wendung, welche das Periphyseon nimmt, ist so eine unerwartet merkwürdige. Wir wissen nicht, ob äußere Zwänge ihn veranlassten, seine vorgeblich nur der ratio folgende Vorgehensweise aufzugeben, oder ob er selbst diese Methode für das noch Ausstehende als unzureichend ansah. Es kann auch sein, dass das Werk seine persönli-

\footnotetext{
${ }^{207}$ Siehe sein Vorwort zur Edition von Buch IV.

${ }^{208}$ Ders.: Das Werk des Johannes Scottus Eriugena im Rahmen des Wissenschaftsverständnisses seiner Zeit, Münster 1982, S. 183-239.

${ }^{209}$ Alain de Libera: La philosophie médiévale, Paris 1993, p. 273.
} 
che schriftstellerische Entwicklung widerspiegelt. Vor dem Periphyseon entstanden die Glossen zu Martianus Capella und das sehr argumentativ aufgebaute Prädestinationsgutachten. Dieser Umstand hat gerade Schrimpf dazu veranlasst, das Periphyseon als dialektisches Werk anzusehen und zu untersuchen. Nach dem Periphyseon verfasste Eriugena die Kommentare zu den himmlischen und kirchlichen Hierarchien sowie der mystischen Theologie des Dionysius Areopagita und schließlich Homilien und Kommentar zum Evangeliumprolog des Johannes. Der Weg geht also von der Dialektik zur Thelogie, vielleicht nicht ungewöhnlich, wenn man auf Augustinus oder Alkuin blickt, aber doch auffällig im Hinblick auf das Periphyseon. All das wäre kaum der Diskussion wert, wenn Eriugena seine dialektische Methode bei seiner Schriftexegese beibehalten würde, wie dies andere Autoren vor ihm geleistet haben. $\mathrm{Ob}$ er dies nicht konnte oder nicht wollte, wird kaum zu klären sein.

Es fällt aufgrund des Gesagten schwer, in den Büchern zwei bis fünf die »Höhe der ersten Philosophie« zu erkennen, welche nach Gombocz das noch schwächelnde erste Buch überflügelt ${ }^{210}$ Denn es stellt sich die Frage, welcher philosophischen Methode auf besagte Höhe Zugriff hat. Umgekehrt, die gewaltigen Thesen aus dem ersten Buch zur Substanz der Dinge und zum Erschaffensein Gottes, zur Körperlehre und hinsichtlich des geschöpflichen Wiederaufstieg, all das findet keine systematische und dialektisch argumentierende Fortsetzung.

Um wenigstens einen groben Einblick in den Inhalt der Bücher zwei und fünf zu geben, sei er in der Folge kurz dargestellt.

Das zweite Buch beginnt mit einer Abhandlung über die vorrangigen Ursachen mit Hinblick auf die Genesis. Ab II, (2190) ${ }^{211}$ geht die Untersuchung auf die rechte Auslegung des Genesis-Satzes in principio fecit deus ein, es ist von Lucifer die Rede, der forma und schließlich vom verbum. In II, (2902) beginnt die Seelenlehre Eriugenas, eine Interpretation dessen, was er bei Maximus Confessor vorfindet und auf Augustins Trinitätslehre herunterbricht. Die These, Gott könne sich selbst nicht erkennen, bildet den Anschluss II, (4256-5176) und ist Anlass für eine

\footnotetext{
${ }^{210}$ Wolfgang L. Gombocz: Geschichte der Philosophie, Bd. IV, München 1997, S. 373.

${ }^{211}$ Wie in der Einleitung angeben, zitiere ich das zweite Buch nach Jeauneaus Kolumnenedition, da in der Synopsis Versionum die vielen Einfügungen von $\mathrm{R}{ }^{2}$ nicht als solche kenntlich sind. Daher hier die Stellenangabe in Klammern.
} 
erneute Betrachtung über die Aussagbarkeit der Kategorien von Gott II, (4389-4798). II, (5176-5425) geht über in eine wiederholte Abhandlung von der göttlichen Allursache, nebst einer ausführlichen Darstellung von bejahender und verneinender Theologie.

Es sei daran erinnert, dass dieses gesamte Buch eigentlich im Gesamten von den erstrangigen Ursachen (causae primordiales) handeln sollte. Indes ist zumeist nur die erste Ursache Gegenstand der Untersuchung, nämlich die Trinität und das Verhältnis von göttlicher essentia und göttlicher substantia. Erst ab II, (5426 bzw. 6429) wird die anfängliche Untersuchung über die erstrangigen Ursachen wieder aufgenommen, ohne nennenswert Neues hinzuzufügen. Das liegt auch daran, dass gut drei Viertel dieser letzten Untersuchung lediglich aus Zitaten aus Dionysius Areopagitas De divinis nominibus bestehen.

Buch III beginnt mit einer Rekapitulation dessen, was über den Status der erstrangigen Ursachen und über die Teilhabe des Seienden am einen Sein im ersten Buch dargelegt wurde. Danach geht der Text über zu einer an der Genesis ausgerichteten Untersuchung über die Materie (III,733-905). Anschließend folgt eine lange Kommentierung einzelner Passagen aus den Büchern des Dionysius Areopagita. Worauf Eriugena dabei hinaus will, bleibt unklar. Es wird im Zusammenhang mit Dionysius wenig gesagt oder geklärt, was nicht im ersten Buch schon ausgesprochen war. Um die Aussage des Dionysius zu erläutern, Gott sei auch erschaffen zu nennen, fügt Eriugena eine Abhandlung über die ersten drei Zahlen sowie über Unendlichkeit und Endlichkeit an (III, 1350-1722). Darauf wird noch einzugehen sein. Danach geht es wieder um die Auslegung des biblischen Schöpfungsberichts, um die Ewigkeit, die Materie und das verbum dei. Nichts Näheres im Hinblick auf die Konstitution der ousia und des Körpers, wie sie im ersten Buch angeführt ist, lässt sich dort finden.

Im vierten Buch erwartet man die Abhandlung über die vierte Natur, die weder schafft, noch erschaffen wird. Und dieses Vorhaben spricht Eriugena in IV, 59-62 aus, um dann sogleich via der eigentlich in den vorangehenden Büchern abgeschlossenen Diskussion über die Schöpfung und speziell die Seele zu einer Anthropologie zu gelangen, die den gesamten restlichen Inhalt ausmacht. Sie setzt sich zusammen aus augustinischem Gedankengut und dem, was Eriugena in Gregor von Nyssas Schrift De imagine (De opificio hominis) vorfindet. 
Das fünfte Buch schließlich kommt der Frage nach der geschöpflichen Rückkehr näher. Auch hier wieder wird viel aus besagter Schrift Gregors zitiert, zudem Maximus Confessor, die Bibel, Ambrosius und andere. Aus allen ihm verfügbaren Quellen trägt Eriugena zusammen, was ihm für die Darlegung der redemptio sinnvoll scheint. Gut zwei Drittel des Buches sind Zitate oder Zitaterläuterungen. Eine eigenständige These oder eine durchgehende Fragestellung sowie deren Behandlung sucht man, offen gesagt, vergeblich. Zugleich nehmen die Monologe N's an Länge zu. Aus diesem Grund fordert das fünfte Buch von seinen Leser viel Geduld und Durchhaltevermögen. Weil es ohnehin erst durch Handschriften aus dem 12. Jh bezeugt ist und im Reimser Autographen fehlt, ist es ein reizvoller, aber nicht begründbarer Verdacht, das gesamte Buch stamme gar nicht aus Eriugenas Feder. Durchaus naheliegend ist indes die Annahme, dass Vieles in diesem fünften Buch, ähnlich wie im zweiten, eine spätere Anfügung von $\mathrm{R}^{2}$ ist und den Urtext noch weiter in die Länge zieht.

Umgekehrt, was sich in den Büchern zwei bis fünf, wenn überhaupt, als durchgängige These auffinden lässt, als Grundannahme, die Argumente stützt, ist gerade dasjenige, was bereits hinsichtlich des ersten Buches herausgearbeitet wurde, die Substanz- und Seinslehre Eriugenas. Gott ist essentia von allem, alles Sein ist nur ihn ihm, nichts ist essentialiter außerhalb von Gott, dies sind die Aussagen, die in den verbleibenden Büchern immer wieder als Begründung auftauchen ${ }^{212}$ Gegen Ende des dritten Buches, in der recapitulatio de obscuris rebus (III, 2852), ist wieder von Gott als creari die Rede nebst den Begründungen aus dem ersten Buch. Aus dieser Perspektive legt Buch I das Fundament für die übrigen.

Nun wurde zur Klärung mancher Aussagen des ersten Buches bereits einiges aus den übrigen Büchern herangezogen. Für eine systematische Untersuchung der Ontologie Eriugenas sind sie also sicherlich nicht wertlos. Um die zuvor genannten Fragen zu klären, ist es daher angebracht, jedem Hinweis aus den übrigen vier Büchern, der zur Klärung beitragen könnte, nachzugehen. Dabei wird zunächst die bisherige Differenzierung der Gesamtnatur zu relativieren sein.

${ }^{212}$ Etwa III, 259-266 und 580-587. 


\subsection{Eine Bedingung für Eriugenas Ontologie: Natur als Einheit}

\subsubsection{Zur Einheit der Natur in Buch II}

Der erste wichtige Hinweis findet sich zu Beginn des zweiten Buches, wo Eriugena die Einteilung der Natur rekapituliert. Schöpfer und Geschöpf sind beide Gott, zumindest secundum esse, wie es im ersten zu lesen war. Damit sind auch die causae primordiales nicht klar von der Allursache zu trennen. Man könnte vermuten, dass der Natur nach beide verschieden sind und so auch Schöpfer und Geschöpf, dem Sein nach aber dasselbe. Doch diese Möglichkeit wird durch I, 545-557 zunichte gemacht, wo eindeutig die göttliche Natur zugleich als creare und creari bestimmt wird. Was also stützt die anfängliche Einteilung der Natur noch?

Im zweiten Buch heißt es, die viergliedrige Einteilung lasse sich rückauflösen in eine zweigliedrige, Schöpfer und Geschöpf, und diese wiederum in göttliche Einheit: »N. Verneinst du etwa, dass Schöpfer und Geschöpf eines sind? - A. Schwerlich könnte ich dies verneinen. - N. Die Gesamtheit also, die Gott und das Geschöpf beinhaltet, welche zuerst in vier Arten eingeteilt ist, wird danach $\mathrm{zu}$ einem Unteilbaren, Anfang nämlich und Ursache und Ende, zurückgeführt. \&213 Inwiefern aber sind Schöpfer und Geschöpf dasselbe? Die folgende Aussage antwortet:

»Wenn du das Geschöpf dem Schöpfer hinzufügst, wirst du da an etwas anderes denken, als daran, dass er allein wahrhaft ist? Nichts nämlich außerhalb von ihm selbst heißt wahrhaft essentiale, weil alle, die von ihm sind, nur in dem Maße sind, als sie an dem teilhaben, der ausgehend von sich selbst allein durch sich selbst besteht. Verneinst du also, dass Schöpfer und Geschöpf eines sind? ${ }^{214}$ Will man darin die neuplatonische Einheit von Hervorgang, Verharren und Rückkehr er-

${ }^{213}$ II, (113-119): N. Num negabis creatorem et creaturam unum esse? - A. Non facile negarim. - N. Universitatis itaque quae deo et creatura continetur prius in quattuor veluti formas divisa iterum ad unum individuum, principium quippe causamque finemque revocatur.

${ }^{214}$ II, (269-277): N. Quid si creaturam creatori adiunxeris ita ut nil aliud in ea intelligas nisi ipsum qui solus vere est? Nil enim extra ipsum vere essentiale dicitur, qui[a] omnia quae ab eo sunt nil aliud sunt in quantum sunt nisi participatio ipsius qui a se ipso solus per se ipsum subsistit. Num negabis creatorem et creaturam unum esse? 
kennen, liegt man sicherlich nicht falsch. Interessant ist aber der Grund für die Einheit: es ist nämlich hier die Einheit des Seins, die diese Trias bedingt.

Welche Funktion nimmt die Einteilung der Natur dann überhaupt noch ein, wenn sie einfach aufzulösen ist? Einteilungsgrund waren die differentiae specificae, die den Naturen zukommen. Es will scheinen, als hebe Eriugena diese differentiae zu Beginn des zweiten Buches auf, weil secundum essentiam alles Gott ist und alles in Gott besteht. Zumindest relativiert er die Einteilung deutlich: »Weil wir im vorangehenden Buch von der gesamtheitlichen Einteilung der gesamten Natur nicht als von einer Gattung in Formen oder deren Ganzes in Teile - (...) - sondern als von einer Betrachtung der gleichsam intelligiblen Gesamtheit (mit Gesamtheit meine ich Gott und das Geschöpf) kurz sprachen, wiederholen wir jetzt eben diese Einteilung der Natur so weit es geht ausführlich. $\ll 215$

Was besagt das? Offensichtlich ist die erste Einteilung keine solche einer Gattung in Arten (species). Doch wird nicht das Eingeteilte in I, 1320 wiederholt species genannt, und gehört nicht zu jeder species auch ein übergeordnetes genus? Darauf gibt es keine Antwort. Vielmehr soll die Einteilung aus dem ersten Buch so verstanden werden, dass es sich um eine comtemplatio intelligibilis universitatis handelt. Warum wird die Einteilung als contemplatio, als eine Betrachtung relativiert?

Ein Grund könnte das Folgende sein: »Von dieser oben genannten gesamtheitlichen Natur gab es also, wie ich meine, eine vierfache Einteilung - wenn die Allursache hinreichend Form oder Art zu nennen ist, die alle Form und Art überragt, da sie formloser Anfang aller Formen und Arten ist. $\langle 216$ Vielleicht sah sich Eriugena der Gefahr ausgesetzt, so verstanden zu werden, als wäre der Schöpfer eine species der Gesamtnatur, und genau diese Lesart drängt sich in I, 1-39 ja auch auf.

${ }^{215} \mathrm{II},(1-4$ \& 21-25): Quoniam in superiore libro de universalis naturae universali divisione non quasi generis in formas seu totius in partes - (...) - sed intelligibili quadam universitatis contemplatione (universitate dico deum et creaturam) breviter diximus, nunc eandem naturae divisionem latius, si videtur, repetamus.

216 II, (34-38): Talis itaque erat, ut opinor, supradicta universalis naturae quadriformis divisio, in eam scilicet formam vel speciem - si rite forma vel species dicenda est prima omnium causa quae superat omnem formam et speciem, dum sit formarum et specierum omnium informe principium. 
Eine solche Unterordnung des Schöpfers wollte er sicherlich vermeiden. Aber reicht das als Erklärung?

Gehen wir einmal einen Schritt zurück und überlegen uns, wovon das Periphyseon ausgeht und wohin es lenkt. Es gibt gute Gründe für die Annahme, dass die Einteilung der Natur nicht Eriugenas eigene Idee ist. Wie gezeigt, teilte schon Alkuin, und zwar ohne nähere Erläuterung, die Gesamtnatur in Schöpfer und Geschöpf ein. Nehmen wir an, Eriugena bringe mit der Natureinteilung zu Beginn nichts Ungewöhnliches, sondern für seine Zeit Wohlvertrautes hervor. Nullo modo haesitare ausim, »darüber wage ich auf keine Weise zu zögern", sagt A ganz zu Beginn nach N's Vorstellung der Natureinteilung (I,35). Eine stärkere Bejahung gibt es nicht. Gesetzt, die Einteilung der Natur sei ein sensus communis, auf dem Eriugena, seiner lateinischen Tradition folgend, seinen Dialog aufbaut: Ergibt sich dann nicht ein anderes Bild? Eriugena wird dann vom Innovator und Verteidiger der Natureinteilung zu deren Überwinder.

Schauen wir noch einmal auf die Aussage A's zu Beginn des zweiten Buches. Es gebe keine Einteilung, heißt es da, die sich nicht wieder in jene Einheit rückauflösen ließe, aus der sie hervorgegangen ist (II, (108-119)). Dieses Verfahren nennt N zuvor das analytische, also wörtlich >rück-auflösender. Wie ist diese Rückauflösung der Natureinteilung möglich? Die Antwort wurde schon angeführt: »Wenn du das Geschöpf dem Schöpfer hinzufügst, wirst du da an etwas anderes denken, als daran, dass er allein wahrhaft ist? « Es ist das vere esse, mit dem die Einheit wiederhergestellt wird, die essentia. Noch immer ist nicht geklärt, was beides genau meint, aber seine Bedeutung für das Periphyseon wird zusehends deutlich.

\subsubsection{Zur Einheit der Natur in Buch III}

Ein Sprung zur nächsten Stelle, wo von der Differenz zwischen Schöpfer und Geschöpf und damit von der Natureinteilung die Rede ist: Sie findet sich in der Mitte des dritten Buches und behandelt die Lehre des Dionysius Areopagita. A sagt über diese: »Und unvergleichlich höher und verwunderlicher als all dies scheint mir das zu sein, was du der Autorität des heiligen Dionysius Areopagita zuerkennst, dass nämlich Gott selbst sowohl der Macher von allem ist als auch in allem gemacht 
ist; dies nämlich ist nicht nur von mir bis jetzt unvernommen und mir unbekannt, sondern vielen und fast allen. Denn wenn dies so ist, wer wird dann nicht unverzüglich in diese Worte ausbrechen und verkünden: Gott ist so alles und alles ist Gott! « ${ }^{217}$ Die Ungeheuerlichkeit dieser Aussage hebt Eriugena deutlich hervor. Fast allen sei sie bislang unbekannt. Und unmittelbar im Anschluss heißt es: "Was auch denen ungeheuerlich erscheint, die sich für weise halten, in der Betrachtung der verschiedenen Vielheiten der sichtbaren und unsichtbaren Dinge. 218 Nehmen wir die Wortwahl Eriugenas ernst, so müssen wir diese Behauptung als die Kernfrage des Periphyseon ansehen, denn nirgendwo sonst präsentiert er solch einen starken Kontrast zwischen dem sensus communis und der autoritären Wahrheit.

Eriugena relativiert diese Aussage, die er bei Dionysius vorzufinden glaubt, nicht, er interpretiert sie nicht um, sondern er rechtfertigt sie. Dabei bedient er sich des arithmetischen Phänomens, wonach die Eins als Prinzip auch in den übrigen Zahlen, also den Nicht-Einsen, enthalten sein muss. Die Ausführung soll im Einzelnen hier übergangen werden, interessanter ist Eriugenas Rückkehr zu Dionysius in III, 2595. Er zitiert eine lange Passage aus De divinis nominibus V und fügt dieser an: »Wer immer die Macht dieser Worte betrachtet, wird nichts anderes als die Überzeugung finden, ja sogar diese verkünden, dass Gott selbst der Macher von allem ist und in allem gemacht ist. «219

$\mathrm{Ob}$ sich diese Aussage tatsächlich bei Dionysius findet, ist später zu untersuchen. Wichtiger im Hinblick auf die vorliegende Frage ist, was sich ab III, 2818 aus dieser Behauptung entwickelt. Eriugena wendet sie auf die Differenz zwischen Schöpfernatur und Geschöpfnatur an: »Und wenn das Geschöpf aus Gott entsprungen ist, wird Gott Ursache sein, das Geschöpf aber die Wirkung. Wenn aber das Geschöpf Wir-

217III, 1328-1334: Et his omnibus incomparabiliter altius et mirabilius mihi videtur quod sancti Dionysii Ariopagitae auctoritate utens asseris, ipsum videlicet deum et omnium factorem esse et in omnibus factum; hoc enim adhuc inauditum et incognitum non solum mihi, sed et multis ac paene omnibus. Nam si sic est, quis non confestim erumpat in hanc vocem et proclamet: Deus itaque omnia est et omnia deus!

${ }^{218}$ III, 1335-1337: Quod monstrosum aestimabitur etiam his qui putantur esse sapientes, mulitipici rerum visibilium et invisibilium varietate considerata.

${ }^{219}$ III, 2633-2635: Quisquis horum verborum virtutem perspexerit, nil aliud reperiet suadere, immo etiam pronuntiare, nisi ipsum deum omnium factorem esse et in omnibus factum. 
kung ist, und Wirkung nichts anderes als die gemachte Ursache, dann folgt, dass Gott die Ursache in ihren Wirkungen gemacht hat. Denn was seiner Natur nach verschieden ist, geht nicht aus der Ursache in seine Wirkungen über. So wie in der Wärme und dem Licht nichts anderes als dieselbe Kraft des Feuers hervortritt. 4220 Das Gemachtsein Gottes, genauer das der göttlichen Ursache, wird hier näher bestimmt: Sie ist in ihren Wirkungen erschaffen.

Was bedeutet das? Die Einteilung der Natur in Anfang und Ende ist nur gegeben durch einen je verschiedenen Betrachtungsstandpunkt. Es ist ein und dieselbe göttliche Natur, die als alle vier species erscheint: »Wie ich meine, bleibt allein das vermittelnde Argument, das durch zweierlei Maß seinen Betrachtern einleuchtet. Das erste Maß, wenn die göttliche Natur als erschaffen und schaffend betrachtet wird. Erschaffen nämlich ist sie von sich selbst in den erstrangigen Ursachen, und erschafft so sich selbst, das heißt, sie fängt an, in ihren Theophanien zu erscheinen aus den verborgensten Naturen, aus deren Tiefen sie hervortreten will (...). Das zweite Maß aber, wenn sie in den äußersten Wirkungen der erstrangigen Ursachen betrachtet wird, in denen sie lediglich als erschaffen, nicht aber als schaffend rechtmässig benannt wird. Erschaffen nämlich steigt sie hinab bis in die äußersten Wirkungen, außerhalb derer nichts erschafft; daher nennt man sie nur erschaffen und nicht schaffend. (...) Erschaffen also und schaffend ist sie in den erstrangigen Ursachen; in ihren Wirkungen aber ist sie erschaffen und schafft nicht. «221

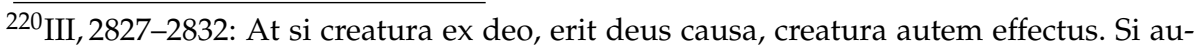
tem creatura est effectus, et nil aliud est effectus nisi causa facta, sequitur deum causam in effectibus suis fieri. Non enim ex causa in effectus suos procedit, quod a sui natura alienum sit. Siquidem in calorem et in lucem nil aliud nisi ipsa vis ignea erumpit.

${ }^{221}$ III, 2897-2914: Rationem medietatis restare solummodo arbitror, quae duplici modo contemplatoribus suis arridet. Primo quidem, quando et creari et creare conspicitur divina natura. Creatur enim a se ipsa in primordialibus causis, ac per hoc se ipsam creat, hoc est, in suis theophaniis incipit apparere ex occultissimis naturae suae sinibus volens emergere (...). Secundo vero, dum in extremis effectibus primordialium causarum perspicitur, in quibus creari tantummodo, non autem creare recte praedicatur. Creatur enim descendens in extremos effectus, ultra quos nil creat; ideoque dicitur creari solummodo et non creare (...).

Creatur ergo et creat in primordialibus causis; in earum vero effectibus creatur et non creat. 
Was Eriugena hier vollführt, ist die Aufhebung jener Natureinteilung, die er zu Anfang vorgestellt hat. Die Betrachtung des Intelligiblen (contemplatio intelligibilis), von der wiederholt die Rede ist (II, (21-22), III, 2898), fasst Gott teils als erschaffend auf, wenn sie auf den Anfang schaut, teils als erschaffend und erschaffen, teils als nur erschaffen, und als weder schaffend noch erschaffen mit Blick auf das Ende. Die Betrachtung Gottes misst also mit zweierlei Maß, je nachdem, ob sie auf die Allursache oder das Geschaffene schaut. So heißt es im Hinblick auf die vierte species: "Siehst Du nicht durch die Vernunft, dass wir ein und dieselbe Natur, die göttliche sicherlich, gemäss dem Betrachten des Anfangs nicht erschaffen sondern schaffend, gemäss der Erforschung des Endes aber weder erschaffen noch schaffend nennen müssen? «222 Wie also die Einteilung der Natur aus dem Anfang von Buch I zu verstehen ist, legt er hier im dritten Buch dar.

Die göttliche Natur ist alle vier Naturen zugleich. Betrachtet man sie in den erstrangigen Ursachen, die secundum essentiam nur in Gott bestehen, dann ist sie schaffend und erschaffen. Betrachtet man sie hingegen in den nichtschaffenden Wirkungen, wo sie als Substanz zugegen ist, dann ist sie lediglich erschaffen. Die vier Arten der Natur sind demnach vier Betrachtungsstandpunkte. In Wahrheit ist die Natur der Wirkung, also des Geschöpfes, dieselbe wie die der Ursache. Schöpfer und Geschöpf sind eins. All das basiert auf der Annahme, das Erschaffen des Geschöpfes sei das subsistere und esse an demselben, also auf Eriugenas Ontologie, wonach essentia etwas Göttliches ist.

\subsection{Der Grundgedanke im viergliedrigen Aufbau des Werks}

Wie Eriugena vorgibt, soll je ein Buch des Periphyseon von je einer Natur handeln. Aber es soll nicht darum auf jede Natur einzeln eingegangen werden, um die Differenzen klar herauszuarbeiten, sondern im Gegenteil, um sie aufzulösen. Diesen Schluss legt das soeben Ausgeführte nahe. Dabei soll es der Weg der Vernunft oder des Schlussfolgerns (via ratiocinandi) sein, der von der viergliedrigen Einteilung zur Einheit zurückführt.

\footnotetext{
${ }^{222}$ III, 2892-2895: Videsne ergo qua ratione unam eandemque naturam, divinam videlicet, iuxta considerationem principii non creatam sed creatricem, iuxta vero finis speculationem nec creatam nec creatricem possumus appellare?
} 
Welche weiteren Argumente gibt es für diese Interpretation des Periphyseon?

1. Die Präsentation in I,19-39 stellt die Natureinteilung als unmittelbar einsichtig dar. Der angestrebte Versuch, eine Begründung für die Einteilung der Natur im Text zu finden, scheiterte.

2. Wenn Eriugena in seinem Dialogaufbau der lateinischen Texttradition folgt, dann beginnt der Text mit einer Aussage, der seine Leser ohne Zögern zustimmen. Unser Zögern wäre dann einem karolingischen Gelehrten fremd. Erinnert sei wiederholt an Alkuin, der einige Jahrzehnte zuvor eine Einteilung der Natur in Schöpfer und Geschöpf ohne weitere Erläuterung anführt.

3. Schon in II, (153-285) löst Eriugena die Einteilung der Natur auf. Wäre er ein Befürworter dieser Einteilung, dann wäre eine Erklärung zu erwarten, warum dennoch für die restliche Untersuchung an ihr festzuhalten ist. Dergleichen findet sich nicht.

4. Warum handeln alle fünf Bücher von Gott, wo zu erwarten wäre, dass lediglich die Bücher I, IV und V von ihm handeln, die übrigen indes von den Ursachen und deren Wirkungen? Ist es stets die eine göttliche Natur, die aus vier Perspektiven zu betrachten ist, beantwortet sich diese Frage von selbst.

Blicken wir auf die sprachlichen Hinweise, die Eriugena im Text gibt. In I, 17-18 verlangt A von seinem Gegenüber N, einen wahren Gedanken (vera ratio) über die Natureinteilung zu hören. Den Schlüssel zur Aufhebung der Natureinteilung bietet die Auffassung, die göttliche Natur sei auch als erschaffen anzusehen. Sie taucht zum ersten Mal in I, 413557 auf. Diesmal bittet $N$ um einen wahren Gedanken (I, 426 , vera ratio) zur Erläuterung dieser Auffassung, doch A zieht es vor, N's Weg des Schlussfolgerns (I, 429, via ratiocinandi) zu folgen, der auch schon in I, 40 als Richtschnur ausgegeben wurde.

In Buch II, (108-119), wo es zum ersten Mal wieder um die Einteilung der Natur geht, meint A, keine Einteilung, welche die vera ratio betrachte, sei nicht wieder auflösbar.

Schließlich Buch III, wo A seine Zweifel hervorbringt bezüglich der Interpretation, wonach Gott alles sei. Was verlangt er daraufhin von 
N? Eine Erklärung auf dem Weg der Vernunft oder des Schlussfolgerns (III, 1349, ratiocinationis via). Ab III, 2818 folgt das höchste Argument (maximum argumentum) für die Behauptung, Gott sei auch erschaffen und daher in allem zugegen. Und in der oben angeführten Passage III, 2892-2895 fragt N, ob A nicht qua ratione einsehe, dass eine göttliche Natur die verschiedenen Arten der Natur zugleich sei.

Ist dies ein sprachlicher Zufall? Es gibt nicht viele Stellen im Periphyseon, an denen sich Eriugena explizit auf die ratio beruft. Auffälligerweise sind es zumeist gerade diejenigen, welche die Erschaffenheit der göttlichen Natur darlegen und damit die Einteilung der Natur in diese zurückführen.

Welche Argumente sprechen gegen diese These der Einteilungsauflösung?

Zunächst ist nirgendwo explizit im Periphyseon gesagt, dass die Einteilung der Natur von nun an aufgehoben sei. Verwirft Eriugena sie, sollte Derartiges zu finden sein.

Doch er will sie nicht aufheben oder für nichtig erklären, sondern will dasjenige, was gemäß der ratio (siehe I, 17-18) zunächst einzuteilen ist, auch wieder in Eines zurückführen. Dialektik besteht für Eriugena aus dem Zerlegen und dem Rückauflösen, und dass diese dialektische Bewegung die Welt bedingt, lernt er von Maximus Confessor. Anders gesagt, im Periphyseon denkt er die Einteilung der Natur zu Ende, und das kann, der dialektischen Regel folgend, nur heißen, er löst sie wieder auf. Die Einteilung der Natur wird dadurch nicht absurd, sondern ist nur der erste Teil einer vollkommenen Betrachtung (contemplatio) der Wirklichkeit. Nicht die Einteilung als solche hält A in II, (278-280) für lächerlich (ridiculosum esse), sondern das Zögern hinsichtlich ihrer Wiederauflösung.

Ein zweiter Einwand betrifft den lateinischen Titel des Werks: De divisione naturae. Warum heißt es nicht De divisione et resolutione naturae? Dem lateinischen Titel nach hält Eriugena über das gesamte Werk hinweg uneingeschränkt an der Einteilung der Natur fest.

Wie indes Jeauneau in der Einleitung zur Edition des ersten Buches angibt, findet sich dieser lateinische Titel in den Bibliothekskatalogen erst seit dem 16. Jh., während das Werk zuvor Physica, De natura, De naturis oder Periphyseon genannt wird. Der erhaltene Autograph trägt keinen Titel. Eriugena selbst nennt die ersten Bücher des Periphyseon in 
Buch IV schlicht Physiologia (IV,1), und in seinem späteren Kommentar zu den himmlischen Hierarchien des Dionysius Areopagita gibt er seinem Werk den Titel Periphyseon, wörtlich »Von Naturen« oder »Über Naturen «.

Man könnte sich dabei an dem Plural stoßen, der doch auf eine Mehrzahl von Naturen und damit auf eine eingeteilte Gesamtnatur verweist. Darum sei noch einmal gesagt: Für alle vier Naturen weist Eriugena einzeln nach, dass sie nichts anderes sind als die eine göttliche. »Von den Naturen « zu handeln, ist also das rechte Versprechen des Titels. Hingegen ist der nachträgliche Titel De divisione naturae wie auch das griechische Pendant Peri physeos merismou unpassend, da es nicht allein um die Einteilung der Natur geht, sondern auch und vor allem um ihre Auflösung. Wie Jeauneau zu diesem letztgenannten Titel anmerkt, ist er nachträglich in den Autographen eingefügt und bezeichnet auch nur den ersten Abschnitt aus Buch I (Zeile 1-50), nicht hingegen das gesamte Werk.

Es sind zwei Behauptungen, auf denen Eriugena seine Darstellung der Rückauflösung aufbaut: Das Erschaffensein Gottes und die Allgegenwärtigkeit Gottes. Und diese wiederum basieren auf der ontologischen Annahme, essentia bzw. esse aller Dinge sei Gott. Beide Behauptungen glaubt er von Dionysius Areopagita erhalten zu haben, letztere Annahme von Dionysius wie von Gregor von Nazianz. Doch weil der Quellenverweis bezüglich der Ersteren noch nicht eingehend geprüft wurde, ist er in der Folge zu klären. Zudem ist auf die genannte Grundannahme noch einmal einzugehen, weil eine Bestimmung von essentia noch aussteht. Da das Gebäude jetzt bekannt ist, geht es darum, dessen Fundament zu prüfen. 



\section{Die Grundlagen der negativen Ontologie}

\subsection{Die Bestimmung Gottes als essentia omnium}

Wie sich gezeigt hat, hängt von dieser Sache, die Eriugena essentia nennt, viel für das Periphyseon ab. Gott sei essentia omnium und esse omnium ist das allgegenwärtige Argument, das Gott als erschaffen (creari) ausweist und damit auch die Einteilung der Natur auflöst. Was aber meint Eriugena mit essentia?

\subsubsection{Die theologische Tradition}

Vor einer Klärung, was essentia genau bezeichnen soll und ob und wie sie sich von den Begriffen esse, substantia und natura unterscheidet, ist $\mathrm{zu}$ fragen, wie es den lateinischen und griechischen Theologen, und damit auch Eriugena, in den Sinn kommt, Gott überhaupt als essentia anzusprechen. Denn alle antiken Theologen lehren, Gott überrage alles Sein und Seiende. Will man diese Fragestellung auch nur annähernd zureichend beantworten, müsste sich die Diskussion hier auf vielerlei Nebenschauplätze einlassen. Es kann nur angerissen werden, welche Fragen und Schwierigkeiten sich ergeben und welche Antworten darauf letztendlich Eriugena zu der Annahme führen, Gott sei essentia omnium rerum.

Der Anfang sei, wie so oft, mit Aristoteles gemacht, und damit mit einem Nichttheologen. $\mathrm{Zu}$ dessen Ursachenlehre sagt Christof Rapp prägnant: »Was Ursache oder Prinzip von einer Substanz ist, muss selbst Substanz sein, da eine Substanz, die ja etwas Selbständiges ist, unmöglich von einer Nichtsubstanz ontologisch abhängig sein kann", und verweist auf Metaphysik 1038b23ff. ${ }^{1}$ Physikalisch und metaphy-

${ }^{1}$ Christof Rapp: Aristoteles - Zur Einführung, Hamburg 2001, S.160. Es ließe sich

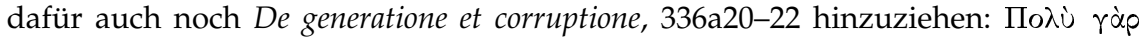

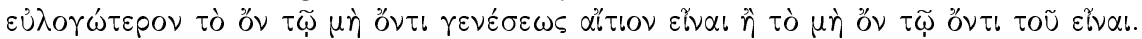
»Denn es ist sehr viel einsichtiger, anzunehmen, dass das, was ist, Ursache für das Entstehen dessen ist, was nicht ist, als anzunehmen, dass das, was nicht ist, die Ursache des Seins ist für dasjenige, was ist.« 
sisch betrachtet ist dies ein weitaus geringeres Problem, als es sich für die Theologen darstellt.

Wenn Gott Ursache der Substanzen ist, muss er selbst auch Substanz sein. Aber soll er nicht gerade allem Geschaffenen enthoben sein, und damit auch der von ihm geschaffenen Substanz? Man merkt hier bereits, dass 'verursachen ‘ weniger problematisch ist, als >erschaffen $<$. Die Ursache muss nicht alleinige Voraussetzung für das Bewirkte sein. Erinnert sei an die verschiedenen Ursachentypen aus der Antike, etwa das Woraus, das Wodurch, das Womit, das Wozu. 'Entstehen lassen< und erst recht serschaffen< sind, wenn Gott nicht nur als platonischer Werkmeister verstanden werden soll, ein allumfassendes Verursachen. Nicht ohne Grund kämpt auch Eriugena lange mit der creatio ex nihilo, die das Problem verschärft. Damit sind mindestens zwei Probleme gegeben: Einerseits ist die Allursache wohl irgendeine Substanz, zum anderen schafft sie alles Substanzielle aus sich heraus. Dennoch ist dieses Verursachende, dies ist theologischer Leitsatz, nicht von solch einer Substanz wie das Verursachte.

Schon der frühe Neuplatonismus, der die Entstehung aller Vielheit aus dem Einen heraus zu erklären versucht, ringt bekanntermaßen um eine plausible Antwort. Zwar soll die Ursache das Verursachte vollständig hervorbringen und bedingen, aber dennoch in keinerlei Verhältnis zu diesem stehen, sondern, allem enthoben, in sich selbst als Vollkommenes unberührt verharren. Als Illustration dieser Problematik sei ein Zitat aus einem neuplatonischen Parmenides-Kommentar angeführt, der in Fragmenten erhalten ist:

»Dies ist, wie wenn wir den Sonnenuntergang betrachten: Sagte man, es gibt keinen Sonnenuntergang, da er eine Erscheinung des Lichts ist und der Ankunft der Nacht und da die Sonne sich niemals verbirgt noch die Nacht sieht, sondern die auf der Erde sind, in den Schatten treten, so sagte man Richtiges, wenn man behauptet, der Untergang ist nur auf der Erde. Ebenso dürfte man nicht vom Sonnenaufgang sprechen. Denn der Aufgang ist eine Belichtung der die Erde umgebenden Luft, nichts ist hingegen für das, was immer im Licht ist, der lichtende Moment der erdumgebenden Luft, denn davon bleibt es unberührt und weiß nichts von Aufgang und Untergang, da es weder belichtet ist, noch verdunkelt. Hingegen übertragen sie diese auf der Erde stattfindenden Vorgänge in Unkenntnis über deren zufälliges Auftreten auch 
auf die Sonne selbst. (...) So ist auch aus Gott alle Verschiedenheit und Selbigkeit und Gleichheit verbannt, da er stets unerreichbar ist für das, was nach ihm ist, aber das darunter Getretene und Unähnliche und sich selbst an ihn anzuschließen Bestrebte glaubt seinerseits, die eigenen Verhältnisse hätten bei ihm ihre Entsprechung. $\times 2^{2}$

Man vergleiche diese bedeutungsschwere Darstellung mit der nüchternen Feststellung, der sich auch die Theologen nicht entziehen können, dass alle verursachte Substanz von einer Substanz verursacht sein muss ${ }_{3}^{3}$ Selbst wenn die Schöpfung nur aus Sicht des Geschöpfes von einem Schöper abhängt, was ist dieser Schöpfer, wenn er nicht nichts ist? Er existiert doch, und zwar als Schöpfer, und spätestens die Frage nach der Existenz Gottes wirft das Problem seines Seins und seiner Substanzialität auf. Dies soll zur Problemdarstellung genügen ${ }_{4}^{4}$

${ }^{2}$ (Pseudo?)-Porphyrios: Über den platonischen Parmenides (ediert von Pierre Hadot in ders.: Porphyre et Victorinus, Paris 1968, 2ieme partie, chapitres du texte

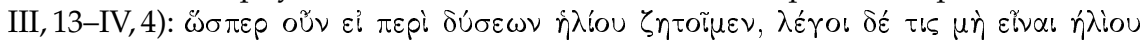

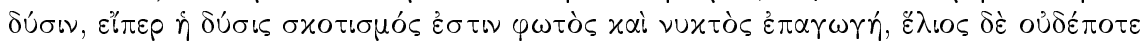

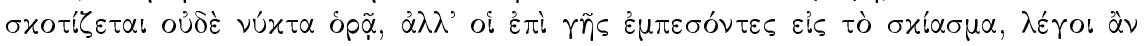

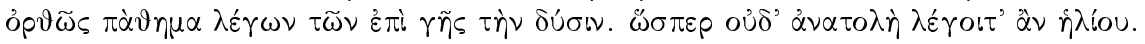

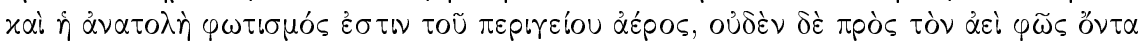

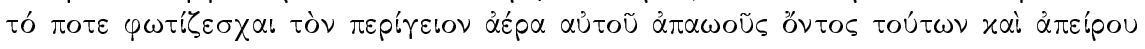

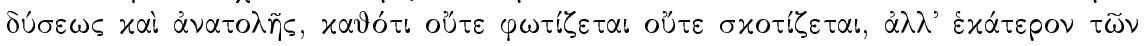

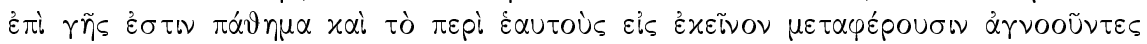

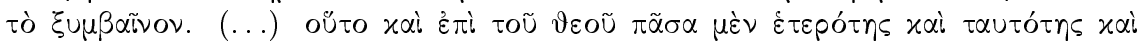

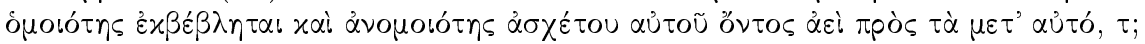

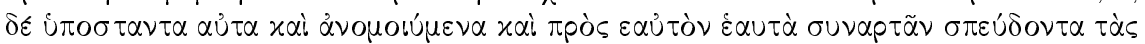

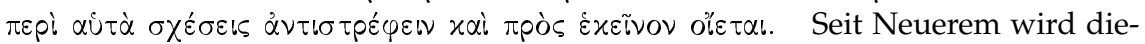
se Zuschreibung an Porphyrios mit schlüssigen Argumenten widerlegt, etwa von Gerald Bechtle: An Anomymous Commetary of Plato's Parmenides, Bern 1999 sowie von Carlos Steel: L'Ame: Modéle et image, in: Blumenthal \& Clark: The divine Iamblichus, London 1993, p. 16-17.

${ }^{3}$ Bei Calcidius findet Eriugena diese Ansicht, wonach ousia Ursache der Seienden ist, als die der Stoiker dargelegt, siehe Commentarius in Timaeum Platonii, in: Plato latinus IV, ed. J.H. Waszink, p. 294,11-12: dicunt (...), at vero quod tam his quam ceteris ut sint causa est, ipsum esse substantiam (Was aber wie von diesen so auch von den übrigen die Ursache ist, damit sie sind, dies sei, so sagen sie, substantia selbst). Nur weil Eriugena die stoische Auffassung verwirft, das Wesen sei der Ur-Körper, ist er deren Lehre nicht grundsätzlich abgeneigt, siehe dazu etwa: Annotationes ad marcianum, ed. Lutz, p. 93, 2-9, wo er Chrysipp als Urheber der analytischen Methode anpreist.

${ }^{4}$ Es stellt sich dabei auch die Frage, ob zwischen der Existenz und der Anwendung des Prädikats >seiend ‘ auf das Existierende zu unterscheiden ist, eine Frage, die 
Desweiteren ein Blick auf das, was der für den Westen so einflussreiche Augustinus dazu sagt, in De trinitate VII, 5, 10: »Daher ist festzustellen, dass Gott missbräuchlich substantia genannt wird, weil im Wortgebrauch essentia als solches aufgefasst wird, was >wahrhaft $<$ und seigentümlich ' genannt wird; derart, dass folglich allein Gott essentia genannt werden kann. Denn er allein ist wahrhaft, da er unveränderlich ist. $[5$ Dies erinnert unweigerlich an das, was in der vorangehenden Untersuchung des ersten Buches zu erläutern war. Gott, hieß es dort, ist darum essentia omnium, weil er allein wahrhaft ist (I, 60, solus vere est). Doch diese Parallele zwischen Augustinus und Eriugena reicht für die Darstellung der Problematik im Periphyseon noch nicht aus. Augustinus' Begründung greift auf den platonischen Gedanken zurück, wonach das Unveränderliche wahrhaft ist, im Gegensatz zum Veränderlichen. Diese Begründung für die Bestimmung Gottes als essentia findet sich im Periphyseon nicht. Es muss demnach einen anderen Grund geben, weshalb Eriugena Gott als essentia bezeichnet.

Sehen wir uns an, was zeitgleich mit Augustinus im griechischen Christentum gelehrt wird. Der einflussreiche kappadokische Theologe Gregor von Nazianz sagt: »Denn gänzlich in sich selbst zusammenfassend, besitzt er [Gott] das Sein (to einai), weder anfangend noch endend, gleich einem Ozean des Seins (ousia). «6 Gott also besitzt das Sein (to einai), weil er es umfasst und gleicht so einem Gefäß für alles Seiende 7

Explizit taucht die Benennung Gottes als ousia und on, um bei den Griechen zu bleiben, wohl erst bei Dionysius Areopagita auf, und dessen Aussagen sind näher zu betrachten, um die Problematik bei Eriu-

nicht nur die christlichen Theologie betrifft. Siehe zu dieser Unterscheidung Michael Frede: Prädikation und Existenz, Göttingen 1967.

${ }^{5}$ Unde manifestum est Deum abusive substantiam vocari, ut nomine usitatione intelligatur essentia, quod vere ad proprie dicitur; ita ut fortasse solum deum dici oporteat essentiam. Est enim vere solus, quia incommutabilis est. Siehe zu Eriugenas Kenntnis dieser Schrift: Goulven Madec: Jean Scot et ses auteurs, Paris 1988, p. 74 .

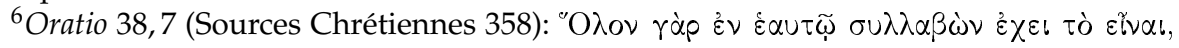

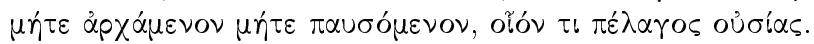

${ }^{7}$ Nur wenn man den abschließenden Genitiv als genitious possesious fasst, ist damit gesagt, dass Gott selbst on, also Seiendes, oder ousia ist. Wenn man hingegen annimmt, Gott sei ein Ozean >für das Sein<, und nicht >des Seins<, so ergibt sich ein anderes Bild. Oder wäre für solch eine Interpretation zwingend ein dativus commodi erforderlich? 


\subsection{Die Bestimmung Gottes als essentia omnium}

gena zu verstehen: »Das Seiende ist nach besten Kräften die überwesenheitliche und schöpferische Ursache des gesamten Seins. (...) Denn Gott ist nicht irgendwie seiend, sondern schlechthin und unbegrenzt, zugleich und ehevor Besitzer des gesamten Seins in sich. (...) Er selbst ist das Sein für das Seiende, und es kommen nicht nur das Seiende, sondern auch das Sein als solches für das Seiende aus dem schon vor der Welt Seienden, denn er selbst ist ja die Ewigkeit der Welt und der vor aller Welt Existierende. $\varangle 8$

Der Reihe nach: Die Ursache des gesamten Seins nennt Dionysius >das Seiendeく. Er begründet dies mit dem kausalen Aspekt: Gott ist vor dem Seienden und besitzt dieses Seiende in sich, noch bevor es geschaffen ist. Dionysius geht davon aus, dass alles Seiende vollständig von Gott verursacht ist, ja nicht nur das, sondern aus ihm heraus entsteht. Damit muss das Seiende zumindest der Möglichkeit nach schon in Gott bestehen, bevor es durch die Schöpfung zu existieren beginnt.$^{9}$ Die Lehre des Dionysius Areopagita entbehrt hier einer erschöpfenden Darstellung. Von Bedeutung ist allein, mit welcher Frage es Eriugena quellengeschichtlich zu tun hat.

Demnach ist Gott über allem Sein, wie es Dionysius Areopagita wiederholt mit den Bestimmungen to hyper-on und to hyper-ousion, d.h. >Überseiendes` und >Überwesenhaftes`, zum Ausdruck bringt, sowie dasjenige, das vor allem Sein ist, to pro-on, d.h. das >Vor-Seiende $<$. Bezeichnenderweise kann dieses pro-on wiederum als >Über-Seiendes< verstanden werden. Daher ist es fraglich, ob die Interpretation des pro-

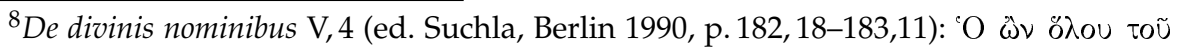

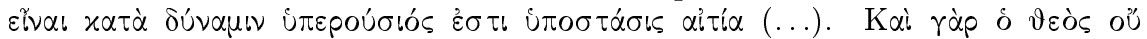

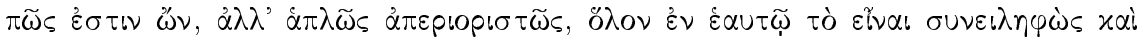

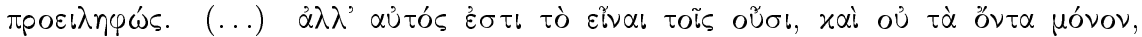

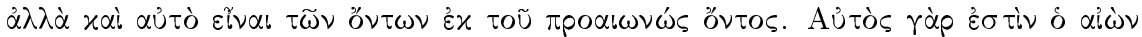

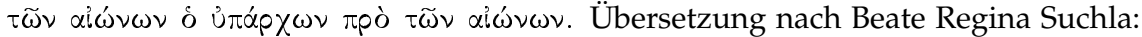
Pseudo-Dionysius Areopagita - Die Namen Gottes, S. 69-70.

${ }^{9}$ Siehe dazu auch: Fran O'Rourke: Being and Non-Being in the Pseudo-Dionysius, in: The Relationship between Neoplatonism and Christianity, ed. by Thomas Finan and Vincent Twomey, Dublin 1992, p. 55-78; O'Rourke macht hier einen Unterschied zwischen der dionysischen Position und dem Neuplatonismus geltend, der in der Frage bestehe, ob man Gott vorangig als den Seienden aufzufassen habe. Dieser Gedanke des Seins Gottes ist nicht Dionysius' Innovation, sondern bereits bei Marius Victorinus und Gregor von Nazianz zugegen. Dionysius musste lediglich vorhandenes christliches Gedankengut aufgreifen. 
on als > Vorseiender $<$ zwingend ist: »Der ehevor Seiende ist also Anfang und Ende von allem Seienden. $<10$ Eine andere Aussage macht deutlich, wie Dionysius die göttliche Allursache nicht nur als Vorseiendes, sondern als Seiendes selbst, als auto-on, auffasst, und darin gerade keinen Widerspruch erkennen will: »Zunächst ist es, um tausendmal Gesagtes auch jetzt wiederaufzunehmen, kein Widerspruch, Gott Kraft an sich oder Leben an sich und zugleich Schöpfer des Lebens an sich oder des Friedens und der Kraft zu nennen. Das eine nämlich nennt man ihn aufgrund des Seienden und insbesondere aufgrund des erstrangig Seienden, weil er der Urheber von allem Seienden ist, das andere hingegen insofern, als er alles und auch das erstrangig Seiende überwesentlich überragt. (...) Wir sagen vielmehr, dass Sein an sich, Leben an sich und Gottheit an sich ursprünglich, göttlich und ursächlich der eine einzige übergrundhafte und überwesentliche Urgrund und Urheber des Universums ist, dass ferner die von Gott, dem Unmittelbaren, verteilten fürsorglichen Kräfte auf dem Weg der Mitteilung die Wesensschaffung an sich, die Lebensschaffung an sich und die Vergottung an sich bedeuten, woran das Seiende auf charakteristische Weise Anteil nimmt und infolgedessen als Existierendes, Lebendes und Gottbegeistertes vorhanden ist und bezeichnet wird. 11 .

Das `Sein an sich soll hier »der eine einzige übergrundhafte und überwesentliche Urgrund und Urheber des Universums « sein, und das autoousiôsis (bei Suchla als >Wesensschaffung a an sich' übersetzt) sind jene Kräfte, an denen alles Seiende teilhat. Bei aller sprachlichen Sperrigkeit, die Dionysius uns hier zumutet, ist seine Darstellung wohl als Ausweg aus der Paradoxie anzusehen, dass Gott einerseits alles

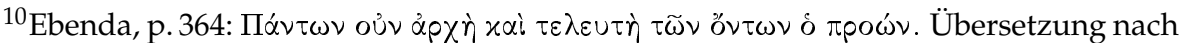
Beate Regina Suchla: Pseudo-Dionysius Areopagita - Die Namen Gottes, S. 74.

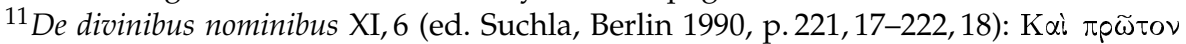

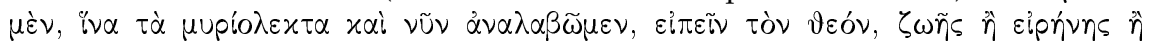

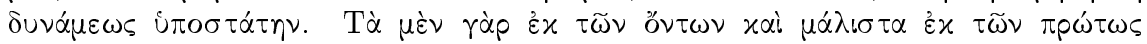

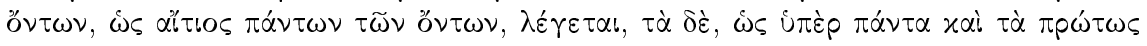

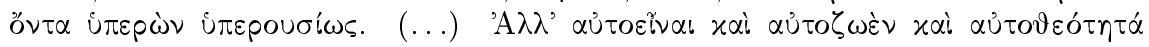

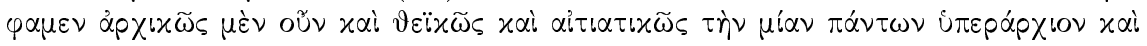

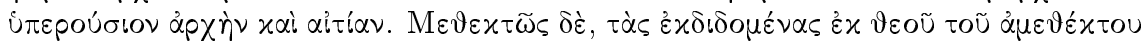

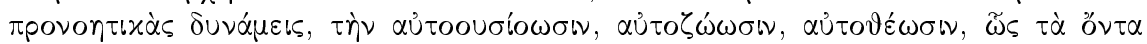

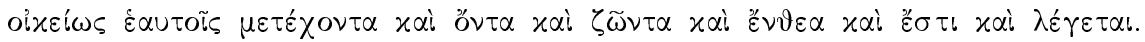
Übersetzung nach Beate Regina Suchla: Pseudo-Dionysius Areopagita - Die Namen Gottes, Stuttgart 1988, S. 97.
} 


\subsection{Die Bestimmung Gottes als essentia omnium}

Sein überragt und andererseits, weil Schöpfer des Seins, als >Sein an sich aufgefasst werden muss. Wie es Suchla treffend anmerkt, erge-

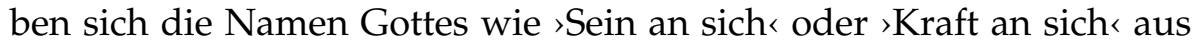
seinen »Schöpfungs- und Heilstaten « ${ }^{12}$ Schon der dabei auftretende Ausdruck »tausendmal Gesagtes« zeigt die Bedeutung, die Dionysius dieser Problematik und ihrer Lösung zuerkennt.

Gut zweihundert Jahre vor Dionysius Areopagita offeriert ein Denker im lateinischen Westen eine etwas elegantere Lösung zu selbigem Problem: Marius Victorinus. Wie Dionysius steht auch er unter neuplatonischem Einfluss, weshalb man bei ihm auf dieselbe Terminologie trifft. Er sagt so zum Vor-Sein und An-sich-Sein Gottes: "Gott also ist das vollständige Vor-Sein, Jesus aber dieses vollständige Sein selbst, dieses schon in der Existenz und im Leben und im Geist befindliche, allgemeine auf alle Weise vollkommene Sein. Dies ist der Sohn, dieses gesamte Wort, das bei Gott und in Gott seiende Wort, dieser Jesus Christus, vor jedem, das ist und wahrhaft ist, die erste und gesamte Existenz, erster und gesamter Geist, das erste und auf alle Weise vollkommene Sein, das Sein selbst (...). 413

Christus ist >das Sein selbst`, während Gott, wohl als Schöpfer verstanden, das Vor-Seiende ist. Wenn wir Gott das Sein an sich nennen, dann benennen wir damit nicht Gott-Vater, sondern Gott-Sohn, also Christus. Marius Victorinus kann sich dabei auf Paulus berufen, bei dem es von Christus und nicht etwa vom Vater heißt: »Denn in ihm ist alles geschaffen (...) es ist alles durch ihn und zu ihm geschaffen. Und er ist vor allem und es besteht alles in ihm. «14

Indes hatte diese Lösung wenig Durchschlagskraft und findet sich schon bei Augustinus nicht mehr. Vielleicht war sie im Hinblick auf das homoousion zu zweideutig, wenngleich sich Marius Victorinus hier gerade für das homoousion stark macht. Ausgehend von einem Bibelzitat glaubt er darlegen zu können, dass Gott als ousia, was er als substantia

\footnotetext{
${ }^{12}$ Beate Regina Suchla: Pseudo-Dionysius Areopagita - Die Namen Gottes, Stuttgart 1988, Einleitung, S. 9.

${ }^{13}$ Ad Candidum 2: Deus igitur est totum rpoóv, Iesus autem ipsum hoc totum ő, sed iam in existentia et vita et intelligentia, universale omnimodis perfectum öv. Hic est filius, hic omnis $\lambda o ́ \gamma o \varsigma$, hic qui apud deum et in deo $\lambda o ́ \gamma o \varsigma$, hic Iesus Christus, ante omnia, quae sunt et quae vere sunt, prima et omnis existentia, prima et omnis intelligentia, primum et omnimodis perfectum őv, ipsum ő $(. .$.$) .$

${ }^{14}$ Kolosser 1, 16-17; Übersetzung nach Luther.
} 
übersetzt wissen will, benennbar sei. Dabei bezieht er sich auf das >ich bin, der ich bin< bzw. >ich bin der Seiende< aus Exodus 3, 14, das vielerorts in der Patristik zur biblischen Rechtfertigung der Annahme, Gott müsse irgendein Sein zugesprochen werden, angeführt wird. ${ }^{15}$

\subsubsection{Dionysius Areopagita als mögliche Vorlage von Eriugenas Substanzlehre}

Eines ist es, Gott ein Sein zuzusprechen, ein anderes aber, ihn als Sein von allem aufzufassen. Wie gelangt Eriugena zu der Überzeugung, Gott sei esse omnium und essentia omnium? Er selbst führt dazu als einzige Quelle einen Satz von Dionysius Areopagita an: Esse enim omnium est super esse divinitas, „das Sein von allem nämlich ist die überseiende Gottheit « ${ }^{16}$ Wie das enim, griechisch gar zeigt, handelt es sich bei diesem Satz um eine Begründung, aber eine Begründung wofür? Schauen wir auf den Zusammenhang, in dem der Satz bei Dionysius steht: »Einerseits also hat alles Unbelebte am Sein desselben [des Hervorsprudelnden] teil, denn das Sein von allem ist die über dem Sein liegende Gottheit, (...).<17 Wenn der mit »denn« beginnende Nebensatz sich auf das Vorangehende bezieht, dann begründet das "Sein von allem « die Teilhabe alles Unbelebten am Sein des zuvorgenannten SichErgießenden.

Eriugena übersetzt wie folgt: Existentia igitur omnia esse ejus participant (esse enim onmium est super esse divinitas) 18 Mag das nun passend übersetzt sein oder nicht, was interessiert, ist Dionysius' Argument. Man könnte meinen, das 'Sein von allem ‘ sei hier lediglich als dasjenige näher bestimmt, woran eben alles Seiende teilhat. Aber Dionysius erläutert hier nicht das 'Sein von allem` als Teilhabe, sondern umgekehrt die Teilhabe mit ihm. Dieser Umstand spielt Eriugenas Interpretation in die Hände. Da Dionysius gerade mit dem `Sein von allem ‘ die Teilhabe begründet, ist diese Begründung als Aussage wohl vorrangiger als das, was begründet wird. Dass die sich ergießende Gottheit das

\footnotetext{
${ }^{15}$ Ad Candidum 14.

${ }^{16}$ Etwa I, 61 und I, 3190.

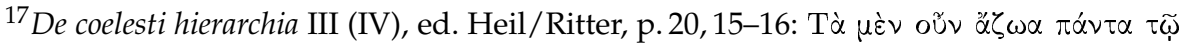

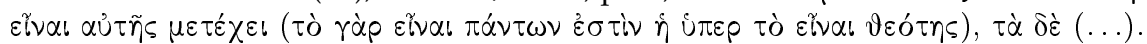

${ }^{18}$ Siehe PL 122, 1046B.
} 
Sein von allem ist, hält er offensichtlich für so evident, dass er die Teilhabe daraus ableitet. Wenn dies zutrifft, dann gibt Eriugena in der Tat in Periphyseon I, 59-61 nur das wieder, was er bei Dionysius vorfindet.

Aber wie ist dieses 'Sein von allem $>$ zu verstehen, kausal, final oder substanziell? Wenn man Dionysius' weitere Ausführungen liest, gilt Ersteres und Zweiteres. Und Albertus Magnus etwa hält es in seinem Kommentar zu dieser Stelle für evident, dass mit esse omnium allein die Kausalursache gemeint sein kann ${ }^{19}$ Doch Eriugena entscheidet sich für die dritte Interpretation, was für seine Ontologie weitreichende Folgen hat.

Erinnern wir uns, was er auf das Zitat des Dionysius in I, 61 folgen lässt: die Behauptung, alle geschöpfliche essentia und substantia sei unbegreiflich, und zwar darum, weil Gott in den Geschöpfen unbegreiflich sei. Gott also ist, so lässt sich schließen, jede einzelne essentia und substantia der Geschöpfe. Der Übergang vom Singular essentia omnium zum Plural unicuique essentiae (I,70) und nullam substantiam (I, 62) zwingt uns zu der Interpretation, dass Eriugena das göttliche essentiaSein als substantia-des-Einzelnen-Sein auffasst. Die vermeintliche Quelle für diese Auffassung, Gregor von Nazianz, wurde bereits angegeben und besprochen.

Ein weiterer Aspekt zur vorliegenden Frage: Dass dasjenige, woran das Seiende (ta onta) teilhat, selbst wiederum ousia ist, sagt Dionysius im unmittelbar vorangehenden Satz: »Denn nichts wäre, wenn es nicht an der ousia und der archê der Seienden teilhat. 20 Die Gleichsetzung von esse omnium und essentia omnium, wie sie im Periphyseon hinsichtlich dieses Zusammenhangs geschieht (I,59-61), ist vor diesem Hintergrund eine durchaus mögliche Lesart. Doch findet sich auch die anschließende Behauptung, die essentiae und substantiae der Geschöpfe seien göttlich, bei Dionysius? Dies ist nicht der Fall.

Vielmehr gibt es im Buch von den göttlichen Namen eine Aussage, die diese Annahme gerade auszuschließen scheint: »(...) in ihm exis-

\footnotetext{
${ }^{19}$ Alberti Magni super Dionysium De caelesti hierarchia, ed. Paulus Simon, Münster 1993, Kap. V, p. 64.

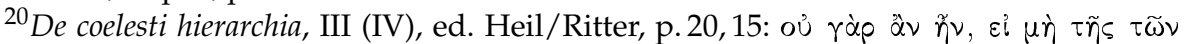

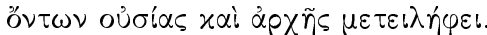


tiert das Sein, aber er selbst existiert nicht in dem Sein. $<{ }^{21}$ Demzufolge ist Gott nicht in irgendeinem Seienden zugegen.

Gehen wir noch einmal zurück zur Textpassage, aus der Eriugena sein Zitat entnommen hat. Der Abschnitt beginnt mit einer Erklärung dessen, was darzulegen ist, und aus dieser Darlegung stammt das Zitat des Periphyseon: "Zuerst aber ist von all diesen Dingen wahrhaft zu verkünden, wie in der Güte bestehend die überwesenhaften Gottursprünglichkeit die ousiai der Seienden zum Sein hinführt. $<{ }^{22}$ Gleich, wie man hier das Partizip hypostêsasa übersetzen will, es lässt sich nicht herauslesen, dass Gott in den ousiai der Seienden besteht, sondern das, worin die >Gottursprünglichkeit ‘ besteht, ist die Güte. Eriugenas Aussage entbehrt damit einer Vorlage bei Dionysius.

\subsection{Gott als creari}

Der Gedanke, Gott sei essentia von allem, lässt sich auch als Interpretation der Aussage auffassen, Gott sei >erschaffen ‘. Immerhin dient sie im dritten Buch als Argument für die Auflösung der Natureinteilung. Dabei sind es dort nicht mehr die unspezifizierten Bücher der heiligen Väter (I, 418, libri sanctorum patrum), sondern es ist nur noch ein Buch, in dem diese Behauptung zu lesen sein soll (III, 586-588, III, 13281331). Jeauneaus Apparat zur Stelle im dritten Buch verweist auf De divinibus nominibus V, 8 und Epistula IX, 3. Der erste der beiden Verweise hilft nicht weiter, da m. E. dort nichts dergleichen gesagt ist, der zweite schon. Wie Jeauneau dabei zurecht anmerkt, ist Eriugenas Wiedergabe des Gedankens, wenn seine Darstellung auf diese Epistula-Stelle Bezug nehmen soll, etwas schief ${ }^{23}$ Nicht Gott nennt Dionysius hier geworden oder werdend (wie wir in I, 420 sehen können, fasst Eriugena fit und creatur als dasselbe auf), sondern, und dies ist unmittelbar einleuchtend, die göttliche Vorsehung (pronoia) 24

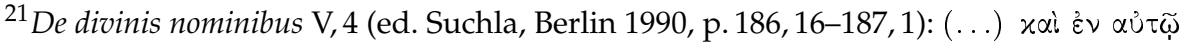

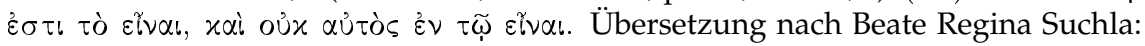
Pseudo-Dionysius Areopagita - Die Namen Gottes, S. 72.

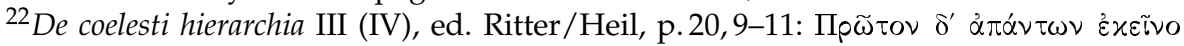

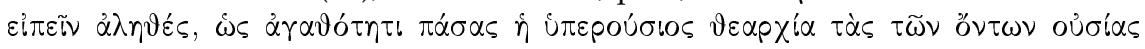

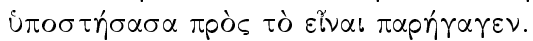

${ }^{23}$ Apparatus in Periphyseon III, p. 22 unten.

${ }^{24}$ Epistula IX, 3, ed. Heil/Ritter, p. 202, 9.
} 
Wovon Dionysius hier spricht, ist also die Finalursache, und so wundert es nicht, wenn er diese pronoia nicht nur als dasjenige bestimmt, was in allem wird (en tô panti gignetai), sondern auch als Ursache von allem (ta panta aitios).

Eriugena spricht bei den Quellenverweisen aber nicht von der pronoia, lateinisch providentia, sondern stellt es so dar, als sprächen die Autoritäten von Gott selbst. Und selbst wenn Gott als diese providentia zu identifizieren ist, so läuft doch die Erklärung im Periphyseon nicht darauf hinaus, Gott sei deshalb serschaffen zu nennen, insofern sich die göttliche Vorsehung in der Schöpfung vollzieht und erfüllt ${ }^{25}$ Eriugenas Erklärungsmuster hebt vielmehr auf die Aussage aus De coelesti hierarchia ab, wonach die überseiende Gottheit das Sein von allem ist (etwa $\mathrm{I}, 60)$.

Interessanterweise stellt Eriugena hier nicht dieselbe Frage wie wir. Er fragt nicht nach einem Argument bei Dionysius, warum man Gott als >erschaffen $<$ benennen kann, sondern er stellt allein heraus, dass diese Autorität Derartiges behauptet. Und diese Behauptung findet sich in der zweiten, von Jeauneau angegebenen Stelle, in De divinis nominibus V, 8. Wohl auf diese Stelle beruft sich Eriugena in III, 2632-2635, wo es heißt, ein jeder, der die Kraft der Worte (horum verborum virtutem) aus De divinis nominibus vernehme, einsehe, dass Gott in allem erschaffen ist. An dieser Stelle bei Dionysius ist bezeichnenderweise zunächst die schon bekannte Aussage zugegen, die überseiende Ursache von allem sei auch das Sein von allem. Daran schließt sich die schwierig zu übersetzende Aussage an (zunächst die Übersetzung von Suchla): »Der wahrhaftig ehevor Seiende wird daher bei jeglichem Nachdenken über das Seiende von der heiligen Schrift um ein Vielfaches vergrößert, und in bezug auf ihn wird die Bezeichnung ser war<, >er ist<, >er wird sein<, >er wurde<, >er wird < und ser wird werden $<$ berechtigt verwendet.< 46

Sehen wir uns an, was Eriugena aus der griechischen Vorlage macht:

${ }^{25}$ Dieselbe Argumentation führt Eriugena im Zusammenhang mit Origenes im fünften Buch an, ohne jedoch seine früheren Aussagen dahingehend einzuschränken. Siehe $\mathrm{V}, 3096-3104$.

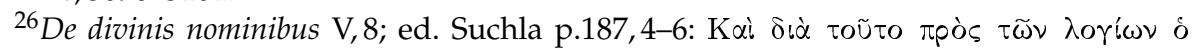

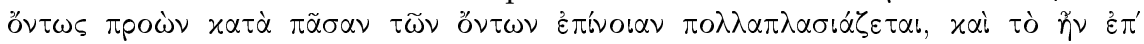

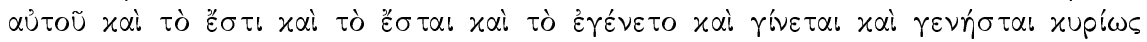
ü $\mu \varepsilon \tilde{i} \tau \alpha$ l. Übersetzung nach Suchla: Pseudo-Dionysius Areopagita - Die Namen Gottes, Stuttgart 1988, S. 72-73. 
»Et propterea ab eloquiis ipse vere anteON iuxta omnem existentium intelligentiam multiplicatur, et quod erat in ipso, et quod est, et quod erit, et quod factum est et fit et fiet, proprie laudatur."Subjekt des Satzes ist der »wahrhaft ehevor Seiende«, wie es Suchla nennt, bei Eriugena ipse vere anteON. Während dieser nach Suchla vergrößert wird, übersetzt Eriugena das pollaplasiazetai als multiplicatur, also als Vervielfachung. Wie er sich diese Vervielfältigung zu denken hat, glaubt er später dann von Maximus Confessor zu erfahren. Gott wird, so heißt es weiter, benannt, und zwar auch mit ser wurde` und mit ser wird<. Genauer gesagt, mit diesen Prädikaten wird er berechtigterweise gelobt (proprie laudatur bei Eriugena). Das heißt für Eriugena wohl, das, was man von Gott sagen könne, sei er auch: die Theologen sagen, er sei erschaffen, also ist er erschaffen. So naiv drückt er es zwar nicht aus, doch die ontologische Dimension, die er der Sache im Periphyseon gibt, ist bei Dionysius so nicht zu greifen. Die Aussage, Gott sei als ein Erschaffener zu loben, ist von geringerer Tragweite als die Aussage, er sei erschaffen.

Nun lässt sich fragen, mit welchem Recht dies von Gott aussagbar ist; einen Grund dafür sollte es ja geben. Er holt sich die Begründung bei Dionysius, wenngleich sie bei diesem nicht als solche auftritt: Weil Gott esse omnium ist, darf er im Hinblick auf das esse als erschaffen angesehen werden. Alles ist in ihm, heißt es bei Dionysius immer wieder, und zwar auch unter Berufung auf Paulus: »'Er ist vor aller Schöpfung, in ihm hat alles Bestand ‘, kurz, wenn irgendetwas eine wie auch immer geartete Existenz aufweist, so existiert es in dem ehevor Seienden und wird in ihm wahrgenommen und bewahrt. $<27$ (Der erste Teil innerhalb der einfachen Anführungszeichen ist ein Zitat aus Kolosser 1,17.)

Es lässt sich darüber streiten, wie das Bestand-haben oder Zusammensein (syneinai) aus dem Paulus-Zitat zu verstehen ist. Und ebenso interpretationsbedürftig ist die Aussage, alles Existierende existiere im Vorseienden und werde in ihm bewahrt. Doch wenn man sich auf derlei Diskussionen einlässt, gesteht man Eriugena bereits eine nicht von vorn herein abwegige, sondern durchaus diskussionswürdige Position ist.

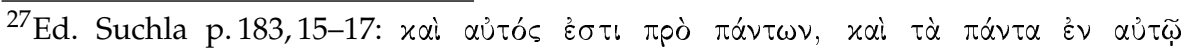

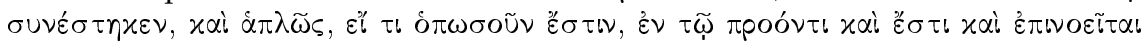

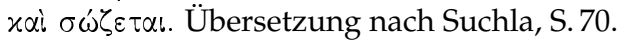


Was er dabei macht und was ihn über seine Quellen hinausgehen lässt, ist die Konkretisierung der bildreichen Aussagen des Paulus und Dionysius Areopagita. Wie hat man sich die Bewahrung der Schöpfung im Schöpfer zu denken? Wie die Existenz der Dinge im Vorseienden?

Eriugena antwortet mit der essentia. Gott sei essentia von allem, substantia. Damit beantwortet er zweierlei: einerseits, inwiefern alles in Gott ist und inwiefern Gott in allem ist. Beides kann man als dasselbe ansehen, muss es aber nicht. Das zeigt sich auch daran, dass sich die erste Aussage, alles sei in Gott, bei Paulus und Dionysius zuhauf finden, die zweite nicht. Insofern Eriugena die metaphorischen Aussagen der beiden mittels der essentia konkretisiert, wird sie einerseits zum Schlüsselbegriff in seinem Denken, andererseits zu dem, das die gesamte Argumentationslast zu tragen hat.

Da Gott substantia bzw. essentia aller Dinge ist, gilt:

- Gott ist das Sein von allem

- Gott ist der Bewahrer von allem

- Gott ist nicht nur >schaffend « sondern auch >erschaffen`.

Damit hat er die seines Erachtens wichtigsten theologischen Aussagen seiner griechischen Quellen konkretisiert. Diese Rolle kann der essentia aber nur zukommen, wenn sie zwei Kriterien erfüllt: zum Einen muss sie ebenso unbegreiflich sein wie Gott selbst, zum Anderen muss die ontologische Unterscheidung zwischen de subiecto und subiectum fallen, damit lediglich Letzteres verbleibt. Wie rechtfertigt er diese Kriterien?

Die gestellte Frage lässt sich nicht zureichend beantworten ohne eine Untersuchung dessen, was Eriugena mit den Ausdrücken essentia und substantia bezeichnet. Darüberhinaus ist noch ungeklärt, was das Kennzeichen der essentia omnium rerum ist und dessen, qui solus vere est.

\subsection{Zur Bedeutung des griechischen ousia und des lateinischen essentia}

Der ousia kommt im Periphyseon eine Doppelrolle zu, die sie nur schwer erfüllen kann: sie ist Form und Materie zugleich. Zwar sind nach Aristoteteles gerade diese beiden aussichtsreiche Kandidaten für die von 
ihm gesuchte ousia, doch hebt er deutlich hervor, inwiefern ousia als Materie und inwiefern sie als Form angesehen werden kann ${ }^{28}$ Solch eine Unterscheidung liegt im Periphyseon nicht vor, weil Eriugena die aristotelische Form/Materie-Unterscheidung nicht ausreichend bekannt ist ${ }^{29}$ Vielmehr dient dieselbe ousia hier sowohl als subiectum und damit als Materie, als auch als Form, ohne die der Gegenstand kein eigentümliche Substanz besitzt. Weil Eriugena diese Doppelrolle aber nicht explizit diskutiert, bleibt sein ousia-Begriff aufgrund der Funktionsvielfalt, der ihm so zukommt, undeutlich.

In diesem Zusammenhang sei daran erinnert, wie er essentia und damit ousia zu Beginn des ersten Buches teils mit ratio, teils mit esse, teils mit vere esse und teils mit substantia gleichsetzt. Bevor man ihm daraufhin eine uneinheitliche und damit unklare Verwendung von essentia vorwirft, ist zu betrachten, wie die Tradition vor ihm mit essentia und dem griechischen Pendant ousia verfährt.

Die Untersuchung wird dabei zweierlei zeigen:

1. Eriugena findet in seinen Quellen keine eindeutige Verwendung von ousia vor.

2. Er findet in den Quellen auch keine einheitliche lateinische Übersetzung vor.

\subsubsection{Zur Verwendung von ousia in der griechischen Tradition}

Wie ein knapper Blick auf die Philosophie- und Theologiegeschichte zeigt, ist es nicht möglich, das dort auftretende Wort ousia eindeutig abzugrenzen oder anders zureichend zu bestimmen. Dabei geht es keineswegs um die Schwierigkeit, dass es seit jeher, wie Aristoteles feststellt, die Frage aller Denker sei, was ousia ist: »Und man kann sogar sagen, dass die alte und heute noch lebendige Frage, die, immer wieder gestellt, jedesmal in Schwierigkeiten führt, die Frage nämlich, was

\footnotetext{
${ }^{28}$ Metaphysik VIII, 1042a3-32.

${ }^{29}$ Zwar weiß Eriugena durch Calcidius grob um Aristoteles' Diskussion über Stoff und Form, aber mittels dieser Vorlage ist die Form/Materie-Unterscheidung für ihn wenig hilfreich. Siehe dazu Calcidii Commentarius in: Plato Latinus IV, ed. Waszink, p. 289, 10-293, 3 .
} 
das Seiende ist, eigentlich die Frage danach ist, was die ousia ist. 430 Es geht vielmehr um die Unmöglichkeit einer sprachlichen Abgrenzung.

Manche im Altertum haben wohl behauptet, die Pythagoräer hätten als erste ousia im philosophischen Sprachgebrauch verwendet, für uns ist es zum ersten Mal bei Plato greifbar ${ }^{31}$ Es ist hier gar nicht möglich, für jeden einzelnen platonischen Dialog eine Bestimmung von ousia anzugeben, und es bleibt allein festzuhalten, dass dessen Verwendung im Hinblick auf alle Dialoge nicht einheitlich ist. F. E. Peters stellt den Versuch an, ousia für die einzelnen Dialoge näher zu bestimmen. Im Theaitetos werde sie dem Nichtseienden gegenübergestellt und bezeichne so die Existenz der seienden Gegenstände. Im Philebos bezeichne ousia das Entstehende. Im Sophistes und Timaios hingegen stehe ousia gerade dem Werden entgegen. Im Phaidon schließlich sei ousia das Wesen einer Sache, das Essentielle, und im Phaidros werde mit ousia eine Bestimmung des Gegenstands angegeben 32

Mögen die Bestimmungen von Peters im Einzelnen zu hinterfragen sein, der von ihm so hervorgehobenen Bedeutungsvielfalt des Begriffs ist sicherlich beizupflichten. Auch Christoph Horn und Christof Rapp geben für Platos Schriften eine Bedeutungsvielfalt von ousia an, die sie wie folgt gliedern: »Bezogen auf sinnlich wahrnehmbare Objekte meint ousia das dauerhafte Wesen, bezogen auf die gesamte Realität steht ousia für die unveränderlichen eidê. Zudem bezeichnet ousia gelegentlich das allem Wirklichen gemeinsame Merkmal `Sein «. 33

Darüberhinaus ist bei Plato und seinen Kommentatoren ousia zum Teil anderen Wörtern in der Bedeutung gleichgestellt. Der schon anonyme Kommentar zum platonischen Parmenides verwendet ousia und to einai (das Sein) gleichbedeutend, ein Vorgehen, das man schon Plato selbst für diesen Dialog unterstellen kann ${ }^{34}$ Eine weitere Bedeutungs-

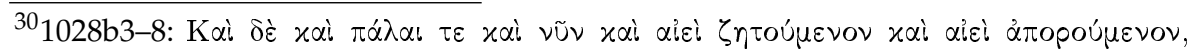

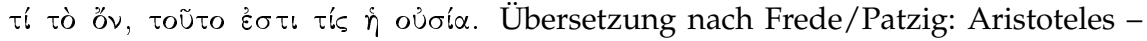
Aristoteles Metaphysik Zeta, Erster Band, München 1988, S. 61-63.

${ }^{31}$ F. E. Peters: Greek Philosophical Terms, New York/London 1967, p. 149-151.

${ }^{32} \mathrm{Zu}$ alledem siehe F. E. Peters: Greek Philosphical Terms, p. 149-151.

${ }^{33}$ Christoph Horn / Christof Rapp: Wörterbuch der antiken Philosophie, München 2002, S. 321.

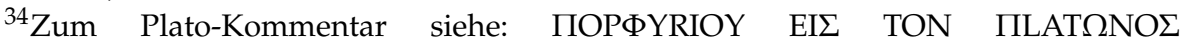
ПAPMHNI $\triangle$ HN, (ed. Pierre Hadot, in: Porphyre et Victorinus II, p.100,1523); zu Plato: Parmenides 142d.
} 
gleichheit bringt Proklos ins Spiel, wenn er behauptet, Plato benutze im Staat ousia gleichbedeutend mit to on (das Seiende) ${ }^{35}$ Einerseits also zeigt sich in der platonischen Philosophie eine Mehrdeutigkeit von ousia, andererseits eine Gleichsetzung dieses Wortes mit anderen. Anders aber als im Periphyseon scheint bei Plato zumindest innerhalb je einer Schrift eine eindeutige Bestimmung und Verwendung vorzuliegen.

Umsicht ist bei Aristoteles geboten. Im Hinblick auf die Metaphysik sind die in Zeta genannten Kandidaten dessen, was ousia sein kann, nicht ohne weiteres mit der Bedeutungsvielfalt des Wortes gleichzusetzen. Man nehme ewa den Anfang aus Metaphysik VII, 3: »Denn sowohl das >Was es heißt, dies zu sein ‘ als auch das Allgemeine, aber auch die Gattung werden als die ousia einer jeden Sache angesehen, dazu noch als viertes das Zugrundeliegende. ${ }^{36} \mathrm{Ob}$ das dokei hier als legetai interpretiert werden darf, also was man ousia nenne, oder eher als Lehrmeinung dessen, was ousia ist, bedürfte ohnehin einer näheren Untersuchung.

Und auch der Gegenstandsumfang von ousia, den Horn und Rapp für die aristotelische Metaphysik angeben, ist nicht unbedingt dasjenige, wonach wir hier fragen. Ousia sei im zwölften Buch, so geben sie an, unterschieden in »erstens die sinnlich wahrnehmbare, vergängliche ousia, zweitens die wahrnehmbare, aber ewige ousia sowie drittens die unveränderliche ewige ousia « ${ }^{37}$ Eine solche Klassifizierung der ousiai ist nicht dasselbe wie die Angabe dessen, was mit dem Wort ousia überhaupt bezeichnet wird.

Für die vorliegende Untersuchung ist wichtig, dass Aristoteles in seinen Schriften eine Verwendung von ousia einführt, die sich bis dahin in der Philosophie offensichtlich nicht findet. In der Physik, der Metaphysik, der Topik und den Zweiten Analytiken ist ousia das vieldiskutierte ,Was es für eine Sache heißt zu sein<, das ti ên einai ${ }^{38}$ Bezeichnender-

\footnotetext{
${ }^{35}$ Procli commentarium in platonis parmenidem (ed. Raimund Klibansky), p. 28, 18:

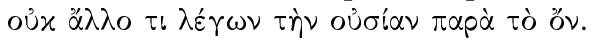

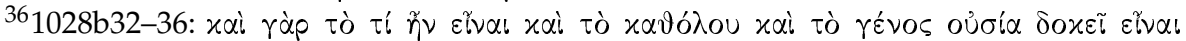

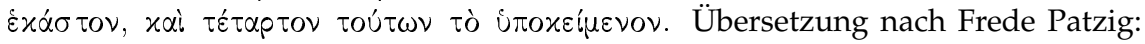
Aristoteles Metaphysik Zeta, München 1988, S. 65.

${ }^{37}$ Christoph Horn/Christoph Rapp: Wörterbuch der antiken Philosophie, S. 322. Siehe zur Bestimmung des aristotelischen Wesensbegriffs auch Michael-Thomas Liske: Aristoteles und der aristotelische Essentialismus, Freiburg 1985, S. 209-259.

${ }^{38}$ Siehe zur Diskussion um diesen aristotelischen Begriff Hermann Weidemann: Zum
} 
weise ist genau diese Bestimmung der ousia nicht oder nur spärlich bis zu Eriugena durchgedrungen.

\subsubsection{Zur Übersetzung von ousia in der lateinischen Tradition}

In der Zeit vor Eriugena wird traditionell ousia zumeist mit substantia übersetzt. Diese Übersetzungsweise lässt sich bis zu Quintilian und Seneca zurückverfolgen, erhält aber möglicherweise erst durch Marius Victorinus durchschlagende Bedeutung ${ }^{39}$ Wir müssen uns dies darum vor Augen halten, weil im Periphyseon beide lateinischen Ausdrücke, essentia und substantia, auftauchen und noch gar nicht klar ist, ob sie dasselbe bezeichnen.

Zur Rechtfertigung des Wortes ousia und damit des homoousion gegen die Arianer fasst Marius Victorinus ousia und hypostasis als gleichbedeutend auf. Dabei wählt er das lateinische substantia als passende Übersetzung für ousia. Kurz gesagt, fasst er ousia als unveränderlich Bestehendes auf, und vor diesem Hintergrund gibt substantia, von sub (unter) und stare (stehen) herkommend, in der Tat die Bedeutung des griechischen Wortes treffend wieder 40

Die wörtliche Übersetzung von ousia ist dennoch essentia. Ousia ist der weiblichen Form des Partizips on (seiend) entlehnt, essentia ist eine Zusammenstellung aus esse (sein) und dessen Partizip ens (seiend). Hypostasis wiederum heißt wörtlich übersetzt >Unter-Stand<, das lateinische substantia ist auf die selbe Weise aus sub (unter) und status (Stand) zusammengesetzt.

Allerdings erklärt der spätantike Kirchenhistoriker Sokrates, es gebe bis in die erste Hälfte des vierten nachchristlichen Jahrhunderts keine allgemein gültige Verwendung für hypostasis, und einige würden anstelle von ousia das Wort hypostasis verwenden ${ }^{41}$ Es sind, darauf ver-

Begriff des ti ên einai und zum Verständnis von Metaphysik Zeta 4 1029b22-1030a6, in Christof Rapp: Metaphysik - Die Substanzbücher, Berlin 1996, S. 75-103.

${ }^{39}$ Siehe hierzu Forcellini: Lexicon Totius Latinintatis, Tome V, p. 555-556 sowie Pierre Hadot: Marius Victorinus, Paris 1971.

${ }^{40}$ Adversus Arium II, 3-7 (Sources Chretiennes 68, p.398-414); siehe dazu auch Hadots Anmerkungen in ders.: Marius Victorinus - Christlicher Platonismus, Zürich 1967, S. 402-404. Eine ausführliche Untersuchung dieser Übersetzungsrechtfertigung steht noch aus.

${ }^{41}$ Siehe hierzu und für die folgenden Angaben zu den Kappadokiern Guido Bausen- 
weist Ingo Bausenhart, erst die drei Kappadokier Basilius von Cäsarea, Gregor von Nyssa und Gregor von Nazianz, die beide Begriffe zumindest theologisch klar voneinander abgrenzen und die einflussreiche Trinitätsformel mia ousia - treis hypostaseis schaffen. Bei allen drei Denkern stehe dabei ousia für das allen Gemeine (to koinon), hypostasis hingegen für das jeweils Eigentümliche (to kath' hekaston / to idion) ${ }^{42}$ Die Trennung erfolgte also zeitlich nach Marius Victorinus' Übersetzungsweise.

Die Unterscheidung der Kappadokier ist bis zu Eriugena gelangt und lautet bei ihm lateinisch una essentia in tribus substantiis 43 Über die lateinischen Kirchenväter sagt er in diesem Kontext: »Auch der heilige Augustinus und die übrigen heiligen Väter, wenn sie ausführlich schreibend den Glauben an die heilige Dreiheit ausdrücken, sagen eine Substanz (substantia) und drei Personen, bezeichnen die Einheit der göttlichen Natur mit dem Namen, der Substanz ist, die dreifache Eigentümlichkeit der Substanzen aber mit den Wörtern der drei Personen. «44 Dieser Hinweis auf die lateinischen Kirchenväter zeigt, dass Eriugena wissentlich von deren Ausdrucksweise abweicht und sich nach jener der griechischen Theologen richtet; so spricht er von der einen göttlichen essentia, und nicht von substantia:

»Weil ja der heilige Dionysius Areopagita und Gregor der Theologe wie auch deren gebildetster Ausleger Maximus sagen, dass ein Unterschied ist zwischen ousia (dies ist essentia) und hypostasis (dies ist substantia), ist ousia freilich zu denken als jene einzige und einfache Natur der göttlichen Güte, hypostasis aber als eigene und unteilbare substantia der einzelnen Personen.<45 Seine Unterscheidung zwischen ousia und

hart: »In uns allen gleich außer der Sünde« - Studien zum Beitrag Maximos' des Bekenners zur altkirchlichen Christologie, Tübingen 1990, S. 46 ff.

${ }^{42}$ Ebenda.

${ }^{43} \mathrm{I}, 671$.

${ }^{44}$ I, 3033-3037: Sanctus quoque Augustinus caeterique sancti patres latialiter scribentes fidem sanctae trinitatis exprimunt dicentes unam substantiam in tribus personis, siginificantes unitatem divinae naturae eo nomine quod est substantia, trinam vero substantiarum proprietatem trium personarum vocabulis.

${ }^{45}$ II, (3025-3031): Sanctus siquidem Dionysius Ariopagita et Gregorius theologus eorumque elegantissimus expositor Maximus differentiam esse dicunt inter oysian (id est essentiam) et YПOCTACIN (id est substantiam), OYCIAN quidem intelligentes unicam illam ac simplicem divinae bonitatis naturam, YПOCTACIN vero singularum personarum propriam et individuam substantiam. 
hypostasis bzw. essentia und substantia in Bezug auf Gott ist damit klar. Zudem kann sein Ausdruck »die übrigen heiligen Väter « nicht Boethius miteinbeziehen, da dieser in Contra Eutychen jene Ausdrücke für die Trinität verwendet, die auch Eriugena vorzieht. Boethius sagt: »Von daher sagen wir auch, dass eine ousia oder ousiôsis ist, das heißt essentia oder subsistentia der Göttlichkeit, aber drei hypostaseis, das heißt drei substantiae. 46 Dies deutet einmal mehr darauf hin, dass Eriugena dieses Werk nicht kannte, zumindest nicht zur Zeit der Abfassung seines ersten Buches des Periphyseon.

Bereits durch Calcidius lernt Eriguena dabei sowohl essentia als auch substantia als passende Übersetzung von ousia kennen, wobei Calcidius die Übersetzung essentia Cicero zuschreibt ${ }^{47}$ Interessant ist in diesem Zusammenhang, dass auch Boethius sich nicht auf eine Variante festlegen will. Im fünften Buch der Opuscula sacra, wo auch er auf Cicero verweist, gibt er an: »Das also ist ousia, was essentia ist, das ousiôsis, was subsistentia, das hypostasis, was substantia, das prosôpon, was persona. 48 Abweichend davon verwendet er in der Übersetzung der aristotelischen Kategorienschrift für ousia ausschließlich substantia, in der Institutio arithmetica wiederum beides, nämlich substantia für das beharrende Prinzip des Geistigen, essentia als Bezeichnung für eine Größe oder Menge 49

Eriugena entscheidet sich für essentia. Schon in seiner ersten Übersetzung eines griechischen Textes, dem Corpus Dionysiacum, weicht er von der Vorlage Hilduins ab, der für ousia das lateinische substantia einsetzte ${ }^{50}$ Daran hält er durch alle seine Übersetzungen hindurch fest und

\footnotetext{
${ }^{46}$ lat. Text nach Michael Elsässer: Boethius, Die theologischen Traktate, Hamburg 1988,

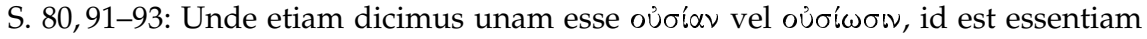
vel subsistentiam deitatis, sed tres $\dot{\pi} \sigma \sigma \tau \alpha \dot{\sigma} \sigma \varepsilon\llcorner\varsigma$, id est tres substantias.

${ }^{47}$ Calcidius Comentarius (ed. Waszink), p. 78, 2.

${ }^{48}$ Lat. Text nach Michael Elsässer: Boethius, Die theologischen Traktate, Hamburg

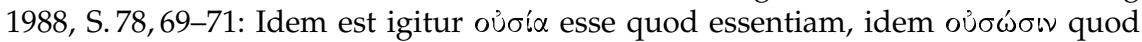

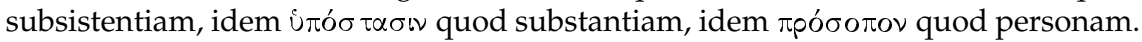

${ }^{49}$ Für die Arithmetik ist allerdings anzumerken, dass er damit wohl die Unterscheidung von hypostasis und ousia aus der griechischen Vorlage beibehalten wollte, da es sich bei dieser Schrift um die Übersetzung einer Abhandlung des Nicomachus von Gerasa handelt, siehe hierzu auch: John Caldwell: The De institutione arithmetica and the De institutione musica, in: Boethius—his life, thougt and influence, ed. by Margaret Gibson, Oxford 1981, p. 135-161.

${ }^{50}$ Für Beispiele siehe die Synopsis aller lateinischen Übersetzungen des Corpus Dio-
} 
verweist auch im Periphyseon immer wieder darauf, essentia entspreche dem griechischen ousia 51

Dabei machen es ihm seine Quellen oft nicht einfach. In einem das Sein behandelnden Abschnitt der Ambigua verwendet Maximus ousia sinngleich mit to einai ${ }^{52}$ Eriugena erkennt bei seiner Übersetzung diese Gleichstellung und setzt, anders als zuvor in der Übersetzung des Corpus Dionysiacum, auch für to einai das lateinische essentia 53

Mitentscheidend für Eriugenas Wahl für essentia als Pendant des griechischen ousia war dabei vielleicht auch eine Wertung Augustins. Dieser sagt wiederholt, essentia sei ein neues Wort (novum nomen), das die Alten nicht gekannt hätten und das ganz trefflich das griechische ousia wiedergebe ${ }^{54}$ Zwar zeigen sowohl Marius Victorinus als auch Calcidius und Boethius, dass essentia nicht eine neuere, sondern ältere Variante ist, doch vor dem Hintergrund der augustinischen Aussage konnte Eriugena essentia nicht allein als die treffendere, sondern auch als die modernere Übersetzung erscheinen.

Doch wenn er sich für essentia festlegt, warum findet sich dann im ersten Buch des Periphyseon ousia dennoch unübersetzt in griechischen Unzialen wieder, und zwar genau dann, wenn von der ersten Kategorie die Rede ist $\sqrt{55}$ Umfasst ousia möglicherweise mehr, als es Eriugena dem lateinischen essentia zuerkennen will?

\subsubsection{Ein Bestimmungsversuch von ousia}

Was benennt ousia Eriugena zufolge? Blicken wir zum Zwecke der Vollständigkeit zunächst auf die Fülle dessen, was in seinen Quellen darüber gesagt ist. Seine erste Begegnung mit ousia erhält er wohl aus der

nysiacum in Dionysiaca Tome I (ed. Philippe Chevallier, Paris/Brügge 1937), etwa p. 565 und 580 .

${ }^{51}$ etwa I, 894-896, I, 1885-1886, I, 2728.

${ }^{52}$ MPG 91, 1177B, 11/1180A, 8-9.

${ }^{53}$ CCSG 18, VI, 1416 (p. 93); Siehe zur Übersetzung des Corpus Dionysiacum etwa die Stelle De caelesti hierarchia IV (Dionysiaca Tome II, ed. Chevalier, Paris 1937, p. 800802, columna 3). Die entsprechenden Textstücke lauten griechisch: Tà $\mu \varepsilon \dot{\nu} \nu$ oư $\alpha \zeta \omega \alpha \alpha$

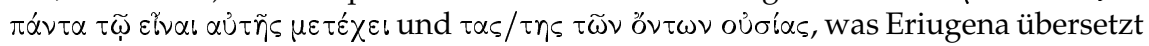
als `Existentia igitur omnia esse eius participant $<$ und >eorum quae sunt essentiae

${ }^{54}$ De civitate dei 12,2; Mor. Manich. 2,2,2; siehe hierzu auch Thesaurus linguae latinae, Bd. V, 2, S. 862.

${ }^{55} \mathrm{Im}$ Grunde durchgängig von I,937-2608. 
lateinischen artes liberales-Tradition und diese wiederum hat ihren ousia-Begriff aus der aristotelischen Kategorienlehre entlehnt. Aussagekräftiger als Martianus Capella war dabei die anonyme Schrift De categoriis Aristotelis.

Dort lernt Eriugena ousia erstens als Zugrundeliegendes (subiectum) der Akzidenzien kennen: »Und weil die, welche hinzukommen, als in der dauerhaften ousia seiend erkannt werden, wollten sie diese ousia hypokeimenon (das heißt >zugrunde liegend`) und snicht-in-einem-Zugrundeliegenden $`$ nennen, $z u$ jenen aber, die hinzukommen, sagten sie en hypokeimenô (das heißt >in-einem-Zugrundeliegenden $<$ )

Zudem wird ousia dort als oberste Gattung der ersten Kategorie bestimmt: »Diese ousia aber, über der nichts ist, wollten sie Gattung nennen. ${ }^{57}$ Dies folgt dem, was Porphyrios in der Eisagoge beispielhaft ausführt und in der als »Baum des Porphyrios« bekannt gewordenen Figur auch bei Martianus Capella vorliegt ${ }^{58}$

Letztlich lernt Eriugena aus dieser Schrift auch die Bestimmung für ousia, wie sie Aristoteles in der Kategorienschrift vorlegte: dies ist, was weder in einem Zugrundeliegenden ist noch von ihm ausgesagt wird 59

\footnotetext{
${ }^{56}$ Paraphrasis Themistiana, in: Aristoteles latinus I, 1-5 (ed. Minio-Paluello) p. 140, 1-6: Et quoniam in permanente usia ea quae accidunt inesse noscuntur, ipsam usian

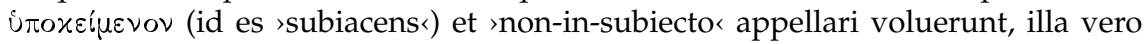
quae accidunt, $\varepsilon \nu$ i $\pi 0 x \varepsilon q \mu \varepsilon v \omega$ (id est >in-subiacenti<) dixerunt.

${ }^{57} 135,11-12$ : Ipsam vero usian, supra quam nihil est, >genus < appellari voluerunt.

${ }^{58}$ De nuptiis philologiae et mercurii, liber IV, 344-346 (ed. James Willis, Leipzig 1983, p.111-112). Es trifft daher nicht zu, wenn Jean Pépin behauptet, Eriugena lerne die arbor porphyriana erst durch Maximus kennen, siehe ders.: Humans and Animals: Aspects of Scriptural Reference in Eriugena's Anthropologie, in: Eriugena: East and West-Papers of the Eight International Colloquium of the Society for the Promotion of Eriugenian Studies, Chicago and Notre Dame, 18-20 October 1991, ed. by Bernard Mc Ginn and Willemien Otten, Notre Dame/London 1991, p.189201.

Was er indes durch Maximus lernt, ist das Vorgehen, dieses dialektische Modell auf den realen Schöpfungsprozess anzuwenden. Siehe zu dieser Annahme Eriugenas die Vorrede zu seiner Übersetzung der Ambigua ad Iohannem, MPG 91, 1061/1062: (...) qualis sit processio, id est multiplicatio divinae bonitatis per omnia quae sunt, a summo usque deorsum, per generalem omnium essentiam primo, deinceps per genera generalissima, deinde per genera generaliora, inde per species specialiores usque ad species specialissimas per differentias proprietasque descendens, (...) ita ut et Deus omnia sit et omnia Deus sint.

Als falsch wird sich erweisen, dass Maximus der Innovator dieses Gedankens ist.

${ }^{59}$ Paraphrasis Themistiana, in: Aristoteles Latinus I, 1-5 (ed. Minio-Paluello) p. 146, 2-4.
} 
Oft wird dabei übersehen, dass Aristoteles in der Kategorienschrift nur eine verneinende Bestimmung angibt. Ousia sei, am treffendsten ausgedrückt, was weder in einem Zugrundeliegenden ist noch von ihm ausgesagt wird (2a11-12). Die beste Bestimmung ist also eine verneinende. Hingegen sagt er nicht, ousia sei hypokeimenon, sondern wenn überhaupt, ousia diene allem Übrigen als hypokeimenon. Ob die Funktion, welche eine Sache für anderes einnimmt, die Sache selbst zureichend bestimmt, bleibt fraglich. Wenngleich also die lateinische Dialektik, wie etwa Martianus Capella, die erste ousia oft als subiectum bestimmt, ist dies möglicherweise nicht zureichend ${ }^{60}$ Denn was ousia als solche ist, wird damit nicht gesagt. Aus diesem Grund wohl äußert Plotin in diesem Zusammenhang: »Überhaupt lässt sich so gar nicht angeben (d.h. mit >Zugrundeliegendem ‘), was ousia ist; denn mag einer auch deren Eigentümlichkeit angeben, damit hat er noch nicht >das, was sie ist < (to ti esti); und auch die Definition >das zahlenmässig ein und dasselbe, welches fähig ist, die Gegensätze aufzunehmen`(=hypokeimenon), passt nicht auf alle Fälle. 4 16

Die Unbestimmbarkeit der ousia gelangt zu Eriugena durch De categoriis Aristotelis, stellt sich dort aber etwas anders dar: »Denn von der ousia, da man es der gültigen Lehre nach nicht bestimmen konnte - weil diese vorschreibt, dass die Bestimmung, damit sie sich weiter ausdehnt, von der Gattung her ihren Anfang nehmen soll, das Wesen selbst aber keine Gattung hat, da es selbst alles trägt (...).462 Und wenig später: »Weil ousia aus den weiter oben angeführten Gründen nicht bestimmt

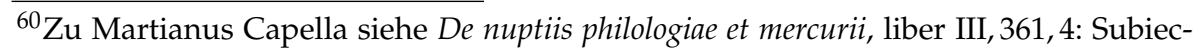
tum est prima substantia (...).

${ }^{61}$ Enneaden, VI, 1 (ed. Rudolf Beutler und Willy Theiler, Hamburg 1967, S. 98, Absatz 2,

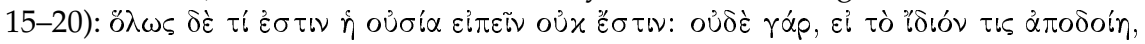

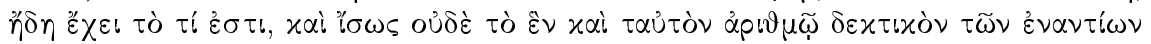

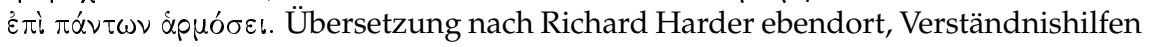
in Klammern von mir eingefügt.

${ }^{62}$ P. 145, 25-28: Sed usian, quoniam secundum artem difiniri non poterat - quae praecepit ut definitio, quo possit tendi latius, a genere sumat exordium, ipsa autem usia genus non habet cum omnia ipsa sustineat (...). Hier liegt der Gedanke zugrunde, eine Definition umfasse das zu Bestimmende, indem sie die Grenze des Gegenstandes angibt. Diese Auffassung findet sich auch im Periphyseon wieder: I, 1819-1839. 
werden konnte, forderte die notwendige Ordnung eine Definition der Akzidenzien. 463

Hier ist ousia eher als höchste Gattung aufgefasst, denn als Zugrundeliegendes, und als höchste Gattung sei sie unbestimmbar. Doch zumindest ist klar, dass Eriugena seine Ansicht, essentia und substantia seien unbestimmbar, quellengeschichtlich nicht gänzlich aus der Luft greift.

\subsubsection{Weitere Quellen für Eriugenas ousia- und essentia-Begriff}

In dem Weltbild, wie es Eriugena in Calcidius' Timaios-Kommentar vermittelt bekommt, ist essentia ein konkretes >dieses oder jenes` (hoc vel illud), zusammengesetzt aus dem Stoff (silva) und der Form (species), entstanden aus dem Vorbild der Idee (ex idea) ${ }^{64}$ Da für Calcidius die Form im Stoff besteht (in silva subsistit), nimmt der Stoff jene Rolle des Zugrundeliegenden ein, die De categoriis Aristotelis der ousia zuschreibt. Beides zusammen genommen hiesse dies, ousia liegt den Akzidenzien zugrunde, dem sinnlichen Ding aber der Stoff 65

Boethius teilt in der von Eriugena hochgeschätzten Institutio Arithmetica zu Beginn die essentiae in Größen (also ausgedehnte Einheiten) und Mengen ein ${ }^{66}$ Es ist also essentia dort etwas Geistiges und für sich selbst unveränderlich Bestehendes. Essentia bzw. ousia als etwas Unveränderliches lernt Eriugena zudem durch Augustin kennen sowie durch De categoriis Aristotelis 67

Diese Eigenschaft der ousia hat für Eriugena hohen Stellenwert, wenngleich sie nicht zu dem passen will, was Maximus darüber lehrt.

\footnotetext{
${ }^{63}$ P. 149, 4-17: Usia, quoniam diffiniri non potuit propter eas causas quas superius memoravi, accidentium diffinitionem necessarius ordo poscebat.

${ }^{64}$ Commentarius in Timaeum Platonii, in: Plato latinus IV, ed. Waszink, London 1962, p.320,10-11: (...) hoc vel illud - haec quippe pronomina sunt essentia signa. Zur Entstehung der essentia bei Calcidius siehe p.320-324.

${ }^{65}$ Ersteres gilt auch im Periphyseon, Letzteres nicht. Hierbei zeigt sich deutlich der stoische Einfluss auf Calcidius.

${ }^{66}$ Institutio Arithmetica I, I, 2-3 (ed. Jean-Yves Guillaumin, Paris 1995, p. 6).

${ }^{67}$ Siehe das schon angeführte Zitat aus De trinitate VII, 5, 10: Unde manifestum est Deum abusive substantiam vocari, ut nomine usitatione intelligatur essentia, quod vere ad proprie dicitur; ita ut fortasse solum deum dici oporteat essentiam. Est enim vere solus, quia incommutabilis est. $\mathrm{Zu}$ De categoriis Aristotelis siehe vorangehende Fußnote 59, wo von der ousia permanens die Rede ist.
} 
Wie schon aufgezeigt, legt dieser in der Ambigua ad Iohannem die Veränderlichkeit der ousia dar, aufgrund der Veränderung, die sie im zerteilenden logos erleidet: »Denn ousia wird nicht nur dasjenige genannt, was werdend und vergehend aufgrund des Werdens und des Vergehens bewegt wird, sondern auch alles Seiende, das in Bewegung ist und bewegt wird aufgrund des Trennens und Zusammenziehens im Geist und im Verfahren. Dieses ousia Genannte nämlich wird ausgehend von der allgemeinsten Gattung durch die allgemeinere Gattung in die Arten hineinbewegt, durch die und in die es naturgemäss zerteilt wird (...), und umgekehrt wieder ausgehend von der speziellsten Art durch das Allgemeinere hindurch in die allgemeinste Gattung zurückgeführt. 468 Dabei fließt in Maximus' Ansicht, nichts außer der ersten Ursache sei unveränderlich, auch Aristotelisches ein 69 Eriugenas Schweigen im Periphyseon zu dieser Auffassung seiner so hoch geschätzten Autorität zeigt, wie wenig sie zu der Unveränderlichkeitslehre der essentia passt, die er, von Augustinus und Boethius beeinflusst, favorisiert.

Schließlich lernt Eriugena durch Calcidius, aber wohl nicht nur durch ihn, die stoische Bestimmung der ousia als den (Ur)-Körper kennen 70

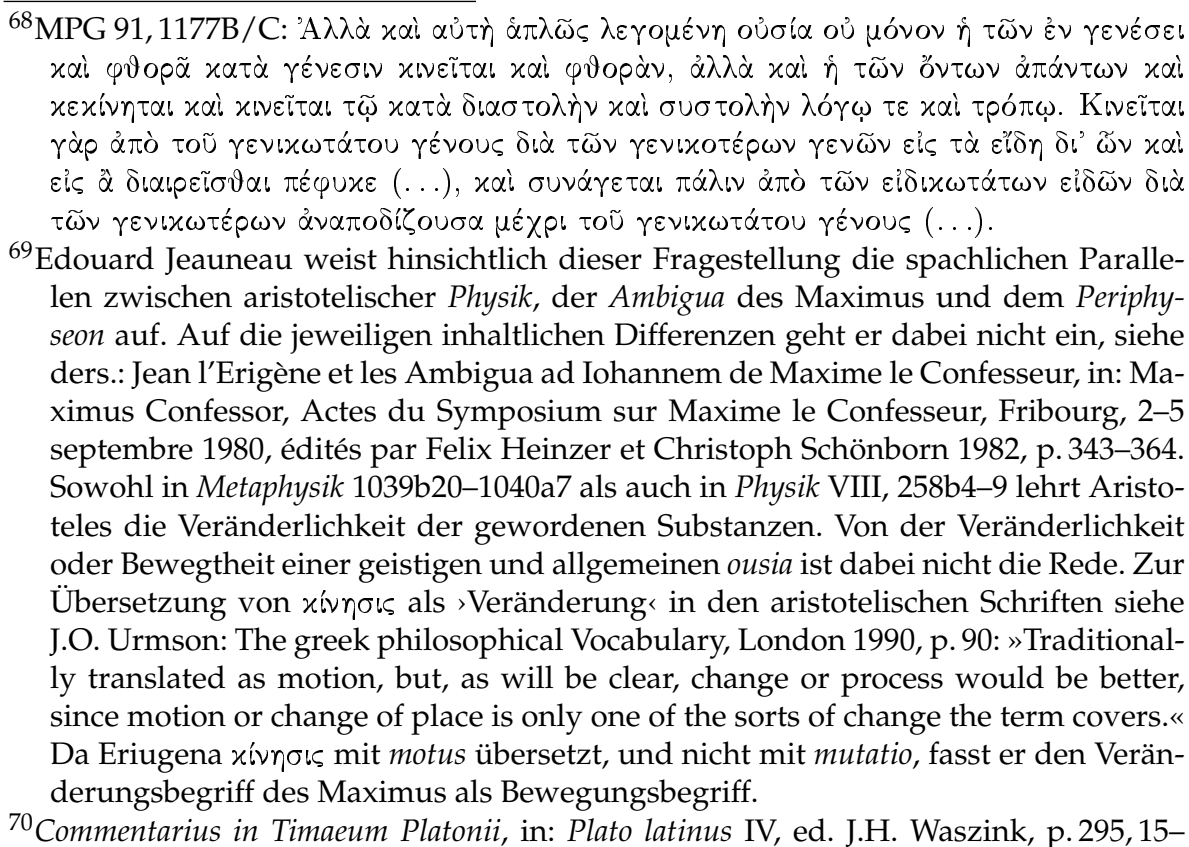


Einen weiteren Einfluss auf das Periphyseon hat die bei den Karolingern verbreitete Tendenz, substantia als Kennzeichen für >nicht-nichtszu-sein ‘ anzusehen. Der Alkuin-Schüler Frigudisus etwa (gest. 840) untersucht die Frage, ob das Nichts und die Finsternis aus dem biblischen Schöpfungsbericht vollständig nichts sei, oder ob ihm doch eine Substanz zukomme, wenngleich die Seinsprädikation ' $x$ ist seiend < auf das Nichts nicht zutreffe 71

Was macht Eriugena aus diesen Quellenvorlagen? Aufgrund der Vielfalt in seinen Quellen liegt es nahe, nach einer eigenen Bestimmung von essentia oder ousia im Periphyseon zu suchen. Dergleichen ist schwer auszumachen. Die Rechtfertigung, Eriugena zufolge könne ja niemand angeben, was essentia ist, befriedigt dabei nicht. Selbstverständlich tun sich hier jene metaphysischen Abgründe auf, die uns Aristoteles in $\mathrm{Me}$ taphysik Zeta vor Augen führt. Wer definieren kann, was ousia ist, wird vielleicht auch ohne Mühe sagen können, was die ousia einer jeweiligen Sache ist. Oder aber, nur die letztere spezifische Bestimmung ist überhaupt sinnvoll, die erstere, allgemeine hingegen gar nicht möglich. Dies sind gewichtige Fragen, die im Hinblick auf das Periphyseon nicht gewinnbringend diskutiert werden können, weil Eriugena dazu nichts sagt. Eine metaphysische Diskussion, wie wir sie uns im Hinblick auf essentia und ousia vielleicht wünschen, findet nicht statt.

\subsubsection{Die frühere Unterscheidung zwischen essentia und substantia}

Es steht die drängende Frage im Raum, ob essentia bzw. ousia Eriugena zufolge allgemeinste Gattung ist oder eher dasjenige, was jedem Individuum zugrunde liegt. Als je beides tritt sie in seinen Quellen auf, als höchste Gattung in De categoriis Aristotelis, als subiectum bei Martianus Capella. Anstatt sich zumindest in ontologischer Hinsicht für eine der beiden Auffassungen zu entscheiden, ist im Periphyseon ousia beides zugleich. Beeinflusst wurde diese Entscheidung Eriugenas sicher-

16: Ergo corpus universum iuxta Stoicos determinatum est et unum et totum et essentia.

${ }^{71}$ Fridugisus: De substantia nihili et tenebrarum, PL 105,751-756 und neu ediert: Fridugiso di Tours e il >de substantia nihili et tenebrarum<, edizione di Concettina Gennano, Padua 1963. Siehe zu dieser Diskussion bei Frigudisus auch Marcia L. Colish: Carolingian Debates over Nihil and Tenebrae-A Study in Theological Method, in: Speculum 59/4 (1984), p. 757-795. 
lich durch die Darstellung des Maximus Confessor, wonach die ousia vom Allgemeinsten ausgehend bis zum Individuellen hinab vervielfältigt wird. Mit der Frage indes, wie diese Vervielfältigung im Einzelnen geschieht, insbesondere auf der Ebene des Individuums, lässt er Eriugena alleine. Wenn wir im Periphyseon lesen, Gott sei essentia omnium, und dieses sowohl als allgemeines esse omnium als auch als subiectum omnium begreifen sollen, begegnet uns hier der ousia-Begriff als ein Hybrid aus der Dialektik des Maximus und der des lateinischen Westens.

Nicht ohne Grund hebt Eriugena die Differenz zwischen erster und zweiter Substanz auf, zwischen de subiecto im subiectum. Diese Aufhebung ist der erste Schritt, um die ousia als mächtigen ontologischen Grundbegriff zu etablieren, der sowohl die allgemeinste Gattung esse wie auch das subiectum umfasst.

Noch in seiner Frühschrift Annotationes in Marcianum bemüht er sich um eine Differenzierung zwischen essentia und substantia. Essentia wird dabei als höchste Gattung beschrieben, substantia als dasjenige, dem die Akzidenzien zukommen: »(Es heißt hier) substantia, nicht essentia, das bedeutet ipostasis, nicht ousia, weil ousia über allen Kategorien liegt und kein Akzidenz annimmt. Von dort aus steigt die essentia zur substantia herab, das bedeutet zur ipostasis, wo sie die Akzidenzien annimmt und den ersten Platz der Kategorien einnimmt. 42

Man sollte nun meinen, damit sei essentia bzw. ousia eindeutig als höchste Gattung bestimmt, doch ergibt sich für das Periphyseon ein anderes Bild. Beeinflusst durch die Darstellung des Maximus Confessor, umfasst die ousia das allgemeine Sein genauso wie das Subjekt des Einzelnen; die Differenz zwischen de subiecto und subiectum ist bereits gefallen: »N. Ist denn ousia in den allgemeinsten Gattungen und den allgemeineren Gattungen, gleichsam in ihren Gattungen und deren Arten, und wiederum in den speziellsten Arten, die atoma (das bedeutet unteilbar) heißen, allumfassend und eigentümlich enthalten? - A. Ich sehe nichts anderes, worin ousia natürlicherweise sein kann, wenn nicht in den Gattungen und Arten von der höchsten bis zur niedersten absteigend (...); so nämlich besteht in diesen natürlichen Teilen die allumfas-

\footnotetext{
${ }^{72}$ Annotationes in Marcianum, ed. Cora E. Lutz, Cambridge Mass., 1939, p. 86,7-11: Substantiam non essentiam, hoc est ipostasin non oủoí $\alpha$ quia oủoí $\alpha$ ultra omnes categorias est et nullum accidens recipit. Deinde descendit ad substantiam, hoc est ad ipostasin, tunc recipit accidentia et primum locum habet in categoriis.
} 
sende ousia. $4{ }^{73}$ Diese Darstellung ist eine Ontologie, die dem Baum des Porphyrios folgt. Entgegen anderen Vermutungen hat diese Ontologisierung des Baums weder durch Gregor von Nyssa noch durch Maximus Confessor stattgefunden ${ }^{74}$ Eriugena bedurfte nicht der Griechen für diese Vorlage. Schon bei Seneca und damit zeitlich vor Porphyrios findet sich eine derartige Hierarchie des Seienden ${ }^{75}$ Einen stoischen Ursprung für die Einteilung und Rückauflösung der Seienden mittels Gattung und Art legt überraschenderweise auch eine Aussage Eriugenas nahe, wonach Chrysipp der Urheber dieser analysis-Methode ist. ${ }^{76}$ Zudem trifft er in der Ambigua des Maximus, wenn auch ohne Angabe der Quelle, in diesem Zusammenhang auf das stoische Modell von diastolê und systolê (Ausdehnung und Zusammenziehung) des Kosmos.77

\subsection{Die Individuation der ousia}

Wie sich die allgemeine Form, etwa die Form >Mensch ist eine viel diskutierte Frage in der Spätantike. Darin spielt die aristotelische Unterscheidung von Substanz und Akzidenz eine entscheidende Rolle. Boethius' Darstellung etwa, die eine gewaltige Einwirkung auf das Mittelalter hatte, erklärt sich die Individuation wie folgt: Grundlage aller numerischen Unterscheidbarkeit sind die Akzidenzien. Die Individuation erfolgt also aufgrund von diesen. Die Akzidenzien aber können keiner Form als solcher anhaften, sondern nur einer Form, die sich mit Materie verbindet. Diese Art von Form ist nicht die Form schlechthin, sondern ein Abbild, ein imago von dieser ${ }^{78}$ Diese

\footnotetext{
${ }^{73}$ I, 1295-1305: N. Num OYCIA in generibus generalissimis et in generibus generalioribus, in ipsis quoque generibus eorumque speciebus, atque iterum specialissimis speciebus, quae atoma (id est individua) dicuntur, universaliter proprieque continetur? - A. Nil aliud esse video, in quo naturaliter inesse OYCIA possit, nisi in generibus et speciebus a summo usque deorsum descendentibus (...); in his enim veluti naturalibus partibus universalis OYCIA subsistit.

${ }^{74}$ Siehe zu Gregor als möglicher Innovator PG 44,145A9-D2 und Hubertus R. Drobner: Gregory of Nyssa as Philosopher: De anima et resurrectione and De hominis opificio, in: Dionysius 18 (2000), p. 69-101.

${ }^{75}$ Epistola 58, 8-11.

${ }^{76}$ Annotationes ad marcianum, ed. Lutz, p. 93, 2-9.

${ }^{77}$ Ambigua ad Iohannem, MPG 91,1177B-D.

${ }^{78}$ Boethius: Quomodo trinitas unus deus ac non tres dii, I und II (Ausgabe Michael Elsässer: A. M.S. Boethius - Die theologischen Traktate, S. 6-10).
} 
Darstellung kannte Eriugena nicht, und er behilft sich so gut es geht mit dem, was er aus Boethius' Arithmetik darüber erfährt sowie in seinen griechischen Quellen.

Insbesondere die sonst so reiche Quelle Maximus Confessor schweigt dazu, wie die Differenz in die zu vervielfältigende ousia gelangt. Dass die Differenz zugegen sein muss, so die Substanzen mehrere und unterscheidbar sein sollen, ist auch Eriugena klar, und so sagt er: »(...) denn die OYCIA eines jeden, obwohl sie als aus der essentia und der essentiellen Differenz zusammengesetzt gedacht wird - denn diese Zusammensetzung kann keiner unkörperlichen essentia fehlen, weil ja auch die göttliche OYCIA selbst, die nicht allein einfach, sondern mehr als einfach gedacht wird, eine wesenhafte Differenz empfängt: sie ist nämlich ungeboren, geboren, hervortretend - über sie also ist trotz dieser Zusammensetzung, die allein mit dem Verstand erkannt wird und in keinem Tun oder Handeln nachgewiesen wird, vernünftigerweise zu urteilen, dass die eine Einfachheit ist. 479

Wenngleich er damit der ousia, so sie als eine unter vielen aufgefasst wird, eigentümliche Differenzen einräumt, will er an ihrer Einfachheit festhalten. Die von Boethius präsentierte Lösung, wonach die Differenzen aufgrund der Akzidenzien an einer abgebildeten Form auftreten, ohne die Form als solche in ihrer Einfachheit zu zerstören, ist hier sicherlich eleganter. Doch Eriugena hat hier weder die dazu erforderliche Form/Materie-Unterscheidung zur Hand, noch die wohl neuplatonische Doktrin, wonach es zwei Arten von Form gibt, eine an sich und eine abgebildete. Und so fehlt im Periphyseon eine klare Antwort auf die Frage, wie die Differenz in die ousia gelangt.

Über allem steht die Einfachheit der ousia, die sie trotz aller Vervielfältigung beibehalten soll: »Die OYCIA aber, obgleich sie allein mit dem Urteilsvermögen in ihre Gattungen und Arten und Zahlen eingeteilt wird, behält trotzdem ihre Unteilbarkeit durch ihr natürliches Vermö-

\footnotetext{
${ }^{79}$ I, 2030-2032: (...) quia omnis OYCIA, quanquam intelligatur ex essentia et essentiali differentia composita esse - hac enim compositione nulla incorporea essentia potest carere, siquidem et ipsa divina OYCIA, quae non solum simplex sed plus quam simplex creditur esse, essentialem differentiam recipit: est enim ingenita, genita, procedens - ipsa tamen compositio, quae sola ratione cognoscitur nulloque actu et operatione fieri comprobatur, rationabiliter simplicitas esse iudicanda est.
} 
gen. « ${ }^{80}$ Und etwas später: »Es widerstrebt nicht der Wahrheit, wie ich meine, wenn wir sagen, dass aus der essentia selbst, die als eines und allgemeines in allem erschaffen ist und allem gemein und daher, weil sie allen teilhaftig ist, es auf keine Weise von den einzelnen Teilhabenden eigentümlich ausgesagt wird, gleichsam die eigentümliche substantia, die nur zu dem gehört, welchem sie eigen ist, im natürlichen Vorgang andauert; diesem ist so auch die eigentümliche Möglichkeit der substantia inne, welche von nirgendwo anders verliehen wird, als aus dem allgemeinen Vermögen der zuvorgenannten allgemeinen essentiae. 81

Hier klingt es so, als sei essentia als ein höchstes Prinzip dasjenige, woran die individuelle substantia teilhabe. Die Teilhabe ist in der Tat dasjenige, was in der neuplatonischen Lösung der Individuationsfrage eine Rolle spielt, doch außer diesem Schlagwort erhält Eriugena aus seinen Quellen wenig darüber. Und so bleibt es im Periphyseon bei einer vagen Beschreibung der Teilhabelehre.

Tendenziell zielt bei Eriugena essentia auf die Indifferenz hin, die substantia auf etwas Differenziertes. So sagt er etwa von der Dreiheit ousia, dynamis und ernergeia, sie verhalte sich »nicht wie substantia und deren Akzidenz, sondern wie eine gewisse essentielle (essentialis) Einheit und substanzielle (substantialis) Verschiedenheit dreier in einem.<82 Ähnliches findet sich auch später: »N. Sind Tun und Leiden in der Zahl der Akzidenzien beinhaltet? - A. Ja. - N. Irgendeiner Substanz also sind sie eigen. Sie fallen nämlich den eigentümlichen substantiis zu, während den allgemeinen essentiis nichts zufällt. ${ }^{83}$ Der Bezug der substantia auf das Individuelle hin findet sich schon bei Calcidius, allerdings ohne

${ }^{80}$ I, 2149-2152: At vero OYCIA, quamvis sola ratione in genera sua speciesque numerosque dividatur, sua tamen naturali virtute individua permanet.

${ }^{81}$ I, 2757-2765: Non enim veritati obstrepat, ut aestimo, si dicamus ex ipsa essentia, quae una et universalis in omnibus creata est omnibusque communis atque ideo, quia omnium se participantium est, nullius propria dicitur esse singulorum se participantium, quandam propriam substantiam, quae nullius alicuius est nisi ipsius solummodo cuius est, naturali progressione manare. Cui etiam substantiae propria possibilitas inest, quae aliunde non assumitur nisi ex ipsa universali virtute ipsius praedictae universalis essentiae.

${ }^{82}$ I, 2733-2734: (...) non ut substantia eiusque accidentia, sed quaedam essentialis unitas substantialisque differentia trium in uno.

${ }^{83}$ I, 2839-2842: Agere et pati accidentium numero continentur? - Etiam. - Cuiuspiam igitur substantiae sunt. Haec etenim propriis accidunt substantiis, nam generalibus essentiis nihil accidit. 
dass diese Differenzierung dort klarer wird: »denn die essentia ist gewiss die substantia von irgendeinem Gegenstand. 84

\subsubsection{Eriugenas Körperlehre}

Im ersten Buch macht Eriugena sich, wie dargelegt, an die Aufgabe, die Individuation zu erklären. Weil er dazu weder bei Dionysius Areopagita noch bei Maximus Confessor Konkretes findet, ist er auf das Wenige angewiesen, was ihm seine übrigen Quellen bieten. Dabei stützt er sich vor allem auf dasjenige, was er bei Gregor von Nyssa und in der vermeintlich augustinischen Schrift De categoriis Aristotelis findet. So gibt er an, der Körper, und damit das Individuum, entstehe Gregor von Nyssa zufolge aus einem Zusammenfall der unkörperlichen Akzidenzien: "Scheint dir denn nicht schon klar, dass nicht ohne Grund von uns gesagt wird, der Körper ist aus dem Zusammenfall der Akzidenzien gemacht, der Autorität des heiligen Gregor von Nyssa folgend, wenn du siehst, dass die anderen griechischen wie lateinischen Autoren zustimmen, der Körper sei aus den Unkörperlichen gemacht? «85

Mit dem Ausdruck latinos auctores meint er sicherlich die erwähnte Schrift De categoriis Aristotelis. Nach einem Zitat aus derselben fügt Eriugena an: »Und wenn daher auch der Körper, der nichts anderes ist als die Größe der ousia, und, um es genauer zu sagen, nicht Größe, sondern das Wiegroß, durch die Ausführung und Tätigkeit oder wenigstens Empfänglichkeit seiner Zerbrechlichkeit in unterschiedliche Teile getrennt würde, so behält sie für sich genommen (das heißt die ousia, deren Wiegroß der Körper ist) das Unsterbliche und Untrennbare ihrer eigentümlichen und natürlichen Kraft.<86

\footnotetext{
${ }^{84}$ Calcidii Commentarius (ed. Waszink), p. 320, 4-5: (...) nam essentia quidem alicuius rei substantia est (...).

${ }^{85}$ I, 2564-2568: Num iam tibi clare lucet non sine ratione nobis dictum esse ex accidentium concursu corpora fieri, auctoritatem sancti Gregorii Nysaei sequentes, cum videas alios sive graecos sive latinos auctores ex incorporalibus asserere corpora fieri?

${ }^{86}$ I, 2155-2160: Atque ideo etsi corpus, quod nihil aliud est quam OYCIAE quantitas et, ut verius dicam, non quantitas sed quantum, actu et operatione vel certe suae fragilitatis passione in diversas segregetur partes, ipsa per se (id est OYCIA, cuius est quantum corpus) immortalis inseparabilisque sua propria naturalique virtute perdurat.
} 
Die zitierte Schrift enthält dabei keine Aussage, wonach der Körper das Wiegroß der ousia ist. Doch sie enthält etwas Anderes, das Eriugenas Interesse weckte. Man könne, so heißt es dort, die oberste Gattung ousia nicht bestimmen. Ihre Fassbarkeit erhalte sie dadurch, indem sie sich in drei Dimensionen ausgedehnt präsentiere 87 Für Eriugena ist dabei klar, dass es sich bei dem Ausgedehnten um den Körper handeln muss. Demnach ist der Körper die quantitative Manifestation der ousia. Die Differenz zwischen einem natürlichen und einem geometrischen Körper liegt nach Eriugena im Anschluss an dieses vermeintliche Augustinus-Zitat gerade darin, dass dem natürlichen eine ousia zugrunde liege, dem geometrischen hingegen nicht 88

Weil Gregor von Nyssa zudem Qualitäten anführt, ohne die ein Körper nicht sein kann, wie etwa `Gestalt` oder `Schwere`, erweitert Eriugena den zusammengesetzten Körper um das Akzidenz qualitas: »Denn diese drei werden in allen natürlichen Körpern aufgefunden: ousia, Größe, Beschaffenheit. \&89

Und so sagt er schließlich zu Gregor von Nyssas Darstellung: »Siehst du denn daher, dass diese größte und stärkste Begründung des zuvor genannten Meisters zureichend ist? Wenn nämlich der Körper anderes wäre als der Zusammenfall der Akzidenzien der ousia, würde er bei Abzug derselben in sich durch sich selbst bestehen bleiben. So wie allem Zugrundeliegenden der Akzidenzien für sich bestehend nicht ermangelt, dass es ist, wie die ousia: ihr nämlich kommen sie [die Akzidenzien] zu oder kommen ihr nicht $\mathrm{zu}$, in ihr sind die, welche ohne sie nicht sein können, von ihr trennen sich die, welche von ihr getrennt werden können allein im Nachdenken oder Ausführen oder Tun, während sie [die ousia] in ihrem natürlichen Rückhalt immer und unveränderlich besteht. 490

${ }^{87}$ Paraphrasis Themistiana, ed. in Aristoteles latinus, Minio-Paluello, I, 1-5, p. 149, 4-17.

${ }^{88}$ I, 2193-2210.

${ }^{89}$ I,2277-2278: Haec etenim tria in omnibus naturalibus inspiciuntur corporibus: OYCIA, quantitas, qualitas.

${ }^{90}$ I, 2604-2612: Num itaque vides maximum fortissimumque praedicti magistri argumentum sufficere? Si enim aliud esset corpus praeter accidentium OYCIAE concursum, subtractis eisdem in se ipso per se ipsum subsisteret. Siquidem omne subiectum per se subsistens accidentium non indiget ut sit, sicut ipsa OYCIA: sive enim accidant ei sive non accidant, sive in ea sint quae sine ea esse non possunt, sive ab ea recedant quae ab ea segregari possunt seu sola cogitatione seu actu et opere suis naturalibus subsidiis semper immutabiliterque subsistit. 
Auffälligerweise ist bei Gregor in diesem Zusammenhang weder von symbebêkos (also dem Akzidenz) noch von ousia die Rede. Das Wort ousia trägt Eriugena vielmehr erst durch seine Lesart hinein. Dies ist ein anschauliches Beispiel dafür, wie er in seinen griechischen Quellen nach dem ousia-Begriff aus der Kategorienschrift sucht.

Es wurde schon darauf hingewiesen, dass Eriugena seine Wirklichkeitslehre aus dem Begriffsarsenal der aristotelischen Kategorienschrift aufbaut. Qualitäten und Eigenschaften fasst er als Akzidenzien, welche nur an einem Zugrundeliegenden, der ousia, bestehen. Von solch einem Träger oder Fundament der Akzidenzien spricht Gregor von Nyssa bei seiner Körperlehre nicht, doch liest Eriugena die Qualität >Farbe`, griechisch chrôma, als `Gegenstand`, griechisch chrêma, wodurch er annimmt, Gregor spreche von einem Dinghaften, das der Körper zu seinem Dasein bedürfe ${ }^{91}$ Dieses chrêma, von ihm als res übersetzt, erläutert er in Klammern mit »dies ist ousia« (id est ousia) ${ }^{92}$ Damit hat er die gesuchte Substanz alles Körperlichen auch in einer griechischen Quelle ausgemacht.

Ungeklärt bleibt dabei, von welcher Beschaffenheit die ousia ist, die allem Körperlichen zugrunde liegt: Ist es eine allgemeine, an welcher der Körper teilhat, oder ist es eine Vielzahl bereits individuierter? Aus theologischer Perspektive würde Eriugena sicherlich antworten, es sei die eine unteilbare göttliche ousia, an der alles teilhabe. Aber da er bereits von der ousia im Plural gesprochen hat, bevor er das Akzidenz quantitas nennt, bleibt die Sache unklar. Hier fehlt ein Differenzierung, wie sie etwa Boethius vorlegt: bei diesem ist es die abbildhafte Form, die durch die Akzidenzien individuiert wird; die Form als solche bleibt davon unberührt. Bei Eriugena gibt es keine Substanzen, welche das göttliche Sein abbilden. Vielmehr soll dieses göttliche Sein selbst das-

${ }^{91}$ I, 2593: Ut enim non est corpus cui res (id est OYCIA) et figura (...) non adsunt. Sowohl die griech. Ausgabe im Migne (PG 44, 213B), die lat. Übersetzung des Dionysius Exiguus (PL 67,388D), als auch die griech. Edition von Forbes (p. 251), geben die Lesart chrôma, color, Farbe an. Sie ist im Sinnzusammenhang des Textes schlüssiger und daher wahrscheinlicher. Man könnte noch annehmen, chrôma bezeichne nicht die Farbe als Qualität, sondern als Pigment, wie es bei Plato in Lysis $217 \mathrm{~b}-\mathrm{e}$ auftritt, aber das Pigment, falls Eriugena daran dachte, als ousia aufzufassen, ist dennoch weit hergeholt. Siehe zu Plato Gerold Prauss: Ding und Eigenschaft bei Plato und Aristoteles, in Kant-Studien 59 (1968), S. 98-117.

${ }^{92} \mathrm{I}, 2593$. 
jenige sein, das allem Seienden zugrunde liegt. Es zeigt sich, wie diese Zusammenziehung der ousia ein schwerwiegendes ontologisches Probleme mit sich bringt: das der Individuation.

Wenn man die Gleichsetzung von esse omnium mit den substantiae der Geschöpfe aus dem Anfang des Periphyseon ernstnimmt, so ist das Sein Gottes als ousia Ursache der Körperkonstitution (causa constitutionis corporis, I, 2315-2316), und zwar indem es subiectum der Akzidenzien ist (I, 2263-2264). Diese doch gewaltige Behauptung folgt, sobald man mit Eriugena die Differenz zwischen der allgemeinsten Gattung esse, die de subiecto ausgesagt wird, und dem subiectum aufhebt. Der Gedanke, Gott schaffe nicht nur die Geschöpfe, sondern erhalte sie auch, ist dabei keinewegs neu. So heißt es etwa bei Augustinus, es sei die Liebe Gottes, welche das Geschöpf erhalte: »Aus zwei Gründen liebt Gott sein Geschöpf: damit es ist und damit es erhalten bleibt. $\left\langle{ }^{93}\right.$ Mag man auch die ousia des Periphyseon als den amor dei Augustins interpretieren wollen, die Aussage, Gott sei Substanz aller Geschöpfe findet sich bei diesem nicht. Schließlich ist es auch eine griechische Quelle, auf die Eriugena im Zuge seiner Zusammenziehung der ousia verweist, nämlich auf Maximus Confessor 94

\subsubsection{Eriugenas Seelenlehre}

Der Auffassung über die ousia aus dem ersten Buch, wonach Gott Substanz aller Dinge ist, folgt die Seelenlehre aus dem zweiten Buch, und mit einem Mal scheint es den erkennenden Geschöpfen vorbehalten zu sein, eine göttliche Substanz zu besitzen. Es sei nämlich ousia dasjenige, was in uns Menschen das Göttliche abbildet:

»N. Glaubst du etwa, dass Gott selbst, der nach seinem Bilde unsere Natur schuf, Körper sei oder Geist? - A. Darin auch nur zu zögern ist lächerlich. Gott nämlich ist Geist, und die ihn verehren, verehren ihn als Geist und Wahrheit. - N. Nicht also dem Körper nach, sondern der Seele nach ist in unserer Natur das Bild Gottes eingedrückt.<55

\footnotetext{
${ }^{93}$ De genesi ad litteram, I, 34 (PL 34, 251): Duo quippe sunt propter quae amat Deus creaturam suam: ut sit et ut maneat.

94 I, 61-64; zudem I, 1245-1249; beide Stellen wurden ausführlich besprochen.

${ }^{95}$ II, (2923-2931): N. Putasne ipsum deum, qui ad imaginem suam nostram creavit naturam, corpus esse an spiritum? - A. Hinc quoque haesitare ridiculum est. Deus
} 
Aus diesem Grund sieht er sich berechtigt, den menschlichen Intellekt mit der Substanz gleichzusetzen: »Denn nous und ousia (dies ist intellectus und essentia) bezeichnen den höchsten Teil unserer Natur. Die essentia unserer Seele ist der intellectus, welche der Gesamtheit der menschlichen Natur voransteht. $\sqrt{96}$ Dies wirft unweigerlich die Frage auf, ob den unbelebten, geistlosen Körpern keine ousia zukomme.

Die Behauptung aus dem ersten Buch vorausgesetzt, wonach der Körper das Quantum der ousia ist, muss man fragen, von welcher ousia dies gilt, von jener, die mit dem Intellekt gleichzusetzen ist oder von einer anderen? Vielleicht meint Eriugena lediglich, dass sich die ousia im Falle des Menschen mit dessen Intellekt gleichsetzen lasse. Aber von welcher ousia ist dann der menschliche Körper das Quantum, etwa vom Intellekt? Oder hat der Mensch, insofern er geistbegabt ist, eine doppelte Substanz, eine, die seinem Intellekt entspricht und eine, die seinen Körper konstituiert? Insofern beide Lehren, die Körperlehre aus dem ersten Buch und die Seelenlehre aus dem zweiten, unvermittelt nebeneinander stehen, liefert der Text auf diese Frage keine Antwort. Eriugena sah diese Schwierigkeit offensichtlich nicht.

Was im zweiten Buch in Eriugenas Substanzlehre unvermittelt einbricht, ist einer Darstellung des Dionysius Areopagita geschuldet, wonach das Erkennen einer Sache dessen Sein ausmacht: »Der Geist von allem nämlich ist essentia von allem. Denn Gott erkannte nicht alles, nachdem es gemacht war, sondern bevor es war, erkannte er alles, was gemacht wurde. Und dies ist das Sonderbare, weswegen alles ist: weil es vorerkannt ist. Nichts anderes nämlich ist essentia von allem, wenn nicht die Erkenntnis von allem in der göttlichen Weisheit. In ihm nämlich leben wir, werden wir bewegt und sind wir. Denn das Erkennen der Seienden, so sagt es der heilige Dionysius, ist das Seiende. $<97$

enim spiritus est, et qui adorant eum in spiritu et veritate adorant. - N. Non ergo secumdum corpus sed secundum animam imago dei nostrae naturae impressa est.

${ }^{96}$ II, (3127-3129/3150-3153/3155-3156, der von $\mathrm{R} i^{2}$ eingefügte Text wurde ausgelassen): Nam NYC et OYCIA (hoc est intellectus et essentia) excelsissimam nostrae naturae partem significant. Essentia (itaque) animae nostrae est intellectus, que universitati humanae naturae praesidet (...).

${ }^{97}$ II, (2378-2400): Intellectus enim omnium essentia omnium est: Non enim deus cognovit omnia postquam facta sunt, sed antequam facta essent cognovit omnia quae facienda erant. Et quod est mirabilius, propterea omnia sunt, quia praecognita sunt. Nil enim est aliud omnium essentia, nisi omnium in divina sapientia cognitio. In 
Nun ist es aus ontologischer Sicht relativ harmlos, wenn Dionysius das Sein der Dinge auf das Erkennen Gottes zurückführt. Diese Überlegung wird im Neuplatonismus ausführlich diskutiert. Doch Eriugena bricht sie auf die Trinitätslehre herunter, wie er sie vor allem von Augustinus erhält. Als Synthese aus beidem entsteht die Behauptung, der menschliche Intellekt sei mit der menschlichen Substanz identisch. Als solche ist diese Darstellung sicherlich der Diskussion wert, doch im Hinblick auf das erste Buch stellt sie einen nicht zu verbindenden Bruch mit dem Vorangehenden dar.

\subsubsection{Der Ausdruck vere esse und die Rolle der Theophanie}

Im Zusammenhang mit der Aussage, Gott sei das Sein von allem, folgte die Begründung, derjenige, der wahrhaft ist, sei die essentia von allem ${ }^{98}$ Hinter dem Ausdruck vere esse verbirgt sich dabei eine Seinsform, die unendlich ist und so mit derjenigen der endlichen Geschöpfe kontrastiert. Dies wird sich im Folgenden zeigen. Dabei wird zugleich klar, inwiefern sich die geschöpfliche essentia von der göttlichen unterscheiden soll: Sie ist keine andere Substanz, sondern ist göttliche Substanz, die begrenzt von Raum und Zeit in Erscheinung tritt.

Möglicherweise geht Eriugenas vere esse auf das griechische ontôs on zurück, das bei Dionysius Areopagita vermehrt auftritt ${ }^{99}$ Schon Marius Victorinus verwendet den Ausdruck ontôs im Zusammenhang mit dem göttlichen Sein, wohl in sprachlicher Anlehnung an Platon (Timaios 28a, Sophistes 240b) sowie Plotin (Enneaden III, 6, 11), und übersetzt ihn als vere ${ }^{100}$ Dem vere esse ist dabei das >bloß-zu-sein ‘ gegenübergestellt (tantum esse). 101

Eine derartige Gegenüberstellung findet sich auch im Periphyseon. Erinnern wir uns an Eriugenas Aussage, wonach die ousia des Einzelnen stets an einem Ort und zu einer Zeit ist. Sie ist also nicht schlechthin, sondern begrenzt: "Niemand kann bestimmen und sagen, was ousia an sich ist. Durch die aber, die ihr unabtrennbar anhaften und ohne die sie

ipso enim vivimus et movemur et sumus. Cognitio enim, ut ait sanctus Dionysius, eorum quae sunt ea quae sunt est.

${ }^{98} \mathrm{I}, 59-60$.

${ }^{99}$ Etwa De divinis nominibus 4, ed. Suchla p. 182, 17.

${ }^{100}$ Ad Candidum 6-8 (SC 68, p. 138-142).

${ }^{101}$ Ebenda, 7, 14. 


\section{Die Grundlagen der negativen Ontologie}

nicht sein kann, durch Ort sage ich und Zeit - denn alle ousia ist, aus dem Nichts erschaffen, ortsgebunden und zeitlich, ortsgebunden weil sie auf eine Weise ist, insofern sie nicht unendlich ist, zeitlich aber, weil sie das anfängt zu sein, was sie zuvor nicht war - kann allein bestimmt werden, dass sie ist. Was ousia ist, lässt sich also auf keine Weise angeben, sondern nur, dass sie ist. ${ }^{102}$ Die gedankliche Vorlage dafür findet sich einmal mehr bei Maximus Confessor 103

Im Kontrast zu dieser stets beschränkten Seinsform der geschöpflichen ousia kennzeichnet das vere esse, an dem das Geschöpf durch die Theophanie teilhaben wird, die Unbeschränktheit. Der von Eriugena zu Beginn des Periphyseon diskutierte Begriff >Theophanie< bezeichnet nach theologischer Definition den >Einbruch Gottes in die Welt< und ist der Epiphanie verwandt ${ }^{104}$ Eine für die christliche Theologie wichtige Abhandlung über Theophanie ist Gregor von Nazianz' Rede zu derselben ${ }^{105}$ Bei Maximus Confessor, der in seiner Ambigua auch Stellen aus dieser Rede erläutert, fällt der Begriff >Theophanie` nicht. Eriugena erhält ihn von Dionysius Areopagita, wenngleich er sich hinsichtlich der Frage, was Theophanie ist, ausdrücklich auf Maximus beruft 106

Über das vere esse heißt es im Zusammenhang mit der Theophanie im dritten Buch: »Wenn nämlich das Denken von allem all dieses Gedachte ist und diese (Bewegung) allein alles denkt, dann ist sie allein all diese Dinge, denn sie allein ist das Erkenntnisvermögen, das alle Dinge kennt, noch bevor sie sind. Und nicht außerhalb ihrer selbst kennt sie alle Dinge, weil außerhalb von ihr nichts ist, sondern nur in ihr. Sie umläuft alles und nichts ist in ihr, insofern es wahrhaft ist, was nicht sie selbst ist, weil sie allein wahrhaft ist. Denn die übrigen Dinge, von

\footnotetext{
102I, 1911-1918: OYCIAN per se ipsam diffinere et dicere quid sit nemo potest. Ex his autem quae inseparabiliter ei adhaerent et sine quibus esse non potest, ex loco dico et tempore - omnis enim OYCIA de nihilo creata localis temporalisque est, localis quidem quia aliquo modo est quoniam infinita non est, temporalis vero quoniam inchoat esse quod non erat - solummodo diffiniri potest quia est. OYCIA itaque nullo modo diffinitur quid est, sed diffinitur quia est.

${ }^{103}$ MPG 91, 1180D-1181A und 1181A-B.

${ }^{104}$ Siehe Lexikon für Theologie und Kirche Bd. 10, S. 85, wonach `Theophanie « nicht mit >Offenbarung gleichzusetzen ist.

${ }^{105}$ Oratio 38, Sources Chrétiennes 358.

${ }^{106}$ Zur dionysischen Vorlage siehe De caelesti hierarchia IV,3; zu Eriugenas Verweis auf Maximus siehe Periphyseon I, 294-347. Er bezieht sich dabei offensichtlich auf folgenden Abschnitt der Ambigua: MPG 91,1068D-1088D.
} 
denen man sagt, dass sie sind, sind ihre Theophanien, die ebenso wahrhaft in ihr selbst bestehen. Gott ist daher alles, was wahrhaft ist, weil er alles hervorbringt und in allem wird. $<107$

Dasjenige also, das nicht wahrhaft ist, sondern nur >seiend < genannt wird, ist die Theophanie des göttlichen Intellekts. Diese Sichtbarwerdung geschieht in Raum und Zeit. Diejenigen, die in der Schöpfung die Theophanie erblicken, also die Sichtbarwerdung Gottes, kehren zu Gott und damit zum unendlichen Sein zurück: »Denn allein Gott erscheint in ihnen, wenn sie die Begrenzungen ihrer Natur übersteigen, nicht, dass in ihnen die Natur vergeht, sondern dass in ihnen nur der erscheint, der allein wahrhaft ist. $<08$ Dies geschehe am Ende der Welt, wenn die Frommen vergöttlicht werden:

»(...) und nichts anderes wird das Ende dieser Welt sein, als dass alle, die den Ruhm der theosis (das heißt der Vergöttlichung) empfangen haben, über Ort und Zeit hinaussteigen. Denn die von Ort und Zeit Eingegrenzten sind endlich; die ewige Schönheit aber ist unendlich; die an der ewigen und unendlichen Schönheit Teilhabenden sind weder vom Ort umgrenzt noch von der Zeit.< 109

Was demzufolge nur noch in dem besteht, das wahrhaft ist, hat das zeitlich und örtlich begrenzte Sein hinter sich gelassen; es geht ein in die göttliche Unendlichkeit: »Allen freilich, die zur Ewigkeit ihrer Ide-

107 III, 577-588: Si enim intellectus omnium est omnia et ipsa sola intelligit omnia, ipsa igitur sola est omnia, quoniam sola gnostica virtus est ipsa quae, priusquam essent omnia, cognovit omnia. Et extra se non cognovit omnia, quia extra eam nihil est, sed intra se. Ambit enim omnia et nihil intra se est, in quantum vere est, nisi ipsa, quia sola vere est. Caetera enim, quae dicuntur esse, ipsius theophaniae sunt, quae etiam in ipsa vere subsistunt. Deus est itaque omne quod vere est, quoniam ipse facit omnia, et fit in omnibus.

Sheldon-Williams übersetzt intellectus als Tätigkeit, >understanding (hier auf deutsch >Denken $>$ ), was in Bezug auf die genannte Bewegung und die nachfolgenden Aussagen die sinnvollere Lesart ist, als `Geist`, englisch >intellect ‘ (Periphyseon Book III, p. 58).

${ }^{108} \mathrm{I}, 1739-1741$ : Solus nanque deus in ipsis apparebit quando terminos suae naturae transcendent, non ut in eis natura pereat, sed ut in eis solus appareat qui solus vere est.

${ }^{109}$ I, 1723-1728: (...) nec alium huius mundi finem fore quam ut omnes qui gloriam theoseos (id est deificationis) accepturi sunt ultra loca et tempora ascendant. Nam qui loco et tempore coartantur finiti sunt; aeterna autem beatitudo infinita est; aeternae igitur beatitudinis atque infinitae participes neque loco circumscribentur neque tempore. 
en, die weder einen zeitlichen Anfang durch das Entstehen in Ort und Zeit noch ein Ende durch die Auflösung haben, noch durch eine örtliche Lage bestimmt werden, auf solche Weise zurückgekehrt sind, dass sie nur in diesen Ideen und nichts anderes sind, fehlt dann jegliches örtliche und zeitliche Ende. $\ll{ }^{110}$ Wenn somit Gott derjenige ist, der allein wahrhaft ist (qui solus vere est, I, 60), ist dieses Sein wohl als ein unendliches aufzufassen.

Damit ist zugleich die essentia omnium, die mit jenem wahrhaft Seienden identisch sein soll, als eine grenzenlose und gänzlich unspezifische essentia bestimmt. Sie ist nicht die des Einzelnen, an Ort und Zeit gebundenen, sondern ist jene vorrangige Ursache, jenes erste Sein, in das alles übrige Seiende, die Grenzen von Ort und Zeit hinter sich lassend, am Ende der Welt übergeht.

\subsubsection{Verborgenes im Geschöpf}

Bislang wurde behauptet, der Gedanke, Gott sei die unbegreifliche essentia bzw. substantia aller Geschöpfe, sei eine Innovation Eriugenas, die er bei Maximus Confessor vorgefunden zu haben glaubt. Gegen die Erstmaligkeit dieses Gedankens lassen sich zwei Einwände vorbringen, von denen einer auf die Kirchenväter verweist, der andere auf die antike Naturphilosophie.

So ist die Unbegreiflichkeit des menschlichen Geistes bereits in Eriugenas Quellen bezeugt, etwa bei Gregor von Nyssa: ")Wer hat den Geist des Herrn erkannt? ‘, ruft der Apostel. Und ich füge diesem hinzu: >Wer hat den eigenen Geist erkannt? ₹rage jene, welche sagen, dass sie die Natur Gottes in sich hervorbringen können durch ein sich-selbstErfassen, ob sie sich selbst verstanden haben? Ob sie die Natur des eigenen Geistes erkannt haben? «111 Und nach einer kurzen Abhandlung über die Unbegreiflichkeit des menschlichen Geistes erläutert er: »Weil

${ }^{110} \mathrm{I}, 1732-1737$ : Omnes siquidem, qui ad aeternas suas rationes quae neque initium temporis per generationem in loco temporeve neque finem per resolutionem habent neque ulla locali positione circumscribuntur reversuri sunt ut solae in eis et nil aliud sint, profecto omni locali temporalique termino carebunt.

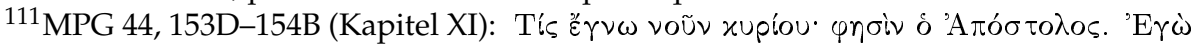

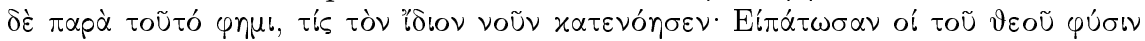

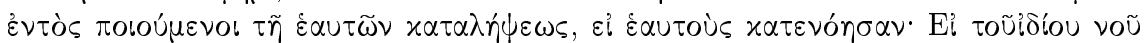

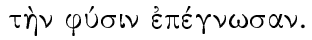


ja dem Erkennen unsere eigene geistige Natur entflieht, die nach dem Ebenbild des Schöpfers ist, eine genaue Ähnlichkeit mit dem Darüberliegenden besitzend, zeigt sich in der Unkenntnis dessen, was dieses (Darüberliegende) an sich ist, die Ausprägung der unbegreiflichen Natur (in der unsrigen). $\ll 112$ Doch wenngleich Eriugena im zweiten Buch die essentia des Menschen mit dessen Geist gleichsetzt, sagt er im ersten Buch immer wieder, die essentia eines jeden Geschöpfes sei unbegreiflich. Der Umfang dessen, was unbegreiflich ist, ist daher um ein Vielfaches größer als bei Gregor.

Hingegen findet sich in Augustins De genesi ad litteram eine Aussage, die sich dahingehend interpretieren lassen kann: »(...) aus verborgenen und unsichtbaren Gründen, die in dem Geschöpf ursächlich versteckt sind, ist das bereits Geschaffene in offenkundigen Gestalten und Naturen hervorgetreten. $<13$ Erinnern wir uns, wie Eriugena in I, 58/59 essentia mit ratio gleichsetzt und als etwas Ursächliches auffasst. Hat er dabei an diese Aussage Augustins gedacht? Wohl nicht, denn warum sonst verweist er unermüdlich auf seine griechischen Quellen für diesen Gedanken? Woran Augustinus dabei dachte und ob er somit Eriugenas Gedanken vorwegnahm, ist eine andere Frage, deren Klärung auf den augustinischen Kontext eingehen müsste.

Daher zum zweiten möglichen Einwand. Zu Anfang des ersten Buches findet sich eine Bestimmung, wo die essentia des Geschöpfes und damit der Schöpfer verborgen liegt: in den »Tiefen der Natur« (naturae sinibus) ${ }^{114}$ Greift Eriugena hier einen Gedanken der Antike auf, wonach die Natur rätselhaft und voll Verborgenem ist? Bereits von Heraklit ist der Spruch überliefert »Die Natur liebt es, sich zu verhüllen «, der in der Antike Berühmheit erlangte ${ }^{115}$ Mag auch die Bedeutung dieser Worte seit jeher umstritten sein, sie stehen am Anfang einer Naturauf-

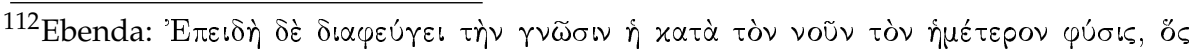

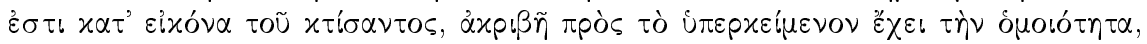

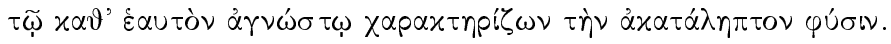

${ }^{113}$ De genesi ad litteram X, 17 (PL 34,346): ea jam facta (...) ex occultis atque invisibilibus rationibus, quae in creatura causaliter latent, in manifestas formas naturasque prodierunt.

${ }^{114} \mathrm{I}, 66$ \& 113.

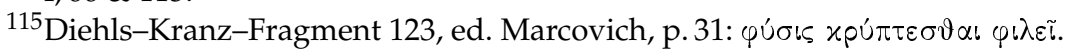


fassung, die bis in die Spätantike und sogar darüber hianus reicht ${ }^{116}$ Quellengeschichtliche Bedeutung erhält dies für das Periphyseon, da mit Macrobius ein Eriugena bekannter Autor dieses Verborgensein der Natur anspricht. So heißt es bei diesem: »Die Philosophen wissen, dass die Natur es nicht liebt, sich unverhüllt und nackt den Blicken auszusetzen: Ebenso wie sie die Kenntnis dessen, was sie ist, den stumpfen Sinnen der Menschen entzogen hat, indem sie sich unter den verschiedenartigen Einkleidungen und Umhüllungen der Dinge verbirgt. «117

Doch obwohl Eriugena den Schöpfer in den »verborgensten Tiefen des Geschöpfes « (I, 66-67: secretissimis sinibus creaturae) und den »verborgensten Tiefen der Natur « (I, 112: secretissimis naturae sinibus) verortet, ist ein entscheidender Unterschied zur Aussage des Macrobius auszumachen. Im Periphyseon ist es nicht die Natur, die sich verbirgt, sondern deren Schöpfer in ihr. Die göttliche essentia, jene vorrangige Ursache aller Geschöpfe, liegt in allem Geschaffenen verborgen. Zurecht identifiziert Jeauneau daher das Verborgene des Geschöpfes mit den causae primordiales: "C'est à cette nature, et donc aux causes primordiales, qu'il pense généralement quand il parle des seins caché de la nature. 418 Im Periphyseon verhüllt sich nicht, wie in der antiken Naturlehre, die Natur, sondern die essentia in den Naturen. Und sie ist verhüllt, weil sie göttlich ist.

${ }^{116}$ Siehe dazu Pierre Hadot: Le voile d'Isis - Essai sur l'histoire de l'idée de Nature, Paris 2004; zu Heraklit vor allem p. 25-52.

${ }^{117}$ Commentarius in Somnium Scipionis I, 2, 17: Sciunt inimicam esse naturae apertam nudamque expositionem sui, quae sicut vulgaribus hominum sensibus intellectum sui vario rerum tegmine operimentoque substraxit, ita a prudentibus arcana sua voluit per fabulosa tractari. Übersetzung nach Pierre Hadot: Zur Idee der Naturgeheimnisse, Mainz 1982, p. 18-21, wo darüberhinaus Einiges über Macrobius' Naturauffassung dargelegt ist. Zu Eriugenas Kenntnis dieser Schrift siehe Goulven Madec: Jean Scot et ses auteurs, Paris 1988, p. 44.

${ }^{118}$ Edouard Jeauneau: Quatre thémes érigéniens, Le caché et l'obscure, in: Etudes érigéniennes, Paris 1987, p.41, (»An diese Natur, und daher an die erstrangigen Ursachen, denkt er, wenn er von den verborgenen Tiefen der Natur spricht «). Problematisch ist nur, dass Eriugena auch von der substantia spricht, die in jedem Geschöpf verborgen ist, und diese zählt er nicht zu den vorrangigen Ursachen (zur Aufzählung der fünfzehn causae primordiales siehe etwa III, 133-195). Diese Unklarkeit löst sich nur auf, wenn, wie schon zuvor, das seinsspendende und das zugrunde liegende Wesen als dasselbe aufgefasst werden: eines heißt dann essentia, das andere substantia, und beides bezeichnet doch denselben Gegenstand. Und dies erklärt zugleich, warum in I, 62 zugleich von essentia und substantia die Rede ist. 


\subsubsection{Essentia und natura: zwei Synonyme?}

Im Zusammenhang mit der Frage, was Eriugena mit essentia bezeichnet, wurde in der Forschung die Ansicht geäußert, essentia sei gleichbedeutend mit natura. Dieser Umstand würde die in dieser Arbeit geäuBerte These kippen, wonach die essentia die Einung der viergliedrigen Natur bewirkt. Secundum essentia ist die Natur eine einzige göttliche, secundum contemplationem creationis eine viergliedrige. Dies wäre eine unpassende Darstellung, wenn essentia mit natura im Periphyseon bedeutungsgleich wäre ${ }^{119}$ Daher ist zu zeigen, inwiefern sich deutliche Unterschiede zwischen beiden Begriffsverwendungen ausmachen lassen. Eriugena spricht oft von sua natura (etwa I,1555-1556), aber nie von sua essentia. Wenn überhaupt, dann steht natura dem Begriff substantia nahe, aber nicht essentia. Zudem hat zwar alles Seiende an der göttlichen essentia teil, aber nie an der göttlichen natura. Gott, so heißt es oft, sei essentia omnium, aber dass er natura omnium sei, davon ist nie die Rede.

Natura kennzeichnet im Periphyseon meist die eigentümliche Natur von etwas. Hadot nennt einen solchen Gebrauch mit Blick auf die Antike einen relativen, im Gegensatz zum absoluten ${ }^{120}$ Zudem bezeichnet natura bei Eriugena im Anfang von Periphyseon I eine Gesamtheit. Auch diese Verwendung ist nicht mit der von essentia identisch.

\footnotetext{
${ }^{119}$ Siehe $\mathrm{zu}$ dieser Behauptung Marta Cristiani: NATURE-ESSENCE ET NATURELANGAGE, Notes sur 1'emploi du terme NATURA dans le PERIPHYSEON de Jean Erigène; in: Miscellanea Mediaevalea 13, 2 (1981), p. 707-717.

${ }^{120}$ Le voile d'Isis - Essai sur l'histoire de l'idée de Nature, Paris 2004, insbesondere p. 25-52; siehe zum Naturbegriff auch D. Bremer: Von der Physis zur Natur. Eine griechische Konzeption und ihr Schicksal, Zeitschrift für philosophische Forschung, 43 (1989), S. 241-264; und Historisches Wörterbuch der Philosophie, Band 6, Stuttgart-Basel 1984, S. 421-478.

Eine Darstellung zum Naturbegriff im Periphyseon findet sich bei Dominic O'Meara: The concept of Natura in John Scottus Eriugena, in: Vivarium XIX, Leiden 1981, reediert in ders.: The Structure of Being and the Search for the Good, Aldershot \& Brookfield 1998, p. 126-145. Dabei entwickelt er, ähnlich wie auch d'Onofri und Schrimpf, den Naturbegriff vor allem in Hinblick auf Boethius' Schrift Contra Eutychen, die Eriugena wohl nicht gekannt hat, wie die bisherige Untersuchung zeigte.

Siehe zu natura im Periphyseon als Prädikat etwa: I, 258-259: natura intellectualis; I, 374-375: tota illorum natura; ebenso, wenn auch ohne Genitiv: I, 84: naturarum creatarum; I, 118: humana natura; I, 432, 505, 935/936: divina natura.
} 
Zudem lässt Eriugena sowohl der essentia als auch den Akzidenzien eine natura zukommen und bezeichnet wohl damit deren An-sich-Sein:

»Denn alle Natur, sei es die der essentiae (essentiarum) oder die von deren Akzidenzien, ist unveränderlich. $\sqrt{121}$ Vor diesem Hintergrund ist eine Unterscheidung aus dem fünften Buch wenig sinnvoll, die natura als generatio essentiae bestimmt und sich als Gegenargument vorbringen ließe ${ }^{122}$ Dieses Verhältnis ergibt, wenn überhaupt, nur dann einen Sinn, wenn natura als Prädikat verwendet wird und essentia als dasjenige, wovon natura prädiziert wird. Damit ist eine Bedeutungsgleichheit ausgeschlossen. Im Übrigen spricht Einiges dafür, dass diese Bestimmung eine spätere Einfügung ist ${ }^{123}$

Und wenn es im ersten Buch heißt, »Und dadurch führen sie (die Eunomianer) aus, dass Vater und Sohn heterousias (das heißt verschiedene essentiae oder naturae) sind ", dann sind damit nur die beiden Weisen angegeben, auf welche die lateinischen Theologen die ousia der göttlichen Trinität übersetzen ${ }^{124}$ Eine generelle Ineinssetzung von essentia und natura ist dies nicht. Festzuhalten bleibt daher: Die wirkungsmächtige Schlüsselrolle, welche der essentia im Periphyseon zukommt, kann nicht auf die natura übertragen werden. Natura ist vielmehr dasjenige, was mittels der essentia überwunden und zur Einheit geführt wird.

Man könnte generell mit Blick auf das Bisherige verlangen, sich nicht länger hinter den Ausdrücken essentia und ousia zu verstecken und sie zwecks Präzisierung zu übersetzen. Aber wie soll man ousia und damit auch essentia im Periphyseon adäquat übersetzen, ohne nicht deren Bedeutungsvielfalt und Bestimmtheit aufzuheben? Das Patristische Grie-

${ }^{121} \mathrm{I}, 1454-1455$ : Omnis siquidem natura seu essentiarum seu eis accidentium immutabilis est (...). Siehe auch I, 1554-1557, wo natura als das An-sich (per se) der Kategorien aufgefasst wird.

${ }^{122}$ V, 275-281: Nam graeci $\Phi$ YCIN pro OYCIA, et OYCIAN pro $\Phi$ YCEI saepissime commutant. Horum siquidem nominum proprietas est OYCIAN (id est essentiam) de quod nec corrumpi nec augeri nec minui in omni creatura sive visibili sive intelligibili potest praedicari, $\Phi Y C I N$ vero (hoc est naturam) de generatione essentiae per loca et tempora in aliqua materia, quae et corrumpi et augeri et minui potest diversisque accidentibus affici.

${ }^{123}$ Siehe zum Editionsproblem von Buch V Abschnitt 1.3. Die Ähnlichkeit zwischen dieser etymologischen Anmerkung in Buch V und der nachweislich später eingefügten in II, (119-152) ist auffällig.

${ }^{124}$ I, 633-634: Ac per hoc conficerent patrem et filium ETEPOYCIAC (hoc est diversae essentiae seu naturae) esse. 
chischlexikon von G.W.H. Lampe widmet dem Wort ousia ganze fünf Seiten. An Bedeutungen unterscheidet es: being, reality, substance, essence, material ${ }^{125}$ Das Wörterbuch von Lidell-Scott gibt als erste Bestimmung von ousia an, sie beziehe sich auf das, »was etwas ist« ${ }^{126}$, das Griechisch-Deutsche Wörterbuch Pape bietet als erste und wörtlichste Übersetzung: das Seiende ${ }^{127}$ Christof Rapp sagt angesichts dieser Vielfalt treffend und resignierend: »Es meint etwa seigentlich Seiendes<, bleibt aber letztendlich unübersetzbar. 128

Letztendlich unübersetzbar ist wohl auch der Ausdruck essentia, wie ihn Eriugena im Periphyseon gebraucht. Soll man ihn mit >Wesen < übersetzen oder mit 'Seiendheit $<$ ? Wie soll das passen, wenn essentia als Ursache der Geschöpfe auftritt oder wenn von der Einheit der essentia in Gattung und Art die Rede ist? Eine Festlegung auf eine Übersetzung bringt hier sicher mehr Einspruch mit sich, als Klärung.

\subsubsection{Die sichtbare Welt als >Echor}

Angeregt durch die Arbeiten von Werner Beierwaltes wird immer wieder auf Eriugenas idealistische Postition hingewiesen, explizit vor allem von Dermot Moran $\sqrt{129}$ Seine Ausführungen können den Eindruck erwecken, als sei die vorliegende Untersuchung über die essentia von einer falschen Voraussetzung ausgegangen, nämlich von einer Interpretation der Aussage, Gott sei essentia aller Dinge, die der idealistischen Position Eriugenas gar nicht gerecht wird ${ }^{130}$ Man könnte mit Moran argumentieren, die Aussage, Gott sei essentia aller Dinge, müsse so verstanden werden, dass die Dinge gar keine Substanz besitzen, sondern nur die eine göttliche Substanz abbilden. Dann wäre die Frage, inwiefern Gott die Substanz des Einzelnen ausmachen kann und

\footnotetext{
${ }^{125}$ Ebenda, S. 980-985.

${ }^{126}$ Ebenda, Bd. II, 1274.

${ }^{127}$ Ebenda, Bd. II, 420; allein das Wörterbuch Menge-Güthling gibt auch die ursprüngliche und unphilosophische Bedeutung des Wortes an: Vermögen, Besitz, Eigentum, Habe (S. 507).

${ }^{128}$ Christof Rapp: Aristoteles - Zur Einführung, Hamburg 2001, S. 158.

${ }^{129}$ Dermot Moran: The Philosophy of John Scottus Eriugena, A study of Idealism in the Middle Ages, Cambridge 1989; ders.: Idealism in Medieval Philosophy: The Case of Johannes Scottus Eriugena, in: Medieval Philosophy and Theology 8 (1999), p. 53-82.
}

${ }^{130}$ Moran, 1999, p. 68-70. 
inwiefern diese Substanz unfassbar ist, obsolet: denn es gäbe die fragliche Substanz gar nicht, sondern nur ein Abbild, einen Widerhall davon. Moran führt in diesem Zusammenhang eine interessante Aussage aus dem fünften Buch an, die sich wie folgt übersetzen lässt:

»Allen freilich, die hinsichtlich der Orte und Zeiten verschieden sind und auf die körperlichen Sinne treffen, sind nicht selbst als substanzielle Dinge und wahrhaft Existierende zu denken, sondern als hinübergegangene Abbilder und Widerhall ihrer wahren Existenz. Ein Beispiel für diesen Gedanken liefert das Abbild der Stimme, welches die Griechen echô nennen, oder Körper und die Schatten desselben, die rein in der Luft geformt oder von den Wassern oder von irgendeiner Sache, von der sie widerhallen, widerhallen; welche sich sämtlich nicht als Dinge, sondern als falsche Abbilder der Dinge auffassen lassen. Daher: so wie die Abbilder der Stimmen und die Schatten der Körper an sich nicht bestehen, weil sie keine Substanzen sind, so sind jene sinnlichen Körper gleichsam Ähnlichkeiten der bestehenden Dinge und unvermögend, für sich zu bestehen. «131

Auf den ersten Blick ist diese Aussage höchst spannend; der Idealismus Eriugenas scheint zum Greifen nah. Doch nichts davon relativiert das Bisherige. Dass die in Ort und Zeit bestehenden Dinge lediglich ein >Echo< dessen darstellen, was allein seiend ist, greift zigmal zuvor Gesagtes noch einmal auf. Auch dass die Körper selbst keine substantiae sind, fand sich ausführlich im ersten Buch dargelegt und begründet. Sie sind eine Sichtbarwerdung der unsichtbaren und unbegrenzten ousia, ihr ausgedehntes Quantum. Das die sinnliche Welt damit als bloßes Abbild des wahrhaft Seienden besteht, wurde bereits im ersten Buch behauptet. Mitnichten negiert oder relativiert Eriugena hier seine bisherige Aussage, wonach jedem Geschöpf, und damit auch dem Körper,

${ }^{131} \mathrm{~V}, 2437-2450$ : Omnia siquidem quae locis temporibusque variantur corporeisque sensibus succumbunt, non ipsae res substantiales vereque existentes, sed ipsarum rerum vere existentium quaedam transitoriae imagines et resultationes intelligenda sunt. Cuius rationis exemplum est vox eiusque imago, quae a graecis IX $\Omega$ vocatur, seu corpora ipsorumque umbrae, quae sive in puro aere formatae sive de acquis sive de qualicumque res unde solent resultare resultant. Quae cuncta non res, sed falsae rerum imagines probantur esse. Itaque sicut imagines vocum umbraeque corporum per se non subsistunt, quia substantia non sunt, sic corpora ista sensibilia veluti rerum subsistentium quaedam similitudines sunt et per se subsistere nesciunt. »Imago vocis resultat « ist dabei ein Ausdruck, der auf Plinius zurückgeht. 
eine substantia zukommt. Ein Körper ohne eine solche, dies hatte sich gezeigt, ist etwa der geometrische.

Ein Körper ist zwar bloß Schatten, Abbild, Echo, aber dennoch liegt ihm eine Substanz zugrunde. Dabei interpretiert Eriugena das subsiste$r e$, zugrunde liegen, auf besondere Weise: Die Substanz des Körpers ist in gewisser Hinsicht seine eigene, so sie mit ihm von Ort und Zeit umgrenzt auftritt. Aufgrund der Unteilbarkeit aber der einen göttlichen Substanz, die der Vielheit der Dinge zugrunde liegt, gibt es aus ontologischer Sicht nur eine wahrhaftige Substanz. Insofern der Körper nicht als solcher besteht, sondern in und aufgrund der göttlichen Substanz, wird er zum Schatten des verborgenen wahrhaft Seienden. Weil allem Seienden, um das Argument aus dem ersten Buch noch einmal aufzugreifen, notwendig eine göttliche Substanz zugrunde liegt, die nicht identisch ist mit dem, wovon sie Substanz ist, vermag man in der Theophanie in allem Seienden Gott zu erblicken, das heißt die Anwesenheit seiner Substanz.

Ein Idealist wäre nun jemand, bei dem es nicht nur Intelligibles gibt, sondern der diesem auch einen höheren Grad an Sein zuschreibt, als den sinnlichen Dingen. Eriugena ist diese Position vertraut, wie die vierte Auslegungsweise von esse zu Beginn des Periphyseon zeigte. Doch er kann sich ihr nicht anschließen, weil er die erste Annahme des Idealisten ablehnt: die, das es Intelligibles gibt. Essentia ist kein geeigneter Kandidat für etwas Intelligibles, weil sie unbegreiflich ist, Intelligibles gerade nicht. Der menschliche intellectus selbst kann für Eriugena ebensowenig intelligibel sein, da er mit der essentia identisch ist, wie sich im zweiten Buch zeigte. Auch das Gute etwa und die Wahrheit und das Schöne sind für Eriugena erstrangige Ursachen (causae primordiales), und insofern sie dieses sind, unbegreiflich.

Was als Kanditat für Intelligibles bleibt, sind die Akzidenzien. Doch auch wenn sie in der Arithmetik des Boethius als Ideen auftreten, kommen sie für Eriugena nicht als Derartiges in Frage. Vielmehr hält er an den dialektischen Grundsatz fest, die Akzidenzien könnten an sich gar nicht bestehen. Noch schlimmer: Gattung und Art hat er zuvor im subiectum aufgelöst. Demnach bleibt im Periphyseon nichts, das als Idee fungieren könnte, nichts, worauf sich der Intellekt erkennend richten kann. Dinge wie das Einssein und die Vielheit, die Ähnlichkeit und die Gleichheit, platonische Kandidaten für das Intelligible, thematisiert 
Eriugena erst gar nicht. Die mögliche Erkenntnis von Geistigem ist somit auf die Theophanie zusammen geschrumpft: was der Geist zu erkennen im Stande ist, das ist die Tatsache, dass Gott in allem Seienden zugegen ist, als dessen Substanz.

Mag Eriugena daher die sinnliche Welt als ein Echo begreifen, sie ist kein Echo des Intelligiblen, sondern ein Echo des einen Schöpfers. Zwar sind auch die erstrangigen Ursachen als Schöpfendes zugegen, doch bestehen sie in Gott und sind ebenso unbegreiflich wie dieser selbst. Indem Eriugena die erstrangigen Ursachen unmittelbar bei Gott verortet, und damit auch die Substanz, gibt es zwischen der Körperwelt und Gott nichts Weiteres. Einem Reich der Ideen, einer Abstufung des Seienden, wie er es etwa bei Dionysius Areopagita noch vorfindet, räumt er im Periphyseon keinen Platz ein.

\subsection{In der Wegspur der Griechen}

Es hat sich gezeigt, dass Eriugena die Einteilung der Natur in eine Einheit zurückführt, da dem Sein nach alles in Gott besteht und Gott ist. Mit demselben Gedanken erläutert er die Aussage des Dionysius Areopagita, Gott sei nicht nur >schaffend « sondern auch >erschaffen ‘ zu nennen. Dessen Aussage, Gott sei das Sein von allem, konkretisiert er mit der Auffassung, Gott sei essentia bzw. substantia aller Geschöpfe. Auf solche Weise sei zudem der Schöpfer in jedem Geschöpf verborgen.

Damit ist klar, dass die substantia der Geschöpfe verborgen und unfassbar sein muss. Ansonsten wäre mit dem Erkennen der substantia auch Gott erkannt. So einmalig die Unbegreiflichkeit der Substanz aus der heutigen philosophiegeschichtlichen Übersicht auch ist, nach Eriugenas Ansicht bedeutet sie nur für den lateinischen Westen und die althergebrachte Dialektik eine Neuerung. Wer den vestigua graecorum folge, den Wegspuren der Theologen Gregor von Nazianz und Maximus Confessor, finde dort die Beweise, wonach die ousia in allem Seienden unbegreiflich sei: »Zudem, wenn Du, den Wegspuren des heiligen Theologen Gregor sowie dessen Erläuterung durch Maximus oftmals folgend, schärfer hinblickst, wirst Du finden, dass die ousia vollständig in allem Seienden an sich unbegreiflich ist, nicht nur für die Sinne, sondern auch für den Intellekt. «132

${ }^{132} \mathrm{I}, 1245-1249$ : Si autem acutius vestigia sancti Gregorii theologi expositorisque sui Ma- 
Dass bei beiden Theologen davon keine Rede ist, wurde gezeigt. Insofern ist Eriugenas Aufforderung, "schärfer" hinzublicken, nur bedingt zutreffend, da genaues Hinblicken und Auslegen, wie gezeigt, in unserem Fall keinen Ertrag brachte.

Diese beiden Denker seien es auch, so fährt er an selbiger Stelle fort, die angäben, was von der ousia überhaupt zu fassen ist, nämlich ihre räumliche Umgrenzung (also ihre Ausdehnung) sowie die zeitliche Grenze. Ein Geschöpf kann mittels der theosis beide Grenzen übersteigen und zum vere esse gelangen, das bei und in Gott angesiedelt ist. AuBerhalb von Gott ist das Geschöpf also nur insofern, als eine räumliche und zeitliche Grenze einnimmt. Seine Substanz ist ewiglich, weil göttlich. Dass Eriugena die essentia bzw. substantia nicht als Form und/oder Materie auffasst, zeigt sich schon daran, dass er sich gegen den möglichen Einwand wehrt, diese beiden könnten die essentia näher bestimmen ${ }^{133}$ Was als Kandidat zur Bestimmung der essentia in Frage kommt, kann nicht selbst das zu Bestimmende sein.

Eriugena meint aber noch mehr, nämlich, dass sich von einer konkreten Sache die essentia nicht angeben lasse, auch nicht, wenn man die Differenzen und die Form angebe, die der Sache zukommen. Dergleichen seien akzidenzielle Bestimmungen, aber keine substanziellen. Wenn man sich vergegenwärtigt, dass seiner Lehre zufolge das substanzielle Sein aller Dinge in Gott besteht, ergibt sich auf die Frage, was ein Mensch seiner Substanz nach sei, die eindeutige Antwort: Gott. Wer die Substanz des Menschen bestimmt, hat Gott bestimmt. So merkwürdig dies für uns klingt, lässt man alle sich ergebenden Schwierigkeiten außen vor, hat das von Eriugena Gesagte eine gewisse Systematik inne. Das Problem der Individuation bzw. der individuellen Substanz hat Eriugena damit sicher nicht gelöst, sondern eher noch verschärft. Den Zusammenhang zwischen essentia und der quid-sit-Frage freilich kennt Eriugena von Cassiodor und Isidor und nennt ihn in an einer Stelle explizit 134

ximi sapientissimi sequens inspexeris, invenies OYCIAN omnino in omnibus quae sunt per se ipsam incomprehensibilem non solum sensui sed etiam intellectui esse.

${ }^{133}$ I, 71-73; die Interpretationsschwierigkeiten, die sich an dieser Stelle ergeben, wurden ausführlich dargelegt, vgl. Abschnitt 2.4.1.

${ }^{134}$ I, 1757-1773. Zu Cassiodor siehe De artibus ac disciplinis Liberalium litterarum II, III, 14;

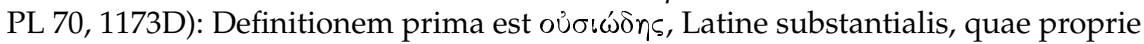
et vere dicitur definitio; ut est, Homo animal rationale mortale, sensus disciplinae- 
Als gewaltige Folge ergibt sich aus dem Gesagten, dass sich keine Definition finden lässt, die einen Gegenstand zureichend, d. h. im Hinblick auf die Substanz, bestimmt. Eine sehr pessimistische Postition, die Eriugena in einer Anmerkung zu einer Passage im vierten Buch gegen die klassische Dialektik verteidigt: »Und nicht fürchte ich jene, die den Menschen bestimmen, (und zwar) nicht hinsichtlich dessen, als was er gedacht wird, sondern aufgrund dessen, was über ihn gedacht wird, indem sie sagen: >Der Mensch ist ein vernünftiges Lebewesen, sterblich, der Sinneswahrnehmung und Wissenschaft fähig und, was verwunderlich ist, diese Bestimmung oysiadis nennen, obwohl sie nicht substanziell ist, sondern mit Bezug auf die Substanz, unter Zuhilfenahme dessen, was durch das Entstehen der Substanz außerhalb hinzukommt. Oysiadis nämlich ist allein und wahrhaft eine Bestimmung, die lediglich das Sein bejaht, und verneint, was etwas ist. 4135

Substanziell sei eine Definition dann, so sagt er hier, wenn sie nichts weiter vom Gegenstand affirmativ aussage als den Umstand, dass er sei. Alle anderen Prädikate seien in einer solchen Definition vom Gegenstand zu verneinen. Was demnach die Theologen im Hinblick auf Gott lehren, vertritt Eriugena im Hinblick auf jeden Gegenstand: man kann nur sagen, dass er ist, aber nicht, was er ist. Alle gängigen Bestimmungen geben demnach nur eine akzidenzielle (extrinsische oder intrinsische) Beschaffenheit an, nicht aber das Was. Knapp gesagt, Eriugenas Ontologie ist eine rein negative, mit allen Konsequenzen. Oder, aristotelisch gesprochen, wer das ti ên einai irgendeines Geschaffenen bestimmen könnte, hätte zugleich Gott bestimmt.

Kurt Flasch soll einmal die aristotelische Metaphysik als ein Steinbruch bezeichnet haben. Wenn diese Metapher passend ist, dann wäre die Konsequenz, dass Eriugenas negative Ontologie diesen Steinbruch

que capax; haec enim definitio per species et differentia descendens, venit ad proprium, et designat plenissime quit sit homo. Derselbe Wortlaut findet sich in Isidors Etymologiae II, XXIX, 2.

${ }^{135} \mathrm{IV}, 1076$, marg. von $\mathrm{R} i{ }^{1}$ (also Eriugena selbst): Nec vereor eos qui diffiniunt hominem non secundum quod intelligitur esse, sed ex his quae circa eum intelliguntur, dicentes: >Homo est animal rationale, mortale, sensus et disciplinae capax « et quod est mirabilius, hanc diffinitionem oysiadem vocant, dum non sit substantialis, sed circa substantiam, ex his quae per generationem substantiae accidunt extrinsecus assumpta. Sola etenim ac vera oysiades diffinitio est, quae affirmat esse, et negat quid esse. 
schlichtweg zu schließen gedenkt. Der Frage nachzugehen, was ousia ist, ist ihr zufolge unsinnig, weil sie der Frage nach der Substanz Gottes gleichkommt.

Die damit verbundene Verwerfung der lateinischen Dialektik ist wohl so ziemlich das Letzte, was man vermutet, wenn ein lateinischer Artes liberales-Lehrer als erster auf das Werk eines byzantinischen Theologen trifft. Und so sah man lange Zeit Eriugenas Hauptbedeutung darin, die neuplatonischen Gedanken des Dionysius Areopagita in den lateinischen Westen gebracht zu haben. Erst Jeauneaus Arbeiten deuteten darauf hin, dass Eriugena vor allem auf Maximus Confessor rekurriert, und die vorliegende Arbeit hat gezeigt, dass gerade die spannenden und innovativen Gedanken im Periphyseon in seiner Auseinandersetzung mit Maximus entwickelt wurden.

Damit einher geht eine Einschränkung, was eine mögliche Bedeutung des Periphyseon für die Philosophie betrifft. Ein Argument für die Unbestimmbarkeit der ousia besteht in der Aussage, Gott sei ousia aller Dinge und diese daher genauso unbegreifbar wie er selbst. Das könnte man das theologische Argument nennen, und es wurde hinreichend dargelegt und diskutiert. Ein weiteres Argument müsste sich mit der Frage auseinandersetzen, warum sich eine Bestimmung der ousia als logisch unmöglich erweist. Nur an zwei Stellen im Periphyseon sagt Eriugena zu dieser Frage etwas, und beides mal in sehr knapper Form und ohne weitere Begründung. Hätte er seine Überlegungen zur Unbestimmbarkeit aller Substanz weiter ausgeführt, mögliche Einwände diskutiert und Gegenargumente ins Spiel gebracht, kurz, hätte er so verfahren, wie es ihn die Dialektik lehrte, käme keine metaphysische Diskussion am Periphyseon vorbei. So aber bleibt das Werk auf halber Strecke stehen und liefert wenig Argumente für eine derartige Diskussion. Darum oder weil die darin dargelegte ontologische Position ohnehin unerkannt blieb, hat sie sich in der unmittelbaren Folge wohl auch nicht etabliert.

Man könnte dieser Untersuchung im Gesamten vorwerfen wollen, sie betrachte die Ontologie des Periphyseon unter Ausklammerung der christlichen Offenbarungs- und Heilstheologie, die gerade in den Büchern vier und fünf zugegen ist, und durch diese Ausklammerung sei ein sinnvoller Zugang zu Eriugenas Lehre von vorne herein ausgeschlossen. Viel wurde darüber geschrieben, dass für einen frühmittel- 
alterlichen Denker Philosophie und Theologie untrennbar verbunden sind, und die christliche Theologie beinhaltet nun einmal den Gedanken der göttlichen Offenbarung ${ }^{136}$ Doch Vieles von dem, was Eriugena in den Büchern vier und fünf behandelt, ist nicht darum außen vor geblieben, weil der Untersuchungsgegenstand uninteressant schien, sondern weil sich der Text aufgrund seiner Methode einer systematischen Herangehensweise verschließt. Wo keine sachlichen Argumente vorliegen, ist nichts zu prüfen. Wo der Text nur auf Autoritäten verweist, bleibt nur, deren Texte genauestens zu studieren, um zu sehen, ob sie als Stütze für das im Periphyseon Gesagte zulässig sind, ein bei der Menge an vorliegenden Verweisen ausuferndes Unternehmen. Zudem nimmt man damit dem Werk jegliche argumentative Eigenständigkeit und damit einen Großteil des philosophischen Werts. Es ist Eriugena selbst, der vor allem im ersten Buch vorgibt, einen Weg der ratio (via rationis) zu beschreiten. Seine Prägung durch die lateinische Dialektik und seine Begeisterung für die Argumente des Maximus zum Erweis theologischer Wahrheiten zeigen hier ihre Wirkung. Warum er von diesem Weg der ratio vor allem in den finalen Büchern vier und fünf abrückt, ließ sich nicht zureichend erklären.

Auch theologische Untersuchungen lassen sich rational führen, das hat Plotin ebenso gezeigt wie Gregor von Nazianz. Und der Vorwurf des Porphyrios an die Christen, sie gäben durch Vernunft einsehbare Wahrheiten als von Gott geoffenbarte Wahrheiten aus, trifft auf Theologen wie Marius Victorinus, Augustinus und Boethius nicht zu, weil diese viel Mühe aufwenden, um der ratio den Weg zu den Glaubenswahrheiten zu ebnen. Gerade diese Mühe und Sorgfalt in der Begründung macht sie für die Philosophie überhaupt erst interessant. Dass das Periphyseon eine derartige Argumentationssorgfalt im ersten Buch zumindest stellenweise walten lässt, in den übrigen Büchern aber davon abrückt, ist eine unbefriedigende Tatsache, die darum aber nicht unausgesprochen bleiben darf. Will das Werk von der philosophischen

${ }^{136}$ Siehe hierzu stellvertretend für die reiche Literatur Ulrich Köpf: Die Anfänge der theologischen Wissenschaftstheorie im 13. Jahrhundert, Tübingen 1974; Metaphysics in the Twelth Century, On the Relationship among Philosophy, Science and Theology, ed. by Matthias Lutz-Bachmann, Alexander Fidora and Andreas Niederberger, Turnhout 2004. 
Forschung ernst genommen werden, darf es sich solch einer Prüfung nicht entziehen.

Das Periphyseon bleibt nicht nur wegen seiner weitestgehend unbekannten Entstehungsgeschichte ein rätselhaftes Werk. Sein Umschwung hinsichtlich Untersuchungsabfolge und Argumentationsmethode lässt es teils als dialektische Abhandlung, teils als Enzyklopädie, teils als Väterverehrung, teils als Mystik und teils als Bibelexegese erscheinen. Eine Systematik lässt sich nur im Hinblick auf die Ontologie finden, und diese wurde hier, soweit es der Text ermöglichte, dargelegt. Da diese Ontologie faszinierend und philosophiegeschichtlich wohl einmalig ist, weckt sie hoffentlich weiteres Interesse. 



\section{Anhang: \\ Philosophiegeschichtliche Einordnung des Werks}

\section{Pantheismus}

Die Frage, ob das Periphyseon einen Pantheismus lehrt, lässt das Forschungsinteresse nicht los, wohl auch, weil dessen theologische Rehabilitierung davon abhängt ${ }^{137}$ Daher ist darauf kurz einzugehen, wenngleich dies zur Klärung des Textes wenig beiträgt, weil die Frage zur Zeit der Textentstehung nicht zur Diskussion stand.

Das Wort >Pantheismus< stammt aus dem späten 17. Jh. und war somit dem gesamten Mittelalter fremd. Man müsste also treffender Fragen, ob die Verurteilung des Periphyseon im 12. Jh. gerechtfertigt war ${ }^{138}$ Nach theologischer Definition bezeichnet Theophanie die "Wesenseinheit von Gott mit allen Dingen « ${ }^{139}$ Wenn hier > Wesen « als dasjenige verstanden wird, was Eriugena essentia nennt, dann sollte das Periphyseon einen Pantheismus vertreten. Da ihm zufolge alles Seiende nur in Gott wahrhaft besteht und Gott esse und essentia von allem nur irgendwie Seienden ist, ist auch eine Wesenseinheit gegeben. Worin sonst als dem esse und der essentia nach besteht denn überhaupt die Einheit, von der im Periphyseon die Rede ist? Gerade die vielmal vorgebrachte Behauptung, Gott sei esse und essentia von allem, stützt ja die Rückauflösung der Natur in eine Einheit.

Angenommen, man definiert Pantheismus mit der gewaltigen Formel ralles ist Gott und Gott ist alles<, entspricht dies der Lehre des Periphyseon? Erinnern wir uns, dass Eriugena genau diese Formel im dritten Buch anspricht, und zwar als eine ungeheuerliche, weil bislang

${ }^{137}$ Siehe als jüngsten Beitrag dazu: Douglas W. Hadley: Eriugena Against Metaphysical Dualism, in Dionysius XIX (2001), p. 137-158.

${ }^{138}$ Siehe zu diesem Ereignis und seinen Folgen den Band von Werner Beierwaltes (Hg.): Eriugena Revivus: Zur Wirkungsgeschichte seines Denkens im Mittelalter und im Übergang zur Neuzeit. Vorträge des V. internationalen Eriugena-Colloquiums, Bad Homburg 26.-30.8.1985, Heidelberg 1987.

${ }^{139}$ Lexikon für Theologie und Kirche Bd. 8, Freiburg 1963, S. 26. 
unbekannte Aussage ${ }^{140}$ Wie begegnet er ihr? Er relativiert oder metaphorisiert sie nicht, sondern bestärkt und belegt sie in ihrer vollen Bedeutung. Gibt es einen stärkeren Beweis für Eriugenas Festhalten an dieser Formel?

Würde man ihn konfrontieren können mit diesem Ausdruck aus dem 17. Jh. und ihm erklären, was er bedeutet, vielleicht würde er akzeptieren, ein Pantheist zu sein. Und vielleicht verwiese er als Beleg für die notwendige Annahme eines solchen Pantheismus nicht nur auf sein $\mathrm{Pe}$ riphyseon und auf Dionysius Areopagita, sondern auch auf den 1. Korintherbrief, 15, 28, wo von ut sit deus omnia in omnibus die Rede ist, jene biblische Formel, auf die sich auch der Eriugena-Bekenner Amalrich von Bena im 12. Jh. berief.

Es liegt allerdings an der Theologie und nicht an der Philosophie, Eriugena theologisch einzuordnen und seine Lehre auf den Pantheismus hin genau zu reflektieren. Dazu ist dann sicherlich auch ein präziser gefasster Pantheismus-Begriff notwendig.

Vielleicht ist dabei dieser Aspekt von Eriugenas Substanz-Lehre nicht einmal der theologisch brisanteste. Er behauptet ja nicht allein die Wesenseinheit der Dinge mit Gott. Seine essentia-Lehre negiert jegliches Sein außerhalb von Gott, legt also die besagte Wesenseinheit in Gott hinein. Allein der Natur nach ist das Geschöpf von Gott verschieden, auch in der finalen theosis. Denn das Geschöpf ist und war nie schaffend. Gott ist dabei nicht nur in allen Geschöpfen als derselbe zugegen, sondern diese sind überhaupt nur, insofern sie in Gott bestehen. Außerhalb von Gott ist nichts Seiendes. Der Konsequenz, wonach die sichtbare Welt dann zu einer bloßen Erscheinung wird, vermag Eriugena eine geschickte positive Wendung abzugewinnen: sie ist nicht bloßer Schatten oder Abglanz, sondern sie vermag für das betrachtende Geschöpf zur Theophanie zu werden, zum »imago imaginis« des Göttlichen 141

\section{Neuplatonismus}

Durch die Arbeiten von Gersh und Beierwaltes gilt Eriugena mittlerweile Vielen als ein Fortführer der neuplatonischen Lehre oder zumin-

${ }^{140}$ III, 1328-1337.

${ }^{141}$ Siehe zu diesem Ausdruck I, 198. 
dest als ein Platoniker. Und um Eriugena überhaupt einen Platz innerhalb der Philosophiegeschichte zu geben, ist diese Zuordnung durchaus hilfreich.

Doch spätestens, wenn aufgrund dieser Zuordnung Äußerungen wie diese, Eriugena sei ein »convinced Platonist «, auftauchen, ist Verwunderung angebracht ${ }^{142}$ Heinrich Dörrie definiert einen Platoniker wie folgt: »Mit >Platonismus<, >platonisch<, >Platoniker wird die Richtung (und ihre Anhänger) bezeichnet, die ihr Philosophieren bewusst auf Plato zurückführte(n). Dem entspricht der antike Terminus platonikoiplatonici.< ${ }^{143}$ Dieser plausiblen Definition gibt es nichts hinzuzufügen, und damit hat zumindest Eriugena selbst sich wohl niemals als Platoniker verstanden, sondern als Dialektiker und Theologe, der aufgrund der ihm verfügbaren Schriften des Dionysius Areopagita und des Maximus Confessor glaubt, am bislang dem Westen verborgenen »heiligen Nektar der Griechen« teilhaben zu können 144

Und selbst wenn er sieht, wie Gregor von Nyssa in seiner Auslegung der Menscherschaffung Manches aus dem platonischen Timaios übernimmt, weil ihm zumindest diese platonische Schrift überhaupt bekannt ist, so folgt noch nicht, dass er die Allgegenwärtigkeit von platonischem Gedankengut bei Augustinus und Dionysius Areopagita auch nur im Ansatz durchschaut und sich darauf beruft. Ein »überzeugter« Platoniker ist er also sicherlich nicht.

Darüberhinaus stellt sich die Frage, ob er aus heutiger systematischer Sicht als Platoniker eingestuft werden kann, und diese Frage ist wohl nicht eindeutig beantwortbar. Seine Annahme, alles Individuelle sei von einem Vorbild verursacht, einem Prototypen (diese Ausdrücke tauchen ja im Periphyseon auf), legt zunächst eine Verwandschaft mit dem Timaios nahe. Doch stellt sich hier bereits die Frage, ob jene Schöpfungsmächtigkeit, die Eriugena seinen erstrangigen Ursachen oder Ideen zuspricht, weil sie in Gott selbst zu verorten sind, eine Vorlage bei Plato

${ }^{142}$ Peter Dronke: Imagination in the Late Pagan and Early Christian World, Firenze 2003, p. 183. Ähnlich merkwürdig verweist Inglis Patrick Sheldon-Williams auf Eriugenas Unkenntnis der platonischen Schriften, will ihn aber zugleich als platonischen Denker einordnen, in ders.: Eriugena's Greek Sources, in: The mind of Eriugena-Papers of a Colloquium, Dublin, 14-18 July 1970, ed. by John J. O’Meara and Ludwig Bieler, Dublin 1973, p. 1.

${ }^{143}$ Heinrich Dörrie: Platonica minora, München 1976, S. 166.

${ }^{144}$ Carmen 20, 1 (ed. Michael W. Herren, Dublin 1993, p. 108): sacro Graecorum nectare. 
hat. Zudem hält Plato aus epistemologischer Sicht das Geistige, nicht Sinnliche für das am meisten Erkennbare. Eriugena hingegen spricht seinen causae primordiales, die er als Ideen benennt, jegliche Erkennbarkeit ab. Sie sind vielleicht eher mit dem zu identifizieren, was Plato als Idee des Guten über alles andere, vielleicht sogar über die Erkennbarkeit stellt.

Weil die Ideen Platons, falls man bei Platon überhaupt von Derartigem reden will, durch den Neuplatonismus ins Transzendente hinübergetragen wurden, ist es schon treffender, Eriugena als Neuplatoniker einzuordnen 145

Doch auch diese Zuordnung ist nicht frei von Schwierigkeiten, da Eriugena aufgrund seines Festhaltens an den Begriffen der lateinischen Dialektik unter einem ontologischen Einfluss der aristotelischen Kategorienschrift steht, den Neuplatoniker wie Plotin gerade einzudämmen versuchten.

Wenn Eriugena die Differenz zwischen de subiecto und subiectum dahingehend auflöst, dass nur das subiectum verbleibt, so presst er die Art und Gattung im Grunde in die Einzelsubstanz hinein. Damit wäre er von allem Neuplatonismus weit entfernt. Weil er aber sogleich dieses subiectum mit der höchsten und allgemeinsten ousia identifiziert, mit der Ursache alles Seienden, rückt er der neuplatonischen Lehre wieder nahe. Zugleich ist eine solche Identifikation der ersten Substanz aus der Kategorienschrift mit aller ousia etwa Plotin höchst suspekt: »Wie soll ousia eine einzige Gattung sein? «146

An einem weiteren Beispiel lässt sich die Schwierigkeit aufzeigen, wenn man Eriugena ohne Einschränkungen als Neuplatoniker einzustufen gedenkt. Eine grundlegende Frage Plotins sei es, gibt Christian Tornau in seinem Kommentar zu einer Enneade an, "wie sich die Einheit des geistigen Seins mit seiner Gegenwart in der Vielheit der an ihm teilhabenden sinnlichen Seienden verträgt. \& 147 Auch Porphyrios, Iamblich und Proklos haben wohl nach Ähnlichem gefragt. Wie steht es mit

\footnotetext{
${ }^{145}$ Siehe zur kontroversen Diskussion um Platons Ideenlehre Wolfgang Wieland: Platon und die Formen des Wissens, Göttingen 1999.

${ }^{146}$ Enneaden VI, I (ed. Rudolf Beutler und Willy Theiler, Hamburg 1967, S. 98, Absatz

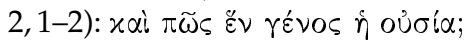

${ }^{147}$ Christian Tornau: Plotin Enneaden VI 4-5 [22-23] - ein Kommentar, Stuttgart/Leipzig 1998, S. 9.
} 
Eriugena? Fragt dieser nicht eher, wie sich die Einheit des göttlichen Seins in die Vielheit der teilhabenden Seienden vervielfältigt?

Wo liegt der Unterschied? Die Neuplatoniker nehmen eine Abstufung des Seienden an, eine Hierarchie ${ }^{148}$ Das geistig Seiende ist dabei mehr Seiendes als das nur körperlich Seiende. Diese Abstufung lässt sich im Periphyseon nicht finden. Gott ist in allem Seienden auf gleiche Weise als essentia zugegen. Zudem, wenn überhaupt irgendetwas zwischen Gott und dem Körperlichen steht, dann sind dies die erstrangigen Ursachen, die letztendlich auch wieder nur in Gott zu verorten sind 149 Erst im zweiten Buch ist überhaupt von der Seele die Rede, ohne das klar wird, welche Funktion sie in einer Stufenfolge vom Geistigen über das Beseelte hin zum Unbeseelten einnimmt.

Dabei ist die Fragestellung Eriugenas derjenigen Plotins durchaus verwandt. Wie Tornau im Zusammenhang mit Plotin anmerkt, lassen sich die Abschnitte VI, 4 und VI, 5 aus den Enneaden im Anschluss an Porphyrios betiteln mit: »Das Sein ist eines und dasselbe und doch überall zugleich ganz. ${ }^{150}$ Und auch anderswo stellt Plotin die Frage, wie »unteilbares Sein in Vielem erscheine «151 Vom unteilbaren Sein und dessen wundersamen Gegenwart in den sichtbaren Einzeldingen ist auch im Periphyseon die Rede. Doch die Lösung, welche Eriugena anbietet, weicht von jener der Neuplatoniker ab, und zwar vor allem darum, weil sie auf ontologisierten Begriffen aus der aristotelischen Kategorienschrift aufbaut.

Wie kann ein christlicher Neuplatonismus aussehen? Eindrucksvoll zeigt sich dies beim lateinischen Rhetor und Theologen Marius Victorinus. Streng platonisch hierarchisiert er das Seiende: »Darum gehört die Seele den Seienden an, wenn sie allein und rein in sich ist; mit dem Stoff verbunden, gehört sie den nicht wahrhaft Nichtseienden an; der Stoff

\footnotetext{
${ }^{148}$ Pierre Hadot formuliert dies wie folgt: "Chaque degré de la réalité ne peut s'expliquer sans le degré supérieur: l'unité du corps sans l'unité de l'âme qui l'anime, la vie de l'âme sans la vie de l'Intelligence supérieure qui l'éclaire (...) «, in ders.: Plotin ou la simplicité du regard, Paris 1998, p. 28.

${ }^{149}$ Siehe zu diesem Problem auch Abschnitt 3.4.2.

${ }^{150}$ Christian Tornau: Plotin Enneaden VI 4-5 [22-23] - ein Kommentar, Stuttgart/Leipzig 1998, S. 9.

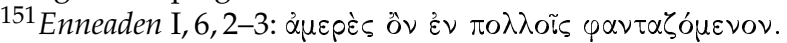


allein eignet den Nichtseienden. $\sqrt{152}$ Und später: »Also sind die wahrhaft Seienden intelligibel, die bloss Seienden intellektuell.< ${ }^{153}$ Wahrhaft seiend ist demnach das Intelligible. Bei Eriugena gibt es derartig Intelligibles gar nicht. Wahrhaft seiend ist Gott, unbegreiflich für allen Intellekt.

Es sei erinnert, wie im Periphyseon Gott die Körperwelt aus sich selbst heraus erschafft und aus seinen Gedanken. Wo ist dabei das Reich des Intelligiblen? Es ist zurückgedrängt auf das, was Eriugena Akzidenzien an sich (accidens per se) nennt, jenes merkwürdige Tribut an die Ideenlehre des Boethius, das er trotz aller Ausrichtung an der Kategorienlehre nicht gänzlich außen vor lässt. Die vorrangigen Ursachen (causae primordiales) sind dabei keine möglichen Kandidaten für das Intelligible, weil sie, wie er es sagt, allen Intellekt überragen. Was seine Lehre vom Seienden angeht, scheint sie zu sehr an die dialektischen Begriffe substantia und accidens gebunden zu sein, um ein Reich des Intelligiblen zwischen Gott und der Körperwelt konstituieren zu können. Eine Differenzierung hinsichtlich der Form und damit des Seins, wie sie Boethius in seinen theologischen Traktaten vorschlägt, liegt ihm fern. Vielmehr hebt Eriugena die von der Dialektik überlieferte und hilfreiche Unterscheidung zwischen de subiecto und dem subiectum einfach auf. Was zwischen Gott und der Körperwelt steht, dies beantwortet erst die Anthropologie aus den Büchern zwei, vier und fünf. Doch auch hier sucht man nach einer Abstufung des Seienden vergeblich 154

\footnotetext{
${ }_{152}$ Ad Candidus 10 (Sources Chretiennes 68, ed. Hadot 1960, p. 146): Et idcirco anima ea est quae sunt, cum ipsa sola pura est, mixta $\tau \tilde{\eta} \tilde{u} \lambda \eta \eta$ ea quae non vere non sunt, sola autem $\mathrm{U} \lambda \eta$ quae non sunt. Übersetzung nach Hadot in: Marius Victorinus Christlicher Neuplatonismus, Zürich 1967, p. 93.

${ }^{153}$ Ad Candidum 7, 13-14 (Sources Chrétiennes 68, ed. Hadot 1960, p. 140): Ergo intellectibilia ea sunt quae vere sunt, intellectualia, quae tantum sunt. Übersetzung nach Pierre Hadot: Marius Victorinus - Christlicher Neuplatonismus, Zürich 1967, S. 90; Zur Unterscheidung von sintelligibel und sintellektuell siehe Hadots Anmerkung an selbigem Ort. Leider geht die Abhandlung von Werner Steinmann: Die Seelenmetaphysik des Marius Victorinus, Hambug 1990, auf diese Seinsauffassung nicht ein.

${ }^{154}$ Es gibt im Periphyseon nur eine Aussage, die Derartiges erahnen lassen könnte. Dort heißt es, der Geist werde zu dem, was er erkenne (I,328-329: quodcunque intellectus comprehendere potuit, id ipsum fit). Der Erkenntnisgrad bedingt somit auf irgendeine Weise den Seinsgrad. Doch zum einen findet sich nirgendwo im Periphyseon eine nähere Erläuterung dieses Gedankens, zum anderen ist bei Maximus, den
} 
Dies lässt sich auch auf den Umstand zurückführen, dass Eriugena alles Seiende unmittelbar am Sein Gottes teilhaben lässt. Bei Proklos etwa hat der Körper an der Natur teil, diese an der Seele und diese wiederum am Geist ${ }^{155}$ Auch Plotin macht deutlich, dass die Teilhabe der Seele am Guten nur mittels des Geistes (dia nou) zustandekommt, ${ }^{156}$ Das Höhere reicht die Teilhabe an das Niedere weiter, ein Modell, das sich bei Dionysius Areopagita (etwa De div. nom. IV) wiederfindet.

Wenn hingegen Gott im Periphyseon nicht nur jenes Sein ist, an dem alles Seiende teilhat, sondern auch subiectum und Fundament eines jeden Geschöpfes, dann ist solch eine graduelle Abstufung dem Sein nach nicht mehr möglich. Ein Mehr oder Weniger in der Teilhabe am Sein, wie es Dionysius Areopagita in De divinis nominibus V darlegt, ist nicht möglich, wenn Gott die substantiae der einzelnen Dinge ausmacht. Denn dies würde bedeuten, Gott sei in einigen Dingen nur unvollständig zugegen. Der Teilhabegedanke lässt einen Abstufungsspielraum, den der Fundamentgedanke nicht ermöglicht.

Zudem soll gerade das Sein, genauer die essentia, die Einheit zwischen Schöpfer und Geschöpf ausmachen, und dieses Sein als das Prinzip der Einheit weisen die späteren Neuplatoniker explizit zurück. ${ }^{157}$

Eriugena hier als Quelle nennt, von einer damit einhergehenden Seinsabstufung nicht die Rede (MPG 91, 1113B-C).

${ }^{155}$ Siehe in seinem Kommentar zu Euklids Elementen, Buch I (ed. Gottfried Friedlein, Leipzig 1873, p. 92,4-13) sowie die englische Übersetzung von Glenn R. Morrow: Proclus-A commentary on the First Book of Euclid's Elements, Princeton 1970, p. 75.

${ }^{156}$ Enneaden I, 7, 2.

${ }^{157}$ Bereits im Sophistes zeigt Plato auf, dass jegliche Seinsform wie auch das vollkommene Sein nicht auf eine Einheit reduzierbar ist, $244 \mathrm{~b}-245 \mathrm{e}$. Proklos weist das SeiendEine als erste Ursache dem Dichter Parmenides zu, während das überseiend Eine im platonischen Parmenides die erste Ursache sei: "And this is where the Platonic Parmenides differs from the one who speaks in the poem, for the latter had the One being in mind and said that it is the cause of everything, but the former is thinking of the One, and mounts from the One being to the One alone which is prior to existence. " Übersetzung nach Glenn Morrow \& John Dillon: Proclus Commentary on Plato's Parmenides, Princeton 1987, p. 579; griechisch ediert von Victor Cousin: Procli Philosophi Platonici - Opera inedita III, Hildesheim 1961, p. 1240, 32-37:

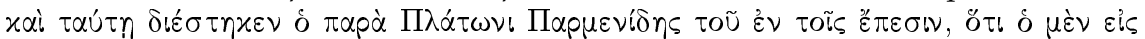

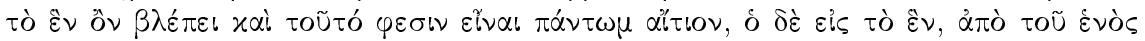

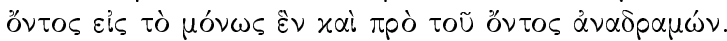


Indes verbindet schon Augustinus das Sein mit dem Einen ${ }^{158}$ Vielleicht ist daher in diesem Punkt Augustins Wirkung auf Eriugenas Denken, und damit die Einwirkung eines lateinischen Kirchenvaters, entscheidend. Der reizvolle und in Hinblick auf das Periphyseon immer wieder verführerische Gedanke, mit Eriugena komme, vermittelt durch Dionysius Areopagita, bislang unbekanntes neuplatonisches Gedankengut in den lateinischen Westen, ist stets der Beweislast ausgesetzt, das Besagte finde sich nicht bereits bei Augustinus. Zudem ist dann zu klären, inwieweit nicht Dionysius Areopagita bereits in Vielem von der neuplatonischen Lehre hin zu einer paulinischen abweicht ${ }^{159}$

Es wäre unsinnig, einen teils gewaltigen neuplatonischen Einfluss auf Eriugenas Denken abstreiten zu wollen. Der Neuplatonismus hallt fasst überall in der Spätantike nach. Doch das ist in Bezug auf Eriugena nur die halbe Wahrheit. Zwar fühlt man sich bei der im Periphyseon oft auftretenden Formel per se ipsum in se ipso ad se ipsum und bei seinem Modell der Rückauflösung der Natur unweigerlich an die neuplatonische Trias des Hervorgangs, des Verharrens und der Rückkehr erinnert. Doch liegt nicht schon bei dem Begründer des Christentums, dem Apostel Paulus, jene von Eriugena verwendete Formel zumindest als zweigliedrige vor? So heißt es in Kolosser 1,16: omnia per ipsum et in ipso creata sunt. Auch findet sich hier der Zusatz creata, für den Eriugena zwar Dionysius als Quelle vorgibt, der bei diesem aber nicht aufzufinden ist. Vielleicht sollte man daher das Periphyseon im selben Grade als eine Ausgestaltung der augustinischen und paulinischen Lehre ansehen, wie man darin Neuplatonisches aufweist. Einmal mehr zeigt sich, wie sich dieses Werk jeder eindeutigen philosophiegeschichtlichen $\mathrm{Zu}$ ordnung zu entziehen weiß.

\footnotetext{
${ }^{158}$ Etwa Confessiones 10,24 ff; siehe hierzu auch Kurt Flasch: Augustin - Einführung in sein Denken, Stuttgart ${ }^{2} 1994$, S. 300.

${ }^{159}$ Siehe zu Dionysius' Umformung der neuplatonischen Hierarchienlehre auch Walther Völker: Kontemplation und Ekstase bei Pseudo-Dionysius Areopagita, Wiesbaden 1958; Kurt Ruh: Die mystische Gotteslehre des Dionysius Areopagita, München 1970; Bernhard Brons: Gott und die Seienden: Untersuchungen zum Verhältnis von neuplatonischer Metaphysik und christlicher Tradition bei Dionysius Areopagita, Göttingen 1976; Endre von Ivanka: Dionysius Areopagita - Von den Namen zum Unbenennbaren, Einsiedeln 1981, Einleitung S.7-12; Paul Rorem: PseudoDionysius, Oxford 1983; Beate Regina Suchla: Das überfließende Eine, in: Theologen der christlichen Antike, Darmstadt 2002, S. 202-220.
} 


\section{Literaturverzeichnis}

\section{Primärtexte}

Iohannis Scotti seu Eriugenae: Periphyseon Libri 1-5, édité par Edouard Jeauneau, Corpus Christianorum Series Latina CLXI-CLXV, Paris 19962003

Iohannis Scotti Eriugenae: Periphyseon, Book I+II, edited and translated by Inglis Patrick Sheldon-Williams, Dublin 1968 \& 1972

Johannes Scottus Eriugena: Über die Einteilung der Natur, Buch 1-3, übersetzt von Ludwig Noack, Berlin 1870, neu herausgegeben Hamburg 1984

Iohannis Scotti: Annotationes in Marcianum, ed. Cora E. Lutz, Cambridge Mass., 1939

Iohannis Scoti: De divina praedestinatione, ed. Goulven Madec, Corpus Christianorum Continuatio Mediaevalis 50, Turnhout 1978

John Scottus Eriugena: Treatise on divine preadestianation, transl. by Mary Brennan, Notre Dame 1998

John Scottus Eriugena: Glossae divinae historiae, the Biblical Glosses of John Scottus Eriugena, ed. by John J. Contreni and Padraig P. O'Neill

Joannis Scoti: Terarchias Sancti Dionysii, Patrologia Latina 122, p.126266

Jean Scot: Homélie sur le prologue de Jean, éd. par Edouard Jeauneau, Paris 1969

Iohannis Scotti Eriugenae: Carmina, ed. Michael W. Herren, Dublin 1993

Mary Brennan: Guide des études érigéniennes, bibliographie commenté des publications 1930-1987, Fribourg 1987

Anselmi: Opera, Tomus I, ed. Franz Schmitt, Stuttgart 1968

Aristoteles: Categoriae, ed. W. Jaeger, Oxford ${ }^{2} 1956$ 
Literaturverzeichnis

Aristoteles: Analytica posteriora, ed. W.D. Ross, Oxford 1964

Aristoteles: Physica, Aristotelis Opera I, ed. Immanuel Bekker, Berlin 1960, p. 184-267

Aristoteles: Metaphysica, Aristotelis Opera IV, ed. Immanuel Bekker, Berlin 1964, p. 519-833

Complete Works of Aristotle - The Revised Oxford Translation, ed. Jonathan Barnes, Princeton 1985

Aristoteles Metaphysik Z Text, Übersetzung und Kommentar von Michael Frede / Günther Patzig, 2 Bde, München 1988

Categoriae translatio Boethii, in: Aristoteles latinus I,1-5, ed. Laurentius Minio-Paluello, Brueges/Paris 1961, p.5-41

Categoriae translatio Guillelmi, in: Aristoteles latinus I,1-5, ed. Laurentius Minio-Paluello, Brueges/Paris 1961, p. 85-117

Augustinus: De genesi ad litteram, Patrologia Latina 34, 219-466

Augustinus: De trinitate libri, CCSL L \& La, Turnhout 1968

Augustinus: De Civitate dei, CCSL XLVII \& XLVIII, Turnhout 1955

Basile de Césarée (Basilius von Cäsarea): Homélies sur l'Hexaéméron, in: Sources Chrétiennes 26, texte grec et français, introduction et traduction de Stanislas Giet, Paris 1949

Beda: De natura rerum, Patrologia Latina 90, 187-278

Boethius: Institutio arithmetica, ed. Jean-Yves Guillaumin, Paris 1995

Boethius: Contra Eutychen, ed. Stewart/Rand, London 1967

Boethius: De hebdomadibus, ed. Stewart/Rand, London 1967

Boethius: In categorias aristotelis liber primus, Patrologia Latina 64, 159294

Boethius: Liber de divisione, Patrologia Latina 64, 875-892

Calcidius: Commentarius in Timaeum Platonii, in: Plato latinus IV, ed. J. H. Waszink, London 1962

Cassiodor: De artibus ac disciplinis Liberalium litterarum, Patrologia Latina $70,1149-1220$ 
Primärtexte

Cicero: Topica, ed. Karl Bayer, München 1993

Cicero: De inventione, ed. C. F. W. Mueller, München 1988

Cicero: De finibus bonorum et malorum, ed. L. D. Reynolds, Oxford 1998

Cicero: Tusculani (Gespräche in Tusculum), Hg. Olof Gigon, München und Zürich 1984

Dexippus: Commentaria in Aristotelem Graeca (CAG) Bd. IV, ed. Adolf Busse, Berlin 1887

Dexippus - On Aristotle's Categories, translated by John Dillon, New York 1990

Dionysiaca, Tome I \& II, éd. par Philippe Chevalier, Paris 1937

Corpus Dionysiacum I - Herausgegeben von Beate Regina Suchla, Berlin 1990

Corpus Dionysiacum II - Herausgegeben von Günter Heil und Adolf Martin Ritter, Berlin 1990

Pseudo-Dionysius Areopagita - Von den göttlichen Namen, herausgegeben und neu übersetzt von Beate Regina Suchla, Stuttgart 1988

Pseudo-Dionysius Areopagita - Über die Mystische Theologie und Briefe, eingeleitet, übersetzt und mit Anmerkungen versehen von Adolf Martin Ritter, Stuttgart 1994

Fridugisus: De substantia nihili et tenebrarum, Patrologia Latina 105, p. $751-756$

Fridugiso di Tours e il >de substantia nihili et tenebrarum<, edizione di Concettina Gennano, Padua 1963

Grégoire de Nazianze (Gregor von Nazianz): Oratio 28, in: Sources Chrétiennes 250, p. 101-175

Grégoire de Nazianze (Gregor von Nazianz): Oratio 38, in: Sources Chrétiennes 358, p. 103-149

Gregorius Nysseni (Gregor von Nyssa): De opificio mundi (De imagine), Patrologia Graeca 44, 123-256 
Literaturverzeichnis

Gregorius Nysseni (Gregor von Nyssa): De anima, Patrologia Graeca 45, 187-222

Heraclitus: Fragmenta, ed. Miroslav Marcovic, Sankt Augustin 2001

Isidori (Hispaniensis): Etymologiarum Tomus I\&II, ed. Wallace Martin Lindsay, Oxford 1962

Marius Victorinus: Ad Candidum / Adversus Arium, Sources Chrétiennes No. 68, ed. Paul Henry et Pierre Hadot, Paris 1960

Marius Victorinus: Liber de definitionibus, ed. Andreas Pronay, Frankfurt 1997

Martianus Capella: De nuptiis philologiae et mercurii, ed. James Willis, Leipzig 1983

Maximus Confessor: Ambigua ad Iohannem Patrologia Graeca 91, 1061ff

Maximus Confessor: Ambigua ad Iohannem; iuxta Iohannis Scotti Eriugenae latinam interpretaionem, édité par Edouard Jeauneau, Corpus Christianorum Series Graeca 18, Turnhout 1988

Maximus Confessor: Quaestiones ad Thalassium, édité par Carl Laga/

Carlos Steel, Corpus Christianorum Series Graeca 7, Turnhout 19801990

Plato: Kratylos, Werke III, Griechischer Text von Léon Robin und Louis Méridier, Deutsche Übersetzung von Friedrich Schleiermacher, Darmstadt 1974

Plato: Parmenides, Werke V, Griechischer Text von Albert Rivaud und Auguste Diés, Deutsche Übersetzung von Dietrich Kurz und Friedrich Schleiermacher, Darmstadt 1981

Plato: Sophistes, Werke VI, Griechischer Text von Auguste Diés, Deutsche Übersetzung von Friedrich Schleiermacher, Darmstadt 1970

Plato: Timaios, Werke VII, Griechischer Text von Albert Rivaud und Auguste Diés, Deutsche Übersetzung von Hieronymus Müller und Friedrich Schleiermacher, Darmstadt 1972

Plotin: Enneaden, ed. Rudolf Beutler und Willy Theiler, Hamburg 1967 
Porphyrios: Commentarius in Categoriis Aristotelis, in: Commentaria in Aristotelem Graeca (CAG) IV. 1, ed. Adolf Busse, Berlin 1887

Porphyry - On Aristotle Categories, translated by Steven K. Strange, London 1992

Porphyriou eis ton platonos Parmeniden, in: Pierre Hadot: Porphyre et Victorinus II, Etudes Augustiniennes, Paris 1968

Proklos: The Elements of Theology. A revised Text with Translation, Introduction and Commentary by Eric R. Dodds, Oxford 1963

Proklos: Procli Commentarius in Platonis Parmenidem, ed. Cousin, Hildesheim 1961

Proclus' Commentary on Plato's Parmenides, translated by Glenn R. Morrow and John M. Dillon, Princeton 1987

Seneca: Philosophische Schriften, lat./dt., hg. von Manfred Rosenbach, Darmstadt 1999

Paraphrasis Themistiana (De categoriis Aristotelis), in: Aristoteles latinus I, 1-5, ed. Laurentius Minio-Paluello, Brueges/Paris 1961

Dialogi in Porphyrium a Victorino translati, Patrologia Latina 64, 9-70

\section{Lexika}

Lexikon für Theologie und Kirche Bd. 8, Freiburg 1963

Historisches Wörterbuch der Philosophie, Band 6, Stuttgart-Basel 1984

Henry George Liddell \& Robert Scott: Oxford greek Dictionary, reedited Oxford 1961

G.W.H. Lampe: A Patristic Greek Lexikon, Oxford 1961

W. Pape: Griechisch-deutsches Handwörterbuch, Graz 1954

F. E. Peters: Greek Philosophical Terms, New York / London 1967

Christof Rapp / Christoph Horn: Wörterbuch der antiken Philosophie, München 2002

J. O. Urmson: The Greek Philosophical Vocabulary, London 1990 
Literaturverzeichnis

Thesaurus Linguae Latinae, Leipzig 1931-

Forcellini: Lexicon Totius Latinitatis, Bonn 1965

Monographien und Aufsätze

Guy H. Allard: Quelques remarques sur la >disputationis series<, in: Jean Scot Erigène et l'histoire de la philosophie, éd. par René Roques, Paris 1977, p. 211-224

G.H. Allard: Periphyseon - Indices Generales, Montreal/Paris 1983

Dirk Ansorge: Johannes Scottus Eriugena: Wahrheit als Prozess - eine theologische Interpretation von Periphyseon, Innsbruck/Wien 1996

A.H. Armstrong (ed.): The Cambridge History of Later Greek and Early Medieval Philosophy, Cambridge 1967

Guido Bausenhart: »In uns allen gleich außer der Sünde« - Studien zum Beitrag Maximos' des Bekenners zur altkirchlichen Christologie, Tübingen 1990

Gerald Bechtle: An Anomymous Commetary of Plato's Parmenides, Bern 1999

Werner Beierwaltes: Eriugena, Frankfurt 1984

Werner Beierwaltes: Denken des Einen, Frankfurt 1985

Werner Beierwaltes (Hg.): Eriugena Revivus: Zur Wirkungsgeschichte seines Denkens im Mittelalter und im Übergang zur Neuzeit. Vorträge des V. internationalen Eriugena-Colloquiums, Bad Homburg 26.30.8.1985, Heidelberg 1987

Werner Beierwaltes (Hg.): Begriff und Metapher -Sprachform des Denkens bei Eriugena, Vorträge des VII. internationalen Eriugena-Colloquiums Bad Homburg 26.-29. Juli 1989, Heidelberg 1990

Ruth Beinhauer: Untersuchungen zu philosophisch-theologischen Termini in De trinitate des Boethius, Wien 1990

Thomas Böhm: Adnotationes zu Maximus Confessor und Johannes Scottus Eriugena, in: Deutsche Mystik im abendländischen Zusammen- 
hang, Hg. Walter Haug und Wolfram Schneider-Lastin, Tübingen 2000, S. 51-60

D. Bremer: Von der Physis zur Natur. Eine griechischen Konzeption und ihr Schicksal, Zeitschrift für philosophische Forschung, 43 (1989), S. 241-264

Mary Brennan: A Guide to Eriugenian Studies. A Survey of Publications 1930-1987 (Vestigina. Etudes et documents de philosophie antique et médiévale, 5), Fribourg/Paris 1989, p.341ff

Bernhard Brons: Gott und die Seienden: Untersuchungen zum Verhältnis von neuplatonischer Metaphysik und christlicher Tradition bei Dionysius Areopagita, Göttingen 1976

Rainer Brueren: Die Schrift als Paradigma der Wahrheit - Gedanken zum Vorbegriff der Metaphysik bei Johannes Scotus Eriugena, in: Begriff und Metapher - Sprachform des Denkens bei Eriugena, Vorträge des VII. internationalen Eriugena-Kolloquiums Bad Homburg 26.29. Juli 1989, herausgegeben von Werner Beierwaltes, Heidelberg 1990, S. $187-201$

John Caldwell: The De institutione arithmetica and the De institutione musica, in: Boethius-His Life, Thougt and Influence, ed. by Margaret Gibson, Oxford 1981, p. 135-161

Maïeul Cappuyns: Jean Scot Erigène, sa vie, son Evvre, sa pensée, Louvain-Paris 1933

Deirdre Carabine: Gregory of Nyssa on the Incomprehensibility of God, in: The Relationship between Neoplatonism and Christianity, ed. by Thomas Finan and Vincent Twomey, Dublin 1992, p. 79-99

Marcia L. Colish: Carolingian Debates over Nihil and Tenebrae-A Study in Theological Method, in: Speculum 59/4 (1984), p. 757-795

Frederick Copleston: History of Philosophy, Vol. II, London 1950

Marta Cristiani: Le problème du lieu et du temps dans le livre Ier du >Periphyseon<, in: The Mind of Eriugena-Papers of a Colloquium, Dublin, 14-18 July 1970, ed. by John J. O'Meara and Ludwig Bieler, Dublin 1973, p. 41-48

Marta Cristiani: NATURE-ESSENCE ET NATURE-LANGAGE, Notes 
sur l'emploi du terme NATURA dans le PERIPHYSEON de Jean Erigène; in: Miscellanea Mediaevalea 13,2 (1981), p. 707-717

Robert D. Crouse: Primordiales Causae in Eriugena's Interpretation of Genesis: Sources and Significance; in: Iohannes Scottus Eriugena-the Bible and Hermeneutics, Proceedings of the Ninth International Colloquium of the Society for the Promotion of Eriugenian Studies, held at Leuven and Louvain-la-Neuve, June 7-10, 1995; ed. by Gerd van Riel, Carlos Steel and James McEvoy, Leuven 1996, p. 209-220

Heinrich Dörrie: Platonica minora, München 1976

Hubertus R. Drobner: Gregory of Nyssa as Philosopher: De anima et resurrectione and De hominis opificio, in: Dionysius 18 (2000), p.69101

Peter Dronke: Imagination in the Late Pagan and Early Christian World, Firenze 2003

Christophe Erismann: Alain de Lille, la métaphysique érigiénne et la pluralité des formes, in: Alain de Lille, le docteur universelle, éd. par Jean-Luc Solére, Anca Vasiliu et Alain Galonnier, Turnhouti 2005, p. 1319

Kurt Flasch: Zur Rehabilitierung der Relation - Die Theorie der Beziehung bei Johannes Eriugena, in: Philosophie als Beziehungswissenschaft, Festschrift für Julius Schaaf, hg. von W. F. Niebel und D. Leisegang, Frankfurt 1974

Kurt Flasch: Augustin - Einführung in sein Denken, Stuttgart 1994

Kurt Flasch: Das philosophische Denken im Mittelalter, Stuttgart 2000

Michael Frede: Prädikation und Existenz, Göttingen 1967

Stephen Gersh: Per se ipsum-The Problem of Immediate and Mediate Causation in Eriugena and his Neuplatonic Predecessors, in: Jean Scot Erigène et 1' histoire de la philosophie, éd. par René Roques, Paris 1977, p.367-376

Stephen Gersh: From Iamblichus to Eriugena, Leiden 1978

Stephen Gersh: Omnipresence in Eriugena-Some Reflections on Augustino-Maximian Elements in Periphyseon, in: Eriugena: Studien zu 
seinen Quellen, Vorträge des III. internationalen Eriugena-Colloqiums, Freiburg 27.-30. August 1979, herausgegeben von Werner Beierwaltes, Heidelberg 1979, S. 55-74

Stephen Gersh: Middleplatonism in the Latin Tradition II, Notre Dame 1986

Alfred Gierer: Eriugena, Al-Kindi, Nikolaus von Kues - Protagonisten einer wissenschaftlichen Wende im philosophischen und theologischen Denken, Halle 1999

Bernard McGinn: Eriugena Mysticus, in: Giovanni Scoto nel suo tempo, Atti del XXIV Convegno storico internazionale, Todi 11-14 ottobre 1987, S. 235-260

Wolfgang L. Gombocz: Geschichte der Philosophie, Bd. IV, München 1997

D. W. Hadley / Carlos Steel: John Scotus Eriugena, in: A Companion to Philosophy in the Middle Ages, ed. by Jorge Gracia, Maldon / Oxford / Melbourne 2003, p. 397-406

Pierre Hadot: Marius Victorinus - Christlicher Neuplatonismus, Zürich 1967

Pierre Hadot: Zur Idee der Naturgeheimnisse, Mainz 1982

Pierre Hadot: Plotin ou la simplicité du regard, Paris 1998

Pierre Hadot: Le voile d'Isis - Essai sur l'histoire de l'idée de Nature, Paris 2004

Johannes Hirschberger: Geschichte der Philosophie, Bd I, Freiburg 1949

Endre von Ivanka: Dionysius Areopagita - Von den Namen zum Unbenennbaren, Einsiedeln 1981

Edouard Jeauneau: Jean l'Erigène et les Ambigua ad Iohannem de Maxime le Confesseur, in: Maximus Confessor, Actes du Symposium sur Maxime le Confesseur, Fribourg, 2-5 septembre 1980, édités par Felix Heinzer et Christoph Schönborn 1982, p. 343-364

Edouard Jeauneau: Etudes érigéniennes, Paris 1987 
Edouard Jeauneau (en collaboration avec Paul Edward Dutton): The autograph of Eriugena, Turnhout 1996

Georgi Kapriev: Eodem sensu utentes? - Die Energienlehre der >Griechen $<$ und die causae primordiales Eriugenas, in: Göttinger Theologische Quartalsschrift, Jg. 2000, S. 289-307

Rosamund McKitterick: Knowledge of Plato's Timaeus in the Ninth Century; in: Haijo Jan Westra: From Athens to Chartres, Leiden 1992, p. 85-95

Ulrich Köpf: Die Anfänge der theologischen Wissenschaftstheorie im 13. Jahrhundert, Tübingen 1974

Johann Kreuzer: Von der Insel der Heiligen ins Zentrum der karolingischen Renaissance: Johannes Scottus Eriugena, in: Markus Knapp/ Theo Kobusch (Hg.): Querdenker - Visionäre und Außenseiter in Philosophie und Theologie, S. 84-94

Frank A. Lewis: Substance and Predication in Aristotle, Cambridge 1991

Alain de Libera: La philosophie médiévale, Paris 1993

Thomas $\mathrm{O}^{\prime}$ Loughlin: Biblical Contradictions in the Periphyseon and the Development of Eriugena' Method; in: Iohannes Scottus Eriugena-the Bible and Hermeneutics, Proceedings of the Ninth International Colloquium of the Society for the Promotion of Eriugenian Studies, held at Leuven and Louvain-la-Neuve, June 7-10, 1995; ed. by. Gerd van Riel, Carlos Steel and James McEvoy, Leuven 1996, p. 103-126

Matthias Lutz-Bachmann, Alexander Fidora, Andreas Niederberger:

Metaphysics in the Twelth Century-On the Relationship among Philosophy, Science and Theology, Turnhout 2004

Goulven Madec: Jean Scot et ses auteurs, Paris 1988

John Marenbon: Johannes Scottus and the >Categoriae decem<, in: Eriugena - Studien zu seinen Quellen, Vorträge des III. internationalen Eriugena-Kolloquiums Freiburg 27.-30. August 1979, herausgegeben von Werner Beierwaltes, Heidelberg 1980, S. 117-134

J.C. Marler: Use of Authority in the Periphyseon, in: Eriugena: East and West-Papers of the Eight International Colloquium of the Society for 
the Promotion of Eriugenian Studies, Chicago and Notre Dame, 1820 October 1991, ed. by. Bernard Mc Ginn and Willemien Otten, Notre Dame/London 1991, p. 95-113

Michael Masi: Boethian Number Theory, A translation of the De institutione Arithmetica, Amsterdam 1983

Dominic O'Meara: The Concept of Natura in John Scottus Eriugena (De divisione naturae book I), in: Vivarium 19 (1981), p. 126-145

Dominic O'Meara (ed): Neoplatonism and Christian Thought, Albany 1982

Dominic O'Meara: Plotinus - An Introduction to the Enneads, Oxford 1993

Dominic O'Meara: The Structure of Being and the Search for the Good, Aldershot \& Brookfield 1998

John Josef O'Meara: Eriugena, Oxford 1988

John Meyendorff: Remarks on Eastern Patristic Thought in John Scottus Eriugena, in: Eriugena: East and West - Papers of the Eight International Colloquium of the Society for the Promotion of Eriugenian Studies, Chicago and Notre Dame, 18-20 October 1991, ed. by. Bernard Mc Ginn and Willemien Otten, Notre Dame/London 1991, p.51-68

Dermot Moran: The Philosophy of John Scottus Eriugena, A study of Idealism in the Middle Ages, Cambridge 1989

Dermot Moran: Idealism in Medieval Philosophy: The Case of Johannes Scottus Eriugena, in: Medieval Philosophy and Theology 8 (1999), p. 53-82

Giulio d'Onofri: A proposito del »magnificus Boethius«: un' indagine sulla presenza degli »Opuscula sacra« e della »Consolatio« nell' opera eriugeniana, in: Eriugena - Studien zu seinen Quellen, Vorträge des III. internationalen Eriugena-Kolloquiums Freiburg 27.-30. August 1979, herausgegeben von Werner Beierwaltes, Heidelberg 1980, S. 189-200

Giulio d'Onofri: Über die Natur der Einteilung. Die dialektische Entfaltung von Eriugenas Denken, in: Begriff und Metapher - Sprachform des Denkens bei Eriugena, Vorträge des VII. internationalen Eriugena- 
Colloquiums Bad Homburg 26.-29. Juli 1989, herausgegeben von Werner Beierwaltes, Heidelberg 1990, S. 17-38

Giulio d'Onofri: The Concordia of Augustine and Dionysius: Towards a Hermeneutic of the Disagreement of Patristic Sources in John the Scot's Periphyseon, Eriugena: East and West-Papers of the Eight International Colloquium of the Society for the Promotion of Eriugenian Studies, Chicago and Notre Dame, 18-20 October 1991, ed. by. Bernard Mc Ginn and Willemien Otten, Notre Dame/London 1991, p. 114-140

Willemien Otten: The Role of Man in the Eriugenian Universe, in: Giovanni Scoto nel suo tempo, Atti del XXIV Convegno storico internazionale, Todi 11-14 ottobre 1987, S. 595-609

Willemien Otten: The Anthropology of Johannes Scottus Eriugena, Leiden 1991

Willemien Otten: The Dialectic of Return in Eriugena's Periphyseon, in: The Harvard Theological Review 84, 4 (1991), p. 399-421

Willemien Otten: The Interplay of Nature and Man in the Periphyseon of John Scot Eriugena, in: Vivarium 28 (1996), p. 1-17

Jean Pépin: Humans and Animals - Aspects of Scriptural Reference in Eriugena's Anthropologie, in: Eriugena: East and West-Papers of the Eight International Colloquium of the Society for the Promotion of Eriugenian Studies, Chicago and Notre Dame, 18-20 October 1991, ed. by Bernard Mc Ginn and Willemien Otten, Notre Dame/London 1991, p. 189-201

Ubaldo Pérez-Paoli: Der plotinische Begriff von ҮПО $\Sigma$ TA $\Sigma$ I $\Sigma$ und die augustinische Bestimmung Gottes als Subiectum, Würzburg 1990

Mischa von Perger: Deliberativa theoria - Eriugenas dialogische Kunst der Erwägung; in: Karl Jacobi: Gespräche lesen - Philosophische Dialoge im Mittelalter, Tübingen 1989, S. 63-99

Gerold Prauss: Auf der Flucht vor individuellen Eigenschaften oder Der verkannte Platon, in: Rainer Enskat: Amicus Plato magis amica veritas, Berlin 1998

Gerold Prauss: Ding und Eigenschaft bei Plato und Aristoteles, in KantStudien 59 (1968), S. 98-117 
Christof Rapp: Aristoteles - Zur Einführung, Hamburg 2001

Christof Rapp: Identität, Persistenz und Substanzialität - Untersuchung zum Verhältnis von sortalen Termen und Aristotelischer Substanz, Freiburg i. Br. 1995

Gerd van Riel: A Bibliographical Survey of Eriugenian Studies 19871995, in: Iohannes Scottus Eriugena-the Bible and Hermeneutics, Proceedings of the Ninth International Colloquium of the Society for the Promotion of Eriugenian Studies, held at Leuven and Louvain-la-Neuve, June 7-10, 1995; ed. by. Gerd van Riel, Carlos Steel and James McEvoy, Leuven 1996, p. 367-400

Fran O'Rourke: Being and Non-Being in the Pseudo-Dionysius, in: The Relationship between Neoplatonism and Christianity, ed. by Thomas Finan and Vincent Twomey, Dublin 1992

René Roques: Remarques sur la signification de Jean Scot Erigène, in: Divinitas XI (1967), p. 253-278

René Roques: Libres sentiers vers l'érigénisme, Rom 1975

René Roques (ed.): Jean Scot Erigène et l'histoire de la philosophie, Paris 1977

Paul Rorem: Pseudo-Dionysius, Oxford 1983

Kurt Ruh: Die mystische Gotteslehre des Dionysius Areopagita, München 1970

Hermann Schmitz: Die Ideenlehre des Aristoteles, 2. Teil, Bonn 1985

Gangolf Schrimpf: Das Werk des Johannes Scottus Eriugena im Rahmen des Wissenschaftsverständnisses seiner Zeit, Münster 1982

Gangolf Schrimpf: Die systematische Bedeutung der beiden Einteilungen (divisiones) zu Beginn von Periphyseon; in: Giovanni Scoto nel suo tempo, Atti del XXIV Convegno storico internazionale, Todi 11-14 ottobre 1987 (publ.: Spoleto 1989), S. 1113-151

Inglis P. Sheldon-Williams: Eriugena's Greek Sources, in: The Mind of Eriugena-Papers of a Colloquium, Dublin, 14-18 July 1970, ed. by John J. O'Meara and Ludwig Bieler, Dublin 1973, p. 1-15 
Literaturverzeichnis

Carlos Steel: L'Ame: Modèle et image, in: Henry Blumenthal \& E. G. Clark: The Divine Iamblichus, London 1993, p. 12-23

Carlos Steel: John Scotus Eriugena, 2003, (siehe: D. W. Hadley)

Holmer Steinfaht: Selbständigkeit und Einfachheit. Zur Sustanztheorie des Aristoteles, Frankfurt 1991

Werner Steinmann: Die Seelenmetaphysik des Marius Victorinus, Hamburg 1990

Brian Stock: >Intelligo me esse «: Eriugenas Cogito, in: René Roques: Jean Scot Erigène et l'histoire de la philosophie, Paris 1977, p. 328-335

Beate Regina Suchla: Das überfließende Eine, in: Theologen der christlichen Antike, Darmstadt 2002, S. 202-220

Lars Thunberg: Man and the Cosmos-The visions of St. Maximus the Confessor, Crestwood 1985

Christian Tornau: Plotin Enneaden VI 4-5 [22-23] - ein Kommentar, Stuttgart/ Leipzig 1998

Walther Völker: Kontemplation und Ekstase bei Pseudo-Dionysius Areopagita, Wiesbaden 1958

Hermann Weidemann: Zum Begriff des ti ên einai und zum Verständnis von Metaphysik Zeta 4 1029b22-1030a6, in: Christof Rapp: Metaphysik - Die Substanzbücher, Berlin 1996, S. 75-103 